\title{
Creativity in Jazz
}

Norman Lawrence Meehan

A thesis

submitted to Massey University and Victoria University of Wellington in fulfilment of the requirements for the degree of

Doctor of Philosophy

New Zealand School of Music

2014 


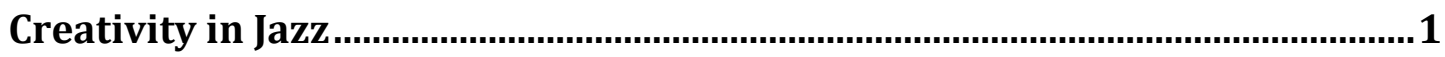

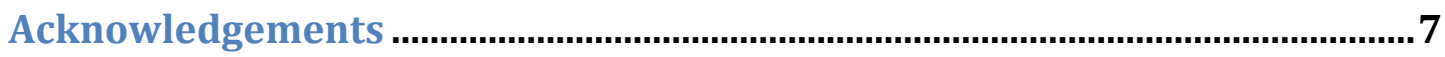

Part One: Creativity and Jazz..............................................................................8

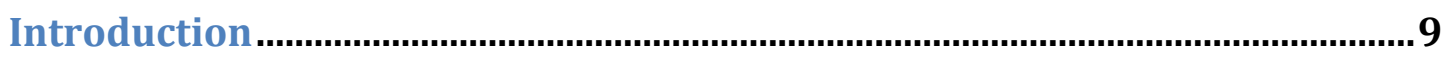

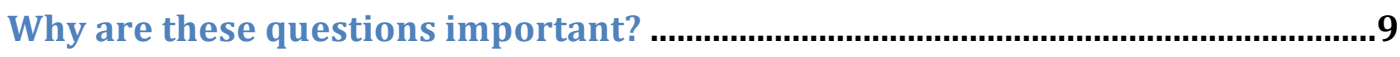

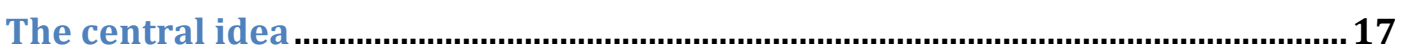

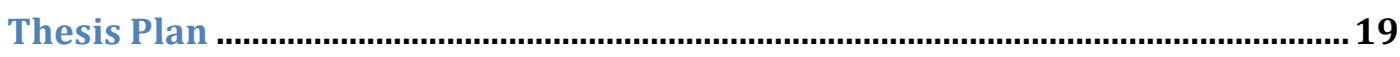

Chapter One: Creativity, and its importance.................................................. 24

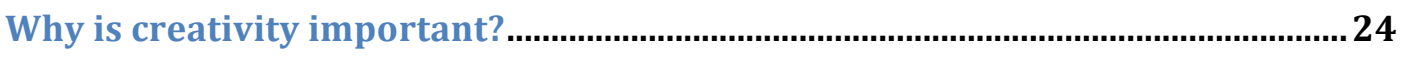

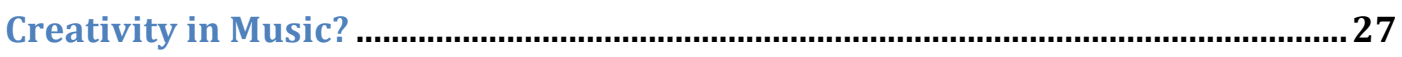

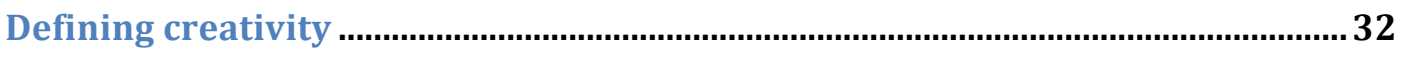

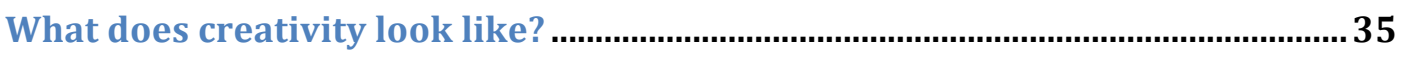

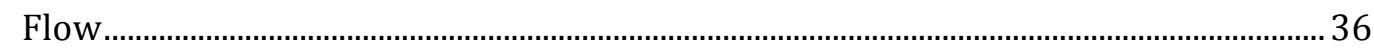

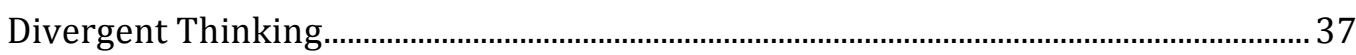

Problem solving and problem finding................................................................................. 38

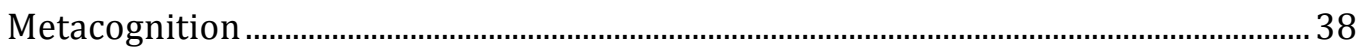

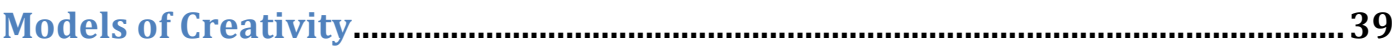

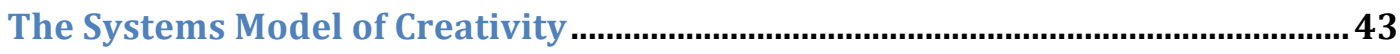

Fidelity to the values of the field .................................................................................... 46

Maximally and minimally structured domains ................................................................. 48

The Radius of Creativity......................................................................................... 51

Creativity as the communication of experience …....................................................53

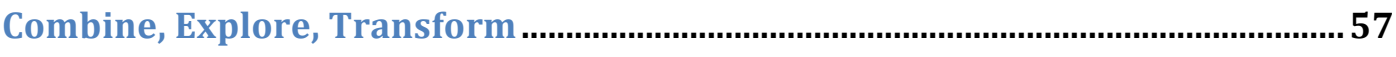

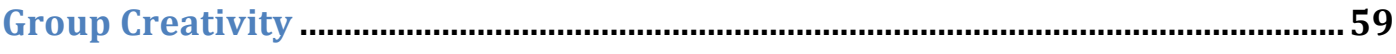

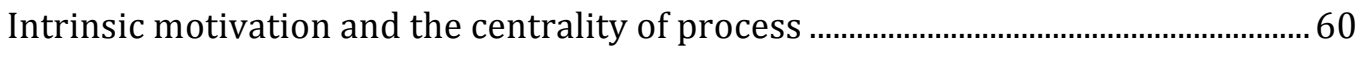

Improvisation, unpredictability and complex communication....................................6 61

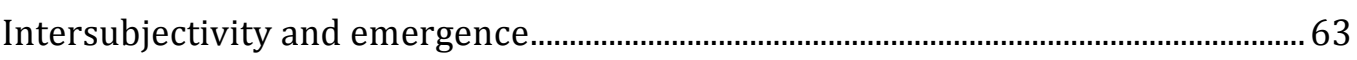

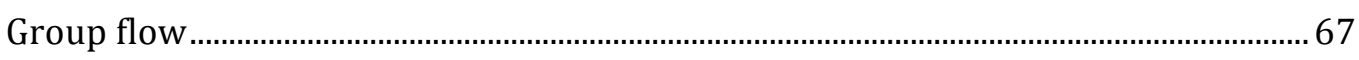

Summary of Group Creativity ……………………….............................................. 68

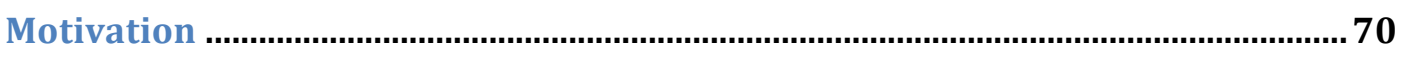

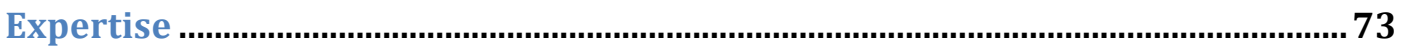

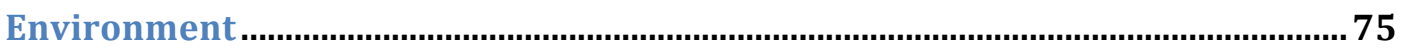

Groups

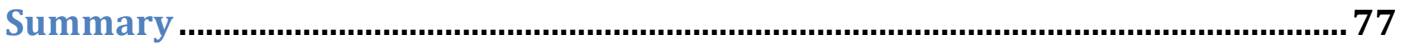


Chapter Two: Jazz..................................................................................................... 84

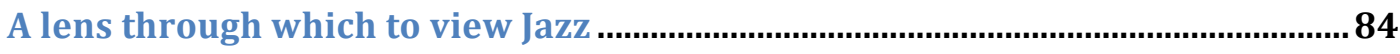

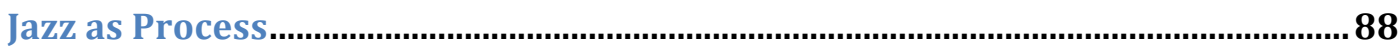

The development and expression of individual voices ...........................................93

Improvised interactivity in group settings .................................................................99

The place of the individual in the collective ………….......................................................99

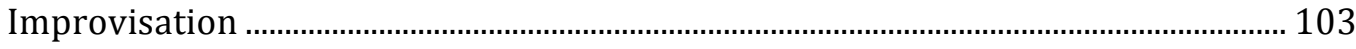

Appropriation and transformation........................................................................ 111

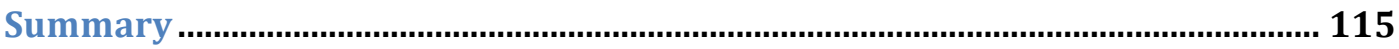

Part Two: Case Studies ........................................................................................117

Introduction to Part Two ..................................................................................118

Chapter Three: Ornette Coleman - Play Your Own Thing ..............................120

Ornette Coleman and the field of jazz ............................................................................... 121

Self-belief and intrinsic motivation ............................................................................... 124

Having the chance to perform ……………………….................................................... 125

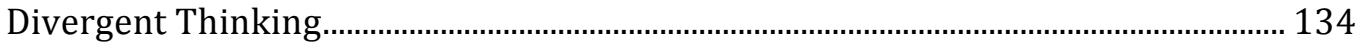

Coleman's compositional techniques ........................................................................... 136

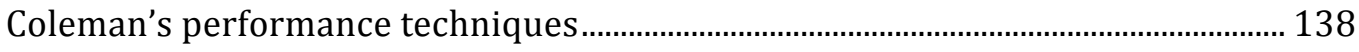

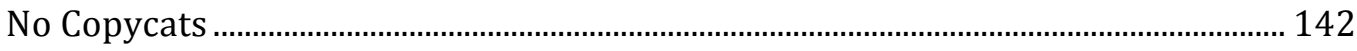

Chapter Four: Miles Davis - Alchemist ....................................................147

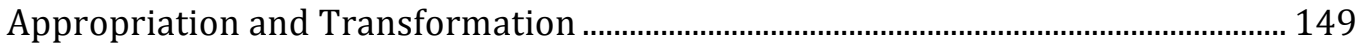

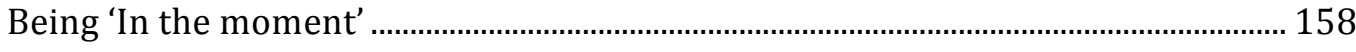

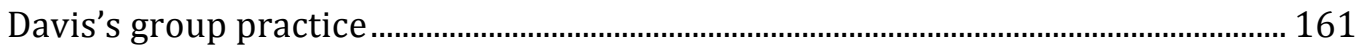

Davis's leadership styles ................................................................................................. 163

Where great art and music happens............................................................................. 173

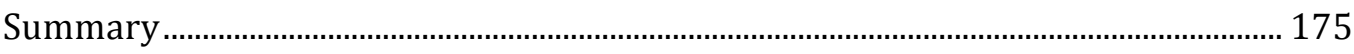

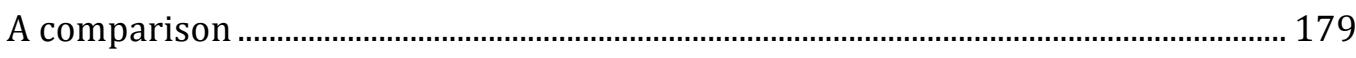

Chapter Five: Duke Ellington - Playing The Band ........................................184

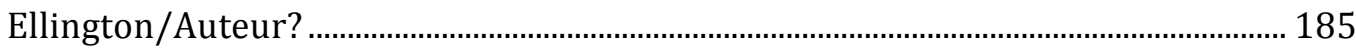

Ellington's Sidemen: Saying Something ……………............................................... 190

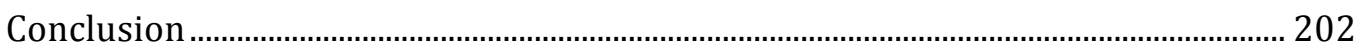

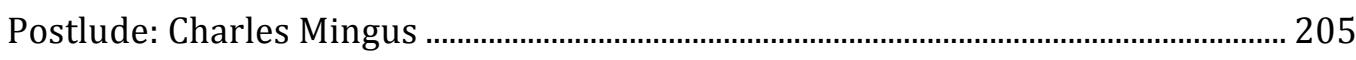

Chapter Six: Jan Garbarek - Future Jazz ........................................................211 
Appropriation and transformation in Garbarek's practice.

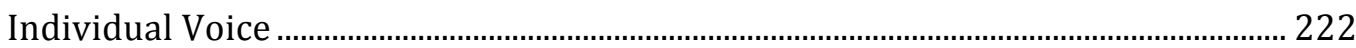

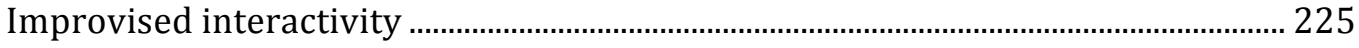

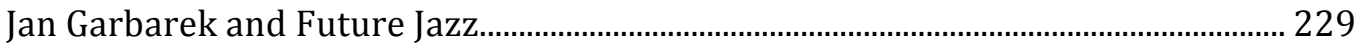

Conclusion ...................................................................................................................... 231

Afterword: Conclusions and Implications .................................................234

Conclusions

Implications: Telling the stories and teaching the music......................................... 238

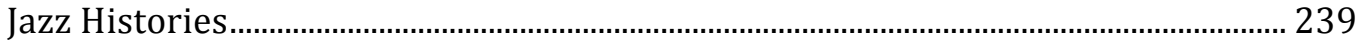

In the classroom

A benediction from Aotearoa ...................................................................................... 250

Appendix 1: Transcriptions ......................................................................253

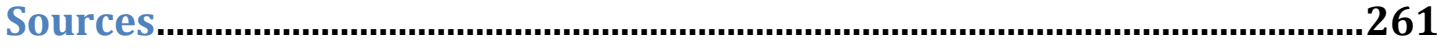

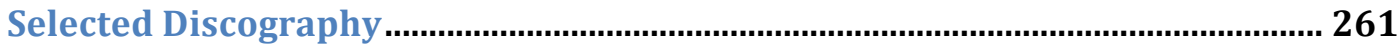

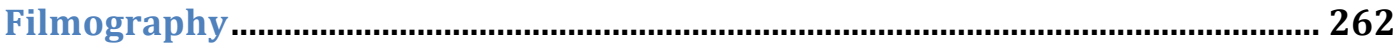

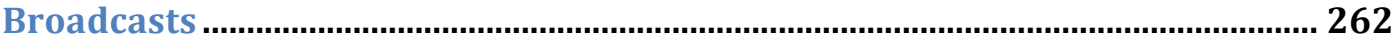

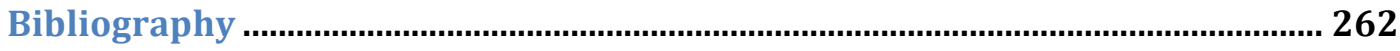




\section{Abstract}

Common discourses around jazz generally acknowledge the centrality of creativity to the music, but scholarship on what precisely creativity is in jazz, and how it might best be enhanced is not well developed. Building on the important work in this area begun by scholars such as Ed Sarath and R. Keith Sawyer, I first investigate the extensive scholarly literature on creativity, drawing predominantly from social science and education contexts, and then apply some of the most relevant frameworks to jazz. These frameworks draw several key aspects of jazz practice into sharp relief, in particular the respective roles of individuals and ensembles and the ways they work in common, and the provenance of musical materials in creative jazz practice. With these key ideas acting as a theoretical lens, I view the historical practice of three unquestionably creative jazz musicians: Ornette Coleman, Miles Davis and Duke Ellington. The choice of these musicians in particular is important because their example, when understood through the lens of creativity, in part authenticates some of the traditional tools by which we investigate jazz, historically, while at the same time pointing towards some different, less commonly discussed attributes. Most important, the creativity lens reveals important ways in which creative practice can be attributable to understandable procedures that are available to all accomplished musicians, not just a few "great men".

Thus my conclusions call into question more traditional modes of jazz history and criticism which, while acknowledging the music's collective nature, tend to emphasise the roles of individuals as primary in jazz. Instead, my research suggests that creativity is best achieved in group contexts where diversely gifted participants work collaboratively in egalitarian, interactive, improvised settings. Individuals do make significant contributions to this mix, and in terms of creative advances in jazz - and in terms of achieving meaningful self-expression - the most important quality individual musicians can pursue is the development and expression of unique musical voices. In addition to improvised interactivity among unique individual voices, the adoption of musical materials from outside of jazz and their transformations (along with similar transformations of musical materials already common currency among 
jazz musicians) can be shown to serve both the expressive goals of musicians and propel jazz in creative and potentially fruitful directions. It is the improvised colloquy of such individual voices, transforming received and newly acquired musical materials in the service of self-expression, that contributed to the lasting allure of the music attributed to Ornette Coleman, Miles Davis and Duke Ellington.

Saxophonist Jan Garbarek is proposed as a contemporary musician who has made use of all of these strategies in forging jazz music that demonstrates fidelity to the core processes of jazz while only provisionally embracing some of the style features of earlier forms of the music - style features that common jazz discourses have tended to emphasise at the expense of the processes that gave rise to them. 


\section{Acknowledgements}

Supervision

Dr. David Cosper

Professor Elizabeth Hudson

$\underline{\text { For advice and suggestions }}$

Dr. Barbara Morincini

Professor Donald Maurice

Professor Karol Berger

Professor Paul Erhlich

Professor Ingrid Monson

For reading, suggestions and questions, wisdom and perspective

Fergus Barrowman

George Mason

Suzi Kerr

... Thank you. 
PART ONE: CREATIVITY AND JAZZ 


\section{Introduction}

This thesis asks the questions: What is creativity in jazz? Is ongoing creativity in jazz possible? I suppose in a way these are strange questions. The words 'creativity' and 'jazz' are sometimes invoked in the same breath, and received wisdom suggests that jazz performers who improvise are amongst the most creative of all musicians. As Anthropologist Eitan Wilf has it, the 'cultural context that has come to epitomize the ethos of Western modernistic creativity [is] jazz music.' ${ }^{1}$ Certainly, jazz at its best is creative, and most knowledgeable listeners can recognise great jazz when they hear it. However, being able to say exactly what it is that is creative in the music - and to explain the conditions that might have produced such creativity - is another matter.

Because the products (or sounding objects) of great jazz (in concert or on recordings) are so alluring, it is easy to confuse these products with the processes from which they emerged. I wonder if it is for this reason that the discourses around jazz are often more concerned with products than process, with matter rather than manner? I wonder too, if our confusion over this distinction has led us unintentionally to emphasise some aspects of the music that are not necessarily creative, at the expense of aspects of the music that are? It is these questions that this thesis engages.

\section{Why are these questions important?}

The title of Stuart Nicholson's 2005 book asks, Is Jazz Dead? Or Has It Moved To A New Address? ${ }^{2}$ Rumours of the demise of jazz have been circulating for almost as long as we have had the music. Ruby Blesh and Winthrop Sargeant lamented the passing of Hot Jazz in the 1940s, and Hsio Wen Shih felt swing, the successor to Hot Jazz, endured a 'death by entropy' that same decade. Louis Armstrong feared

\footnotetext{
${ }^{1}$ Eitan Wilf, 'Rituals of Creativity: Tradition, Modernity, and the "Acoustic Unconscious" in a U.S. Collegiate Jazz Music Program’, American Anthropologist 114/1 (2012), 33.

${ }^{2}$ Stuart Nicholson, Is Jazz Dead (or has it moved to a new address)? (New York: Routledge, 2005).
} 
bebop would kill jazz, while John Tynan pointed the finger of blame at Ornette Coleman for music recorded in $1960 .^{3}$

Time magazine reported that 'Straight ahead jazz music almost died in the 1970s as record companies embraced the electronically enhanced amalgam known as fusion', ${ }^{4}$ and Scott DeVeaux has noted that some critics interpret the retrospective aesthetics that came to dominate jazz in the 1980s as 'all the evidence one might need that jazz is dead. ${ }^{5}$ More recently Benjamin Schwarz argued that jazz keeled over when the milieu that had provided much of its repertoire - the 'Songbook' of Tin Pan Alley - ceased to produce 'popular, sophisticated music [that] was aimed at musically knowledgeable adults'. He concludes, '[b]oth jazz and its progenitor are worthy of radical-indeed, reactionary-efforts to preserve them. But [...] there is no reason to believe that jazz can be a living, evolving art form decades after its major source-and the source that linked it to the main currents of popular culture and sentiment-has dried up. Jazz, like the Songbook, is a relic.'6

Possibly reflecting the rumoured demise of jazz, the financial situation of jazz musicians has become increasingly parlous. Jazz scholar David Ake reports, 'One NEA-sponsored study reveals that in 2000 almost 66 percent of San Francisco Bay Area's estimated 18,700 self-identified jazz musicians earned less than $\$ 7,000$ per year for their gigs. ${ }^{77}$ And in 2014 the New Orleans Jazz and Heritage Festival - presumably, given its name, a festival mooted to celebrate the idiom to which the city gave birth - boasted headline acts (the first six acts

\footnotetext{
3 Ruby Blesh, Shining Trumpets: A History of Jazz (New York: Alfred Knopf, 1946), 11; Winthrop Sargeant quoted in Scott DeVeaux, 'Constructing the Jazz Tradition', Black American Literature Forum 25/3 (Fall, 1991), 535; Shih, quoted in Ibid., 543; Ernest Borneman, ' 'Bop Will Kill Business Unless It Kills Itself First'-Louis Armstrong', Downbeat (7 April 1948). <http://www.downbeat.com/default.asp?sect=stories\&subsect=story_detail\&sid=1048> (7 April 2014); John Tynan, 'Critical Reception of Free Jazz', in Keeping Time: Readings in Jazz History, ed. Rob Walser (New York: Oxford University Press, 1999), 254-255.

4 Thomas Sancton, 'Horns of Plenty', Time (22 October 1990), 66.

5 DeVeaux, 'Constructing the Jazz Tradition', 527.

${ }^{6}$ Benjamin Schwarz, 'The end of Jazz: How America's most vibrant music became a relic', The Atlantic (November 2012) < http://www.theatlantic.com/magazine/archive/2012/11/the-endof-jazz/309112/> (7 April 2014).

7 David Ake, Jazz Matters (Berkeley: University of California Press, 2010), 9.
} 
identified on the website) including Eric Clapton, Bruce Springsteen, Christina Aguilera, Phish, Arcade Fire and Santana. The music was probably wonderful, but this lineup is not good news for jazz musicians seeking opportunities to ply their trade. ${ }^{8}$ Are the persistent rumours concerning the demise of jazz really exaggerated, or has jazz passed its use-by-date?

In the 1930s and early 1940s jazz was popular music and the stars of the idiom were household names. In the 1950s and 1960s jazz musicians were featured on the cover of Time magazine and jazz was played on popular radio. The music underwent extraordinary development and some of the most celebrated recordings of jazz were captured. Jazz, it would seem, was great. Mainstream jazz now, however, which was once an idiom populated by utterly distinctive individuals capable of surprising listeners and accomplishing the kind of dramatic re-inventions the music underwent between the 1920s and the 1960s can seem - on first appearances anyway - to be a shadow of its former self. The artists celebrated today in the most widely circulated jazz periodicals and in jazz education circles release albums and present concerts in which perfect instrumental skills are employed performing music of considerable technical sophistication. ${ }^{9}$ Some of this music, which is remarkably well achieved and which is sometimes greeted with adulation by audiences, can leave reviewers and commentators pretty cold; it leaves me pretty cold, too.

Music commentator Greg Tate believes that jazz is in a state of crisis - 'a crisis of stasis' - and asks, 'Why are there no young Black jazz musicians - as in under 45 - with as immediately recognisable a voice as Miles, Ornette and Cecil? Or Arthur Blythe and Henry Threadgill and David Murray, for that matter? What happened in the 1980s that made identity anathema and technical facility a mask for soul? Why hasn't there been one new standard written in jazz in almost

$8<\underline{\text { http://lineup.nojazzfest.com }>}$ (4 April 2014).

${ }^{9}$ The mainstream music I am talking about here is that predominantly featured in the jazz periodicals I encounter: Downbeat, Jazziz, Jazz Times, Jazz Improv Magazine and Jazz Journal. Online, there's AllAboutJazz.com. As a teacher of jazz a lot of my interactions are mediated by the educational milieu in which I am professionally engaged. In this context and from the periodicals listed there seems to be a reasonably strong and surprisingly consistent tacit message about what the mainstream of jazz is. Currently active jazz musicians whose music I really love include people like Ornette Coleman, Mike Gibbs, Peter Apfelbaum, Jon Balke, Tomasz Stanko and Paul Plimley. Coleman aside, these folk are not on the covers of these magazines, and are almost never mentioned in their pages. 
30 years?'10 Tate is not alone in expressing his concerns; they are echoed in the work of writers Stuart Nicholson, Geoff Dwyer and Eric Nissensen and in comments from musicians as respected as Pat Metheny, Anthony Braxton and Anthony Davis. ${ }^{11}$ It is a concern implicit in the work of musician and scholar George Lewis, and the musicians he cites. ${ }^{12}$

If this 'crisis of stasis' is real, what is the cause? Is this a function of the role of the academy ${ }^{13}$ and institutions such as Jazz at Lincoln Center in promulgating an approach to jazz that treats the styles of the past with more piety than the attitudes and processes that gave rise to those styles ${ }^{14}$ Is it a function of reissue programmes from the major record labels crowding the market to the point where new players have trouble making an impression? Is it a function of rapid advances in the technologies of dissemination, which have seen consumers offered more and more entertainment options and more and more music 'for free'? In the 1920s and 1930s radio and cinema were the main popular competitors to live music (although phonograph records were certainly emerging very rapidly as a significant competitor). Since then the advent of

${ }^{10}$ Greg Tate, in Howard Mandel, Miles, Ornette, Cecil: Jazz Beyond Jazz (New York: Routledge, 2008), xi. Tate is also referring to 'mainstream' jazz here - the 'Young Lions' in particular. I don't think 'creative' jazz simply stopped in the 1980s - but it appears that popular, critical and pedagogical attention turned to more conservative expressions of jazz.

${ }^{11}$ Nicholson, Is Jazz Dead? ; Eric Nisensen, Blue: The Murder of Jazz, (New York: Da Capo, 2000); Pat Metheny, quoted in Nicholson, Is Jazz Dead, 102; Anthony Braxton and Anthony Davis quoted in George Lewis, A Power Stronger Than Itself (Chicago: University of Chicago Press, 2008), 445.

12 Lewis's work, by drawing on the testimony of a number of experimental musicians, astutely critiques the mainstream field of jazz (which I elaborate in Chapter One) rather than the work of particular musicians. Lewis, A Power Stronger Than Itself, 441-447.

13 By which I refer to university-level jazz programmes. David Ake (Jazz Matters, 103-104) and Eitan Wilf ('Rituals of creativity') both point to the fundamentally altered context in which jazz occurs in the twenty-first century. Wilf summarises the situation as produced (and characterised) by 'The disappearance of thriving extracurricular jazz scenes, the decline in commercial demand for jazz, and the concomitant institutionalisation of jazz training in higher education' (33). In my view this has seen the rise of a kind of orthodoxy (which is fine), one presented for example by the now-defunct International Association of Jazz Educators, or the 'ABC' of jazz educators - (Jamey) Aebersold, (David) Baker and (Jerry) Coker. There are clear reasons why such orthodoxy emerged; see Ken Prouty, "The "Finite" Art of Improvisation: Pedagogy and Power in Jazz Education'. Critical Studies in Improvisation 4/1 (2008) <http://www.criticalimprov.com/article/view/346/966>. (12 May 2014).

${ }^{14}$ George Lewis suggests: 'The promulgation of a revisionist canon that emphasized a unitary, "classic" tradition of jazz eventually took on an institutional cast with the 1991 creation of Jazz at Lincoln Center (JALC) [...] the term "classical" became less a description of a musical tradition than of an attitude - one of reverence and preservation.' A Power Stronger Than Itself, 441-442. 
television, home cinema options (of which DVDs and flat screen televisions are only the most recent manifestation), home computers and the seeming infinitude of entertainment options made available through various types of games and the world wide web has meant that going out to hear music is now only one option among many, one that requires an investment of time to travel and often high concert or club prices. Even sales of recordings - which have at times been a useful adjunct to the incomes of musicians as well as an effective means for disseminating music - have seen a dramatic decline in recent years. ${ }^{15}$ Maybe it is simply that jazz, like Western Swing perhaps, or David Cassidy, was popular music of a historical moment, and that moment has passed? Perhaps the crisis of stasis Tate identifies is a function of all of these things: of life in a world of accelerated change and increasing uncertainty, which has seen music shaped by reactionary agendas in the service of nostalgia ${ }^{16}$ Or have the musicians who play jazz simply lost their way ${ }^{17}$

Greg Tate suggests, 'The question of what jazz signifies today besides great chops has been at issue since the 1990s [...] besides history, nostalgia and professionalism, does all of today's virtuosity signify a lick? [...] The spirits of Ellington and Su Ra are arguably more alive in any hip hop record than in any jazz released over the last quarter century.'18 Tate attributes what he sees as lassitude to a failure on the part of jazz musicians to link their art to 'cultural resistance movements'. Jazz violinist Leroy Jenkins, similarly disappointed with the conservatism of jazz in the 1990s, blames reactionary strategies on the part

\footnotetext{
15 This trend has fundamentally affected the economics not only of jazz, but also popular and classical music as well.

16 When the Glenn Miller Orchestra toured New Zealand in 2013 (almost 70 years after Miller's death) they sold out 21 of their 28 shows around the country (in mainly large venues; those shows that did not sell out were close to sold-out). Leroy Jenkins suggested (in 1997) that in the 1980s records were released that mimicked the models of the past: '...record labels pursuing younger musicians playing music more familiar to people [because] "this is what should sell".' Jenkins, quoted in Lewis, A Power Stronger Than Itself, 446.

17 These ideas have been canvassed in numerous books and articles that have explored the notion that jazz is in decline. For example: Stuart Nicholson, Is Jazz Dead?; Larry Kant, 'Provocative Opinion: The Death of Jazz'. Black Music Research Journal 10/1 (Spring 1990) 76-81; Marc Meyers, Why Jazz Happened (Berkeley: University of California Press, 2012); Nisenson, Blue.

18 Greg Tate, 'Black Artists Group', Wire, 329 (July 2011), 56-7.
} 
of record companies, and implicates the college training of jazz musicians in his calculation. ${ }^{19}$ As long ago as 1988 jazz historian Ted Gioia suggested that a lot of jazz was simply boring. ${ }^{20}$

Yet by some measures jazz is in excellent health: more records are being made than ever before; more students are graduating from more schools with a level of facility and musical understanding that were unimaginable to most musicians just 60 years ago; college jazz programmes themselves have grown by an astonishing degree, and are now represented alongside classical programmes in almost every top-level conservatory in the United States and elsewhere. ${ }^{21} \mathrm{Jazz}$ enjoys the endorsement of institutions as august as Lincoln Center and has been recognised by the United States Congress as a National Treasure. ${ }^{22}$ But if Tate and Gioia (and Nicholson and Metheny and others) are right, then something has been lost.

When I first encountered jazz (around 1980) it was the most exciting music I had ever heard. Something about the feeling I got from the music energised me in ways that Supertramp, Pink Floyd and Tom Petty and the Heartbreakers just didn't. The music of Miles Davis and Chick Corea and Dave Brubeck and Billy Cobham and Keith Jarrett thrilled me to such an extent that the other music to which I was listening seemed to fade away. It is a fascination that has stayed with me, and I now find myself a senior academic in a jazz programme at a university trying to assist young musicians in their pursuit of

${ }^{19}$ Lewis, A Power Stronger Than Itself, 445-446.

20 Ted Gioia, The Imperfect Art (Stanford: Standard Alumni Association with Oxford University Press, 1988).

21 Jazz.about.com lists more than 300 university level programmes in the United States alone offering jazz papers and programmes.

<http://jazz.about.com/gi/o.htm?zi=1/XJ\&zTi=1\&sdn=jazz\&cdn=entertainment\&tm=29\&f=00\& $\mathrm{tt}=14 \& \mathrm{bt}=8 \& \mathrm{bts}=8 \& \mathrm{zu}=\mathrm{http} \% 3 \mathrm{~A} / / \mathrm{www}$.jazzinamerica.org/JazzResources/JazzEducation/Page $>$ (8 April 2014).

${ }^{22}$ H.Con.Res.57. < http://www.hr57.org/hconres57.html> (April 8 2014) Together, these counter arguments suggest that the sites in which jazz is currently flourishing are institutionalised sites; this in turn may suggest that the field of jazz (which I explain in Chapter One) has shifted from being predominantly steered by the market and musicians to one determined more by pedagogues and federally funded institutions. Given the ritualised values (see Chapter One) championed by such agencies, growing conservatism in jazz is perhaps inevitable. On jazz education, see Prouty, 'The "Finite" Art of Improvisation'. On the institutional status of jazz and the conservatism required of such status, see Lewis, A Power Stronger Than Itself, 443-444. 
this music. And yet it is rare that I will put on a new record from a contemporary artist and feel the thrill that I did the first time I heard Miles play 'My Man's Gone Now' or Chick Corea's 'Spain'.23 Of course I am now a lot older, I know a lot more and have heard a lot more; back then it was all new, so the thrill then and the lack of thrill now shouldn't be a surprise. But from time to time I still get that feeling listening to a new album or contemporary artist, and in those moments, and on reflection subsequent to those moments, I can't help thinking that something fundamental has changed; that the sense of discovery and newness in the music that I first heard more than 30 years ago and that still thrills me - even after hundreds of plays - is missing from so much of the jazz I hear being made now. It does seem to me that uncertainty, spontaneity, flying-by-the-seat-of your-pants-ness, the feeling that the musicians aren't quite sure what's going on but they'll make something up anyway - that creativity - is a significant part of what I value in jazz. I used to feel like the musicians were discovering something for the first time, and so was I, and that it mattered. And now it feels like we're all just going through the motions.

My motivation for seeking to understand what creativity is, and what it might look like in jazz contexts, is two-fold. First: I suspect my own practice as a musician (and as a listener to this music) can be enriched by a clearer understanding of creativity and its role in jazz; and second, because I want to be able to communicate with my students - students in Aotearoa/New Zealand, far away from the purported heartland of jazz - a better understanding of what it is that I believe is so fundamentally important about jazz. Not just what is intriguing, or technically remarkable, or beautiful (although those qualities have value for me too), but what is actually important. ${ }^{24}$

\footnotetext{
23 Miles Davis, We Want Miles, Columbia C2 38005, 1981; Chick Corea, Light As A Feather, Polydor 2310 247, 1972.

${ }^{24}$ Many years ago guitarist Geoff Hughes said to me 'Jazz is about freedom'. It was a statement that struck a chord for me. I might put some qualifiers around such a statement now, but fundamentally there may be a lot of truth to Geoff's claim. I think such freedom is one of the 'important' things about jazz. In the U.S. it may be that such a claim assumes political resonance, but in Aotearoa/New Zealand I suspect the freedom associated with jazz has more to do with individual experience and agency. Jazz in Aotearoa (amongst the musicians that I have spoken with about this, anyway) is first, it would seem, a sound and a feeling, something linked to personal expression, and an opportunity to say something musically.
} 
This study considers what creativity is and interrogates its role in jazz. At heart, it seems to me, jazz practice is a creative practice; it's a notion that is widely taken for granted, as well. However, there aren't many good explanations that really illuminate what makes jazz creative. There is a great deal of writing by journalists and commentators, scholars and educators about historical developments in jazz; about the formal and stylistic conventions of the idiom; about the materials jazz musicians use when they improvise; about the social and political contexts in which jazz musicians have operated. But discussions of creativity in jazz (which I survey in Chapter One) generally strike me as inadequate. For people committed to developing a deep understanding of the music - and for musicians, an understanding that can be reified in creative jazz practice - these other aspects of the music that scholars and educators focus on are important. However, while historical and social context, technique and familiarity with the conventions of the idiom are necessary for jazz, they are not sufficient. What more is required? By using ideas promulgated by creativity researchers to fashion a lens through which to view jazz, it becomes possible to address that question.

Examining jazz in light of the nature of creativity yields (at least) two different intuitions. On the one hand, it can seem to illuminate aspects of jazz practice that we already understand to be good and intuit to be creative. On the other hand, however, it draws attention to aspects of the music, and of particular musicians' work, that might seem obvious and that are in fact often mentioned, but the consequences of which are not generally celebrated, explored, and applied by either scholars or educators. While I discuss aspects of jazz practice that are widely accepted to be creative in this thesis, it is this second set of values - those often mentioned but not widely examined or applied - with which I am primarily concerned. My hypothesis is that using an understanding of creativity to assay jazz will allow us to comprehend aspects of great jazz practice in new ways; and that moreover, these insights may offer a challenge to current practice and to educators, because it illuminates aspects of the jazz tradition that are sometimes undervalued.

To examine creative jazz requires selection of a representative sample, and my choices are obvious ones - musicians widely regarded as 'great' and 
accepted as being creative. However, looking to the so-called 'jazz greats' to define what can make jazz great is a double-edged sword. Advantageously, study of most canonical jazz figures (Louis Armstrong, Duke Ellington, Lester Young, Charlie Parker, John Coltrane et al.) reveals them to be musicians with individual approaches (or 'voices') whose work was to some degree at odds with preceding practice and yet effectively communicated something to their audiences. What is less helpful is that the work of these musicians has sometimes been characterised solely in terms of its sounding features - Armstrong's melodic vocabulary; the harmonic games of Ellington's music; Count Basie's swing feel; Parker's rhythmic complexity - thus generating a checklist of style features that have been used to define the jazz tradition. The burden of such a tradition can become a prescriptive force (and I get the sense that this has been the case for the last twenty or thirty years, and perhaps before that, too ${ }^{25}$ ) and the tension between creativity and faithfulness to the (usually stylistic) mores of that tradition have been recognised to have stifled creativity in jazz performance, at least to a certain extent. ${ }^{26}$ This tension has had real consequences for jazz musicians. Trombonist Bob Brookmeyer recalled that the acceptance of the bebop idiom as the lingua franca of jazz in the 1950s meant that some musicians - musicians whose work was unquestionably creative but who failed to conform to the style conventions of bebop and related styles - were denied opportunities to work, presumably because they were somehow out of step with 'real jazz'.27

\section{The central idea}

My central argument rests on the idea that if jazz is to remain a vital music, it is more fruitful to view the music in terms of its processes than its products. ${ }^{28}$

\footnotetext{
${ }^{25}$ Witness Charles Mingus's comments about the slavish imitation of Charlie Parker that so bothered him during the 1950s. Brian Priestly, Mingus: A Critical Biography (New York: Da Capo, 1982), 70.

${ }^{26}$ Paul Rinzler, The Contradictions of Jazz (Lanham, MA: The Scarecrow Press, 2008), 124-134; Ed Sarath, Improvisation, Creativity and Consciousness (Albany: SUNY Press, 2013), 150-154.

${ }^{27}$ Nicholson, Is Jazz Dead?, 114.

${ }^{28}$ As suggested earlier, emphasis on exemplary style features potentially removes focus from the practise of particular musicians, musicians whose work is valuable because it effectively communicated with audiences by offering something a little different to what had been available before. That difference may have been subtle or revolutionary, but understanding how these
} 
Scholarly emphasis on the processes of jazz is not new, and in the last 20 years quite a bit of groundbreaking work has focused on these processes. This scholarship (which I survey in Chapter Two) has in some cases adopted an analytical focus, which necessarily turns attention to the nature of the musical materials. While this work has been tremendously valuable, it has tended to retain (and in some cases assume as an unquestioned basis) an emphasis on the style features of the music. ${ }^{29}$ What creativity research invites us to do, alternatively, is to focus on broader questions of process that are not tied to the specific surface features of the music. Adopting a view of jazz from the standpoint of creativity offers us a way of discussing musical procedures that bypasses issues around genre definition in jazz. Which is to say, such an approach valorises process as primary and acknowledges surface details and style features only as the sounding manifestations of those processes. These emergent sounding properties, as wonderful as they might be, are the fruit rather than the tree, and therefore (when using creativity as our theoretical lens) a secondary concern.

Creativity research draws attention to three processes that are already widely recognised as intrinsic to jazz at various historical junctures: the development of individual ideas (and in particular, individual 'voice'); collective, interactive practice that makes use of improvisation as an enabling strategy for creative work; and appropriation and transformation of (received and newly acquired) materials. However, viewing these processes as they occur in jazz through an array of concepts drawn from creativity research encourages us to focus on aspects of those processes that might seem obvious to practising musicians, but that are not commonly explored in the context of historical, critical or theoretical work on jazz. By adopting this approach, I hope this thesis supplements the important discussions of jazz found in the work of scholars who have attended to the music's processes; these include Paul Berliner, Ingrid

musicians arrived at something different provides testimony to the way(s) they exercised personal agency in making that music.

${ }^{29}$ For example, Paul Berliner's exceptional study of jazz processes in Thinking in Jazz: The infinite art of improvisation, (Chicago: University of Chicago Press, 1994) tends to place emphasis on the sounding products of those processes. This is very useful analytically but can also (intentionally or not) reinforce genre boundaries defined in terms of style. 
Monson, Travis Jackson and others. While these scholars write about the process dimension of the music and argue for its appropriate status, this thesis advances on their work by examining the mechanics of what those processes might involve. In adding dimensions to their work, I hope to be able to offer insights that may be useful for stimulating creativity for jazz musicians in ways that a) are compatible with the jazz practice I find most inspiring, and b) might propel their work into interesting and potentially surprising directions.

\section{Thesis Plan}

\section{Part One: Creativity and Jazz}

In order to understand some of the key drivers of creativity in jazz musics, I lay out my basic perspective in two opening chapters. To explore the possibilities for the ongoing presence of creativity in jazz, I will begin in Chapter One by cherry-picking a number of definitions, understandings and models of creativity that are applicable to jazz from the current (and very extensive) scholarly literature on creativity. I also consider the ways that creativity models have been previously applied to jazz. In addition, this chapter mines scholarship that identifies conditions conducive to creativity, in order to isolate what might constitute good practice for enabling creativity in jazz contexts.

In Chapter Two, I turn to jazz itself. I begin by identifying some key practices that have informed jazz, historically, in order to propose a constellation of ideas that together provide a fruitful lens through which to view subsequent jazz practice. This theoretical lens - valorising as it does process over product - offers a view of jazz practice that draws attention to values that are isomorphous with those emphasised as conducive to creativity in academic discourses on creativity. If jazz is a creative discourse, I am seeking to find ways to map what I understand to be the central principles of creativity onto that (jazz) discourse. By drawing attention to the processes themselves it becomes possible to tell a subtly different story about jazz; one that reveals the sources of creativity in historical jazz practice and which might be useful in fostering creative practice for musicians going forward. 


\section{Part Two: Creativity in Jazz}

Following the conceptual frame proposed in Part One, the second part of the thesis offers a number of case studies that primarily consider the music and practice of four jazz musicians and the musicians associated with them whose work (in their ensembles) illustrates the principles I have drawn out in Part One, and that can be used to formulate some principles that may enable creative jazz practice generally. Because jazz musicians are vitally active agents in all aspects and processes of the music they make - as composers, improvisers, performers, leaders and sidemen - they are not simply faceless intermediaries between an absent composer and an ideal audience. In light of this, and as many scholars have found, the testimony of musicians is extremely useful if we are to understand the creative processes engaged in the making of jazz. ${ }^{30}$ Thus, following models of jazz scholarship that privilege the testimony of participants in jazz performance, ${ }^{31}$ I draw on the accounts of the musicians involved: accounts that are subjective, opinionated and speculative. Bruce Johnson has suggested that this approach is itself a notable feature of studies that perceive jazz to be significantly more process than product focused, stating:

A major problem with these Modernist based accounts is that they do not take sufficient account of the actual circumstances in which the music is produced, central to which is the performer at the moment of performance. ${ }^{32}$ I suggest that this is one reason why the 'voice' of jazz is more vivid in the anecdotes of its exponents than in the analyses of critics [...] The shift in attention from the art work to the conditions of its production and consumption is leading to a focus on those moments in the lives of the participants which are not clearly visible in the art work, moments which are necessary in the continuous process of its

\footnotetext{
30 This approach differs from that of scholarship dealing predominantly with the sounding objects musicians produce (and in many cases, scores of that sounding object). Much jazz analysis up to the 1990s made use of such approaches, and includes work by Gunther Schuller, Steve Larsen, Henry Martin, Barry Kernfield. Other approaches have included phenomenological studies (for example, Greg Smith) and the adoption of linguistic models (for example, Jeff Pressing). Useful surveys of a range of approaches are found in John Brownell, 'Analytical Models of Jazz Improvisation', Jazz Research 26 (1994), 9-29; and Gary Potter, 'Analyzing Improvised Jazz', College Music Symposium 32 (1990), 143-60.

31 See: Berliner, Thinking in Jazz; Ingrid Monson, Saying Something: Jazz Improvisation and Interaction (Chicago: University of Chicago Press, 1996); R. Keith Sawyer, Group Creativity: Music, Theatre, Collaboration (London: Lawrence Erlbaum Associates, 2003); Travis Jackson, Blowin' the Blues Away: Performance and Meaning on the New York Jazz Scene (Berkeley: University of California Press, 2012).

32 Johnson is referring specifically to the modernist frame adopted in Gioia's The Imperfect Art and Chris Goddard's Jazz Away From Home (New York: Paddington Press, 1979).
} 
production and reception, and which sometimes acquire a brief incandescence which frames them as 'anecdote', in which seems to be concentrated the meaning to which all the other unnoticed but necessary moments contribute. 33

Clearly the circumstances of production are germane to the purposes of this thesis, but the sounding objects that emerge from those moments also have important things to tell us about the music. Accordingly, my account will give consideration to both.

My historical case studies examine the music and musical processes of Ornette Coleman, Miles Davis and Duke Ellington. Although there are many other musicians I could have included to illustrate the points I wish to make, these musicians are good choices because all are more or less universally accepted as members of the jazz guild, and in all cases their work and practices have been extensively documented, providing the material necessary to construct the case studies. I also include a discussion of Jan Garbarek in my penultimate chapter. Garbarek is useful for my purposes because he is not African-American. He is not even from the United States. Introducing Garbarek allows me to suggest ways in which the lessons drawn from the musicians I examine in the case studies might be applied in generalisable ways, which is to say, applicable to constituencies not geographically and culturally tied to the birth-place of jazz, but who have adopted the processes jazz entails. It is my hope that these generalisable lessons may, in turn, suggest possible future directions for jazz creativity.

I begin by discussing saxophonist Ornette Coleman (b. 1930). Coleman's music provides an excellent insight into the ways individuals (and groups) negotiate the fields that make determinations about the acceptability of their work. As an illustration of Mihaly Csikszentmihalyi's Systems Model of creativity Coleman is exemplary, and consideration of the reception of his work over time provides clear evidence of the way fields ${ }^{34}$ sometimes take a little while to catch up with their most innovative practitioners. ${ }^{35}$ Further, Coleman's example

\footnotetext{
33 Bruce Johnson, "Hear me talkin' to ya: problems of jazz discourse," in Popular Music 12/1 (1993), 10.

34 'Fields' and 'domains' will be fully explained in Chapter One.

35 Mihaly Csikszentmihalyi, Creativity (New York: HarperCollins, 1996).
} 
emphasises the self-belief, intrinsic motivation and divergent thinking that are often required of practitioners whose work troubles the limits of the domains in which they operate.

My discussion of trumpeter Miles Davis (1926-1991) reveals the applicability of Jason Toynbee's Radius of Creativity model to jazz, illuminating the ways genre constraints influence reception of music as it moves closer to or further away from the constellation of values that define a genre. ${ }^{36}$ Related to the ways Davis's music troubled genre constraints, we find in his work a variety of approaches to music making. These include musical exploration using the conventions of the genre, and exploration that admits and transforms materials and procedures from outside of jazz. Where Davis mixed in elements from outside of jazz, his work moved commensurably further away from the genre's centre. This movement affected critical and public reception of his work in a number of different ways and directions.

We already know a great deal about Davis and his performance practices. If viewing jazz through the lens of creativity provides further nuance to familiar discussions about Davis and his role in jazz history, it is found in the elaboration of those working practices - which might be termed routine (for Davis) - and that provides us with different insights into aspects of Davis's extraordinary impact on the field. By looking at the nature of Davis's leadership style in relation to key concepts of creativity, it becomes clear that it was the way he acted in relation to other musicians that fostered some of the most unusual creative work in the field of jazz.

As a kind of afterword to this chapter I offer a comparison between Miles Davis's practice and that of one of his most celebrated sidemen, pianist Bill Evans. I do so to reveal the utility of Davis's approaches as a means to produce creative music that troubles the limits of the jazz genre. I contrast Davis's work with that of Evans, which appears to achieve a crystallisation of the style features of the genre more than any transgression of them.

My third case study, which focuses on Duke Ellington and several of his sidemen, elaborates an idea introduced in Chapter One: that creativity is

\footnotetext{
36 Jason Toynbee, Making Popular Music (London: Arnold, 2000).
} 
valuable not only because it provides new and useful ideas, but also because creativity is a means by which individuals can exercise agency. With this idea as a basis, it becomes possible to explore how creative practice in jazz can be understood both in terms of individuals and their agency, and in relation to the dynamic of the collective. Such discussion points to a dichotomy that exists between a discourse that celebrates jazz 'greats' (the heroic individuals that populate jazz histories) and an understanding of the essentially collective processes that characterise almost all jazz. Rather than forcing a choice between these poles, the grid of creativity instead reveals the interrelationship of the two.

The final chapter discusses the possible implications of an emphasis on creative processes for current and future jazz as manifest in the music and practice of Jan Garbarek. The trajectory of Garbarek's development and career in some ways mirrors that of many of the noteworthy musicians of jazz, but while employing very similar processes, he draws from a different pool of musical materials. Garbarek strikes me as a potent example of a musician who has adopted the processes of jazz without being too attached to some of the style features that were emergent qualities of those processes when practised by the North-American musicians in my case studies. The robustness of Garbarek's work illustrates the translatability of these processes to other musical traditions, and given the historical moment in which they emerged, might reasonably suggest fertile avenues of exploration for jazz musicians now and in the coming years.

Finally, I offer an afterword that proposes some conclusions and possible implications that might be drawn from this thesis. This passage is meant as a meditation rather than as some kind of 'state of the jazz nation' denouement. Given that the values I emphasise as most important to jazz as a creative practice are not entirely congruent with those that have primarily informed many jazz discourses (and in particular college jazz curricula and most jazz histories), I briefly touch on what the central ideas of this thesis might mean for those institutions. I have framed these ideas mindful of the Aotearoa/New Zealand context from which I view and practise the music, and in which I endeavour to teach it. 


\section{Chapter One: Creativity, and its importance}

\section{Why is creativity important?}

Creativity is a very fashionable word in this new century, and it is used as much in discussions about business practice and in self-help books as in relation to the arts or their psychological, sociological and anthropological underpinnings. The generally tacit subtext of much of this literature is that creativity is good, something we all aspire to achieve. Psychologist Dean Simonton describes creativity as an 'exceptional human asset.' ${ }^{37}$ In purely economic terms, a recent article in The Atlantic claimed 'Creative workers are good for the economy,'38 while others have suggested creativity is 'often essential for personal and professional success. ${ }^{\prime 39}$ Lars Rhyammar and Catarina Brolin point out that creativity in Greek, Judaic, Christian and Islamic traditions was initially considered sufficiently virtuous as to be attributable to divine inspiration. ${ }^{40}$ Complementing this subtext of virtue, a common theme in much of the current popular literature focused on creativity is that there are things we can do or behaviours we can adopt that will see us experience more creativity in our lives. ${ }^{41}$ This perspective is particularly evident in books in the popular press that promote themselves as 'how-to' manuals on creativity, and include authors

\footnotetext{
37 Dean Simonton, 'Creative Wisdom: Similarities, contrasts, integration and application', in Creativity, wisdom, and trusteeship: exploring the role of education, ed. Anna Craft and Howard Gardner and Guy Claxton (Thousand Oaks, CA: Corwin Press, 2008), 68.

38 Richard Florida, 'Why Creative Workers Are Good For The Economy', The Atlantic (September 13, 2013) <http://www.theatlanticcities.com/jobs-and-economy/2013/09/real-reasoncreative-workers-are-good-economy/6804/> (17 February 2014).

${ }^{39}$ Chi-Ying Cheng and Jeffrey Sanchez and Fiona Lee, 'Connecting the dots within Creative Performance and Identity Integration', Journal for the Association for Psychological Science 19/11 (2008), 1179.

${ }^{40}$ Lars Rhyammar and Catarina Brolin, 'Creativity Research: Historical considerations and main lines of development', Scandinavian Journal of Education Research 43/3 (1999), 259-237.

41 See: James Kaufman. Creativity 101 (New York: Springer Publishing Company, 2009); Robert Sternberg and Todd Lubart, 'The concept of creativity: prospects and paradigms', in Handbook of Creativity, ed. Robert Sternberg (Cambridge: Cambridge University Press, 1999), 3-15.
} 
concerned with business and with the arts. ${ }^{42}$ The 'how-to' theme is also present, though to a lesser extent and more as a subtext, in the academic work of some scholarly writers dedicated to the subject. ${ }^{43}$

It would appear that the main, common-sense reason creativity is valued in these conversations, and is such a familiar talking point in the press, in policy circles and even in business schools, is because the products that arise from creative work are useful (and indeed indispensable in some cases) as drivers of industry and the economy. ${ }^{44}$ Evidence of creative products' usefulness and economic utility is everywhere around us, from pencil sharpeners to penicillin, from tetra packs to touch-screen phones, and modern life and the modern economy would be unimaginable without the extraordinary creativity that has furnished the present-day world with the goods and ideas we take for granted.

Further, creativity is often presented as the capacity that will equip workers for the changing world in which we live. A Canadian Ministry of Education document states: 'In view of the new social and economic realities, all students, regardless of their immediate plans following school, will need to develop a flexibility and versatility undreamed of by previous generations $[\ldots$

42 A very brief survey of the popular literature on creativity at the beginning of 2014 ranges from the somewhat breathless, Creativity Workout: 62 Exercises to Unlock Your Most Creative Ideas; or, Creativity: NOW! Top Keys to Unleash Your Creativity, Come Up With Brilliant Ideas and Increase Your Productivity; and ARTstarters: A Spiritual Process for Using Creativity and Art-Making to Ignite Your Life: More than 100 creative prompts and projects to spark inspiration! to the (slightly) more sober: Steal Like An Artist: 10 Things Nobody Told You About Being Creative; Creative Confidence: Unleashing the Creative Potential Within Us All and Creativity, 63 short exercises to a Happier Life. Scholars who have written for this market include Csikszentmihalyi (1996) and Sawyer (2006).

43 For example: Teresa Amabile, 'How to kill creativity', Harvard Business Review (September 1998), 77-87; Billy Collins and Teresa Amabile, 'Motivation and Creativity', in Handbook of Creativity, ed. Robert Sternberg (Cambridge: Cambridge University Press, 1999), 297-312; Raymond Nickerson, 'Enhancing Creativity', in Handbook of Creativity, ed. Robert Sternberg (Cambridge: Cambridge University Press, 1999), 392-430.

44 For example: Florida, 'Why Creative Workers Are Good For The Economy'; Annie Paul, 'What the jazz greats knew about creativity', Time (12 March 2012).

<http://ideas.time.com/2012/03/21/learning-creativity-from-the-jazz-greats/> (29 April 2014); for policy relevance see: Bob Jeffrey and Anna Craft, 'The universalization of creativity,' in Creativity in Education, ed. Anna Craft and Bob Jeffrey and Mike Leibling (London: Continuum, 2001), 1-13; Anna Craft, 'Tensions in Creativity and Education: Enter wisdom and trusteeship? In Creativity, wisdom, and trusteeship: exploring the role of education, ed. Anna Craft and Howard Gardner and Guy Claxton (Thousand Oaks, CA: Corwin Press, 2008), 16-34. The Harvard Business School has made creativity a focus in aspects of its curriculum through the work of Professor Teresa Amabile. See < http://hbswk.hbs.edu/topics/creativity.html> (18 February 2014). 
and] employ critical and creative skills to solve problems and make decisions.' ${ }^{45}$ Ken Robinson, a well-known champion of creativity, observes that we live in an extremely unpredictable world with a very uncertain future. He concludes that:

I believe our only hope for the future is to adopt a new conception of human ecology [...] We have to [...] avert some of the scenarios we've talked about, and the only way we'll do it is by seeing our creative capacities for the richness they are, and seeing our children for the hope that they are. Our task is to educate their whole being so they can face this future. ${ }^{46}$

All of the above constitute compelling reasons to valorise creativity, and if these commentators are correct, the benefits of understanding and enabling creativity appear to be vitally important for the ongoing prosperity - and perhaps even survival - of the human species.

Creativity is also particularly highly valued in the arts. In common with discussions about creativity in industry, science, business and education, creativity is frequently valued in artistic contexts for the products that emerge from it. In these contexts creativity is usually celebrated because it leads to new work and propels artistic fields forward. Painters such as Henri Matisse and Pablo Picasso, writers including James Joyce and T.S. Eliot and composers Igor Stravinsky and Arnold Schoenberg (among others) are celebrated not primarily because their craft was good, but because their innovative thinking propelled their disciplines in new and valuable directions. However, as important as the products of creativity are in the context of this thesis, focusing as it does on artistic creativity in the domain of music, the experience of creativity and the salutary affects that experience has on the lives of those who engage with it are perhaps even more significant.

Psychologist and creativity researcher Raymond Nickerson emphasises such personal values in his discussion of creativity: 'Creative expression is usually desirable, because it usually contributes positively to the quality of life of the individual who engages in it and often enriches the lives of others as well.'47 Philosopher Jonathan Rowson makes the case even more strongly:

\footnotetext{
45 Quoted in Craft, 'Tensions in Creativity and Education', 17.

${ }^{46}$ Ken Robinson, 'How schools kill creativity', TED talk (February 2006)

$<$ http://www.ted.com/talks/ken_robinson_says_schools_kill_creativity.html>. (17 February 2014).

47 Nickerson, 'Enhancing Creativity', 392.
} 
[T] he most fundamental reason we value creativity is that we tacitly associate it with the experience and expression of free will. Our creativity often manifests as a capacity, within the systems, structures and events that shape us, to go beyond our conditioned reactions and be more effectively responsive within those constraints. ${ }^{48}$

Musicologist Keith Negus and cultural theorist Michael Pickering develop this idea more fully, linking creativity to the development of selfhood:

The aim of self-creation requires appropriate models, and chief among these is art. The link forged between artistic creation and self-discovery or self-making remains important as an alternative resource to religious faith, or to scientism and the 'iron cage' of reason. Ideas about creativity have become integral to the modern sense of individuality because the sense of being ourselves implies expressing ourselves, in speech and in action, and so arriving at what is distinct and special about us, or what it is we strive toward. 49

Such a definition links creativity to our notions of selfhood as actors in the world, and as such perhaps defines values we yearn for not only as individuals, but also as communities, in business, and as nations. If creativity is in fact a key to understanding ourselves and achieving whatever it is we strive towards, it is little wonder that whatever creativity is, it is widely embraced as a virtue both for its material products and for the more subjective personal and communal benefits people gain from engaging with it.

\section{Creativity in Music?}

Although music is commonly associated with creativity, for the most part literature making explicit links between music and creativity is sparse relative to more general literature on creativity..$^{50}$ Of the numerous books and articles published that specifically address creativity in music contexts, many focus primarily on composition as the principal site for musical creativity. The work of

\footnotetext{
48 Jonathan Rowson, 'How are we disposed to be creative?', in Creativity, wisdom, and trusteeship: exploring the role of education, ed. Anna Craft and Howard Gardner and Guy Claxton (Thousand Oaks, CA: Corwin Press, 2008), 85-86.

${ }^{49}$ Keith Negus and Michael Pickering, Creativity, Communication and Cultural Value (London: Sage, 2004), 8-9.

50 The literature dedicated to creativity is admittedly extensive and includes a number of dedicated journals and numerous sub-disciplines. As a field creativity research is thought to have begun around 1950 with J. P. Guilford's presidential address to the American Psychological Association on the subject. For reasonably complete surveys of the literature to date, see Kaufman, Creativity 101; Mark Runco, Creativity. Theories and Themes: Research, development and practice (San Diego: Elsevier Academic Press, 2007).
} 
David Cope and Guerino Mazzola, Joomi Park and Florian Thalmann for example, makes use of semiotic approaches to consider the processes of composition (and improvisation in the case of Mazzola et al.) and propose computer models that reproduce those processes. ${ }^{51}$ While this work has some bearing on the present discussion, emphasis on composition as a procedure that generally involves a single actor operating outside of a fixed temporal frame means these scholars emphasise different processes from those privileged in the moment-to-moment improvised performances of jazz ensembles - the focus of this dissertation. ${ }^{52}$

Education appears to be the discipline that has produced the most creativity research in music. A useful summary of the many perspectives educationalists consider when thinking about creativity is found in Creativity and Music Education. ${ }^{53}$ Recent work by Irene Deliege and Geraint Wiggins (Musical Creativity: Multidisciplinary Research in Theory and Practice) represents a useful step forward for the field in that along with composition and education, the writers consider further generative musical activities (performance, improvisation) as well as other sites of musical creativity including reception, analysis, modeling and music therapy. The relative paucity of research linking musical practice and creativity (amongst creativity studies) was underscored by

\footnotetext{
51 David Cope, Computer Models of Musical Creativity (Cambridge, MA: MIT Press, 2006); Guerimo Mazzola, Joomi Park and Florian Thalmann, Musical Creativity: Strategies and Tools in Composition and Improvisation (New York: Springer Publishing Company, 2011). Conflating composition and improvisation is common: Lucy Green (Music, Gender, Education, (Cambridge: Cambridge University Press, 1997)) speaks of 'the total dissolution of composition into performance as in the free improvisation of modern jazz.' (83). As Ed Sarath argues however, the distinctions between the two practices comprise more than just how they relate to the time taken to complete them ('A New Look at Improvisation', Journal of Music Theory 40/1 [Spring, 1996], 1-38).
}

52 Fundamentally, the frame of reference in Cope's (et al.) work, privileging as it does the work of composers, is at best tangential to discussions of jazz. As Lydia Goehr suggests (in The Imaginary Museum of Musical Works: An essay in the philosophy of music [Oxford: Oxford University Press, 2007]), in western art music traditions creative work has been fixed in the act of composition, thus defining composers as 'creative', and performers as 're-creative'. This historically situated frame, which is taken for granted in relation to the classical tradition, is disrupted by jazz, where performers exercise considerable autonomy in the act of performance.

53 Timothy Sullivan and Lee Willingham (Eds.) Creativity and Music Education (Montreal: Canadian Music Educators' Association, 2003). 
a reviewer of Deliege and Wiggins's volume, who believed that the book was the first 'devoted entirely to this phenomenon.'54

Amongst scholarship devoted to jazz and germane to this thesis, creativity is frequently mentioned and generally advanced as a marker of positive value, but is rarely theorised in a rigorous way. For example, Scott Reeves's optimistically titled Creative Jazz Improvisation offers about a page of discussion on creativity (in very general terms), followed by more than 200 pages of style analysis. ${ }^{55}$ Albert Murray, in a paper entitled 'Improvisation and the Creative Process', suggests he will 'talk about the nature of the creative process; about improvisation, which has to do with how you do what you do [...and which requires that one] know everything to do with what in jazz is called "the break"; and that is what improvisation has to do with.'56 And yet creativity is not in any way defined in this paper, nor is it made clear how it relates to improvisation.

Lloyd Peterson's Music and the Creative Spirit: Innovators in Jazz, Improvisation and the Avant Garde usefully locates creativity in the practice of improvising musicians, many of whom theorise that practice in useful ways. ${ }^{57}$ However, comprising only relatively brief interviews with musicians, ideas about what constitutes creativity are not rigorously interrogated and the range of conditions under which it might occur is not systematically explored. Paul Rinzler offers some useful insights into creativity in jazz contexts, but relative to my focus on processes in jazz, his work adopts an alternate lens and yields different insights. ${ }^{58}$ Elina Hytönen-Ng's book Experiencing 'Flow' in Jazz Performance offers a qualitative survey of jazz musicians' experiences of flow

\footnotetext{
54 Petri Toiviainen, 'Review [untitled]', Music Perception: An Interdisciplinary Journal 25/3 (February 2008), 257.

55 Scott Reeves. Creative Improvisation (New Jersey: Prentice Hall, 1988). By style analysis I refer to the melodic, harmonic and rhythmic features that Reeves emphasises. ${ }^{56}$ Albert Murray. 'Improvisation and the Creative Process', in The Jazz Cadence of American
Culture, ed. Robert O’Meally (New York: Columbia University Press, 1998), 112.

57 Lloyd Peterson. Music and the Creative Spirit: Innovators in Jazz, Improvisation and the Avant Garde (Lanham MA: The Scarecrow Press, 2006).

58 Paul Rinzler, The Contradictions of Jazz (Lanham, MA: The Scarecrow Press, 2008).
} 
states in jazz contexts. ${ }^{59}$ As such her work offers collaborative testimony to the claims made by creativity researchers, particularly with regard to the conditions conducive to creative practice. However, creativity itself is discussed only tangentially in the text: her work is more concerned with documenting the subjective experiences of her informants.

Edward Sarath's recent book Improvisation, Creativity and Consciousness offers many useful insights into creativity in music and jazz in particular. ${ }^{60} \mathrm{His}$ work is significant to the current thesis in two important respects (although his thought permeates my work in more general ways too). First, Sarath's understanding of jazz as a tradition that accommodates trans-traditional practice is useful in discussions of Jan Garbarek's music in Chapter Six and lends weight to the conclusions I draw about the need for the kind of syncretic procedures evident in Garbarek's work. Second, Sarath's ideas have significantly informed my own ideas about the possibilities for creative education in musical contexts (and particularly in jazz), and which are discussed in the afterword to this thesis. However, Sarath's emphasis on contemplative studies and meditation are somewhat orthogonal to my approach; I locate jazz within the ambit of a set of procedures that differ from those championed by Sarath. 61

Another writer (along with Sarath) whose work deeply engages with creativity in jazz contexts is education and creativity researcher Keith Sawyer. ${ }^{62}$ Sawyer's work is extremely relevant to this study and in particular usefully addresses questions around the ways groups operate in some jazz settings. The main limitation of his work (vis a vis its relevance to this study) is that the view he adopts toward jazz is limited to small group practice in very conventional settings. ${ }^{63}$ Further, even though Sawyer is a practising jazz musician, the critical

\footnotetext{
59 Elina Hytönen-Ng, Experiencing 'Flow' in Jazz Performance (Farnham: Ashgate, 2013).

60 Sarath, Improvisation, Creativity and Consciousness.

61 I don't disagree with Sarath's formulation; I am simply offering a different set of emphases.

62 Jason Toynbee, whom I also invoke, makes use of jazz to illustrate some of the principles his work promotes, but to a far lesser degree than Sawyer.

63 'Conventional' meaning consistent with standard post-bop practice in terms of instrumentation, repertory and performance approaches.
} 
lens he employs in considering jazz is that of a social scientist. ${ }^{64}$ In order to make his (very good) arguments, Sawyer accepts a fairly monolithic view of jazz practice, one that will be familiar to anyone conversant with the orthodoxy many college jazz programmes embrace. The definition he offers for ('canonical' small group) jazz comprises adoption of particular 'scales, harmonic patterns, and styles [drawn from 'jazz greats']' and a repertoire centred on song-forms or standards. ${ }^{65}$ While Sawyer acknowledges 'the importance of breaking with tradition, of going beyond the domain definition', his rhetoric consistently emphasises agreed, conventional musical vocabularies and forms.'66 Finally, Sawyer's arguments hinge on jazz musicians being solely intrinsically motivated. Which is to say, Sawyer claims musicians play jazz only because they want to play it, not for any other reward. As my discussion of jazz in Chapter Two reveals, jazz musicians constantly negotiate economic concerns (and thus financial reward) in their professional lives. ${ }^{67}$

Despite the ways in which creativity would appear to be under-theorised in jazz contexts, and particularly with regard to the socially contingent generative processes that have consistently characterised the music (Sarath and Sawyer excepted), creativity writ large (a very complex phenomenon) has in fact been much discussed over the last sixty years; there is a considerable and burgeoning literature dedicated to inquiry into the nature and workings of

\footnotetext{
${ }^{64}$ Sawyer, Group Creativity, 29.

65 Ibid., 31.

66 Ibid., 53-54.
}

${ }^{67}$ I don't wish to diminish Sawyer's work in any way, but given his focus on group creativity generally (rather than jazz practice specifically) he necessarily adopts a circumscribed and somewhat idealised view of jazz practice. (Idealised, for example in that he claims that for jazz groups 'the process is the product and there is no other external goal.' [30] As Scott DeVeaux [The Birth of Bebop: A social and musical history \{Berkeley: University of California Press, 1997\}] clearly explains jazz musicians are variously motivated and there is rather more to their ongoing involvement with the idiom than simply the pleasure of playing.) Such a view will almost always admit modest levels of group creativity (and occasionally more extreme creative advances) but does not adequately take into account the development and importance of individual 'voices'. This means that while many of the claims Sawyer makes are tremendously useful to this thesis (and are frequently cited), they are of limited applicability to the more broadly defined jazz practice this work traverses. 
creativity. ${ }^{68}$ In particular, many scholars have addressed creativity from psychological and sociological perspectives, theorising creativity in ways that are generalisable and yet also pertinent to this study. ${ }^{69}$ Rather than summarising all of those findings, I will draw a number of key ideas from that literature germane to this thesis. I begin by presenting a concise definition of creativity as agreed by many social scientists, but expand that to include what has been called 'routine creativity'. I follow this with a discussion of some of the common forms creative behaviours take.

The second section of this chapter comprises a survey of five models of creativity that I employ to explore jazz. Included with this section is a rationale defending the ideas I have included (and those I have omitted) in making my selection. The final section of this chapter explores the conditions that researchers have identified as being most conducive to creativity. I conclude the chapter with a summary of the ideas explored and gesture toward their implications for the study of creativity in jazz.

\section{Defining creativity}

Given the variety of reasons creativity is valued (of which only a few are rehearsed in any detail here) and the wide range of contexts in which creativity is said to be significant, it is unsurprising that defining creativity has been a fraught endeavour. The growing interest in creativity over recent years has been accompanied by numerous discussions about precise definitions of the concept, but a lack of a standard definition for creativity remains. This lack has been discussed by Robert Sternberg, Calvin Taylor, Howard Parkhurst and James Kaufman among others. ${ }^{70}$ Jonathan Plucker (et al.) suggests that this lack of an agreed-upon definition poses numerous problems for the study of creativity:

\footnotetext{
${ }^{68}$ For reasonably extensive summaries, see: Sternberg and Lubart, 'The concept of creativity', 315; Runco, Creativity; Kaufman, Creativity 101; Marissa Mayer, 'Fifty years of creativity research', in Handbook of Creativity, ed. Robert Sternberg (Cambridge: Cambridge University Press, 1999), 449-460.

${ }^{69}$ Cognitive science has also significantly contributed to creativity research, with many dedicated studies and volumes, but that research is beyond the scope of the present inquiry.

70 Robert Sternberg, 'A three-facet model of creativity', in The Nature of Creativity, ed. Robert Sternberg (New York: Cambridge University Press, 1988), 125-147; Calvin Taylor, 'Various
} 
Without a clear definition, creativity becomes a hollow construct - one that can easily be filled with an array of myths, co-opted to represent any number of processes, and further confuse what is (and is not) known about the construct. ${ }^{71}$

Drawing from a survey of then-recent literature, these writers go on to propose a 'synthesised definition' of creativity:

Creativity is the interaction among aptitude, process, and environment by which an individual or group produces a perceptible product that is both novel and useful as defined within a social context. (Original emphasis) ${ }^{72}$

Psychologist and creativity researcher James Kaufman acknowledges this as perhaps the most useful definition available and paraphrases it as, 'the how (ability and process) and the where and when (environment) made by the who (individual or group) making the what (a specific product both new and useful). ${ }^{73}$ Kaufman proposes that what it boils down to is this:

Creativity must represent something different, new, or innovative. [...] Unlike 'originality', simply being novel is not enough to qualify as 'creative' [...] because creativity must be appropriate to the task at hand. A creative response is useful and relevant. ${ }^{74}$

The combination of novelty and utility gives rise to the most common definitions of creativity, which run along the lines of: creativity manifests as outcomes that are novel and useful or relevant (which is to say, appropriate to their context). And here's the rub: what is novel in one discipline may be routine in another; what is useful or appropriate in one domain may be of little or no use, or completely inappropriate in other domains. Thus understanding or even identifying creativity is entirely contingent upon its context.

approaches to and definitions of creativity', in The nature of creativity, ed. Robert Sternberg (New York: Cambridge University Press, 1988), 99-121; Howard Parkhurst, 'Confusion, lack of consensus, and the definition of creativity as a construct', Journal of creative behavior 33 (1999), 1-21; Kaufman, Creativity 101. For an extensive summary, see Jonathan Plucker, Ronald Beghetto and Graham Dow, 'Why isn't creativity more important to educational psychologists? Potential, pitfalls, and future directions in creativity research', Educational Psychologist 39 (2004), 83-96.

71 Plucker, Beghetto, and Dow, 'Why isn't creativity more important', 90.

72 Ibid.

73 Kaufman, Creativity 101, 52. Kaufman adds that when considering motivation and creativity a central concern of the literature - the "how" becomes a particularly important consideration. This understanding is both recent and contingent. Ideas about what creativity might be, and what sparks it, have changed considerably over time. For a useful (and succinct) history of conceptions of creativity see Keith Sawyer (Explaining Creativity: The Science of Human Innovation (New York: Oxford University Press, 2006.). In particular, his critique of Romantic notions of creativity is salutary in considering artistic work (15-18).

${ }^{74}$ Kaufman, Creativity 101, 19. 
Plucker et al. suggest that creativity is only made evident by the 'perceptible products' that arise from its action. ${ }^{75}$ These perceptible products may be principally apparent in material objects (perhaps a new kind of bicycle), in new ideas (Newton's theory concerning thermodynamics, say), or acts manifest in performance (an improvised theatre piece, for example). If creativity is to do with novelty and usefulness or appropriateness, then it is by examining creative outcomes that we can test their novelty and usefulness/appropriateness, and so determine if they are in fact the results of creativity as defined by these researchers.

However, by placing so much emphasis on the products of creative action, such definitions discount the value of the experience of creativity, and the salutary effects that experience has on the lives of those who engage in creative work. As I indicated in the Introduction, Negus and Pickering suggest that 'Ideas about creativity have become integral to the modern sense of individuality because the sense of being ourselves implies expressing ourselves. ${ }^{76}$ If creativity only occurs where novel and useful products or ideas are generated, where does that leave routine practice in musical performance, or in an amateur's execution of a watercolour painting, or a home-gardener working out where to plant annuals? Such practices rarely offer anything particularly new to the sum total of human knowledge and yet reward those who accomplish such work at least some kind of personal expression. The work of Negus and Pickering is helpful in this regard. ${ }^{77}$ They observe that the ways in which the meaning of the word creativity (in relation to music, although the principles are generalisable) has changed over time obligates us to 'move away from elitist conceptions of creative exclusivity and consider creativity in its more mundane forms. ${ }^{78}$ In order to do so, these writers place emphasis upon processes of production, and propose an alternate, inclusive definition of creativity to sit alongside the more

\footnotetext{
${ }^{75}$ See also: Csikszentmihalyi, Creativity, 23-25; David Perkins, The Mind's Best Work (Cambridge, MA: Harvard University Press, 1981), 6-7.

${ }^{76}$ Keith Negus and Michael Pickering, 'Creativity and musical experience', in Popular Music Studies, ed. David Hesmondhalgh and Keith Negus (London: Arnold, 2002), 8-9.

77 Ibid., 9.

78 Ibid., 189.
} 
commonly accepted exclusive definitions. In rough and ready terms these contrasting approaches to defining creativity can be summarised as:

1. An exclusive definition: Where creative action leads to the generation of products that are novel and useful/appropriate to their context.

2. An inclusive definition: Where creative action may be 'a task executed with considerable skill, a problem solved with imagination and panache, an act performed with grace, vivacity or élan, or even an interpretation of a particular artifact such as a song [...] which is judged to be particularly insightful, or at least ingenious. ${ }^{79}$

For these authors, separating exceptional creativity from routine practice (which they describe as 'routine creativity') is to look only for greatness, divorcing creativity from its contingent place in time and space. An approach capable of accommodating these two modes of practice (exceptional and routine) suggests a different view of creativity, one especially fertile for this study. It is a view that Negus and Pickering develop into a model of creativity that is useful to this thesis and that I will explore in detail below (Models of Creativity).

\section{What does creativity look like?}

In order to understand fully the models of creativity that I discuss below, it will be helpful first briefly to sketch out some of the characteristic appearances of creative action: in particular, flow; divergent thinking; problem solving and problem finding; and metacognition. Defining each of these terms is also useful in that they provide vocabulary for my general discussion of creative practice in jazz found in Chapter Two, and for isolating particular aspects of creative practice in the case studies in Part Two of this thesis. All of these terms were coined or originally applied to creativity in general creative contexts. However, flow and problem solving/problem finding have been specifically invoked in discussions of creativity in jazz. ${ }^{80}$ At the conclusion of this section I will discuss the ways in which the work of this thesis extends earlier applications of these terms to jazz.

\footnotetext{
${ }^{79}$ Negus and Pickering, 'Creativity and musical experience', 181.

${ }^{80}$ Sawyer, Group Creativity, 39-47; 167-170; 104-106.
} 
Russian composer Pyotr Ilyich Tchaikovsky wrote:

It would be vain to try to put into words that immeasurable sense of bliss which comes over me directly [when] a new idea awakens in me and begins to assume a definite form. I forget everything and behave like a madman. Everything within me starts pushing and quivering; hardly have I begun the sketch ere one thought follows another. ${ }^{81}$

The experience Tchaikovsky describes here is an example of what well-known psychologist and creativity expert Mihaly Csikszentmihalyi calls 'flow'. When in flow 'people are so involved in an activity that nothing else seems to matter; the experience itself is so enjoyable that people will do it even at great cost, for the sheer sake of doing it.'82 In flow states - sometimes characterised as 'optimal experience' - individuals usually feel that their abilities are a match (or even an exact match) for the challenges of the task they confront. ${ }^{83}$ In this respect training and/or experience are an essential precursor to flow. The effect of achieving flow, where training, experience, and focus on the task at hand combine, is that participants are not self-conscious or worried about failure; they are undistracted by what is around them, and their sense of time is often distorted. ${ }^{84}$ Keith Sawyer describes such a distorted sense of time as being a kind of 'non-consciousness,' and reports that performers, particularly those involved in improvised group activity, believe that 'non-conscious' experience is an important part of their creative work:

Improvisers believe that their performances are better when they are maximally non-conscious. Yet performers realize that some conscious awareness is always essential: The inner performance state must be balanced with a simultaneous awareness of the other performers, and of the conventions, etiquette, and expectations of the genre..$^{85}$

\footnotetext{
81 Quoted in Jason Toynbee, 'Music, Culture, and Creativity', in The Cultural Study of Music: a critical introduction, ed. Richard Middleton (New York: Routledge, 2003), 103.

82 Mihaly Csikszentmihalyi, Flow: The Psychology of Optimal Experience (New York: Harper and Row, 1990), 4.

${ }^{83}$ Kaufman, Creativity 101, 36-37; Sawyer, Group Creativity, 41.

${ }^{84}$ Csikszentmihayi, Creativity, 112-113

85 Sawyer, Group Creativity, 107-126.
} 
Sawyer contrasts group work, where 'the non-conscious contribution is reported to be salient, continuous and essential', with occasions where individuals act in greater isolation and where creativity is thought to be predominantly the result of conscious processes. ${ }^{86}$ Flow and flow states are important for this study, particularly in group settings, because they are thought to provide conditions optimal for creativity. I will develop these ideas more fully in my discussion of group creativity later in this chapter.

\section{Divergent Thinking}

Divergent thinking is a concept and disposition often considered when creativity is discussed. This concept - which can be briefly defined as thought processes or intellectual method(s) that produce unique, original and innovative (which is to say, creative) ideas by considering many possibilities - emerged from psychologist Joy Paul Guilford's work. ${ }^{87}$ Guilford conceptualised creative thinking in four categories: fluency (how many ideas); flexibility (different types of ideas); originality (uniqueness of ideas) and elaboration (amount of detail in ideas). Divergent thinking depends most upon fluency, flexibility and originality, and is contrasted with convergent thinking. Convergent thinking is that which is measured by IQ tests and may involve finding solutions to well-defined problems; such thinking could be described as iterative. Mihaly Csikszentmihalyi elegantly summarises Guilford:

Divergent thinking leads to no [previously] agreed upon solution. It involves fluency, or the ability to generate a great quantity of ideas; flexibility, or the ability to switch from one perspective to another; and originality in picking unusual associations of ideas. 88

As we shall see, creativity isn't only (or simply) divergent thinking, but divergent thinking is a vitally important part of accepted understandings of creativity, and a useful concept in thinking about some of the forms creativity has taken in jazz.

\footnotetext{
${ }^{86}$ Sawyer, Group Creativity, 68.

87 Joy P. Guilford, The nature of human intelligence (Columbus. OH.: McGraw-Hill, 1967).

${ }^{88}$ Csikszentmihalyi, Creativity, 60.
} 


\section{Problem solving and problem finding}

Creativity often involves solving problems, but the act of finding problems has also exercised creativity researchers. Keith Sawyer suggests:

A "problem finding" painter is constantly searching for the visual problem while painting - improvising a painting rather than executing one. In contrast, a problem-solving style involves starting with a relatively detailed plan for a composition and then simply painting it; "problem solving" because the painter defines the visual problem before staring, with the execution of the painting consisting of "solving" the problem. ${ }^{89}$

Sawyer considers problem finding to be a manifestation of divergent thinking, and as such integral to the process of creative work in real-time. To begin with a plan that is seen through to completion is the province of the craftsperson; whereas 'The unexpected turn, something which the artist himself does not definitely foresee, is a condition of the felicitous quality of a work of art; it saves it from being mechanical.'90 The French artist Marcel Duchamp understood the importance of problem finding. Once, when visiting an art school, he observed a painter working on a canvas and asked the artist what he was doing. 'I don't know what the fuck I'm doing' the painter replied. Duchamp reportedly patted the man on the back and advised, 'Keep up the good work.' ${ }^{91}$ As the testimony of musicians discussed in Chapter Two and Part Two of this thesis will reveal, not knowing what one is doing (in the context of a discipline in which one is expert) can be a valuable aspect of an improvising musician's practice.

\section{Metacognition}

Related to problem finding and important in the study of creativity more generally is metacognition, 'the ability to monitor one's own learning, perform self-evaluation and then make plans accordingly.' ${ }^{92}$ It is an important index of creativity, and numerous studies reveal that individuals with high metacognitive

\footnotetext{
89 Sawyer, Group Creativity,105.

90 John Dewey, quoted in Sawyer, Group Creativity, 106.

${ }^{91}$ Morton Feldman and Bernard Friedman, Give My Regards to Eighth Street: Collected Writings of Morton Feldman (Cambridge: Exact Change, 2000), 167.

92 Kaufman, Creativity 101, 93.
} 
ability are able to identify their limitations, address those limits and accurately estimate their success in a given endeavour. ${ }^{93}$ In the context of this study metacognition manifests in two ways: as an ex post evaluation of work that leads to modified practice going forward; or in the moment-to-moment evaluations that practitioners make during the course of performance.

Scientists and scholars from many disciplines have developed models to describe the processes that lead to creative action, models that draw attention to these four characteristic appearances of creative practice (flow, divergent thinking, problem finding and metacognition). In the next section I will summarise a number of models that employ these concepts, models that I make use of in examining jazz and analyzing my case studies in Chapter Two and Part Two of this thesis.

\section{Models of Creativity}

The models of creativity I focus my attention on in this chapter were selected from amongst a number of available models. My selection was informed by the subject of study, namely, music as a mode of cultural production. The nature of my sample (sound recordings and secondary sources relaying the testimony of participants in jazz) and the substance of the scholarship that provides a lens through which I view it (cultural and theoretical discussions of jazz and its cultural, social and musical contexts) meant that cognitive science models of creativity were not appropriate, focusing as they do on brain function, the relationships between intelligence and behaviour, and their roles in creativity. While cognitive science enquiry is no doubt instructive, it seems less immediately relevant to the essentially social and cultural practice of jazz performance as examined in this thesis. ${ }^{94}$

\footnotetext{
93 The capacity for self-reflective work may be related to self-efficacy (or self-belief: 'I think I can, I think I can') and studies suggest higher self-efficacy is associated with higher creativity. (See Kaufmann, Creativity 101, 94, for a summary of this research.) The claim that there is a relationship between self-reflective work and self-efficacy tallies with the claims many jazz musicians have made about the importance of confidence and self-belief.

94 For a survey of cognitive science and creativity, see Ronald Finke, Thomas Ward, and Steven Smith, Creative Cognition: Theory, Research, and Applications (Cambridge: Bradford Books, 1996).
} 
There are other scholars whose work I did not find particularly useful. Joy Paul Guilford and E. Paul Torrance, for instance, scholars well known for their work on creativity, were of limited application to this project for similar reasons: they are primarily concerned with the structure of the intellect and consequent relationship to creativity and the relationship between creativity and intelligence respectively. ${ }^{95}$ There is also an extensive literature that links madness and other pathologies to creativity. While there are probably interesting parallels that could be drawn between such pathologies and the practice of some jazz musicians, the exclusive focus that literature places on individuals is at odds with my emphasis on ensemble jazz.

Among other models considered and discarded are those of: Graham Wallas (predicated on an idea disavowed by David Perkins ${ }^{96}$ ), which to some extent is a common sense application of planning with a dose of metacognition (if the model were to be applied to jazz performance); Joseph Rossman, who builds upon Wallas's ideas usefully, but whose model is more applicable to scientific enquiry than to cultural practice, I think; Alex Osborn (who developed brainstorming), whose model I like and might have been used here, although applying his seven-step process to the creative practices of jazz musicians probably wouldn't have revealed very much more about those practices than was obvious from the act of parsing them into those steps in the first place. There are numerous other models too, which have been helpfully summarised by Silvano Arieti in his book Creativity: The Magic Synthesis. ${ }^{97}$ For the most part, these models seemed unable to accommodate the variety of practice I have found amongst the jazz musicians considered. The five models I have adopted each tells a part of the story, and as such can be combined in useful ways that make sense of the music and the musicians I am considering.

\footnotetext{
95 Guilford, The nature of human intelligence; Torrance, E. Paul. Torrance test of Creative Thinking: Directions manual and scoring guide (Bensenville, IL: Scholastic testing Service, 1966). A useful summary of Guilford and Torrance's work is found in Kaufmann, Creativity 101, 15-16.

96 Perkins, The Mind's Best Work, 49-73.

97 Silvano Arieti, Creativity: The Magic Synthesis (New York: Basic Books, 1976). A more recent survey has been complied by Paul Plsek, 'Models for the Creative Process' (1996) <http://www.directedcreativity.com/pages/WPModels.html> (24 March 2014).
} 
As a general principle, I accept Thomas Kuhn, Jason Toynbee, Howard Becker and Keith Sawyer's claims that creativity is primarily socially achieved: that creativity is the product of groups rather than individuals. While I do not discount the possibility that individuals can achieve creative outcomes working alone, for the purposes of this study - which focuses on ensemble jazz performance - a social paradigm makes the most sense to me. In light of this, some well-known writers who might normally be expected to be included in a study of creativity - such as Edward DeBono - have been omitted because their work focuses on areas that are marginal to my central, social focus. ${ }^{98}$ While such omissions narrow the focus of my work, I believe such a narrowing deepens the work rather than impoverishes it.

I begin with Mihaly Csikszentmihaly's Systems Model of Creativity, because it offers a disciplinary view of creativity, describing the ways a range of participants in particular domains (or disciplines) act as gatekeepers for their domain. ${ }^{99}$ This model also makes distinctions between different kinds of domains and the degree to which they accommodate variation. Both of these phenomena are significant to my discussion of jazz in Chapter Two because what is and is not considered jazz is contested by various factions of the field (that is, the gatekeepers), and because in some ways those disagreements come down to what it is considered acceptable to vary, or include, or omit, when playing jazz. These notions have obvious consequences for the sounding objects that musicians produce.

The second model I discuss is sociologist Jason Toynbee's Radius of Creativity Model. ${ }^{100}$ Toynbee's model is particularly useful for this study because it makes comprehensible the way artistic work ranges from being so much a crystallisation of the style features of a particular genre that it might be said that creativity has not occurred at all, through to artistic work that is so eccentric that it is in fact rejected by the field (and so from the domain) in which it occurs.

\footnotetext{
${ }^{98}$ Edward DeBono's work on a domain-general dimension of creativity (Lateral Thinking [New York: Harper Colophon, 1973]) would be difficult (and perhaps capricious) to empirically demonstrate given the sample I am using.

${ }^{99}$ Csikszentmihalyi, Creativity.

100 Toynbee, Making Popular Music.
} 
This model dovetails elegantly with Csikszentmihaly's Systems Model, and provides a useful lens for understanding different kinds (and degrees) of variation that may be accommodated within particular domains.

The third model examined is Negus and Pickering's understanding of Creativity as the Communication of Experience. ${ }^{101}$ Two aspects in particular make this model applicable to my thesis. First, the writers' acceptance of an inclusive definition of creativity (as described above) provides a means to accommodate much of the 'routine creativity' that is part and parcel of the working lives of artists in all kinds of genres (including jazz musicians). Second, this model locates moments of creative breakthrough (or paradigm shifts) in the context of routine practice, an approach that makes sense of many of the moments of game-changing creativity in jazz, some of which are discussed in Part Two.

The fourth model I consider is perhaps more a taxonomy than a model as such, but Margaret Boden's framework of Combine, Explore, Transform offers an excellent rubric for understanding various mechanisms of creative action. ${ }^{102}$ Boden's model is useful in interpreting why certain creative work occupies particular spaces in Toynbee's Radius of Creativity model, and also helpfully distinguishes between different kinds of creative work in the domain of jazz as examined in Chapter Two of this thesis.

Finally, I discuss Keith Sawyer's model of Group Creativity. ${ }^{103}$ Sawyer's model is particularly significant because it underscores the role of the ensemble or group as being indispensible to the creative moment, and illustrates the importance of improvisation, group flow and emergence, all of which generally characterise jazz performance (as discussed in Chapter Two).

Of the five models I make use of, only Keith Sawyer's model of group creativity has been applied to jazz in significant degree. To some extent my conclusions reflect his, but differ in two important ways. First, my analysis includes specific examples of exceptional creativity where the constraints of the

\footnotetext{
101 Negus and Pickering, Creativity, Communication and Cultural Value.

102 Margaret Boden, 'Creativity: How does it work?', in The Idea of Creativity, ed. Michael Krausz, Dennis Dutton and Karen Bardsley (Boston: Brill, 2009), 237-250.

103 Sawyer, Group Creativity.
} 
genre were exceeded as a result of group action (something Sawyer's work implies may be possible, but does not elaborate in any detail). In some of the instances I examine the genre of jazz was advanced (or at least changed) as a result of this creativity, an eventuality Sawyer's work does not really address. Second, I examine instances when group practices have been deliberately unsettled by leaders in ways that result in enhanced creative practice on the part of their groups. This idea is suggested by Sawyer in very general terms (and detailed to a greater extent by Teresa Amabile, although without a particular context being specified ${ }^{104}$ ) but has not been explored by either writer in the kind of detail I provide here. In these ways I believe my work carries forward the ideas that Sawyer promulgates.

Jason Toynbee makes reference to jazz (and in particular bassist and composer Charles Mingus) in his discussion of social authorship, but the particular aspects of his Radius of Creativity model that I make use of are not applied to jazz in any rigorous way in his work. Likewise, Keith Negus and Michael Pickering use jazz musician Miles Davis as an incidental example of a creative actor, but do not systematically apply their model to jazz musicians per se. As far as I am aware, no one has applied Margaret Boden's Combine, Explore, Transform taxonomy to jazz, or made a systematic application of Mihaly Csikszentmihalyi's Systems Model to jazz in the ways that I explore it in this thesis.

\section{The Systems Model of Creativity}

Mihaly Csikszentmihalyi proposes that while it is 'perfectly possible to make a creative contribution without being brilliant or personally creative' and equally possible that some personally creative people 'will never contribute a thing to culture,' there are nevertheless kinds of creativity that leave 'a trace in the cultural matrix.' ${ }^{105}$ Csikszentmihalyi identifies three platforms necessary for creativity to occur and be recognised: domains, fields, and individuals. By domain, he refers to 'a set of symbolic rules and procedures. Mathematics is a

\footnotetext{
104 Amabile, 'How to kill creativity', 77-87.

105 Csikszentmihalyi, Creativity, 27.
} 
domain [...] Domains are in turn nested in what we usually call culture.'106 Fields include 'all the individuals who act as gatekeepers to the domain.' For visual arts, the field comprises art teachers, curators of museums and foundation administrators, collectors and critics of art, and government agencies concerned with culture. In the domain of jazz music, the field would be generally thought to comprise teachers, curators of festivals, journalists and critics, booking agents, record company representatives, and jazz musicians themselves. Finally, Csikszentmihalyi identifies the individual as significant, and from this trio of actors generates a useful litmus for creativity:

Creativity occurs when a person using the symbols of a given domain, such as music, engineering, business, or mathematics, has a new idea or sees a new pattern, and when this novelty is accepted by the appropriate field for inclusion in the relevant domain. ${ }^{107}$

Csikszentmihalyi goes on to suggest that, 'Creativity is any act, idea, or product that changes an existing domain, or that transforms an existing domain into a new one' and that a creative person is one whose 'thoughts or actions change a domain, or establish a new domain.' He adds the caveat that this domain change is not solely determined by the merit the idea or innovation autonomously possesses, but by 'the explicit or implicit consent of [the] field responsible for it.' In other words, for someone to be deemed 'creative' in Csikszentmihaly's schema is not necessarily a function of their personal creativity but rather whether what 'he or she produces is accepted for inclusion in the domain.'108

Because creativity is jointly constituted by the interaction among domain, field and person, the trait of personal creativity may help generate the novelty that will change a domain, but it is neither a sufficient nor a necessary condition for it. 109

Csikszentmihalyi acknowledges the most important implication of this (systems) model - and one germane to the present study - is that:

[T] he level of creativity in a given place at a given time does not depend only on the amount of individual creativity. It depends just as much on how well suited the respective domains and fields are to the recognition and diffusion of novel ideas [...] Because we are used to thinking that creativity begins and ends with

\footnotetext{
106 Csikszentmihalyi, Creativity, 28.

107 Ibid.

108 Ibid.

109 Ibid., 29.
} 
the person, it is easy to miss the fact that [within this model] the greatest spur to it may come from changes outside the individual. 110

Howard Gardner elegantly reinforces the idea that creativity is socially constituted, embedding it within his definition of creativity: 'In my view, creativity is best described as the human capacity regularly to solve problems or fashion products in a domain, in a way that is initially novel but ultimately acceptable in a culture.'111 However, Gardner's definition is less exclusive than Csikszentmihalyi's: for the latter, creative work is that which will change the domain in which it is found. Gardner's expectation is more modest; if the work is novel, then it need only be found acceptable within the conventions of a domain to be considered creative. The distinction between these two kinds of creativity (if we are to accept both as creative) is commonly described in the creativity literature and is often referred to as 'Big-C' and 'little-c' creativity. James Kaufman glosses Big-C creativity as 'big time, genius level creativity. Big C is Mozart, Shakespeare, Louis Armstrong, Einstein and Alexander Fleming. Big-C is the kind of creativity that lasts generations.' ${ }^{112}$ Little-c creativity is the everyday 'home and garden' variety of creativity. It is less concerned with analytical ability, and is more focused on 'unconventionality, inquisitiveness, imagination, and freedom.'113 It's the kind of creativity that we use to work out what to use as a substitute for nutmeg in a recipe, or informs the doodles we draw on the note pad while talking on the phone. A further degree of granularity is admitted into this continuum by Margaret Boden, who identifies H-creative, for 'historically' creative ideas, which is to say, those that change domains; and P-creative, for 'personally' creative, those moderately interesting ideas that most people come up with that may already be known to others, but which are novel to the person who had them. ${ }^{114} \mathrm{H}$ Creativity is broadly speaking homologous with Big-C

\footnotetext{
110 Csikszentmihalyi, Creativity, 31. See Dean Simonton ('Creative cultures, nations, and civilizations', in Group Creativity: Innovation Through Collaboration, ed. Paul Paulus and Bernard Nijstad [Oxford: Oxford University Press, 2003], 304-325) for an extensive discussion of the influence of ortgeist and zeitgeist.

${ }^{111}$ Howard Gardener, quoted in Nickerson, 'Enhancing Creativity', 392-393.

112 Kaufman, Creativity 101, 44.

113 Ibid., 45.

114 Boden, 'Creativity: How does it work?', 237.
} 
creativity, and some $\mathrm{P}$ creativity (that which does not change a domain but which is none-the-less genuinely novel) could also be described as little-c creativity. However, some P creativity would fail to meet Csikszentmihalyi or Gardener's definitions because while the ideas generated may be new to the person who has just thought of them, they are in fact well known.

If we think of these different kinds of creativity (Big-C, little-c, and P where it is not in fact novel) as lying at points along a continuum, the point at which any particular creative act lies is determined by the field to which that creative action belongs. These distinctions are of considerable importance to the present study because a great deal of what is commonly considered creative work in jazz fails to meet Csikszentmihalyi's criteria for creativity: it does not change the domain (jazz music) in which it operates. I will return to this point below, and using the work of Negus and Pickering suggest that a 'both/and' approach to this distinction ('Big C' / 'little c' / 'P' creativities) is appropriate for this study. ${ }^{115}$

Csikszentmihalyi's work is vital for my applications of creativity research to the field of jazz because it offers two distinct ideas to that I will draw on below: first, that creativity itself is socially constructed; and second, that differences in fields may lead to greater or lesser receptivity toward various kinds and degrees of innovation. In order to understand the significance of these two ideas to the current thesis, it is useful to consider both the degree to which fields require practitioners to exercise fidelity to the customs of the domains they oversee; and related to this first idea, the degree to which domains themselves appear to be more or less flexible. I will address these points in turn to conclude my discussion of Csikszentmihalyi's Systems Model of Creativity.

\section{Fidelity to the values of the field}

Csikszentmihaly's model posits that the gate-keeping actions of the field determine the content of a domain. The relative conservatism or liberality of a field therefore has obvious consequences for the degree to which novelty is permissible in any creative product that is found acceptable, an idea that I will develop with particular regard to notions of genre. There are two key markers

\footnotetext{
115 Negus and Pickering, 'Creativity and musical experience'; Negus and Pickering, Creativity,
} Communication and Cultural Value. 
germane to my purposes here: at what point is there sufficient novelty for a new idea or product to be deemed creative at all? And at what point does too much novelty lead to its exclusion from a domain? The first question is one that has exercised a number of writers. Raymond Nickerson points out that:

With respect to novelty or originality as a criterion of creativity, it is important to note that even the most original or novel of these products or ideas that have been widely recognized as unusually creative have not represented complete breaks with the past but have built upon preceding products and ideas. ${ }^{116}$

Psychologist Thomas Ward - quoted in Nickerson - suggests: 'Creative thinking moves beyond what has been done only slowly, and when it does, it is more a modification of the past than a rejection of it.'117 That isn't always the case propulsive creativity (to use Sternberg's term, consonant with

Csikszentmihalyi's definition of creativity as that which changes its domain) may in fact reject the past and is significant in Kuhnian models of scientific enquiry but much of the time, as Jason Toynbee suggests specifically with regard to music, creative advances are modest and build on the work that precedes them. ${ }^{118}$ Evidence supporting Toynbee's claim, and also specific to music, can be found in Dean Simonton's study of the reception of musical compositions. ${ }^{119} \mathrm{He}$ found that compositions regarded as creative generally tend to be original by departing only somewhat from prevailing norms. Although there are many more 'innovative' pieces - which evidence more radical departures from standard procedures - those pieces do not usually go on to become widely acclaimed. ${ }^{120}$

Clearly the values of the field are central to the reception of creative ideas, and these values affect practitioners. Metacognition, defined earlier, is one of the key characteristics of the balancing act creative workers manage in order

\footnotetext{
116 Nickerson, 'Enhancing Creativity', 393. (My emphasis)

117 Ibid.

118 Robert Sternberg, James Kaufman, James and Jean Pretz, The creativity conundrum (Philadelphia: Psychology Press, 2001); Thomas Kuhn, The structure of scientific revolutions (Chicago: Chicago University Press, 1962, 2012); Toynbee, Making Popular Music, 35.

119 Dean Simonton, 'Thematic fame, melodic originality, and musical zeitgeist: A biographical and transhistorical content analysis', Journal of Personality and Social Psychology 38 (1980), 972-983.

120 Harry Partch is perhaps a good example of a composer whose work, although lionised by some commentators, was such a radical departure from standard procedures that his music is not widely known.
} 
to accommodate the (sometimes extreme) possibilities they dream up, with the constraints of the field(s) in which they work. Norbert Elias calls this process 'sublimation', which consists of 'the ability of an individual to self-reflexively monitor and control the spontaneous and free-flowing fantasy and dreams of their autonomous mental play and harmonise these with aesthetic conventions and the social canon without losing their spontaneity.' ${ }^{121}$ If actors are to operate creatively within the constraints of a domain (which is to say, the expectations of its field) then this capacity - which is some combination of: the product of conscious, rational choices; and the unconscious consequence of training and experience - is a necessary filtering mechanism. This is an idea that adds nuance to our understanding of the music of Miles Davis, as discussed in Chapter Four.

\section{Maximally and minimally structured domains}

The determinations of fields, which decide if particular work or workers are included or excluded from a domain, accrete to give overall shape to that domain. The degree to which different domains are constrained on this more global level has led some creativity researchers to distinguish between domains that are more (maximally) or less (minimally) structured. Keith Sawyer summarises the differences:

Maximally improvisational performance genres, while always manifesting recognizable style and genre constraints, are by definition receptive to innovations, and in fact might be said to require innovations. [Maximally structured] Ritualized performance genres are more firmly defined and are more difficult to change than loosely structured improvisational genres. ${ }^{122}$

Sawyer goes on to suggest that ritualised - which is to say, maximally structured - genres are slow to accept innovative entailments (i.e. innovations that have implications for subsequent practice in the domain), but when innovations are accepted, they last for some time. In improvisational domains innovative entailments are adopted more readily, but are also generally shorter lived. He summarises:

In paradigmatic product domains, a product must satisfy numerous criteria before it is accepted into the domain by the field. Because changes are less

\footnotetext{
${ }^{121}$ Norbert Elias, quoted in Negus and Pickering, 'Creativity and musical experience',183.

122 Sawyer, Group Creativity, 126-127.
} 
frequent, each product that successfully enters the domain is likely to stay in the domain, perhaps until the next revolutionary period. In non-paradigmatic domains, the criteria for product acceptance are much less certain and provisional. Because novel products are being accepted at a higher rate, the domain is changing more rapidly, and each product is likely to lose its relevance more quickly. ${ }^{123}$

These respective characteristics appear to have implications for the valuation of various domains/sub-domains. In Sawyer's view, ritualised genres enjoy high cultural valuation, while improvised genres are considered less valuable. ${ }^{124}$ Speaking specifically of music, Sawyer claims, 'Improvisational musical genres are rarely accorded the same status as more ritualized [notated] forms [...] In all cultures having both [ritualized and improvised] forms of group creativity, the more ritualized forms are culturally privileged.'125 Given that high cultural valuation is attended by considerable benefits (inclusion in exhibitions, publication by the 'quality' press, access to grants and other forms of funding and so forth) such valuation is understandably a priority (even if tacit) for some creative workers and as well as those who constitute the fields of their domains. This sheds light on why some fields (and some creative workers within those fields) tend to become more conservative over time.

Modernist poetry provides an instructive example of how conflicts between fields and those cultural workers who remain committed to creative freedom might play out, and what this may mean in terms of the ultimate power of the field. North American poet Charles Olsen, drawing on the example of his mentor William Carlos Williams, argued for poetry as a spontaneous act (what he called 'Projective Verse') free from the constraints of syntax or traditional forms. This modernist stance was nevertheless insurrectionary in the literary climate of the times, where the 'New Criticism' of the day viewed T.S. Eliot as the modernist poet par excellence. Eliot had written that poetic forms constituted an enduring heritage, and the true test of a modern poet was, 'the ability to bring

\footnotetext{
123 Sawyer, Group Creativity, 128.

124 Ibid., 139.

125 Ibid., 148. In the same passage, Sawyer mentions 'the ideologically tinged debate over accepting jazz into the high art arena.' Whether or not jazz is accepted as 'high art' depends not only on how (and why) jazz is valued, but also raises questions about what jazz is, if indeed it is any one thing.
} 
new content to these forms.' ${ }^{126}$ In contrast to Eliot's reactionary view, Olsen, like Williams before him, 'conceived of poetic forms as ephemeral structures housing fleeting meanings. Because forms at once became obsolete, they constantly had to be recreated in the new content of the present.'127 History has revealed both approaches to be valuable, and the work of Eliot, Williams and Olsen are all celebrated today.

There are two points I want to make here. First, that fields may possess a range of views about what is and is not acceptable for their domains, and that these sometimes divergent viewpoints are contingent, historically specific, and may be representative of only one part of a field. The cautionary note sounded here is that fields are not the monolithic arbiters of taste Csikszentmihalyi's model seems to imply. Rather, the determination as to what is or is not acceptable as creative practice in a domain is much more nuanced and contingent. In Part Two, this idea is helpful in making sense of the ways the music of Ornette Coleman and Miles Davis have been regarded by the field, and the effect their music has ultimately had upon the field.

Second, although the work of Williams and Olsen was considered radical at the time they were writing, their work is now an established part of the poetic canon. As canonical poets, the strategies and content evident in their work can now potentially be used as prescriptive examples, in the way that Eliot championed existing poetic forms as the necessary vessels for new work. For anthropologist Stanley Tambiah, cultural practices universally tend toward ossification and the ritualisation of forms; such a reading might be applied to way the work of Williams and Olsen went from being that of radical outsiders to inclusion in the canon. ${ }^{128}$ The important lesson we can draw from Williams and Olsen (in terms of creative endeavour) is not the use of projective verse (which might become a kind of ritualised practice), but their determination to follow

126 Daniel Belgrad, The Culture of Spontaneity: Improvisation and the Arts in Postwar America (Chicago: University of Chicago Press, 1998), 30. Belgrad draws from Eliot's essays 'Tradition and the Individual Talent', and 'Blake', from The Sacred Wood, 1920.

127 Ibid.

128 Stanley Tambiah, Culture, Thought and Action. An anthropological perspective (Cambridge: Harvard University Press, 1985), 165. For a discussion of the application of Tambiah's ideas to creativity, see Sawyer, Group Creativity, 140-141. 
their own ideas through to some sort of conclusion. It is this attitude - from which their innovative work sprang - that is a key to creativity that can move fields in new directions. It is this attitude that predicated the work of Ornette Coleman and Miles Davis.

\section{The Radius of Creativity}

Drawing from Roland Barthes, Michael Pickering and Keith Negus, Howard Becker and others, Jason Toynbee asserts that the value of creativity as found in musical artefacts can only be measured to the extent that listeners recognise it. ${ }^{129}$ Toynbee draws from Howard Becker in suggesting that artworks emerge from the interaction among artists, their co-workers and audiences, and argues that:

When interaction is intensely repeated, it may solidify in conventions that organize both the way the artist works and the audience responds. Rather, in making a creative choice he or she works intuitively. Becker calls this the "editorial moment", that is, when the artist identifies creative options and then selects from them according to informal criteria that represent, in the case of music, an ideal listener's point of audition. For Becker, then, creation involves small amounts of individual agency and large amounts of regular, if complex, social interaction. ${ }^{130}$

Allying these ideas to literary theorist Mikhail Bakhtin ${ }^{131}$ - and with the expected caveats about the distinctions between language and music - Toynbee

\footnotetext{
${ }^{129}$ Roland Barthes, Image - Music - Text (New York: Hill and Wang, 1977); Howard Becker, Art Worlds (Berkeley: University of California Press, 1982); Michael Pickering and Keith Negus, 'Rethinking Creative Genius'. Popular Music 23/2 (2004), 198-203; Toynbee, 'Music, Culture, and Creativity', 103. Assigning to listeners the authority to determine value is a more nuanced expression of Csikszentmihalyi's notion of the role of the field, and privileges audiences in interesting ways. Keith Negus and Michael Pickering (2004) usefully suggest: 'Yet it is surely crucial to distinguish between artistic and cultural production on the one hand, and its critical acceptance and celebration on the other. They cannot simply be conflated. In Beethoven's case, this is an impoverishment of the historical imagination. It fails to address the question as to why his music endures beyond the time and place in which he lived, or how it connects with huge numbers of people. Is this only due to a social and political construction of belief in his genius, which serves elites, and nothing to do with the popular appeal of the music?' (201) This point is generalisable across the arts and might equally be applied to the work of William Shakespeare or the paintings of John Constable.
}

130 Toynbee, 'Music, Culture, and Creativity', 104.

${ }^{131}$ Mikhail Bakhtin, The Dialogic Imagination: Four Essays (Austin: University of Texas, 1981). 
concludes that music 'needs to be understood as an ensemble of coded voices.'132 Mastery of the coded voices and the systems used to organise them into a comprehensible dialogue is what constitutes the competent social author. Such competence will mean authors are able to meet 'a minimum threshold of stylistic accomplishment. However,' Toynbee cautions, 'this does not necessarily amount to creativity.' Sometimes what listeners identify as creative in a work is in fact a relationship between that work and a stylistic norm. 'This [relationship] may involve transcendence of the norm, or even, in the case of avant-garde aesthetics, its transgression. But just as often, the work will strive to implement or express the norm completely. This is a centripetal tendency where what is at stake is crystallization of a style.'133

I would agree with Toynbee that, when creative practice is guided by the stylistic norms of an idiom, creativity is limited (and perhaps not present at all if the work simply crystallises the elements of the style). Toynbee suggests that possibilities for expressions of greater creativity do occur, but that they are toward the outside of the radius of creativity (i.e. remote from the generally agreed characteristics of the genre). Such an occurrence may be transgressive, but will still need to use coded voices that are meaningful if the work is to be acceptable to those who encounter it. What is not clear from Toynbee's account is whether these coded utterances will be from within the argot of the style or genre in question, or from outside of it but still recognisable to the audience. I would suggest that incursions from outside of a domain are more often than not a pre-requisite for transgressive creative acts (as 'combination creativity') although when Margaret Boden's 'transformational creativity' occurs that coded voice may just as well originate within the genre, albeit altered in some fundamental way (Boden's terms are more precisely defined later in this chapter). ${ }^{134}$ When creative choices are genuinely eccentric, it is the combination

\footnotetext{
132 Toynbee, 'Music, Culture, and Creativity', 105. Once again, this principle is generalisable and might apply to any group creativity including improvised theatre practice, some team sports, conversation and so forth.

133 Toynbee, 'Music, Culture, and Creativity', 105.

134 Boden, 'Creativity: How does it work?' The contrast between combination and transformational creativity in the work of a single artist will illuminate this distinction in the case studies that follow.
} 
of the surprising with the familiar, or the transformation of the unexpected to correspond somehow with the familiar (or vice versa) that yields the creative insight. ${ }^{135}$ Toynbee makes the point that choices of this kind are often made by social authors who are in the field but not necessarily conditioned by it and proposes Hector Berlioz as an example: a composer whose less than adequate training in composition led him to make less than conventional choices, and which in turn led to something new. From the world of fine arts, painter JeanMichel Basquiat is another example: a graffiti artist untrained in the academy, yet who produced work that continues to be celebrated by the field.

Toynbee's model is extremely useful for describing some of the kinds of creativity that we will examine in this study, and is consonant with the inclusive view of creativity Negus and Pickering adopt. ${ }^{136}$ These writers propose a model that explicitly makes room for both inclusive and exclusive definitions of creativity and so is sufficiently open to accommodate modest (little c) creative work of the kind Toynbee is primarily concerned with - that achieved using shop-worn materials in what might be considered routine ways - and exceptional (Big-C) creativity. Of particular relevance to this study, their model suggests that exceptional or paradigm-shifting creativity depends upon routine ('little-c') work.

\section{Creativity as the communication of experience}

The third model of creativity I make use of is drawn from the work of Keith Negus and Michael Pickering and has two significant implications for this study. ${ }^{137}$ First, it proposes an inclusive definition of creativity, one that accommodates routine practice and the low-level, incremental progress that cultural workers make as they seek to reinterpret the traditions within which they operate. This model ascribes value to the cultural products of these 'small

\footnotetext{
135 Such genuinely eccentric choices most often appear in the form of Boden's 'combination creativity' [see below] or Arthur Koestler's 'bisociation' (The act of creation, (New York: MacMillan, 1964, reprinted 1975)) although choices might also appear eccentric because of a fundamental alteration to a style dimension, leading to Boden's 'transformational creativity.'

136 Negus and Pickering, 'Creativity and musical experience.'

137 Negus and Pickering, Creativity, Communication and Cultural Value.
} 
steps' when such products effectively communicate experience. Second, these writers suggest that in the context of such day-to-day practice (which they term 'routine creativity'), moments of exceptional, domain-changing creativity may occur. I shall speak to these two ideas in turn.

Fundamental to Negus and Pickering's model is a definition of creativity that encompasses not only exceptional creative products (in line with Csikszentmihalyi's [and many others] rather exclusive rule of thumb: 'new and useful,') but also includes the way routine cultural practices are continually used, modified and updated in everyday life. Identifying a number of customary examples of such activity - an unusual, and so comic or dramatic application of a common figure of speech, for example - they conclude, 'What happens in such cases is modification and variation, leading to degrees of newness in relation to what is established and already in social circulation.' ${ }^{138}$ Negus and Pickering argue for such a definition because they believe that creativity is a fundamental expression of human agency: 'Ideas about creativity have become integral to the modern sense of individuality because the sense of being ourselves implies expressing ourselves, in speech and in action, and so arriving at what is distinctive about us, or what it is we strive toward.'139 Therefore, it is in exercising this kind of agency in the use of inherited cultural materials that people express themselves and so enact a kind of self-creation.

Developing this idea, these writers propose that concepts of creativity (as they pertain to the arts) can be usefully formulated from a viewpoint of communicated experience. Raymond Williams has suggested that art is the 'organisation of experience, especially in its effect on a spectator or an audience,' and that further, art is successful when it, 'Convey[s] an experience to others in such a form that the experience is actively re-created - not contemplated, not examined, not passively received, but by response to the means, actually lived through, by those to whom it is offered.' ${ }^{140}$ An important qualification to this

\footnotetext{
${ }^{138}$ Negus and Pickering, Creativity, Communication and Cultural Value, 14. (My emphasis) 139 Ibid.,9.

140 Raymond Williams (The Long Revolution [Harmonsworth: Penguin, 1961]) quoted in Negus and Pickering, Creativity, Communication and Cultural Value, 37-38. Williams concludes his statement by noting that 'At this stage, a number of art-works already fail.' A consequence of this
} 
statement is that what audiences or consumers of an artwork experience will probably never be identical to the experience or intention of the author, but rather comprise a consumer's or audience member's 'take' on what they have encountered through the artwork. 'Interpreted experience as we encounter it in a song or musical performance is always reinterpreted in relation to what we ourselves bring to it and what we attempt to take from it.' ${ }^{141}$ Roberta Flack immortalised this kind of reinterpretation in her performance of 'Killing me softly with his song.' ${ }^{142}$ The lyrics recount an experience of hearing a singer whose performance was deeply affecting:

Strumming my pain with his fingers, singing my life with his words Killing me softly with his song, telling my whole life with his words Killing me softly with his song I felt all flushed with fever, embarrassed by the crowd I felt he found my letters and read each one out loud I prayed that he would finish, but he just kept right on Strumming my pain with his fingers...

While we might expect (or at least hope for) emotional resonance of this kind (if not always of this depth) with cultural work in its original context, cultural products (that endure) assume meanings beyond their immediate sites of creation and initial reception. Negus and Pickering identify three artists whose work has achieved this status, and suggest reasons why it has done so:

The genius - for want of a better word - of Mozart, Miles Davis and Bob Marley is [... that] their particular modes of expression - the harmonic order of Mozart's work, the sensitive human voice of Davis's trumpet, the elegant lyricism of Marley's songs - allow all sorts of people a point of entry which enables

conception of cultural practice as socially inclusive is that it leads us away from a focus concentrated on the 'text itself.' 'The whole point of trying to understand creativity in terms of the quality of communicated experience and the forms in which experience is re-created is that it refuses the reification of artistic or cultural work.' (38)

${ }^{141}$ Negus and Pickering, 'Creativity and musical experience', 188. See music historian Richard Taruskin's ‘The Poietic Fallacy' (The Musical Times 145/1886 (Spring 2004), 7-34). Taruskin concludes with the hope that (composers of) serious music might (once again) take 'adequate account of [music's] function as a communicative medium.' (34) Negus and Pickering put it this way: 'In referring to expression, we are not suggesting that a musician, songwriter or performer is engaged in directly relaying either a pre-given psychological state or social experience. Instead, it is within their art and practice that they give voice to or convey a potent sense of such states and experiences as combinations of sounds, words and imagery.' ('Creativity and musical experience', 186).

142 'Killing Me Softy With His Song'. Composed by Charles Fox, Lori Lieberman, with lyrics by Norman Gimbel. 
participation in the work, and activates some connection between what is performed and what is lived. 143

The key here, it seems to me, is the 'connection between what is performed and what is lived.' The creative work invoked (music in this instance) is valued because it means something to those who appreciate it. And because the music has the capacity to mean something to a broad constituency of listeners, it has clearly 'move[d] between specifically local moments of production and initial recognition, and patterns of reception and assimilation which are broader both geographically and historically.' 144 In instances when the work of such artists communicates so widely, their creative 'genius' is evident.

But these are only instances - Mozart, Miles and Marley also produced indifferent or mediocre work. Recognising that artists are inconsistent in this way, Negus and Pickering argue against an absolute conception of genius, or treating the person/subject as genius, and instead prefer an understanding of genius as involving an interflow of artist and theme that produces moments of innovation or instances of exceptional production over time that change a cultural tradition through the lasting value and significance they come to have.'145 It is by viewing an artist's career, rather than particular moments of creation, that an understanding of this interflow becomes possible:

Genius may often be narrated in terms of exceptional moments of musical insight or breakthrough, but these are always firmly embedded in an extended process of arduous toil and preparation before a musician is able to become at one with their art and synthesise from a range of existing cultural elements. ${ }^{146}$

Cultural workers generally spend many years developing their craft and perform/paint/write/practise hundreds (and usually thousands) of times as

\footnotetext{
${ }^{143}$ Negus and Pickering, 'Creativity and musical experience', 189. Once again, the principle is generalisable. In the domain of poetry we might identify Dylan Thomas, Khalil Gibran and Ovid as poets whose work has acquired and maintained meaning for readers/writers in many contexts removed geographically and temporally from its creation and continues to be celebrated by the fields of poetry and by lay audiences.

${ }^{144}$ Negus and Pickering, 'Creativity and musical experience', 189.

145 Negus and Pickering, Creativity, Communication and Cultural Value, 202. It is worth noting that 'innovation' and 'moments of exceptional production' are not necessarily the same thing. Davis's music on Relaxin' (1956) might be exceptional, but it is not innovative in the ways that his music on Bitches Brew (1970) might be considered innovative, and is perhaps not innovative at all, depending upon one's criteria.
}

146 Ibid., 203. 
they cultivate their artistic approach. In light of this, Negus and Pickering's model helpfully situates moments of exceptional creativity within the routine of day-to-day artistic practice that is the lot of cultural workers. As such, their model requires consideration of the processes that characterise the work of these musicians as much as it requires consideration of the products of those processes. Further, such a model is useful because it allows for creativity in the exclusive sense - novel and appropriate production - as well as work that is creative simply because it has been made in a way that communicates something. By viewing creative work as that which achieves communicative value, it becomes possible, 'to grasp the dynamic, and often paradoxical - even dialectical - connections that link the ordinariness and exceptionality of creativity.'147 This perspective is useful for this thesis because jazz practice ranges from the ordinary to the exceptional; if the criteria for the presence of creativity is relaxed to include that which communicates as well as that which changes a domain, then our perspective admits the importance of individual agency.

\section{Combine, Explore, Transform}

While Csikszentmihalyi's model offers insight into the ways domains are governed by fields, Toynbee's work suggests that the processes employed by creative actors produce outcomes ranging from 'not creative', to 'creative', to being so eccentric they are 'not acceptable' to a particular field. Negus and Pickering add nuance to this range of work, suggesting that some of what might be considered 'not creative' in Toynbee's model is in fact acceptable when using different criteria for creativity. Margaret Boden's work complements the insights of these writers by offering a lens through which to distinguish between the various processes that give rise to creative products. ${ }^{148}$ On the basis of these processes and their outcomes she identifies three classes of creativity: Combination, Exploratory and Transformational creativity.

\footnotetext{
147 Negus and Pickering, Creativity, Communication and Cultural Value, 202-203.

148 Boden, 'Creativity: How does it work?'
} 
Combination Creativity is the result of 'unfamiliar (and interesting) combinations of familiar ideas. ${ }^{149}$ A second type of creativity in Boden's taxonomy is Exploratory Creativity in which 'existing stylistic rules or conventions are used to generate novel structures (ideas).'150 Boden claims that '[t]he vast majority of creative work in the arts and sciences is of this kind.'151 The third class Boden identifies is Transformational Creativity. This kind of creativity adopts the same procedures as exploratory creativity, but is more extreme because 'the variation is greater and the stylistic dimension being varied is deeper.' The distinction between the two is one of degree. Boden qualifies her definition of transformational creativity by suggesting that 'not every dimension of the style will have to be changed. So there will be both structural continuities and structural discontinuities between the untransformed space and its seemingly impossible successor. The nature of these continuities will affect the valuations of the new idea.' ${ }^{152}$ According to Boden, transformational creativity is more highly valued than the others, and is correspondingly more rare. She claims that the three are distinct because they involve 'different types of psychological process for generating p-novel [which is to say: 'little c'] ideas.'153

Boden's taxonomy is useful to my purposes in this thesis because the distinction between combination creativity and exploratory/transformational creativity is illuminating when applied to the work of the jazz musicians in my sample. Moments of significant innovation leading to disciplinary rupture have

\footnotetext{
149 Boden, 'Creativity: How does it work?' 240.

150 Ibid., 241.

151 Boden's category of exploratory creativity corresponds to the Kuhnian idea of normal science. Kuhn, The structure of scientific revolutions. Kuhn distinguishes between 'normal' and 'revolutionary' science. While both may lead to creativity, normal science expands upon existing paradigms, whereas revolutionary science proposes new paradigms. The expression 'paradigm shift' is derived from Kuhn's work.

152 Boden, 'Creativity: How does it work?', 243.

153 Boden (Ibid., 244-246) claims creativity can be computer modeled, but only exploratory creativity. This appears to be consonant with the claims of David Cope (Computer Models of Musical Creativity) whose work involves programming computers to write in the style of significant historical composers. Presumably Boden makes these claims because the production of such works involves processes that are, at least in part, iterative.
} 
been the result of both types (combination and transformational) of creative action, and in turn often led to division in the field. Sometimes this division healed over time, and in other cases exceptional innovation has resulted in ongoing contestation of the fundamental values of the field. Such contestation has resulted either in a divided field, or the emergence of multiple fields. My discussion of both Ornette Coleman and Miles Davis in Part Two of the thesis reveals that both outcomes (division of the field; emergence of additional fields and sub-domains) occurred as a result of their work.

\section{Group Creativity}

The final model I make use of differs from the others enumerated here in that it considers creativity specifically in the contexts of groups. The importance of groups to creative practice has long been recognised. Fifty years ago Thomas Kuhn observed that discovery is a team effort and many scholars have subsequently rehearsed and further explored this idea. ${ }^{154}$ Keith Sawyer's work on group creativity is central to that field of scholarship. His books Group Creativity (2003) and Group Genius (2007) provide excellent discussions of the key ideas associated with group creativity, which Sawyer defines as 'two or more people, creating together at the same time.'155 Sawyer's scholarship (which draws in part from the study of jazz musicians) is extremely useful to this thesis. However, before summarising his findings I want to be clear that the principles I draw from his work in the context of this discussion of group creativity are ones that are generalisable and can apply to theatre, sports, conversation, or to jazz. ${ }^{156}$

Sawyer, Howard Becker, Jason Toynbee and Dean Simonton all identify key features of group creativity that have bearing on this thesis. ${ }^{157}$ These can be summarised as: intrinsic motivation; unpredictability; intersubjectivity; and

\footnotetext{
154 Kuhn, The structure of scientific revolutions, 31.

155 Sawyer, Group Creativity, 4.

156 I have some reservations about the wholesale applicability of Sawyer's work to this thesis, reservations laid out in the section entitled Creativity in Music, earlier in this chapter.

157 Becker, Art Worlds; Toynbee, Making Popular Music; Simonton, 'Creative cultures', 304-325.
} 
emergence. The key processes common to these last three characteristics (and which probably contribute to stimulating the first - intrinsic motivation - for most participants) are improvisation and complex communication. I will explore each of these in some detail, and in doing so link them to the broader purposes of this study.

\section{Intrinsic motivation and the centrality of process}

Psychologists Beth Hennessey and Teresa Amabile define intrinsic motivation as that experienced by participants in an activity who 'feel motivated primarily by interest, enjoyment, satisfaction, and challenge of the work itself - not by external pressures.'158 Most creative cultural workers are significantly intrinsically motivated by their work (and the group collaborations that may attend such work). While the product or outcome of their endeavours may be one of their objectives, they also (and in some cases primarily, or very occasionally even exclusively) 'do it just to do it.' Such intrinsic motivation means that the processes that constitute the experience of creative workers are an important consideration in studying collaborative creative endeavour. These processes have been a focus in recent work on group creativity. ${ }^{159}$ For Sawyer, 'In group creativity, the process is the essence of the genre, and it must be the focus of any scientific study.' 160 While I think the reasons Sawyer gives for the primacy of process over product are somewhat idealistic (and which I will speak to in Part Two), his claim strikes me as reasonable: performances by improvised theatre groups, or conversations amongst groups of people possessing shared knowledge, can only be partly understood through contemplation of the product of their interactions. In order to understand better how those products emerged, or how such products might be improved or refined or shaped to yield different outcomes, consideration must be given to the processes those groups engage in order to achieve their final outcomes. For this reason I make processes a central

\footnotetext{
158 Beth Hennessey and Teresa Amabile, 'The conditions of creativity', in The Nature of Creativity: Contemporary Psychological Perspectives, ed. Robert Sternberg (Cambridge: Cambridge University Press, 1988), 11.

159 In particular, Sawyer, 2003; Toynbee, 2000.

160 Sawyer, Group Creativity.
} 
focus in my consideration of the musicians in Part Two of this thesis. Two processes in particular are important to group creativity generally (and which, as I explain in Chapter Two, are also central to jazz): improvisation and complex communication.

\section{Improvisation, unpredictability and complex communication}

In his discussion of group work by musicians and actors leading to creative outcomes, Sawyer identifies in-the-moment interactivity as a key factor.

In group creativity, interaction between performers is immediate, durationally constrained to the moment of creation, and is mediated by musical or verbal signs [in improvised theatre and jazz]. The process of group creativity is coincident with the moment of reception and interpretation by other participants. 161

In Sawyer's estimation, improvisation - a central practice in conversation, some team sports, jazz and improvised theatre - 'exaggerates the key characteristics of all group creativity: process, unpredictability, inter-subjectivity, complex communication, and emergence.' ${ }^{162}$ As such, Sawyer considers improvisation to be an essential process for enabling group creativity. In his view, and given my focus on jazz I tend to agree, improvised performance genres are exemplary sites for group creativity because 'no single [participant] can determine the flow of the performance: it emerges out of the [idiomatic] conversation, the give-andtake as performers propose new ideas, respond to other's ideas, and elaborate or modify those ideas as the performance moves forward.' 163 Clearly, when this kind of group improvisation takes place, there is a great deal of unpredictability. In ritualised domains, where the radius of creativity is narrow, participants may feel reasonably confident about the direction and final outcome of the activity, but as improvisation becomes a significant part of the actions of the group, then the outcome of the group's work becomes increasingly uncertain. For such improvised collaborative work to be successful (in whatever terms the relevant genre or discipline defines 'success') there needs to be a high level of

\footnotetext{
161 Sawyer, Group Creativity, 86.

162 Ibid., 5.

163 Ibid., 4.
} 
communication between participants if they are to respond constructively to unexpected events as they emerge. Such communication can be said to be complex in as much as it must take into account multiple considerations.

These considerations are evident in the examples of some team sports (for example, basketball) or improvised theatre. In these examples, the performance or activity is constructed from moment to moment by means of the ongoing negotiations (tacit or otherwise) between the participants. For the ensemble to operate effectively the players must all be listening deeply or observing very closely what is happening so that they can tailor their responses to suit the unfolding action. Such deep listening/careful observation facilitates team members contributing to one-another's actions or ideas. It is only by such cooperation that the team will enjoy success: as important as a star player or a lead actor may be, without mutually supportive collaboration amongst the team members, the team will probably not succeed. The kind of communication needed to enable such cooperation in improvised settings is challenging because, first, actions are durationally constrained, so there is often little or no time (or opportunity) for communication. In the case of improvised theatre, or musical or dance performances, not only is there no time for communication the performance rolls out in 'real time' - there is often no provision within the genre to admit verbal or physical cues; the participants must depend upon their experience and intuition to achieve communicative rapport with their colleagues. Second, the collaboration may involve many players, each of whom generally has a slightly different perspective on what is happening or may be going to happen, and what they think they should be doing about it. And third, most actions have consequences for some or all of the other players, introducing what Sawyer calls 'combinatorial complexity.' Which is to say, a large number of possible 'next actions' exist, and choosing any one may lead the flow of the game or performance in radically different directions. ${ }^{164}$ The complexity of collaborations like these is in part a function of the extreme interdependence of participants. Such interdependence, when parsed as a verb, has been called intersubjectivity.

${ }^{164}$ Sawyer, Group Creativity, 7. 


\section{Intersubjectivity and emergence}

Intersubjectivity is also known as 'mutual understanding.'165 As I have suggested and in line with Sawyer, during activities where the action is constructed collectively in a moment-to-moment manner by autonomous actors, each individual possess a slightly different perspective on the action and what their next, best response or contribution needs to be. In spite of such independence, when participants enjoy mutual understanding or intersubjectivity they are able to coordinate their individual efforts in pursuit of the group's objectives. This kind of coordination is evident in a successful basketball play, or a well-achieved passage in an improvised theatre performance. Drawing from psychologist Eugene Matusov, Sawyer suggests, 'The key question about intersubjectivity in group creativity is not how performers come to share identical [mental] representations [of what is going on], but rather, how a coherent interaction can proceed even when they do not.'166 It's a good question: sometimes the convergent behaviour of groups in collectively improvised settings borders on magical; it was this kind of synergy that Miles Davis celebrated when he named his 1965 studio album, the first by his new quintet, E.S.P. In order to address this question it is helpful to introduce the idea of emergence.

Informal conversations (that is, unscripted conversations) are the product of group creativity ${ }^{167}$ and as such offer an instructive example of how emergence operates. Linguistic theorists emphasise the pragmatics of language; that is, how language is used in social settings. An understanding of informal language use has allowed these theorists to remain mindful of the indeterminacy that is in fact always present when people converse, and not to accept transcripts of conversations as reifications of those events - which is to say, as capturing all that is going on. John Gumperz states, for example, that 'Although we are dealing with a structured ordering of message elements that represents the speakers' expectations about what will happen next, yet [conversation] is not

\footnotetext{
165 Sawyer, Group Creativity, 9.

166 Ibid.

167 Ibid., 82-83.
} 
a static structure, but rather it reflects a dynamic process which develops and changes as the participants interact.'168 Overarching structure in conversation, then, is an emergent property of conversations as they proceed.

Sawyer claims all forms of group creativity that make use of improvisation (including conversation) exhibit 'collaboratively emergent social process[es]' and as such their analysis should focus on interaction, practice and pragmatics. ${ }^{169}$ Sawyer does so by adopting socio-linguistic models, and demonstrates that the emergent (which is to say, the performance or game or conversation) in improvised group practices is not reducible simply to the sum of the parts that make up that emergent at the moment it is considered or captured. Rather, the emergent involves a balance between what has gone before, the implications of what has gone before (for the moment being considered), and the implications or implied future strategies suggested by both what has passed and what is now occurring. ${ }^{170}$ Sawyer summarises:

The emergent is structured but ephemeral, changes with each performance act, and emerges from the indexical presuppositions accumulated through the prior collective interaction. It is an emergent social fact; it is not determined by any single performer, and only partially constrained by genre definition. For the interaction to continue as an inter-subjective shared activity, the performers must work together in creating the emergent. ${ }^{171}$

This 'working together,' which is not automatic and requires the participants to listen deeply and to surrender to the group process, has been defined by sociologist and philosopher Jürgen Habermas as communicative action: 'the type of interaction in which all participants harmonize their individual plans of action with one another and thus pursue their illocutionary aims without reservation.' 172 In group creativity, such communicative action is

\footnotetext{
168 John Gumperz, Discourse Strategies (New York: Cambridge University Press, 1982), 131.

169 Sawyer, Group Creativity, 78. For group creativity that is performed without a script or score (group creativity generally, in Sawyer's estimation) there is a continuum that runs from ritualised to improvisational performance. (81) In this taxonomy ritualised performance genres are 'shared social facts, reproduced anew in each performance' (81) and exist at the end of the spectrum where the possibility for creativity is close to zero.

170 Sawyer, Group Creativity, 82-84.

171 Ibid., 87. (My emphasis)

172 Habermas, 1987, Vol. 1, p. 294, quoted in Sawyer, Group Creativity, 88. (Original emphasis) See also Sawyer, Group Genius, 14, 44-53, where Sawyer identifies critical pre-conditions for group creativity.
} 
the product of each participant contributing something to the performance or activity. Each contribution (or indexical entailment, to use Sawyer's term, because each contribution does in most cases have consequences for the emergent) may project either a higher or lower degree of constraining force, which will decrease or increase the range of possible actions other participants may subsequently make. ${ }^{173}$ Actions that project a lower constraining force (i.e. are not prescriptive) 'have the effect of keeping the emergent open and full of possibility', whereas actions that project a high constraining force 'tend to bring about convergence more quickly.'174 Theorising the different effects of actions in these improvised collaborative acts leads Sawyer to a useful description of group creativity:

A performer, constrained by the collectively emergent, originates an action with some indexical entailment; the other performers, through their responses in subsequent actions, collectively determine the extent to which this act enters the emergent; the new emergent then similarly constrains the subsequent performers. Throughout, the "meta-constraint" of genre definition controls many properties of this interactional process: how much indexical entailment is considered acceptable, how performers acts are allocated, how performers create acts which retain coherence with the emergent. ${ }^{175}$

In order to optimise creative freedom for all participants, it follows that improvisational interaction needs to be highly contingent. Such flexible, open interactivity leads to a combinatorial efflorescence that triggers a multiplying number of possible directions and results. These potential trajectories result in unpredictable emergence. ${ }^{176}$

Maintaining maximum creative freedom for all participants within an activity is challenging. Sawyer reports that cognitive psychologists believe 'improvisational genres evolve over time in such a way that individual creative

\footnotetext{
173 Some forms of group creativity do not depend upon this kind of convergence. For example, the hoary anecdote told about the differences between free jazz in Europe and in Britain is enlightening: In Britain, it was said, if you couldn't hear the bass player, the other musicians needed to turn down; in Europe, if you couldn't hear the bass player, it was his problem. Clearly in genres where deliberate disregard for the choices of other participants is paradigmatic, Sawyer's observations with regard to indexical entailment do not hold.

174 Sawyer, Group Creativity, 89.

175 Ibid., 89-90.

176 Ibid., 91.
} 
choice is limited.'177 The reasons this occurs are complex and may be related to the cognitive processes associated with improvisation ${ }^{178}$ or perhaps to the ways ritualised performance traditions enjoy higher social valuation and so incline fields to move away from highly improvised practices toward more ritualised practice (related to what musicologist George Lewis might call 'Ford-ism'). ${ }^{179}$ It is fair to say that traditions that possess very clearly defined genre constraints and understandable functional processes are more amenable to inclusion in official histories and college curricula. ${ }^{180}$ Whatever the reasons, some genres that boast improvisation as a core value, including jazz, do evidence strong generic and apparently constraining attributes, particularly as those genres age.

Nevertheless, emergence as a product of overall synergy in creative groups remains vital to understanding successful collaboration in groups and is elegantly described by sociologist Herbert Blumer: 'Both such joint activity and individual conduct are formed in and through this ongoing [synergistic] process; they are not mere expressions or products of what people bring to their interaction or of conditions that are antecedent to their interaction.' ${ }^{181}$ If Blumer is correct, then the results of group creativity are not predictable on the basis of prior conditions, nor are they attributable to a single participant. Sawyer adopts this view, claiming, 'In group creativity, the essence of the creative process is social and interactional, and cannot be reduced to the inspiration or mental process of any single actor.' 182 It is the mix of participants and what they do together that makes the emergent interesting. In Part Two, I will illustrate this general principle in my examination of the leadership practices of Duke Ellington and Miles Davis.

\footnotetext{
177 Sawyer, Group Creativity, 92.

178 Philip Johnson-Laird, 'Freedom and constraint in creativity', in The Nature of Creativity, ed. Robert Sternberg (New York: Cambridge University Press, 1988), 202-219; John Sloboda, The Musical Mind: The cognitive psychology of music (New York: Oxford University Press, 1985).

179 Lewis, A Power Stronger than itself, 441-443.

${ }^{180}$ For a discussion of this phenomena as it relates to jazz, see Prouty, 'The finite art of improvisation'.

181 Quoted in Sawyer, Group Creativity, 96.

182 Ibid., 104.
} 


\section{Group flow}

When a group is 'in tune' and working together toward a common goal, or when emergence occurs as a result of synergy within the group, a flow state may on occasion be achieved. As discussed above, flow states occur when the skills of individuals are matched to the task(s) at hand. ${ }^{183}$ In Keith Sawyer's opinion, 'Groups attain flow by staying in the improvisation zone between complete predictability and going too far, between their shared knowledge about conventional situations, and doing something so inconsistent that it doesn't make sense.' ${ }^{184}$ Here innovation and tradition (or ritualistic and improvisational approaches) find a middle ground that is conducive to creativity. In Sawyer's parlance this flow is an emergent property of the ensemble's actions and a very specific example of what Jürgen Habermas described as communicative action. Sawyer, like Jason Toynbee, believes that generally, 'In group creativity, the group leads each individual to perform at a higher level than he or she would have been capable alone.' 185 This phenomenon is further amplified when groups achieve flow states, because on those occasions the individuals that comprise the group are also in flow. ${ }^{186}$ The benefits of group flow are considerable, and as well as inspiring individuals to perform 'beyond themselves' may also lead to collective products that exceed what one might reasonably expect a particular group to achieve given the individual talents of the participants. ${ }^{187}$

The leaders of groups that make use of improvisation do have a role to play in the apparently egalitarian phenomenon of group flow. Improvisation is an unpredictable way to attain flow - it doesn't always occur - and any failure may be a public one. But good leaders can do a lot to mitigate this risk.

Effective directors are capable of identifying group combinations that are more likely to achieve group flow; they have a rare ability to think simultaneously at

\footnotetext{
183 Csikszentmihalyi, Creativity, 112-114; Kaufmann, Creativity 101, 36-7; Sawyer, Group Creativity, 41.

184 Sawyer, Group Creativity, 41.

185 Ibid., 11. (My emphasis)

186 Ibid., 46.

187 Ibid., 62.
} 
both the individual level and the group level. They can see beyond the talents of individual performers in isolation, and envision how the group will work together. ${ }^{188}$

The general principles Sawyer points towards here are useful in making sense of some of the leadership strategies employed by the musicians considered in Part Two of this thesis.

\section{Summary of Group Creativity}

By drawing from Howard Becker, Jason Toynbee and Keith Sawyer I have isolated three key features, which characterise the creative practice of groups that make routine use of improvisation: 189

1. Group creativity is qualitatively different from individual creativity and should ideally be analyzed as a collective and social phenomenon (i.e. process).

2. Groups that make routine use of improvisation are likely to produce more creative work.

3. Interaction and communication among participants is central to group creativity.

These findings complement Jason Toynbee's observations about specifically musical creativity (in popular contexts):

[C]reativity in music needs to be reconceived as a cultural process rather than a heroic act. New music - in other words, significantly different music - is made by social authors who work in networks, collaborating (and sometimes fighting) with coworkers, critics, industry, and audiences. Social authorship also implies a social semiotics in that creation is a matter of selecting from a pool of coded voices that are shared within a given musical community. ${ }^{190}$

Subsequent work by Sawyer further reinforces these claims. In Group Genius, Sawyer repudiates the notion that individuals acting alone can achieve significant creative work. Instead, he favors a model that suggests: 'Collaboration is the secret to breakthrough creativity.' ${ }^{191}$ Given the evidence provided by the

\footnotetext{
188 Sawyer, Group Creativity, 50.

189 Becker, Art Worlds; Toynbee, Making Popular Music; Toynbee, 'Music, Culture, and Creativity'; Sawyer, Group Creativity; Sawyer, Group Genius.

190 Toynbee, 'Music, Culture, and Creativity', 110.

191 Sawyer, Group Genius, ix.
} 
writers cited here, I think it fair to say that most of the time, and certainly in the case of jazz, creativity is the property of groups rather than of individuals. ${ }^{192}$

\section{Conditions for creativity}

The second part of my thesis question concerns ongoing creativity in jazz. In order to address this concern, which I do with my Conclusion and Afterword, it is helpful to understand the conditions that fostered creativity in the examples I consider in my case studies. Many of the writers concerned with creativity particularly those in the popular press - are exercised by the question of how creativity can be encouraged. Margaret Boden, in addressing this question, first suggests that 'any cultural attitudes that punish people for providing [novelty and surprise] will thereby hinder their creativity.' Boden goes on to say, 'Evidence suggests that what makes for an especially H-creative person is not their having any special idea-generating mechanisms in their heads. Rather, it is their motivation, self-confidence, and single-minded commitment to the domain in question.' 193 Teresa Amabile proposes a similar cocktail: 'Within every individual, creativity is a function of three components: expertise, creativethinking skills, and motivation.' ${ }^{194}$ These observations correspond with Robert Sternberg's claim that creativity is as much a decision about, and an attitude toward, life, as it is a matter of ability. 195 The attitudes and qualities that creativity researchers consistently identify as enabling creativity include: strong motivation; expertise; a suitable environment; and particular group strategies. I will address these four ideas in turn.

\footnotetext{
192 There are of course counterfactuals to this claim. I will address some of these in Part Two.

193 Boden, 'Creativity: How does it work?', 247.

${ }^{194}$ Amabile, 'How to kill creativity', 78.

195 Robert Sternberg, 'The development of creativity as a decision making process', in Creativity and Development, ed. R. Keith Sawyer and Vera John-Steiner and Seana Moran (New York: Oxford University Press, 2003), 98.
} 


\section{Motivation}

A number of creativity scholars consistently identify motivation as a critical condition for enhancing creativity. Hennessey and Amabile identify intrinsic motivation (defined above) as one of the most important conditions for creativity. ${ }^{196}$ Csikszentmihalyi confirms this finding, observing that in his extensive study of a large number of highly creative people, 'They all love what they do' and that is what drives them on. ${ }^{197}$ According to Hennessey and Amabile, individuals are intrinsically motivated when they are engaged in activities 'primarily because of their own interest in those activities,' so interested in fact that the 'performance of a task appears to be a goal in itself.'198 Extensive research has shown such intrinsic motivation to be a function of individuals' innate desire for competence in their fields of endeavour. ${ }^{199}$ More essentially however, it results 'from a desire to experience personal causation,' or, as an expression of self-determination. ${ }^{200}$ Such desire for personal causation corresponds exactly with Jonathan Rowson's claim that we value creativity because we understand it to be an expression of free will. ${ }^{201}$

Hennessey and Amabile distinguish between intrinsic and extrinsic motivation - where the goal of the task is external to the task itself - and show that these different motivations lead to 'significant differences' in the resulting performance of creative tasks. Of particular relevance to this study, their research suggests that heuristic or creativity tasks are adversely affected by the introduction of external rewards. They suggest ' $\mathrm{t}]$ he experience of performing a task for money significantly decreases subjects' intrinsic motivation for that

\footnotetext{
196 Hennessey and Amabile, 'The conditions of creativity', 11.

197 Csikszentmihalyi, Creativity, 107.

198 Hennessey and Amabile, 'The conditions of creativity', 12.

199 Including: Sternberg, 2003; Hennessey and Amabile, 1988; Collins and Amabile, 1999.

200 Hennessey and Amabile, 'The conditions of creativity', 13.

201 Rowson, 'How are we disposed to be creative?', 85.
} 
activity.'202 Other conditions or circumstances that hindered creativity identified by Hennessey and Amabile's study included surveillance, deadlines, the expectation of evaluation (unless that evaluation contained specific information about competence), and specification of means. For these authors, the deleterious effects of such constraints are summed up as: 'For subjects who initially display a high level of interest in a task, working for an expected reward decreases their motivation and undermines the globally assessed quality of their performance.'203

It would be easy to suggest, in light of this finding, that creative practitioners who work for money produce work that is somehow less creative than those who work for no money. I think such a view is mistaken, and a misreading of Hennessy and Amabile's claims. As I see it, creative artists (and I include musicians significantly involved in jazz in this set) are not primarily engaged in their practice out of a desire to make money; they continue to pursue their art because they are profoundly interested in the work, not 'for an expected [economic] reward'. These cultural workers need incomes to live, but that income is facilitative rather than a 'reward' - their income enables them to continue. The difference is subtle in appearance, but significant in effect, and for the jazz musicians I survey in the cases studies (and many, many others not mentioned but involved in jazz) attachment to the music is what drives them, rather than extrinsic factors. ${ }^{204}$

\footnotetext{
202 Hennessey and Amabile, 'The conditions of creativity', 17. The countervailing view is discussed by Negus and Pickering (Creativity, Communication and Cultural Value), citing James Ettema and Charles Whitney (Individuals in Mass Media Organisations: Creativity and Constraint [London: Sage, 1982]) to suggest, 'commerce is sometimes viewed as the condition that inspires creativity.' (47) This circumstance is considered by Hennessey and Amabile, and discussed in their article, 'The conditions of creativity', 29-31 (see footnote 25).
}

203 Hennessey and Amabile, 'The conditions of creativity', 20. The writers add a caveat to their conclusions, noting that in some studies participants learned to overcome the negative effects of rewards by conceptualising any reward(s) as something that added to their motivation. These subjects were intrinsically motivated both before and after reward, and seemed to treat any reward(s) as informational (and signifying competence) rather than as an incentive. (29-31)

204 This is a somewhat idealised position, but one that my reading suggests is the case. Further, musicians with the skills necessary to perform jazz at a high level could pursue more lucrative musical styles if motivated solely by financial (or other) rewards. In fact, many jazz players have balanced the two: studio work or similar to pay the bills, and jazz until the money runs out. There is perhaps another, quite deep issue flagged here. A position that is 'anti commerce' is sometimes used to define 'high art', as though such work were beyond or 'above' commercial considerations. And yet sometimes an 'art for art's sake' attitude is used to mask what is actually 
One of the most significant positive forces acting to reinforce intrinsic motivation and so enhance creativity is self-esteem, described by Hennessey and Amabile as 'strong self-acceptance and positive self-evaluation behavior.'205 Psychologist Stanley Coopersmith's work on self-esteem reinforces this link between personal confidence and creativity:

[T] he individual must believe that his perceptions are meaningful and valid and be willing to rely upon his own interpretations. He must trust himself sufficiently that even when persons express opinions counter to his own he can proceed on the basis of his own perceptions and convictions [...] An essential component of the creative process, whether it be analysis, synthesis, or the development of a new perspective or more comprehensive theory, is the conviction that one's judgment in interpreting the events can be trusted.206

Such self-belief is indispensable for those engaged in work that troubles the paradigms of the domain in which they operate, but is probably necessary for any creative act that involves an attempt to communicate experience.

Hennessey and Amabile observe that both environmental factors and an actor's perception of their influence inform that actor's level of intrinsic motivation and hence creativity. In light of this observation, they suggest that 'conditions of creativity' must be understood as 'complex interactions between and among both internal and external conditions. ${ }^{207}$ One external condition in particular that is significant for intrinsic motivation is freedom. Amabile reckons that for organisations hoping to stimulate creative outcomes from their workers, granting freedom is key. However, 'the key to creativity is giving people autonomy concerning the means - that is, concerning the process - but not necessarily the ends.'208

Finally with regard to motivation, Guy Claxton (in Creativity, Wisdom and Trusteeship) identifies egocentric and allocentric motivation as being useful in

\footnotetext{
economic commodification of artworks. For example, the categorising of musical compositions as 'works' manages at the same to time to elevate them to 'high art' while also packaging them as economic commodities. See Goehr, The Imaginary Museum of Musical Works, 228-229.

205 Hennessey and Amabile, 'The conditions of creativity', 32.

${ }^{206}$ Stanley Coopersmith, The Antecedents of Self-esteem (San Francisco: Freeman, 1967), 58-59.

207 Hennessey and Amabile, 'The conditions of creativity', 35.

${ }^{208}$ Amabile, 'How To Kill Creativity', 86.
} 
speaking to the psychological and ethical predicates of interest itself. ${ }^{209}$ In the same volume, Jonathan Rowson develops this idea against the backdrop of creative work within groups. Drawing on linguistics scholar Shirley Heath, Rowson suggests that when creative work is directed toward a community goal, motivation may change: 'If you feel that you have an important contribution to make to a group project that you care about, and sense that your overriding goal is shared by everybody else, the experience of your contribution becomes both its own reward and a means to a greater end.'210 On the basis of the evidence presented in Part Two, the kind of allocentric motivation Rowson invokes here appears to be a key factor in the work of individuals in the groups considered.

\section{Expertise}

Dean Simonton claims, 'Outstanding creativity is not the business of amateurs.' 211 Such an emphasis on expertise is a common trope in discussions around creativity. ${ }^{212}$ It is a view reiterated by Thomas Priest in a study of creativity in musical composition: 'Craftsmanship may be viewed as an essential component of creativity.'213 Keith Sawyer, drawing from an extensive literature, claims, 'One of the most solid findings in creativity research is the ten year rule: It takes a minimum of ten years of hard work and practice before attaining the high level of performance that results in great creativity.'214 Malcolm Gladwell

\footnotetext{
209 Guy Claxton, 'Wisdom: Advanced Creativity?', in Creativity, wisdom, and trusteeship: exploring the role of education, ed. Anna Craft and Howard Gardner and Guy Claxton (Thousand Oaks, CA: Corwin Press, 2008), 35-48.

210 Rowson, 'How are we disposed to be creative?', 87.

211 Simonton, 'Creative cultures, nations, and civilisations', 308.

212 An ongoing conversation in the creativity literature surrounds ideas of domain-specific (i.e. discipline specific) verses domain-general perspectives on creativity (and by extension domainspecific versus domain-general expertise or skill). Perhaps the key value the debate throws up for this study is the distinction between domain specific skills (which jazz musicians must have if they are to function) and domain general conceptual capacities (which some but not all jazz musicians make use of).

213 Thomas Priest, 'Using Creativity Assessment Experience to Nurture and Predict Compositional Creativity', Journal of Research in Music Education 49/3 (Autumn 2001), 247.

${ }^{214}$ Sawyer, Group Genius, 124.
} 
endorses this view, and in his book Outliers talks about the '10,000 hour rule.' Acquiring expertise takes a long time..$^{215}$

Raymond Nickerson provides a useful summary of the creativity literature specifically advocating for expertise. He summarises those findings: '[P] eople who do noteworthy creative work in any given domain are almost invariably very knowledgeable about the domain.' Of the arts in particular, he claims, 'As a rule great artists have mastered the prevailing techniques of their art form before they have begun to innovate and to influence its further development.'216 Thomas Ward, Steven Smith and Ronald Finke argue for expertise both in the relevant domain, and in terms of more universal creativity skills. ${ }^{217}$ In pursuit of domain-changing creativity, the subject of The Creativity Conundrum, authors Robert Sternberg et. al. present a counter-argument: 'Even though knowledge may be necessary for creativity, it is not sufficient, and it may be as likely to interfere with paradigm-breaking ideas as to facilitate them.'218 It would seem that over-familiarity with the practices of a discipline might disincline participants to question some of the fundamental predicates of that discipline, so robbing them of access to potentially fruitful avenues of inquiry. As Thomas Kuhn observes, 'In both good science and good art the mind must suspend its usual assumptions in order to meditate on something fundamentally new', and sometimes that is easier for participants who are not completely entangled in a domain. ${ }^{219}$ More often than not, however, significant innovation is the province of experts.

\footnotetext{
215 Malcolm Gladwell. Outliers: The Story of Success (New York: Little, Brown and Company, 2008).

216 Nickerson, 'Enhancing Creativity', 409.

217 Thomas Ward, Steven Smith and Ronald Finke. 'Creative Cognition', in Handbook of Creativity, ed. Robert Sternberg (Cambridge: Cambridge University Press, 1999), 207-208. While it would be fascinating to explore this idea as it affects the performance of jazz musicians, it is beyond the scope of this thesis.

218 Sternberg, Kaufman and Pretz, The creativity conundrum, 107.

${ }^{219}$ Kuhn, The Structure of Scientific Revolutions, 50.
} 


\section{Environment}

Dean Simonton suggests that 'societal-level effects complement and expand rather than render utterly irrelevant a genuine psychological understanding of creativity.'220 His work explores the impact ortgeist (spirit of the place) and zeitgeist (spirit of the times) has upon creativity, and draws on the work of anthropologist Robert Carneiro to illustrate this point. Carneiro identified the ten most complex known societies, using 354 distinct societal traits to make his determination. ${ }^{221}$ All these complex societies accommodate(d) full-time cultural workers, leading Simonton to conclude:

Having such full-time practitioners probably enhances the prospects for true genius to emerge, given the tremendous amount of effort that is required to develop technique and knowledge to the highest possible level. Outstanding creativity is not the business of amateurs. 222

One particular aspect of the environment that Simonton emphasises is the zeitgeist. ${ }^{223}$ Drawing on his own study of classical composers, he suggests:

[C]omposers have been shown to alter the style of their melodies and harmonies when works are produced under wartime conditions. In particular, the melodies become much more chaotic and unpredictable, in a sense reflecting the external circumstances in which composition is conceived. 224

Ideological diversity, political instability, and those occasions when civilisations are open to an influx of ideas from abroad often contribute to a surge in creative activity. In summary, Simonton's research demonstrates that 'a specific set of political, economic, social, and cultural circumstances are associated with a high level of creative activity at a particular place or time.'225

Consideration of ortgeist and zeitgeist are not enough on their own however, and he further concludes:

\footnotetext{
220 Simonton, 'Creative cultures, nations, and civilizations', 320.

${ }^{221}$ Robert Carneiro, 'A Theory of the Origin of the State', Science 169 (1970), 733-738.

222 Simonton, 'Creative cultures, nations, and civilizations', 320.

223 In discussions such as Simonton's, zeitgeist tends to be presented as a kind of monolithic determinant exerting pressure on all actors and facets of life. While this might be useful as a broad-brush gesture toward some general trends (as used here), zeitgeist remains an unspecific term difficult to define or defend with any sort of scholarly rigour.

224 Simonton, 'Creative cultures, nations, and civilizations', 313.

225 Ibid., 319.
} 
Not all creators in the same generation are equally creative; and the most illustrious creators of a generation may conform less to the prevalent milieu than do less illustrious creators - and this independence of thought may be combined with a tendency to advocate extreme positions, and conceive systems and ideas that combine beliefs in unusual combinations. ${ }^{226}$

Nevertheless, even accounting for these outliers (who may in some cases be the most significant creators in their societies) it appears that there are times and places where creative action is more likely to occur than others, and Simonton's research offers clues as to the reasons for these occurrences. In light of Simonton's conclusions, and in line with jazz scholarship of the past few decades, consideration will be given to the broader social and political contexts within which jazz has been performed and its creative practice discussed in Chapter Two.

\section{Groups}

Teresa Amabile and Keith Sawyer both suggest that groups populated with diverse individuals are potentially the most creative. ${ }^{227}$ Amabile suggests that such groups are more creative because the combination of different intellectual foundations and approaches can lead to exciting and useful ideas. ${ }^{228}$ She further suggests that to be successful team members will all: be excited about the group's goal(s); be willing to help one another; and recognise the value(s) offered by each of the group's members. Taken together, 'These factors enhance not only intrinsic motivation but also expertise and creative-thinking skills.'229

Keith Sawyer suggests, 'Effective teams require participants who coordinate, communicate, resolve conflicts, solve problems, make decisions, and negotiate.'230 Sawyer describes communication in this context as involving deep listening, adding, 'most people spend too much time planning their own actions

\footnotetext{
226 Simonton, 'Creative cultures, nations, and civilizations', 319-320.

227 Amabile, 'How To Kill Creativity'; Sawyer, Group Creativity.

228 See also Sawyer, Group Creativity, 47-49; Sawyer, Group Genius, 51.

${ }^{229}$ Amabile, 'How To Kill Creativity', 21.

230 Sawyer, Group Creativity, 185.
} 
and not enough time listening and observing others.'231 In Sawyer's view, groups who engage improvisation as a standard practice offer the best sites for innovation because they are good at finding new problems rather than simply solving existing problems. ${ }^{232}$ These groups are also less structured, because 'improvisational groups are self-organising systems', leading to the emergence of (sometimes surprising) internal networks that are conducive to innovation and creativity. Such groups are often more effective when the participants are familiar with one another. Sawyer cautions that creativity takes time, both for the work to be accomplished and for the meaning of that work to become clear. He concludes by suggesting that 'the most effective collaborations involve some structure but not too much, and of a type appropriate' to what the group seeks to achieve. ${ }^{233}$ Taken together, these qualities provide a useful prism for considering the groups examined in Part Two.

\section{Summary}

This brief survey of the literature on creativity, filtered to accommodate my purposes, provides a tacit framework for Part Two of this thesis, which explores ideas presented in this chapter as manifest in jazz performances. In that section, I argue that a number of core values present at key moments of jazz achievement (and which I lay out in the next Chapter) are both fundamental to the music and conducive to creativity.

One of the key principles unanimously agreed by the writers I've drawn from is that creative work always builds on the foundations of the domain in which it operates, and on the creative work that preceded it (even if by means of transgression). ${ }^{234}$ Notions of tradition or convention or precedent are common to all fields of endeavour, and aligning new ideas to existing paradigms is one of the ways people make sense of what they encounter. Sometimes new work or

\footnotetext{
231 Sawyer, Group Genius, 14.

232 Ibid., 14-16, 25.

${ }^{233}$ Sawyer, Group Creativity, 181-186; Sawyer, Group Genius, 51-52. In Group Creativity Sawyer's remarks draw from empirical studies and are primarily focused on collaboration in education settings. His 2007 work suggest the claims are valid for many other kinds of group work as well.

${ }^{234}$ Nickerson, 'Enhancing Creativity'; Toynbee, Making Popular Music.
} 
ideas trouble our existing understanding with regard to the boundaries of a domain or the constraints of a definition - is a collage by Robert Rauschenberg really a painting, or is it something else? If it is a painting, then perhaps accepted notions of what a painting is may need to shift a little? - but generally, and whatever we make of new ideas, observers interpret them through the lens of convention.

This interpretation (and subsequent acceptance or rejection of an idea) is the province of the fields that govern domains. For example, Miles Davis's music from around 1970 and on the album Bitches Brew in particular has been the subject of debate, largely focused on whether or not the music is jazz. ${ }^{235}$ The crux of the matter, in this context, is which tradition Bitches Brew builds upon: if rock music, then perhaps the album is contentious in some ways (no vocals; complex improvisational strategies; considerable abstraction in places); if jazz, Bitches Brew would appear to be contentious in other ways (the use of electronic instruments and extensive studio manipulation; straight-eighth feels and backbeats). However, whichever way one cuts it, Bitches Brew emerged from prior practice, not as an immaculate, ex nihilo creation. Ultimately fields make decisions about acceptability, but (in the case of Bitches Brew) determinations about the acceptability or otherwise of the album's evident discontinuities with jazz (or rock) are complex and engage a range of issues including: aesthetics; cultural privilege; economics; and race (among others).

A key finding of the work of creativity researchers marshaled here is that to understand optimal creative work, the importance of considering the processes engaged trumps the importance of consideration of the product. ${ }^{236}$ This is material when considering group creativity (and according to Thomas Kuhn, Howard Becker, Jason Toynbee and Keith Sawyer, all creative work is the result of group action) because to understand the work, consideration needs to be

\footnotetext{
235 See, for example, Stanley Crouch's comments regarding Bitches Brew in 'Play The Right Thing', in The Miles Davis Companion, ed. Gary Garner (New York: Schirmer, 1990), 21-40. Ted Gioia (in The History of Jazz [Oxford: Oxford University Press, 1997]) is happy to include Bitches Brew as jazz in his history of the music.

${ }^{236}$ Amabile, 'How To Kill Creativity'; Sawyer, Group Genius.
} 
given to the social processes that enabled its realisation. ${ }^{237}$ In line with Bruce Johnson's advocacy for taking the testimony of participants into account when interpreting improvised group practices, I will draw on the testimony of musicians and others involved in the work of making the music cited in my case studies. ${ }^{238}$ This practice corresponds to the ethnographic work of Paul Berliner, Ingrid Monson and Travis Jackson, although my sources are all secondary. ${ }^{239}$

Accomplishing the best creative work in groups depends upon a number of conditions at both individual and group levels. At an individual level, optimal conditions for creativity include: the presence of divergent thinking (and in particular the generation of many ideas); a match between skills and experience, and the difficulty or complexity of the tasks undertaken; intrinsic motivation; self-monitoring (which takes several forms including metacognition or sublimation); and self-belief. For groups, optimal conditions for creativity include: mutual respect among team members; common group goals; and deep listening and/or careful observation within the group. ${ }^{240}$

A number of strategies may be employed by group leaders to stimulate these conditions, including: employing improvisational strategies in pursuit of group goals; facilitating sites for group work that are non-judgmental; offering participants freedom, particularly concerning means; and ensuring that there is sufficient time for the group members to become familiar with one another and have time properly to address the work at hand. ${ }^{241}$

Leaders themselves can optimise conditions for creativity from the outset by identifying good combinations of team members who possess similar levels of expertise yet are diversely gifted. The best leaders achieve good results because

\footnotetext{
237 Becker, Art Worlds; Kuhn, The Structure of Scientific Revolutions; Toynbee, Making Popular Music; Sawyer, Group Genius.

238 Johnson, 'Hear me talkin' to ya', 1-12.

239 Berliner, Thinking in Jazz; Monson, Saying Something; Travis Jackson, 'Jazz Performance as Ritual', in The African Diaspora: A Musical Perspective, ed. Ingrid Monson (New York: Garland, 2000), 23-82; Sawyer, Group Creativity.
}

240 Amabile, 'How to kill creativity', 77-87; Sawyer, Group Creativity.

${ }^{241}$ Sawyer, Group Genius. 
they have the capacity to think simultaneously at individual and group levels. ${ }^{242}$ None of the group leaders in the case studies exhibits all of these traits, but they all possessed the ability to assemble strong groups. And all of them made use of many of the strategies identified here, so enabling conditions conducive to creativity. The case studies in Part Two draw attention to these conditions and strategies, and suggest a correlation between them and the creative work the groups considered achieved. Causality is difficult to argue for anything, but the evidence I offer reveals that the conditions listed above and the creative achievements of the groups considered were frequently co-extensive, which is at least highly suggestive of a positive correlation.

We have seen, in this brief overview, that creativity is complex and assumes many forms. These forms have been categorised in various ways and mapped onto the manner in which creative work has affected the fields and domains to which it belongs. Creativity researchers concerned with products of creative action have suggested a continuum that ranges from crystallisation of style (where the conventions of an idiom are perfectly captured but where no new insight is offered) where it is thought creativity is not present (perhaps, for example, an idiomatically 'perfect' performance of a Bach invention by a programmed sequencer); through to ideas that change history (for example, the discovery of penicillin). ${ }^{243}$ In between are ideas that may be new to the individual who had them but which are in fact well-known (and which Margaret Boden describes as P [for personally] creative); through ideas that are new but do not change the domains in which they are accepted and which are described as 'little c' creative; on to those which add something significant to their domain, potentially changing the domain or in extreme cases initiating a new domain described as $\mathrm{H}$ creative (for Historically creative) or as 'Big C' creativity. ${ }^{244}$ This range of creative achievement is significant in this study because all of the musicians I consider accomplished work at both ends of the continuum between $\mathrm{P}$ creativity and $\mathrm{H}$ creativity and at many points in between. As I shall argue, the

\footnotetext{
242 Sawyer, Group Genius; Amabile, 'How to kill creativity', 77-87.

243 Toynbee, Making Popular Music, 105; Kaufman, Creativity 101, 44.

${ }^{244}$ Boden, 'Creativity: How does it work?', 237-250.
} 
historically creative work - for which these musicians are primarily celebrated depended upon their more modest achievements. In light of this all of the creative work of a subject is important in a discussion of their creativity when it is focused on tangible outcomes.

To further develop the distinction made between different kinds of creativity and their effects upon their domains, Margaret Boden identifies three categories of creative action. Of particular significance to this study are the two mechanisms these three types employ. Exploratory and Transformational creativity operate in an iterative manner, making use of conventions to incrementally progress a domain. Most creative work is exploratory in nature, and in general the gains of such work (in terms of evolution of the domain) are modest. $^{245}$ In some cases however, one of the conventions of standard procedure is changed in a manner that leads to a radical innovation. An example from the literary world might be James Joyce’s innovative admission of interior monologue from multiple actors in a literary text, thereby initiating stream of consciousness writing with Ulysses. In the case of Joyce, we are left with something that is still a novel, still uses words familiar to the reader, but offers an utterly new experience because Joyce offers an innovative way to mediate the voice of the narrator(s).

Such exploratory and transformational creativity has also occurred in jazz contexts. In Part Two of this thesis, Boden's Exploratory and Transformational categories are used to view the incremental work of jazz musicians as they make use of the conventions of jazz in developing unique sounds and approaches. The examples I invoke include the work of Miles Davis, with particular attention paid to the 'problem-finding' strategies he used.

The second mechanism Boden identifies is found in her category of combination creativity (homologous to Arthur Koestler's idea of 'bisociation'). ${ }^{246}$ Creativity of this kind combines conventional ideas from a genre with ideas from outside of that genre, leading to a new combination. This kind of

\footnotetext{
245 Boden, 'Creativity: How does it work?', 241.

${ }^{246}$ Koestler, The Act of Creation.
} 
combinatorial approach has been valuable in jazz creativity and in the case studies can be found in the music of Miles Davis and Jan Garbarek in particular.

Finally, there is the question of value. The products of creative work are generally considered valuable for the benefits that inhere within the work produced: a new piece of software is valuable because it makes our computers operate more efficiently, thereby saving disc space and time, for example. In this way, a new album by Wayne Shorter is valuable because as a product of creative action it provides (among other things) income for Shorter and the musicians with whom he recorded, the record company who manufacture and distribute the album, and the retailers who on-sell it. It is valuable to listeners because they gain personal benefit from listening to the music (or perhaps from 'owning' it). Finally, and in rare cases, it may be valuable because it offers a new idea (or ideas) that influences the field of jazz, moving it in new directions.

However, there are other kinds of value associated with creative work. An important one from the example just offered (for my purposes) is the experience of agency available to Wayne Shorter (and his fellow-musicians) in realising musical ideas. The work of Jonathan Rowson, Keith Negus and Michael Pickering suggests that it is this experience of agency that galvanises people to engage creativity in their lives, both in quotidian matters and in more traditionally defined 'creative' work (such as writing poetry). ${ }^{247}$ Specifically within the sphere of the creative arts, Negus and Pickering suggest that work is creative when it communicates experience. Such an inclusive definition embraces work that is creative in generally accepted terms (which is to say, novel and useful), but also admits work as creative even when that work does not actually offer anything particularly new. All work that achieves this threshold (i.e. communication of experience) is valuable in Negus and Pickering's framework because it affords those who make the work an opportunity to express themselves (thereby achieving a kind of self-creation) and affords audiences of that work the kind of emotional connection that is one of the reasons we value the arts - because artworks 'speak to us'. This framework is applied tacitly to the work of all of the musicians I consider in Part Two, and explicitly in discussions

247 Rowson, 'How are we disposed to be creative?'; Negus and Pickering, Creativity, Communication and Cultural Value. 
of the work of musicians when their practice did not offer anything particularly new, but did achieve the kind of communicative value that we ascribe to musicians when they are 'saying something'. 


\section{Chapter Two: Jazz}

\section{A lens through which to view Jazz}

Jazz is a big word. It has been called upon to cover a lot of ground. Depending on whom you ask, jazz is Louis Armstrong. Or jazz is Charlie Parker. Jazz is also Glenn Miller. Jazz is the Beatles. ${ }^{248} \mathrm{Jazz}$ is a fragrance by Yves Saint Laurent, an apartment complex in Bogota, and a car manufactured by Honda. I could fill a page with uses the noun 'jazz' has been employed to cover. In light of this, definitions of jazz are understandably diverse and, depending on whom you ask, contested. ${ }^{249}$ Seeking or spelling out a comprehensive definition of jazz in the context of this thesis would activate such a raft of issues that to adequately address them (if indeed that were possible) would require more words than I have available to me. Instead, I will draw four principles from Chapter One that I will use as a lens through which to view music that is generally accepted as belonging to the musical genre jazz. I make no claims about the comprehensiveness of such an approach; my objective is to consider what creativity in jazz might be, and then to meditate upon whether - in light of the answers I propose to that question - such creativity might be fostered going forward.

The first principle that informs my methodological lens is the primacy of process over product. ${ }^{250}$ Contemplating creative work through examination of its products is meaningful when exclusive definitions of creativity are invoked. However, for the purposes of this thesis I have engaged more inclusive definitions of creativity, as proposed by Keith Negus and Michael Pickering. ${ }^{251}$ When applied to artistic endeavour, an inclusive definition implies the need to

248 The Boys and Girl from County Clare, 2003. Dir. John Irvin.

${ }^{249}$ DeVeaux, 'Constructing the Jazz Tradition', 528-529.

250 Such a privileging of process does not represent a more 'true' picture of jazz, but rather casts jazz in a light that allows us to see more clearly aspects of the music that are sometimes occluded. Jazz, like all music I expect, involves the interaction of processes and content (or musical materials). To say one is more important than the other fails to recognise their mutual dependence. I do not claim process is more important, but adopt a process focus because it affords a different view of the music from one that privileges content.

${ }^{251}$ Negus and Pickering, 'Creativity and musical experience', 181. 
accept both ordinary and exceptional practice and requires that any analysis accommodate both, for the latter is only possible in the context of the former. ${ }^{252}$ Because the processes of both ordinary and exceptional creativity are alike, contemplation of those processes offers us an inclusive view of creativity that accommodates both the ordinary and the exceptional products that arise from them. ${ }^{253}$ This idea is powerfully reinforced when applied to the consideration of creative work in group settings where improvisation is employed (i.e. the activity is not entirely scripted or planned, but has scope for the individuals within the group to exercise choices about their individual actions). In these instances (and all the jazz I consider in this thesis is included in this set) the outcome is an emergent product of the processes engaged, and as Keith Sawyer argues, can only be fully understood if the processes that gave rise to the emergent are considered. ${ }^{254}$

There are three processes I draw from the creativity literature discussed in Chapter One as being centrally important to jazz as conceptualised in this thesis. These three processes form the remainder of my methodological lens. The first process I emphasise, related to Keith Negus and Michael Pickering's definition of creativity as 'communicated experience', is the development and expression of an individual voice. ${ }^{255}$ As Negus and Pickering suggest, communicating experience implies expression, and that expression involves a 'particular style or manner that emerges as a defining aspect of creating or performing.' Such expression may be related to 'what is characteristic of particular individuals' or emerges as 'an aspect of collective identity.'256 I will argue that expression in jazz is, ideally, both of these.

\footnotetext{
252 Negus and Pickering, 'Creativity and musical experience', 189.

${ }^{253}$ Boden, 'Creativity: How does it work?' identifies two processes, one iterative and one involving combinations. (240-243) These processes (which are not mutually exclusive) appear to be common to all creative activity. What differs most markedly is the degree to which the results of these processes are novel and creative (or communicate experience) on a case-by-case basis, rather than the mechanisms by which they are accomplished.

${ }^{254}$ Sawyer, Group Creativity, 78.

255 Negus and Pickering, Creativity, Communication and Cultural Value, 37-38.

256 Ibid., 26.
} 
The relationship between individual voices and collective identities may be theorised as a function of the second process I privilege: improvised interactivity within group settings. As Keith Sawyer argues, group creativity (in verbal and musical contexts) is a 'collaboratively emergent social process, and its analysis requires a focus on interaction, practice and pragmatics.'257 Furthermore, improvisation is a crucial aspect of collaborative work; for Sawyer, if a group is to be creative then the presence of improvisation is not in question, only the degree to which it is employed. ${ }^{258}$ Sawyer suggests that improvisation is present in group creative activities on a continuum that ranges from (minimally improvised) ritualised genres to (maximally) improvisational genres. ${ }^{259}$ Among musical performances commonly accepted as jazz (those one might find captured on recordings in the CD store and filed under 'Jazz', for example) there are performances at all points along this continuum.

The third process I employ in order to view jazz through the lens of creative practice is the appropriation and transformation of received and newly discovered materials. Margaret Boden's work both emphasises the centrality of this practice in accomplishing creative work, and provides a useful taxonomy for distinguishing amongst its various manifestations. ${ }^{260}$ In the framework I am drawing here, these appropriations and transformations involve 'a series of encounters between old and new cultural forms and practices, traditional and emergent ways of seeing, listening and thinking about the world.'261 These encounters not only involve the old and the new, but also imply negotiations between the local and the global, a prospect that leads Keith Negus and Michael Pickering to suggest that, 'creativity arises not from a cultural context which exists in monolithic isolation, but from cultural borrowings and transactions.'262

\footnotetext{
257 Sawyer, Group Creativity, 78.

258 Sawyer, Group Genius, 23-29. Here I employ a commonsense definition of improvisation: 'making stuff up on a moment-to-moment basis'.

259 Sawyer, Group Creativity, 81.

260 Boden, 'Creativity: How does it work?' 240-243.

261 Negus and Pickering, Creativity, Communication and Cultural Value, 39.

262 Ibid., 40.
} 
As will become clear, these practices have been evident in jazz across the entire history of the idiom.

Jazz is commonly associated with African American culture, and most histories of jazz make explicit links between African cultural retentions among African American communities in the United States and the musical practices that are central to jazz. ${ }^{263}$ I find the ideas these histories promulgate fascinating and compelling, and the notion that jazz can be understood to be predicated upon principles of cultural production that are consistent with diasporic values that survived the Middle Passage is one I find persuasive. ${ }^{264}$ However, I am also conscious of how problematic ideas about the African diaspora have become in recent years. Kofi Agawu's critique of generalised ideas of Africa (the error of 'the putative claim that African music constitutes a homogenous body of music' for example) at the very least problematises claims about what African cultural retentions might actually look like in any one of the sites of the African diaspora. ${ }^{265}$ My emphasis on creativity to a large extent glosses any significance African cultural retentions may have in jazz. This is not to imply an undervaluation or subordination of such influences but rather to underscore a dimension of the music that has itself been subordinated in current scholarship.

My examination of jazz will proceed by considering in turn each of the four lenses through which I am viewing the music. Each concept or process will initially be positioned relative to the cultural practices that scholars and historians have identified as being consistently present in jazz, practices that have animated the music and made it distinguishable from other genres. I am

\footnotetext{
${ }^{263}$ For example, see: Gioia, The History of Jazz; Mark Gridley, Jazz Styles (Harlow (UK): Pearson, 1994); Christopher Small, Music of the Common Tongue: Survival and celebration in AfroAmerican Music (New York: Riverrun Press, 1987); Alyn Shipton, A New History of Jazz (London: Continuum, 2001); Eileen Southern, The Music of Black Americans (New York: W.H. Norton, 1983); Gunther Schuller, Early Jazz: Its roots and musical development (New York: Oxford, 1968).

264 In particular: Paul Gilroy, The Black Atlantic (Cambridge: Harvard University Press, 1993); Ingrid Monson, Freedom Sounds: Civil Rights Call Out to Jazz and Africa (Oxford: Oxford University Press, 2007, and especially 66-106); John S. Roberts, Black Music of Two Worlds (New York: William Morrow, 1972); Olly Wilson, 'Black Music as an Art Form', Black Music Research Journal 3 (1983), 1-22; and the contributors to The African Diaspora: A Musical Perspective (New York: Garland Publishing, 2000).

265 Kofi Agawu, 'The Invention of "African Rhythm"', Journal of the American Musicological Society 48/3 (Autumn 1995), 384. This idea is one of the starting points for Gilroy's The Black Atlantic.
} 
making use of these values because they offer a view of jazz that (although admittedly contingent) is valid - taking into account as it does core values of the music that have consistently characterised its production - and that brings some of the ways creativity has operated across the history of the music into sharper relief.

\section{Jazz as Process}

It is common (in jazz histories at least) to discuss jazz in terms of a body of works tracing an evolutionary stylistic arc from a kind of folk expression in New Orleans at the turn of the nineteenth century to the so-called neo-classicism of the 1980s and 1990s. ${ }^{266}$ The remarkable changes that jazz performance styles have undergone over the past century attest to the mutability of the idiom. However, if jazz is defined solely in terms of its style features, it is difficult to isolate a definition that could accommodate music as diverse as Jelly Roll Morton's 'Black Bottom Stomp', Charlie Parker and Dizzy Gillespie’s 'Koko', Charles Mingus's 'Epitaph' and Miles Davis's 'Spanish Key' - all performances that are included in contemporary accounts of the music. ${ }^{267}$ However, there are processes common to all of these performances that do suggest points of unity.

In its earliest incarnations, jazz was played by African American musicians in the south of the United States and as such is generally described as African American music. ${ }^{268}$ Christopher Small suggests that African American music (of which jazz is said to be a subset) is primarily 'an approach to the act of music making, a way of playing and responding to music.'269 He later elaborates,

\footnotetext{
266 Mark Gridley's college textbook is a case in point, and is titled Jazz Styles. Ted Gioia's The History of Jazz does similar work, as does Henry Martin's Jazz: The First 100 Years (London: Cengage Learning, 2011). In recent years a 'standard collection' of the masterworks of jazz has been Ken Burns: Jazz, a 5-CD canonical statement to accompany the PBS television series (and book).
}

267 A similar point is made by James Young and Carl Matheson, in 'The Metaphysics of Jazz', The Journal of Aesthetics and Art Criticism 58/2: Special Issue on Improvisation in the Arts (Spring, 2000), 125.

\footnotetext{
268 Alyn Shipton (in A New History of Jazz) suggests, contrary to other writers (such as Gioia, The History of Jazz) that jazz emerged more or less simultaneously in multiple sites across the United States. What writers do appear to agree upon is that African American musicians were the principle actors in the first flowering of jazz.

269 Small, Music of the Common Tongue, 14.
} 
suggesting that music 'is not primarily a thing or a collection of things, but an activity in which we engage. One might say that it is not properly a noun at all, but a verb.'270 This corresponds to composer and scholar Olly Wilson's claims about African American music, which he argues consists of:

... the common sharing of a core of conceptual approaches to the process of music making and, hence, is not basically quantitative but qualitative. The particular forms of black music which evolved in America are specific realizations of this shared conceptual framework which reflects the peculiarities of the American black experience. As such, the essence of their Africaness is not a static body of something which can be depleted, but rather a conceptual approach, the manifestations of which are infinite. The common core of this Africaness consists of the way of doing something, not simply something that is done. ${ }^{271}$

Wilson asserts that African American music exhibits a set of conceptual approaches, which are ubiquitous but present in different forms across two distinct traditions of African American music. Wilson illustrates his claims with analysis of a performance representative of each tradition: a work song, and a late-1950s performance by the Miles Davis Quintet. ${ }^{272}$

Wilson describes the first of these as belonging to the 'folk African American tradition', claiming that such music evolved directly from African musical traditions, sharing most of the basic concepts of those traditions while 'selectively incorporating important aspects of western musical practice.'273 This 'folk African American tradition' includes hollers, early spirituals, work and play songs, rural work songs, gospel music, urban blues and soul music as its principle manifestations.

The second tradition Wilson identifies is one characterised by 'a greater interaction and interpenetration of African and Euro-American elements, although the fundamental qualities which make it unique are rooted in African conceptual approaches to music making. ${ }^{274}$ According to Wilson this tradition

\footnotetext{
270 Small, Music of the Common Tongue, 50. (Original emphasis).

271 Olly Wilson, 'The significance of the relationship between Afro-American and West African Music', Black Music Perspective in Music 2/1 (Spring 1974), 20.

272 Wilson, 'Black Music as an Art Form', 3 (for list of conceptual approaches); 11-21 (for analyses).

273 Ibid., 9.

274 Ibid.
} 
involves 'reshaping the Euro-American qualities of the music to African

American norms. The process of cultural transformation became the salient characteristic of this tradition.'275 This process of transformation is one to which I will return in greater detail later in this chapter, but for now the point I want to emphasise is not that these processes might be exclusively ascribed to African Americans or to African cultural retentions, but that processes themselves can reasonably be given priority in descriptions of jazz. As Wilson claims, 'much of the entire jazz tradition [is an expression] of this second tradition.'276

In recent scholarship Ingrid Monson suggests that such primacy of process leads to evolving traditions, thus explaining both the changing styles of jazz, and the gradual evolution the processes used to generate the music have themselves experienced. Jazz is not alone in this regard; in her introduction to The African Diaspora, Monson posits that: 'All cultural systems, even in the absence of external influences, are inevitably engaged in processes of reproducing themselves through time that include not only duplication but also contestation and synthesis (often intergenerational).'277 What I want to point toward here is that while Wilson seems to view the six conceptions he delineates as foundational and essential to the music, Monson suggests they may 'change over time' and in some cases be traded for other conceptions: ${ }^{278}$

In the late 1940s and early 1950s jazz drew upon a multiplicity of aesthetic perspectives in fashioning individual sounds, including the African-American vernacular aesthetics, the aesthetics of the American popular song, the aesthetics of classical music, and also, for some artists, African diasporic sounds such as Afro-Cuban sacred and secular music, Nigerian talking drums, and

\footnotetext{
275 Wilson, 'Black Music as an Art Form', 10.

276 Ibid.

277 Ingrid Monson, 'Introduction', in The African Diaspora: A musical perspective, 10. (My emphasis)

278 Ingrid Monson, Freedom Sounds: Civil Rights Call Out to Jazz and Africa (Oxford: Oxford University Press, 2007), 27. There is scope for ambiguity in interpreting Monson's claims in this context. While the traditions she identifies here offer conceptions of music making (i.e. certain procedures) they also consider musical materials (particular instruments, sounds, rhythms, and so forth). Aesthetic agency may therefore take the form of adoption of procedures from other traditions (for example, Lennie Tristano's application of counterpoint [which was informed by his study of J.S. Bach] to his jazz music) or adoption of materials or instruments from other traditions (for example, Yusef Lateef's use of Middle Eastern instruments such as the schwaam). Either way, the notion that making jazz engages exclusively African-American conceptual approaches is troubled by such examples.
} 
Trinidadian calypso. Individual musicians, regardless of their ethnic home base, can and did exercise aesthetic agency by exploring musical aesthetics from both within and beyond their expected ethnic categories. ${ }^{279}$

Jazz musicians have continued to exercise aesthetic agency by incorporating, for example, ideas from rock music in the 1960s and 1970s, and in recent years from electronic dance music, into their jazz performances. ${ }^{280}$ Monson's remarks about the ways cultural principles (analogous to Wilson's 'conceptions' of music making) evolve over time, experiencing subtle transformation themselves as they act on (or are mixed with) new materials, can be read either in terms of particular style features or musical materials (contrapuntal surface features in Dave Brubeck's music, or turntable effects in Herbie Hancock's, for example) or in terms of processes (evolving conceptions of improvisation, for example). ${ }^{281}$ What I wish to emphasise is that processes have significantly determined the sounding objects that result from jazz performances. Understanding these processes - which have evolved and been used to transform an increasingly diverse range of musical materials over the past century - can help us make sense of the extraordinary range of styles those sounding objects have exhibited.

The distinction between product and process - between what is done and how it is done - is to a degree at the heart of a heated debate that has exercised the jazz community for some years. The questions raised by this debate (sometimes called 'the jazz wars') are contested because they are central to

\footnotetext{
279 Monson, Freedom Sounds, 27. George Lewis ('Improvised Music After 1950: Afrological and Eurological Perspectives', in The Other Side of Nowhere: Jazz, improvisation, and communities in dialogue, ed. David Fischlin and Ajay Heble [Middleton, Connecticut: Wesleyan University Press, 2004, 131-162]) notes that such cross-genre borrowing has continued to the present day, although more commonly in the field of "improvised music" - music free of idiomatic constraints - rather than specifically in jazz.

${ }^{280}$ For example, Miles Davis's adoption of rock music instruments and procedures in the late 1960s, or Nils Petter Molvær's appropriation of performance strategies from electronic dance music in the 1990s. There are many other examples of this kind of aesthetic agency, such as Paul Bley's flirtation with serial music techniques $(12+6$ In A Row $)$ or John Coltrane's investigation of Spanish music (for example, Olé Coltrane). See Nicholson's Is Jazz Dead?, and in particular chapters 6 ('Altered Realities and Fresh Possibilities: Future Jazz') and 7 ('Out of Sight and Out of Mind: Jazz in the Global Village').

${ }^{281} \mathrm{An}$ instructive example might be a comparison between the improvisational approaches adopted by jazz soloists Louis Armstrong, Charlie Parker, Ornette Coleman and Steve Coleman.
} 
defining the aesthetics of jazz. ${ }^{282}$ Musician and scholar Jerome Harris identifies two camps in the jazz community that dispute what constitutes valid jazz aesthetics. He describes these respective camps as adopting either a 'canon' or 'process' approach to jazz. The canon position 'extols the art's continuity with past historical practice' and sees jazz as 'a music defined by a specific African American-originated canon and socially constituted guild.' Conversely, the process position tends to 'valorize change, risk, surprise, and the development or discovery of fresh varieties of expression and beauty,' and views jazz as 'the results of certain African American-originated processes and aesthetics manifested in music.'283

Harris points out that, 'both sides can rightly lay claim to embodying aspects of jazz "tradition" and to promoting "innovation" within the style parameters they have chosen.'284 However, he also posits:

For musicians and audiences in non-American [sic] cultures, jazz must almost inevitably be considered a process - first, because members of these communities naturally bring their own musical and cultural backgrounds to bear on the music they make, market and listen to; and, second, because their distance from the music's home base is such that it is impractical (if not quixotic) to build a local aesthetic on the approval of canonmakers in the United States. 285

Now, if this is the case, what can we say of those who were the originators of jazz? Given they did not have an inherited tradition called 'jazz' to guide their music making (a tradition that might prescribe: particular forms, melodic vocabularies, standard repertoire or agreed style features), what did inform it?

Clearly, given the nature of the music that emerged - music that contains traces of blues and spirituals, ragtime and popular dance music of the day (in other words, 'the musical and cultural backgrounds' of the musicians making early jazz), amalgamated and transformed into something quite different - the

\footnotetext{
282 Stanley Crouch, Considering Genius (New York: Basic Books, 2006). Crouch includes a chapter called 'Battle Royale' in which some of his fusillade in this dispute is documented. Nicholson's Is Jazz Dead? presents a alternate view of some of the same issues.

283 Jerome Harris, 'Jazz on the global stage', in The African Diaspora: A Musical Perspective, ed. Ingrid Monson (New York: Garland, 2000), 120-121. (Original emphasis)

284 Ibid., 120.

285 Ibid., 121-122. David Murray's comments about playing jazz as an African-American in Europe are illuminating in this regard. See Peterson, Music and the Creative Spirit, 211-214.
} 
transformations to which these musical materials were subjected was a key determinant in the final shape of the music. For Jerome Harris, these transformations were the result of 'certain African-American-originated processes and aesthetics', and it is these values that he champions. ${ }^{286}$ While Harris is careful to provide caveats that ensure he avoid charges of racial essentialism, he does nevertheless claim that, "The influence of a traditionally African-American jazz aesthetic is still strong, of course; it remains the prime determinant of how (by what processes) jazz is constructed. But the what of jazz - the set of elements utilized in this process of construction - often includes [non-'jazz'] content.'287 In this Harris's comments broadly align with the view adopted by Ingrid Monson, Olly Wilson, Paul Gilroy, John Storm Roberts, Travis Jackson and Eileen Southern. ${ }^{288}$ My point here is that jazz is usefully understood as a set of processes (enacted, admittedly, on a set of musical materials with which they interact): processes historically emergent from African-American expressive culture, as shaped by - and in response to - specifically $20^{\text {th }}$-century African American experience, but available to all. I will turn now to the three processes that I believe are most helpful in offering a view of jazz that illuminates the ongoing presence of creativity in the music's production.

\section{The development and expression of individual voices}

Louis Armstrong, who is considered by many to be, if not the most important, then certainly the first important soloist in jazz history, is thought to be largely responsible for transforming jazz from the predominantly collective ensemblebased music it had been up to that point (c. mid-1920s) into music oriented primarily toward individual expression in which the soloist stood out from the

\footnotetext{
286 This is also the argument made by Eileen Southern in The Music of Black Americans, and by Olly Wilson in the essays cited earlier in this chapter. It is a central plank of Gunther Schuller's thesis in Early Jazz, 63-89.
}

287 Harris, 'Jazz on the global stage', 122 (original emphasis). Harris rejects the idea that jazz is an exclusively African American art form: he believes that 'the notion of "cultural purity" is largely specious and that such notions generally reflect not reality but a common psychological desire for comforting social boundaries and definitions of self.' (123)

288 Monson, 'Introduction' to The African Diaspora; Monson, Freedom Sounds; Wilson, 'Black Music as an Art Form'; Gilroy, The Black Atlantic; Roberts, Black Music of Two Worlds; Jackson, 'Jazz Performance as Ritual'; Southern, The Music of Black Americans. 
group. ${ }^{289}$ Yet even before Armstrong moved to the front of the group (and certainly after that), jazz has almost always been characterised by the use of personalised performance techniques.

Kevin Whitehead posits that 'playing jazz is about making a personal statement.'290 Such personal statements are intimately linked to players possessing an individual 'voice' (that is, a unique, identifiable sound or approach). ${ }^{291}$ When a musician's musical utterances are thought to possess unique qualities, that musician is said to have 'a sound', an attribute that has remained a consistently prized value and is a familiar trope in discourse about jazz. Eileen Southern, for example, in her seminal work The Music of Black Americans identifies a personal voice as the most important feature of the music. In her view, jazz - like the blues - is vocally oriented music, and performers use their instruments to reproduce their individual singing style. Traditional melodies or common harmonic frameworks may serve as a launching point for improvisation, 'but it is the personality of the player and the way he or she improvises that produces the music.'292

These individual voices are a fundamental characteristic of music's function in the African American culture in which jazz emerged. Further, the kind of self-expression they offer is absolutely central to jazz. Ronald Radano writes:

In colonial and antebellum slavery, voice represented the most sonically conspicuous possession of a body otherwise possessed. The vocal utterance provided slaves with an expressive tool, an audible social force that served to construct group networks and structures of meaning. Within the economy of slavery, African-American slaves identified a way of crafting cultural possessions within the vessel of their own possessed self - out of the possession itself $-\mathrm{a}$ force that challenged the control of the master-owner [...] More than any other expressive phenomenon, the "vocal" sound of black music has represented the crucial place from which African-Americans have told their

\footnotetext{
${ }^{289}$ For example, see: James Lincoln Collier, The Making of Jazz: A comprehensive history (London: Delacorte, 1979); Mark Gridley, Jazz Styles; Ken Burns, Jazz.

${ }^{290}$ Kevin Whitehead, Why Jazz? A concise guide (New York: Oxford University Press, 2011), 15. Also, Nat Shapiro and Nat Hentoff, Hear Me Talkin' To Ya: The story of jazz as told by the men who made it (New York: Dover, 1955).

291 'Voice' is a ubiquitous term that has emerged from musicians' discourse.

292 Southern, The Music of Black Americans, 366-367. (My emphasis)
} 
stories [...] "Black voice," then, can be understood [first] as the literal, audible utterance empowering the singing or speaking subject...293

One reading of Radano's claims might be that it was with the singing and speaking voice that enslaved African Americans were afforded agency, were able to declare independent identities as people. It could be said that one of the ways the first African Americans constituted themselves - claimed for themselves autonomous identities - was through vocal (and by extension, musical) expression.

For Radano, "the "vocal" sound of black music has represented the crucial place from which African Americans have told their stories.'294 The idea that a performance 'tells the musician's story' is a familiar trope in jazz. As Allan Morrison said in his discussion of Lester Young, 'In jazz more than any other way of music, a man's music will reflect the man, his thoughts, his emotions.'295 Saxophonist J.R. Monterose writes: 'Why not play your own music if you're a jazz player? Jazz is supposed to be self-expression. You've got to have a need to say something on your instrument - to get it out. If I can't be myself, there's no point in being in jazz.'296 Ingrid Monson emphasises this value with the title of her book on the ensemble in jazz, Saying Something. ${ }^{297}$

293 Ronald Radano, Lying Up A Nation: Race and Black Music (Chicago: University of Chicago Press, 2003), 14-15. (My emphasis)

294 Ibid.

295 Alan Morrison, 'You Gotta be Original, Man', in A Lester Young Reader, ed. Lewis Porter (Washington: Smithsonian Institution, 1991), 132.

296 J.R. Monterose (sleeve note to Straight Ahead. New York: Xanadu, 1975). David Ake, in Jazz Matters complicates this idea. Observing that musicians make musical choices based not only on their preferences (which in turn have been shaped by their cultural, historical and geographical settings, and also their education, experience and immediate environment) but also by the demands of club owners, record company executives, fellow musicians, teachers and listeners, Ake concludes: 'The structure, timbre or style of music does not automatically correlate directly to the personality, mood or biography of the person(s) who performed or composed that music.' (8.) While the externalities Ake lists definitely inform the music, they do not ultimately determine the sum total of its shape. Creative musicians do make compromises, but at a point, if the compromises are unacceptable, they find another way to do what it is they want to do. Coltrane chose to work with Bob Theile, who gave him the kind of artistic license he desired. (Ashley Kahn, A Love Supreme: The Story of John Coltrane's Signature Album [New York: Penguin, 2002], 84-86); Ellington broke with Irving Mills in part because he had grown tired of Mills' intrusions into musical decisions. (Terry Teachout, Duke: The Life of Duke Ellington [London: Robson, 2013], 182.) In this way I would argue that most creative musicians eventually find a way to work that allows them to produce the music they want to produce, music that reflects their artistic personality, to use Ben Ratliff's expression. Of course such work is mediated by the circumstances of their professional situations, but ultimately (and I would suggest in most cases) 
Having a 'sound' or a 'voice' in jazz involves exercising control over many things: the timbre of one's instrument; the way one plays relative to the time; the harmonic and melodic games that characterise one's music; the kind of repertoire adopted and the conceptual approaches routinely invoked. Perhaps the most obvious aspect of a musician's sound is the sonic qualities of the noise(s) they produce. As Ben Ratliff claims, 'every musician finally needs a sound, a full and sensible embodiment of his [or her] artistic personality, such that it can be heard, at best, in a single note. Miles Davis was fragile and pointed. Coleman Hawkins was ripe and mellow and generous. John Coltrane's was large and dry, slightly undercooked and urgent.'298 However, such a sound is not a monochromatic or unmodulated sonic phenomenon. Olly Wilson emphasises that in jazz (and other African American musical forms), timbral variety characterised individual performances, aligning those performances to speech and hence individual musical 'voice'. 'Within that [jazz] tradition, the single-line soloist is expected to explore a wide range of timbral variations, so much so that some observers have spoken of the tradition of making the instrument simulate vocal technique, or 'talk' or 'speak'.'299

Developing an individual sound is not an easy thing to achieve. Ralph Ellison's description of the jam session as a rite of passage gives an indication of how difficult it is to achieve one's own voice:

Although since the twenties many jazzmen have had conservatory training and were well grounded in formal theory and instrumental technique, when we approach jazz we are entering quite a different sphere of training. Here it is more meaningful to speak, not of courses of study, of grades and degrees, but of apprenticeship, ordeals, and initiation ceremonies, of rebirth. For after the jazzman has learned the fundamentals of his instrument and the traditional techniques of jazz - the intonations, the mute work, manipulation of timbre, the body of traditional styles - he must then "find himself," must be reborn, must find, as it were, his soul. All this through achieving that subtle identification

creative musicians do decide what is performed, composed, released, even if in collusion with their record companies or whoever is pulling some of the strings. The limitations imposed by circumstances may even enable greater creativity.

297 Monson, Saying Something.

298 Ben Ratliff, Coltrane: the story of a sound (New York: Farrar, Straus and Giroux, 2007), x.

299 Olly Wilson, 'The Heterogeneous Sound Ideal in African-American Music', in New Perspectives of Music: Essays in Honor of Eileen Southern, ed. Josephine Wright \& Samuel Floyd (Warren, MI: Harmonie Press, 1992), 329. 
between his instrument and his deepest drives which will allow him to express his own unique ideas and his own unique voice. He must achieve, in short, his own self-determined identity. 300

Pianist Mike Nock has worked with many of the great jazz musicians of the last fifty years and his remarks also acknowledge how very difficult, and how important it is for musicians to develop their own sound. Commenting on saxophonist Sam Rivers, Nock said:

Sam was one of the very few guys who had an individual sound. So did Yusef Lateef. They both had highly identifiable approaches. Nowadays most of the saxophone players sound very similar. Many of them have followed the [John] Coltrane or Michael Brecker route, just about without exception. ${ }^{301}$ Which is a shame, because jazz is about freedom - express yourself, be yourself, try to find your own stuff - that was what it was all about. ${ }^{302}$

Sam Rivers himself emphasises this point, reporting:

I worked out my own chord substitutions, wrote my own exercises to practice [...] I listened to everyone I could hear to make sure I didn't sound like them. I wasn't taking any chances; I wanted to be sure I didn't sound like anyone else. A person doesn't have to sound like Charlie Parker or John Coltrane. It takes more work, but it can be done. 303

As Sam Rivers attests, all of the aspects I've laid out (timbre, time [or 'feel'], harmonic and melodic approaches, repertoire) can contribute to the formation of a personal sound. Taken together, these characteristics make musicians readily identifiable to those familiar with their work. However, once established, a musician's sound is not a 'once-for-all-time' characteristic, and musicians do continue to evolve and change.

The evolution of musicians' sounds reflect not only their development as players, but also the changing circumstances of their lives, and often the

\footnotetext{
300 Ralph Ellison, Shadow and Act (New York: Random House, 1964), 208-209. For examples of musicians engaged in this process of self-discovery, see: Ross Russell's Bird Lives (New York: Quartet, 1980) for an account of Charlie Parker's beginnings and journeyman years; and Jack Chambers' Milestones: The Music And Times Of Miles Davis (New York: Da Capo Press, 1998) for a similar history of Miles Davis's development.

301 By which Nock implies their improvisational languages, approaches and sounds.

302 Norman Meehan, Serious Fun: The life and music of Mike Nock (Wellington: Victoria University Press, 2010), 69. Jazz saxophonist Lester Young was extremely dismissive of the kind of epigonism among jazz players that Nock describes here. See Young's remarks, quoted in Morrison's essay “You Gotta be Original, Man”, 131-135. See also Priestly, Mingus: A Critical Biography, 68-70 for Charles Mingus's views on imitation versus originality.
}

303 Sam Rivers, quoted in Robert Palmer's liner notes to Sam Rivers, Dimensions and Extensions (New York: Blue Note BST 84261, 1987). 
influence of the new ideas and music to which they are exposed. ${ }^{304}$ In other words, the musicians' music changes because they change, from day to day, from year to year and from generation to generation. It was this understanding Albert Ayler articulated when he said, 'I have lived more than I can express in bebop terms.' ${ }^{305}$ If musical expression is informed by the changing lives of its makers, as Ayler's claim suggests, then constant adaptation and change become inevitable. But such adaptation and change is not generally for its own sake; it is most often in the service of music that reflects the evolving tastes and circumstances (and therefore, the lives) of its makers. ${ }^{306}$

How music can actually reflect its makers' lives is somewhat mysterious, but we needn't reject this idea simply because it is difficult to quantify. Jazz scholar Travis Jackson interviewed a number of jazz musicians, who he said:

... were largely silent on the processes whereby the experiences of daily life are translated into musical performance. The silence, however, is an indicator not of illegitimacy of the concept, but of the difficulty of verbalizing experiential and musical concepts that are deeply felt. ${ }^{307}$

A signal feature of these individual (and I suggest, self-expressive) voices in jazz - certainly during the first half of the twentieth century when the music emerged - is that while individuals played an essential role, it was a role that was integral, and to some extent subservient to, the functioning of the collective. ${ }^{308}$ Even as

\footnotetext{
304 This often manifests as a kind of hybridity, but as Paul Gilroy argues, such hybridity doesn't stop the music being individual or a marker for identity (The Black Atlantic, 131). In fact, given the way even quite singular musicians 'tried on' the styles of influential players (early Miles Davis owes a debt to Dizzy Gillespie; early John Coltrane owes a debt to Dexter Gordon, and so forth), ultimately adopting aspects of their models and discarding others, hybridity is an inevitable consequence emulative learning in oral traditions, including jazz.
}

305 Albert Ayler, quoted in Nat Hentoff, 'The truth is marching in: an interview with Albert and Don Ayler', Downbeat 33/23 (November 17, 1966), 40.

306 Brian Ward (Just my soul responding: Rhythm and blues, black consciousness and race relations [London: UCL Press, 1998]) also makes this point.

307 Jackson, 'Jazz Performance as Ritual', 46.

308 Ingrid Monson's ('Riffs, Repetition, and Globalization', Ethnomusicology, 43/1 (1999), 31-65) discussion of musical grooves (which specifically invokes jazz) is a useful one to keep in mind here. As Monson tells it, musical grooves (which are essential to most jazz) involve layered repetitions [that] construct a context in which musical creativity can take place over successive periodic units.' (51) In this context (drawing from Chernoff [1979] and extending the principles of West African music to jazz, as Monson seems to do) it is possible to suggest that individuality emerges through participation in a densely overlapping framework of repeated patterns, and where the mastery of social conventions provides a context in which personalized expressions take place.' (51) In this framework, individual expression is only possible because of the work 
jazz has evolved to embrace practices beyond the parameters of African American cultural expression, the development of individual voices and their expression within interactive ensembles have remained centrally important processes in jazz creativity.

\section{Improvised interactivity in group settings}

\section{The place of the individual in the collective}

Jazz is sometimes described as a soloist's art and the stories commonly told about jazz, the conventional canon, and most histories lionise a relatively small number of heroic individuals. ${ }^{309}$ The role of the individual is essential to jazz, but in accepted jazz narratives that role is frequently overplayed at the expense of the communal values that also underscore the music. Jazz guitarist and scholar Jerome Harris suggests one of the reasons individuals have tended to be emphasised in these accounts is because a central tenet of jazz is the idea of 'freedom of expression', an idea commonly associated with individuality. ${ }^{310}$

This association, manifested musically in improvisation, is especially highlighted in the image of the "heroic" star soloist. It is congruent with the broad iconic concept of American [sic] individualistic freedom. In some periods and styles of jazz, the individualistic focus has obscured the role of the group ("sidemen" or community or culture), which forms the necessary context for the individual's expressive freedom. ${ }^{311}$

James Stewart is forceful in his renunciation of the way individuals came to be lionised in jazz during the late 1930s and early 1940s and which has continued to the present day. He described this tendency as 'the monstrous display of an

\footnotetext{
and context provided by the collective. For a discussion of groove in this collective context, see Charles Keil, 'The theory of participatory discrepancies: A progress report', Ethnomusicology, 39 (1995), 1-19. For a qualifier to Keil's work and a more nuanced proposal as to the sources (and to some extant nature) of groove, see Matthew Butterfield, 'Participatory discrepancies and the perception of beats in jazz', Music Perception: An Interdisciplinary Journal 27/3 (February 2010), 157-176, particularly the conclusions on 173.

${ }^{309}$ Gioia, The Imperfect Art, 15; DeVeaux, 'Constructing the jazz tradition', 525.

${ }^{310}$ Harris. 'Jazz on the global stage', 117.

311 Ibid., 127, fn 21.
} 
aesthetic individualism (an antiquated white Renaissance concept) during the Bop movement.'312

While Stewart's trenchant argument seems predicated more on political concerns than musical considerations, his criticism of the priority given soloists - above concern for the collective - is nevertheless telling. Examination of much popular writing on jazz, and most pedagogical texts too, reveal solo improvisation to be the musical practice most commonly associated with jazz (along with 'swing'). ${ }^{313}$ Further, it is almost always more highly valued than the collective actions that I argue are absolutely central to the music. ${ }^{314}$

In emphasising collectivity I do not mean to suggest that individuality is somehow dispensable in jazz: it is not. However, in ensemble jazz (which is to say, most jazz) individuality is always made manifest in the context of the collective, and for the most part is made meaningful by that context. Miles Davis's solos assume whatever meaning they have for us at least in part because of how his lines and sound interact with Bill Evans (or Herbie Hancock or Red Garland or Chick Corea) and how they operate in contrast to the playing of John Coltrane (or Wayne Shorter or Charlie Parker or John Scofield).

In earlier forms of jazz, collective or communitarian principles found expression in the way ensembles coordinated their actions to establish a groove, and in the practice of collective improvisation, whereby all (or all front-line) instruments improvised simultaneously. This practice created a musical texture that highlighted the mosaic-like timbral quality of the ensemble: not monophonic, not unanimous, but heterophonic. Olly Wilson identifies such heterophony as a core conceptual procedure in African American music. ${ }^{315}$ Significant to the current discussion, the heterogeneous sound ideal showcases

\footnotetext{
312 James Stewart, 'Introduction to Black Aesthetics in Music', in The Black Aesthetic, ed. Addison Gayle (New York: Doubleday, 1971), 87.

313 For example, Mark Gridley, Jazz Styles, 4.

${ }^{314} \mathrm{~A}$ brief review of the voluminous transcription literature that has emerged in the last 40 years, along with a literature that primarily celebrates the work of soloists while rarely focusing on interaction or ensemble values, testifies to this.

315 Wilson, 'Black Music as an Art Form', 3.
} 
the ensemble, and provides a context that allows the individual to shine within the group..$^{316}$

Even as jazz performance styles have moved away from the collectively improvised polyphony that was a dominant feature of early jazz, the mutual dependence of individuals and the collective has remained a key characteristic of the music. However, it is a value that can be easily missed by observers not attuned to the nuances of jazz. Cultural historian Gena Caponi suggests some observers, 'often miss the balancing act in African American artistic expression altogether; they see only the tightrope walker and ignore the crowd standing in a circle around the performer, not only cheering him on, but holding up the rope, as well.' ${ }^{317}$ Ralph Ellison, writing some years earlier, also emphasises the balance jazz requires of amongst individuals and groups, and highlights their interdependence:

... true jazz is an art of individual assertion within and against the group. Each true jazz moment (as distinct from the uninspired commercial performance) springs from a contest in which each artist challenges all the rest; each solo flight, or improvisation, represents (like the successive canvases of a painter) a definition of his identity: as individual, as member of a collectivity and as a link in the chain of tradition. 318

In the same volume, Ellison speaks of ' $\mathrm{t}$ ] he delicate balance struck between strong individual personality and the group,' describing it as a 'marvel of social organization.'319

Sociologist Howard Becker's 'etiquette of improvisation' offers guidelines that suggest how competing tendencies are balanced in a way that allows this

\footnotetext{
316 Ingrid Monson (Introduction' to The African Diaspora) suggests that the collective nature of the music is important beyond the immediate context of music making: 'African Americans have viewed their individual possibilities as linked to the fate of their larger racial community to a greater degree other ethnic groups in the United States.' (14) This manifests in many ways, including the way performers are held politically accountable (in particular, see Eric Porter, What is this thing called Jazz? [Berkeley: University of California Press, 2002]), but is also absolutely central to music making in that culture. This point is underscored by Jackson, 'Jazz Performance as Ritual', 66; and Gabriel Solis, 'A unique chunk of jazz reality': Authorship, musical work concepts and Thelonious Monk's live recordings from The Five Spot', Ethnomusicology 48/3 (Fall, 2004), 337.

317 Gena Caponi, 'Introduction: The case for an African American Aesthetic', in Signifyin(g), Sanctifyin', \& Slam Dunking: A Reader in African American Expressive Culture, (ed.) Gena Caponi (Amherst: University of Michigan, 1999), 6.

318 Ellison, Shadow and Act, 234.

319 Ibid., 189.
} 
marvel of social organisation to function: jazz is democratic, with all the musicians free to express themselves; and players are mutually dependent and should limit their freedom in order to serve the needs of the group. ${ }^{320}$ For Becker, the standard procedures of jazz allow participants to negotiate this dialectic, and 'jazz musicians have developed conventions that capitalise on the formal structure of the music to integrate the individual creativity of musicians into a seamless, unitary, coordinated behaviour.'321 These conventions (or etiquette, to use Becker's expression) could be described as 'the rules' of jazz improvisation, and - being implicit and explicit, formal and informal - partly define the genre. What I want to emphasise here is that these conventions operate in the service of 'unitary, coordinated behaviour' between individuals and groups, and that such coordination is achieved through musical communication, or dialogue. In her book Saying Something, Ingrid Monson focused on the dialogic nature of jazz performances - performances that are mutiply-authored (and so undermine the priority of a single author) - and their processual qualities. These processual qualities manifest in a number of primary ways in jazz, and especially in: the generation of cross-rhythms and metrical ambiguity; antiphonal musical structures; and periods of dense, coordinated musical activity. ${ }^{322}$ These are all characteristics of jazz that Olly Wilson identifies as processes that inform the music, processes that yield coherent results only when enacted by communicating, coordinated ensembles. ${ }^{323}$

It is when individuals within a group are able to enter into dialogue with the ensemble, and with their 'self-determined identity' assert themselves 'within and against the group' that Ellison's 'true jazz moment' occurs. Keith Sawyer reinforces the necessity of this dialogue among jazz musicians:

\footnotetext{
${ }^{320}$ Howard Becker, 'The Etiquette of Improvisation', Mind, Culture, and Activity, 7 (2000), 171176. See also Sawyer, Group Creativity, 50; Berliner, Thinking in Jazz, 417; Monson, Saying Something, 14.

321 David Bastien and Todd Hostager, 'Cooperation as communicative accomplishment: A symbolic interaction analysis of an improvised Jazz Concert', Communication Studies 43/2 (1992), 102.

322 Monson, Saying Something, 74-133.

323 Olly Wilson, 'Afro-American and West African Music', 6.
} 
It takes a high level of skill to get to the point where one can sound like a famous musician. But this is nonetheless only the first step in a lifetime of learning how to improvise in a group. Young musicians who have wonderful technique on their instruments - who can play extremely fast and flawlessly - often tend to be poor improvisers, because they lack feeling, and because they haven't yet learned how to communicate musically with the group. ${ }^{324}$

This kind of balance, and the integration of individual and group, is consonant with Samuel Floyd's discussion of the ring shout as a site of cultural production characterised by 'individuality within the aggregate.' ${ }^{225}$ It is this practice - a collective approach to music making that creates opportunity for all to speak that has remained one of the abiding processes of jazz. It is also one of the practices that has ensured jazz remain a fertile site for creativity.

\section{Improvisation}

For most people, I suspect improvisation implies making something up in the moment. Formal definitions of improvisation also emphasise its extemporaneous nature: 'compose, utter without preparation' in the Collins English Dictionary. ${ }^{326}$ Barry Kernfeld (in The New Grove Dictionary of Jazz) claims, 'Improvisation is generally regarded as the principal element of jazz since it offers the possibilities of spontaneity, surprise, experiment and discovery, without which most jazz would be devoid of interest.'327 This claim, emphasising as it does newness, is not without problems, as I shall suggest when discussion turns to Russell Procope and the music of Duke Ellington in Part Two. Kernfeld later glosses improvisation as 'the opportunity for creativity of a high order.' ${ }^{328}$ While this may sometimes be the case, statements of this nature tend

\footnotetext{
${ }^{324}$ Sawyer, Group Creativity, 54.

325 Samuel Floyd, The Power of Black Music: Interpreting its history from Africa to the United States (New York: Oxford University Press, 1995), 228. George Lewis further emphasises the point, suggesting, 'individualism within an egalitarian frame has been central not only to the jazz moment, but also to African American music before and since that moment.' Lewis concludes his observations about the importance of the collective in African American cultural production with the penetrating observation that, 'It seems fitting that in the wake of the radical physical and even mental silencing of slavery [...] African Americans developed an array of musical practices that encouraged all to speak.' Lewis, A Power Stronger Than Itself, xii.

326 Or, 'To speak or perform without preparation' according to Merriam-Webster.

${ }^{327}$ Barry Kernfeld (ed.), The New Grove Dictionary of Jazz (London: MacMillan, 1988), 554.

328 Ibid., 562.
} 
to imply that creativity of less than 'the highest order' is somehow inferior or of less value. As will become apparent, improvisation in jazz contexts is only sometimes an opportunity for 'high order' creativity (by which I think Grove implies startlingly new and surprising music). However, improvisation almost always has the potential to provide an opportunity for musicians to achieve some kind of communication of experience, to invest some of their musical individuality into the performance, to 'say something'. In jazz, it seems to me, improvisation can operate along a continuum from the crystallisation of style (where perhaps no personal or emotional communication is achieved, only technique and professionalism) to music so surprising that it invites wonder, and possibly incomprehension.

By employing Negus and Pickering's inclusive definition of creativity, it becomes possible to accommodate most of this continuum. ${ }^{329}$ Creative improvisation in jazz then runs from performances that communicate experience (or perhaps demonstrate character, to use John Miller Chernoff's formulation ${ }^{330}$ ) but vary little from the conventions of the genre, to performances that create something utterly novel. Music that only reproduces the surface features of the genre without achieving any kind of communicative import, even in a schema informed by Negus and Pickering's proposition, would fall well toward the lower end of the creative scale. ${ }^{331}$ Jazz pianist Mike Nock offered comments on the music of Yusef Lateef that are perhaps representative of the work of many jazz players within the boundaries of this continuum.

Yusef was a musical searcher [...] but he played pretty much the same solos a lot of the time, using the same lines. He would put them together in different ways, but they were his lines: an immediately identifiable 'Yusef' way of doing the stuff. Some musicians play different stuff all the time, some musicians play the same stuff every time, but it's still improvising. The whole idea is to make the music seem fresh. Classical musicians can be really good at this and they have less leeway than jazz and folk musicians, who can change some stuff, or they can

\footnotetext{
${ }^{329}$ Negus and Pickering, 'Creativity and musical experience', 181.

330 John Miller Chernoff, African Rhythm and African Sensibility (Chicago: Chicago University Press, 1979), 58-61.

331 Whether or not music is 'communicative' is a subjective determination. Like definitions of creativity (where fields arbitrate), it is context-dependent and difficult - perhaps impossible - to determine objectively.
} 
change it all. But it doesn't matter if it's played 'in the moment'. Yusef did tend to play the same stuff, but it was always such great stuff. 332

In Nock's estimation, there appear to be two qualities that made Lateef's performances valuable: the music was personal, or particular to Lateef as a performer ('...an immediately identifiable 'Yusef' way of doing the stuff', which is to say, it communicated 'him', or 'his experience'); and the music sounded 'fresh', in Nock's opinion because it was played 'in the moment'.

Playing music 'in the moment' is a somewhat ambiguous expression, but judging by Nock's comments (here and elsewhere), I think he is referring to the way music can be played that is entirely appropriate to its context. ${ }^{333}$ That context (in jazz ensemble settings) has a great deal to do with what the other musicians on the bandstand are playing and the performance considerations that arise as a result. ${ }^{334}$ This includes musical choices concerning matters such as: where in the groove the notes and phrases are placed; tempi; volume; timbre; content (perhaps a bebop line or a blues phrase where that seems appropriate or needed); architectonic form of solos, and the like. 'In the moment' probably also implies considering the audience present; Nock, speaking of his time with Yusef Lateef, said, 'We were playing the chitlin' circuit, doing clubs where everybody wants you to get down, so Yusef would throw in a blues to get everybody, but we were also playing some of the spaciest shit I've ever played.'335 To be 'great' the music didn't need to be new or even particularly novel, but it did need to communicate a 'Yusef' way of doing the stuff to those present.

\footnotetext{
332 Meehan, Serious Fun, 75.

333 'In the moment' might reasonably be used to describe flow states.

334 This may not always be the case. Scott DeVeaux (The Birth of Bebop) suggests saxophonist Coleman Hawkins was 'notoriously oblivious to his musical surroundings' (135), a trait that earned him brickbats because he performed 'as the star, not as a fully integrated member of the band.' (91) However, what listeners hear is the full ensemble, including the soloist; that critics identified a certain dissonance between Coleman and the groups with whom he performed is evidence that both were clearly audible. If they are not coordinated, then in most cases the music will be less concerted and so (depending on your taste) perhaps less effective.
}

335 Nock, quoted in Lauren Means, Bret Primack, 'Mike Nock: Journeyman Keyboardist Rediscovers Acoustic Jazz', Contemporary Keyboard 5/9 (September 1979), 19. 
Following on from Nock's comments, there are two related lines of inquiry I wish to explore. I will begin by considering the improvised acts of individual players. In order to understand the role of individuals in the context of the collective, it is first helpful to understand what individuals actually do. This discussion will also help to illuminate what individual improvised acts might mean in terms of the definitions of creativity I have privileged in this study, an idea fleshed out in Part Two. Second, I will consider the effects of the ensemble on that musician's improvising as he or she performs, contextualising the individual's work in the collective setting.

\section{Improvising soloists}

There is an abundant literature that uses reductive analytical techniques to describe the musical vocabulary of jazz musicians (Thomas Owens's examinations of Charlie Parker's music and Barry Kernfeld's work on the music of John Coltrane are perhaps the best known) and this scholarship suggests that jazz soloists - even those lionised as the most innovative and virtuosic - draw on finite resources which they manipulate in definable ways. ${ }^{336}$ Examination of improvised solos - even by players as revered as those examined by Owens and Kernfeld - frequently reveals that there is little material difference in the details of their solos on a tune from one performance to another. ${ }^{337}$

The very finite nature of improvisation in jazz contexts suggests two ideas important to this thesis. ${ }^{338}$ First: that for the most part what a musician plays (and in particular the musical materials they use) is reasonably consistent

336 Thomas Owens, Charlie Parker: Techniques of improvisation (PhD dissertation, UMI, 1974); Thomas Owens, Bebop: The music and its players (New York: Oxford University Press, 1995); Barry Kernfeld, 'Two Coltranes', Annual Review of Jazz Studies 2 (1983), 7-66.

337 See Larry Gushee ('Lester Young's “Shoeshine Boy”', International Musicological Society, 12 ${ }^{\text {th }}$ Congress (1977), 151-69) in particular. For a different perspective, see George Lewis's ('Improvised Music After 1950') discussion of architectonic form in jazz solos. 'As with any music, close listening and analysis of improvised music requires attention to information at different laminar depths. Thus, each of the numerous released recordings of, say, Coltrane's "Giant Steps," regarded at the level of individual passages, is the result of careful preparation "ausgearbeitet." At the same time, each improvisation, taken as a whole, maintains its character as unique and spontaneous.' (108)

338 This expression reflects the title of Ken Prouty's paper exploring improvisational training for jazz musicians, 'The "Finite" Art of Improvisation.' Prouty is also playing on the title of Paul Berliner's 1994 book, Thinking in Jazz: The Infinite Art of Improvisation. 
from performance to performance. This is not always the case, and exceptionally inventive improvisers do manage to introduce considerable variation into performances of the same composition from one occasion to the next. Sonny Rollins for example is adept in this space. Nevertheless, even Sonny Rollins is immediately identifiable to a knowledgeable listener, not only because of his recognisable sound, but also because of the phrases and melodic strategies he routinely employs. Much more common however is the situation Mike Nock described regarding Yusef Lateef, where what was played was fairly uniform from night to night. This kind of consistent practice has been described by jazz pianist Chick Corea, who suggests that improvised solos on a particular composition settle into a reasonably predictable shape over the course of a series of performances. ${ }^{339}$ This is evident in the evolving and presumably (at least partly) improvised but clearly related architecture of Miles Davis's solos on 'My Funny Valentine' between 1956 and 1964. ${ }^{340}$

Such consistency in turn suggests that during idiomatic performances on familiar vehicles, creativity (in terms of novelty) is limited (as Jason Toynbee argues). ${ }^{341}$ It would seem that for many individual players, the sites offering opportunity for the greatest creativity (by which I mean, offering the greatest opportunity for novelty) during an idiomatic performance may be before the performance takes place, or in terms of the architecture of the solo (reflected in Nock's comments about Yusef Lateef's relatively stable vocabulary being assembled into different edifices: 'He would put [his lines] together in different ways'). ${ }^{342}$

'Before the performance takes place' may be at a kind of global level (and generally early in musicians' careers) when choices are made and skills are acquired that lead to the formation of an individual's voice. In Nock's parlance this might be the period when Yusef Lateef developed an 'identifiable 'Yusef' way

\footnotetext{
339 Tom Darter and Bob Doerschuk, 'Chick Corea', Contemporary Keyboard (July, 1983), 54-60.

340 Howard Brofsky, 'Miles Davis and My Funny Valentine: The Evolution of a Solo', Black Music Research Journal 3 (1983), 23-45.

341 Toynbee, Making Popular Music, 105.

342 Meehan, Serious Fun, 75.
} 
of doing the stuff'. It is this period that Sam Rivers describes above, the period early in his career when he worked out his own approach.

Preparing for the performance may also involve more local decisions. Sometimes musicians decide on a specific strategy to employ in approaching particular performances - for example, Paul Bley's use of tone rows in his improvising on $12+6$ in a Row. His playing on these recordings is quite different (in some dimensions) from the more personal style he is best known for (for example, on any of the various recorded versions of 'Ida Lupino'). ${ }^{343}$ And sometimes (perhaps often?) musicians make decisions immediately before a solo about what they intend to do in that solo, such as, for example, Herbie Hancock deciding to omit thirds and sevenths from his next solo at a gig at Lennie's on the Turnpike (a club in Peabody, near Boston) after Miles Davis had advised him, 'Don't play the butter notes.'344

The second implication of the finite nature of improvisation in jazz contexts is that it is not what is played that is most important, but rather how it is played. This emphasis on manner over matter is reasonable first, because it is consistent with the aesthetic values that characterised early jazz and have continued to exemplify the idiom. ${ }^{345}$ And second, as saxophonist Branford Marsalis has confessed, as a general principle there simply isn't time during performance to make particularly conscious choices about all of the notes that are played. ${ }^{346}$ There is, however, time to think about the shape and sound of musical gestures, to attend to the actions of other musicians, and to make choices around groove, playing or not playing, dynamics. In other words, time to make choices about the performative and expressive qualities of the music. It is these choices that are most 'in the moment', that are made consciously but without preparation. The improvised solo in this schema becomes an

\footnotetext{
343 Paul Bley. 12 + 6 (In A Row). hatOLOGY 649; 'Ida Lupino' can be heard on numerous of Bley's records including: Closer; Open, To Love; Paul Plays Carla.

344 Herbie Hancock, 'The 2014 Norton Lectures' (3 February 2014)

<http://vimeo.com/86264725> (11 April 2014).

345 Ellison, Shadow and Act, 208; Wilson, 'The Heterogeneous Sound Ideal', 329.

346 Marsalis quoted in Ben Sidran, Talking Jazz (New York: Da Capo, 1995), 295-309. See also Sawyer, Group Creativity, 92; Sloboda, The Musical Mind: The cognitive psychology of music; Johnson-Laird, 'Freedom and constraint in creativity'.
} 
opportunity to 'say something' that is one's own, or offer 'an immediately identifiable [insert musicians name here] way of doing the stuff' in Nock's formulation. Which is to say, a site for the communication of experience. These links between individuals, their experience and musical expression, as Travis Jackson has suggested, are hard to pin down. ${ }^{347}$ Perhaps, along lines argued by Bruce Johnson, they assume their greatest resonance in anecdote. Art Pepper's account of a performance with saxophonist Sonny Stitt is a revealing example. While this is only one musician's account of one performance, it usefully illustrates the links between improvisation, experience and 'saying something': I said, "What do you want to play?" Sonny [Stitt] says, "Let's play 'Cherokee.' “ That's a song jazz musicians used to play. The bridge, which is the middle part, has all kinds of chord changes in it. It's very difficult. If you can play that... If some kid came around, and he wanted to play, you'd say, "Let's play 'Cherokee," " and you'd count it off real fast. I said, "Well, beat it off." He went, "One-two, onetwo;" he was flying. We played the head, the melody, and then he took the first solo. He played, I don't know, about forty choruses. He played for an hour maybe, did everything that could be done on a saxophone, everything you could play, as much as Charlie Parker could have played if he'd been there. Then he stopped. And he looked at me. Gave me one of those looks, "All right, suckah, your turn." And it's my job; it's my gig. I was strung out. I was hooked. I was drunk. I was having a hassle with my wife, Diane, who'd threatened to kill herself in our hotel room next door. I had marks on my arm. I thought there were narcs in the club, and all of a sudden realized that it was me. He'd done all those things, and now I had to put up or shut up or get off or forget it or quit or kill myself or do something.

I forgot everything and everything came out. I played way over my head. I played completely different than he did. I searched and found my own way, and what I said reached the people. I played myself, and I knew I was right, and people loved it, and they felt it. I blew and I blew, and when I finally finished I was shaking all over; my heart was pounding; I was soaked in sweat; and people were screaming; the people were clapping and I looked at Sonny, but I just kind of nodded, and he went, "All right." And that was it. That's what it's all about. 348

Pepper's recollection of the 'what' of this performance is limited to the tune, the tempo and Sonny Stitt's presence. His recollection of the 'how' is vague in precise details, but rich in metaphor and, I would argue, in meaning. And it was the 'how' of his performance that reached the audience ('I played myself ..and people loved it'), that satisfied Stitt, and that for Pepper summed up what jazz was 'all about.'

347 Jackson, 'Jazz Performance as Ritual', 46.

${ }^{348}$ Art Pepper and Laurie Pepper, Straight Life: The Story of Art Pepper (New York: Da Capo, 2009), 476. 


\section{Improvisation in the collective context}

While improvisation is certainly important in jazz, the self-expressive qualities it possesses and virtuosity often associated with it have tended to be promoted in a way that puts the spotlight on individuals. ${ }^{349}$ This emphasis obscures the place improvisation enjoys as a collective practice in jazz, an emphasis I argue is important across the entire history of the music. Olly Wilson, in discussing the heterogeneous sound ideal as a 'basic concept' of early jazz, pinpoints simultaneous group improvisation as one manifestation of collective practice. 350 Such collective improvisation, as well as providing early jazz with a distinctive style marker - improvised heterophony ${ }^{351}$ - also emphasised improvisation as a means toward creation of a context in which individual voices could be sounded autonomously in a group setting. 352

While most accounts of jazz played after about 1925 have seemed to place emphasis on improvising soloists, I think this final point de-emphasises the centrality of the improvising prowess of individual stars in jazz, and creates an opportunity for us to re-scope the roles of individuals as equal members of groups rather than heroes who stand at the front of the band. ${ }^{353}$ Even if, in most

\footnotetext{
${ }^{349}$ Harris, 'Jazz on the global stage', 127. For example, in the late 1950s as Charles Mingus cultivated a profile as a leader and composer, 'he featured his instrumental prowess less and his compositions more', as a consequence of which 'his position in the popularity polls slipped.' Priestly, Mingus, 88.

350 Wilson, 'The Heterogeneous Sound Ideal in African-American Music', 336.

351 In Olly Wilson's analysis ('The significance of the relationship between Afro-American and West African Music', 15) this kind of group heterophony also created a new paradigm, a distinctly African-American means of realising a fundamentally African idea.
}

352 Travis Jackson (in 'Jazz Performance as Ritual', 66) and Gabriel Solis (in 'A unique chunk of jazz reality', 337) both suggest that individual voices heard in the group context in this way is a central tenet of African music, one that survived the Middle Passage to inform African American music. This may well be the case, but the practice of musical collectivity and the benefits such practice has in terms of creative work (rather than the provenance of such practice) is my concern here.

353 As virtuosic star soloists, Louis Armstrong, Lester Young, Charlie Parker and John Coltrane are accepted without reservation into the pantheon of 'jazz greats', while Miles Davis, whose own trumpet performances could be said to have fallen short of some notions of virtuosity, was accepted, but considered somewhat problematic. (For example, see Rob Walser, 'Out of Notes: Signification, Interpretation, and the Problem of Miles Davis', The Musical Quarterly 77/2 [Summer 1993], 343-365.) I propose that it is not Davis's performances that are problematic, but 
jazz in the last ninety years, the front line has not been collectively improvising, the other players are generally improvising and engaging in dialogue with the soloist (be it simultaneously as members of the rhythm section, or consecutively as one of a series of soloists). ${ }^{354}$ For me, as a listener, the magic of a successful jazz performance - when 'it is really happening' in Geoff Dwyer's expression emerges from this marvel of social organisation. ${ }^{355}$ Further, conceptualising the operation of jazz groups in these collective terms reveals why such groups have been a wellspring for musical creativity.

\section{Appropriation and transformation}

The third process I wish to engage as part of my methodological lens is appropriation and transformation of received and newly introduced musical materials. Jazz emerged as a distinct musical genre (even if it did not yet possess that name), during the first two decades of the twentieth century. It was not a genre that grew in an evolutionary manner out of a single precursor but, historians suggest, was a product of the admixture of ragtime, spirituals and the blues (and their antecedents, field hollers and work songs), and popular (dance) music, among other bits and pieces. ${ }^{356}$ In its earliest incarnations jazz was African American music and its capacity to absorb influences from a plethora of sources appears to be a characteristic of all of the genres that fall under that rubric. Brian Ward makes the case:

As black poet, journalist and jazz critic Frank Marshall Davis once explained, "Both culturally and ideologically we are a goulash of Europeans, Africans, and American Indians - with African dominant". As Davis was well aware, AfricanAmerican music has always been characterized by its willingness and seemingly endless capacity to fuse many varied, often apparently incompatible, influences

rather critiques that privilege individual improvisational virtuosity ahead of other aspects of music making.

354 Ingrid Monson, Saying Something, 134-192; Paul Berliner, Thinking in Jazz, chapters 13 ('Give and Take: The Collective Conversation and Musical Journey') and 14 ('When The Music's Happening And When It's Not: Evaluating Group Performances'); Robert Hodson, Interaction, improvisation and interplay in jazz, 22.

355 Geoff Dwyer, But Beautiful (New York: North Point Press, 1996), 199.

356 Schuller, Early Jazz, 63-87. Other bits and pieces might include minstrelsy and vaudeville both contributors to early blues, and the 'Spanish tinge' that Jelly Roll Morton claimed was a vital ingredient in jazz. 
into a succession of styles which have reflected and articulated the changing circumstances, consciousness and aspirations of black Americans; black Americans who have themselves been differentiated by class, gender and geography, and doubly defined by their immanent American, as well as more distant African, heritages. ${ }^{357}$

For the purposes of this thesis, there are two values I wish to draw out from Ward's claims. First, the capacity of African American musicians - and in particular those who made the earliest jazz - to 'fuse many varied, often apparently incompatible, influences' into what settled into identifiable formations, albeit evolving ones. These formations include jazz. The second point I draw from Ward is that these musical fusions reflected and articulated 'the changing circumstances, consciousness and aspirations' of those who made them. I will elaborate the first point, and then use the second point to contextualise my claims about musical fusions and transformations within the broader purposes of this thesis.

As discussed earlier (under 'Jazz as process'), Olly Wilson identified two African American musical traditions, the second of which - characterised by 'a greater interaction and interpenetration of African and Euro-American elements' - is exemplified by jazz. ${ }^{358}$ Drawing from Eileen Southern, Wilson suggests this second tradition of African American musical practice originated during the eighteenth and nineteenth centuries and began with idiosyncratic or 'peculiar' performances of Euro-American music that in effect transformed the repertoire being interpreted into something qualitatively different. ${ }^{359}$ In Wilson's view, 'The process of cultural transformation became the salient characteristic of this tradition.'360 Further, 'It was precisely that transformation which made the music unique, and as a consequence, highly desired by whites' who in earlier periods were the 'owners' or employers of the musicians, and in

\footnotetext{
357 Ward, Just my soul responding, 11.

358 Wilson, 'Black Music as an Art Form', 10.

359 Southern, The Music of Black Americans, 63-126.

360 Ibid. (My emphasis)
} 
later periods were numbered among the paying consumers of such transformative music.'361

The musical materials adopted for transformation included not only repertoire and particular styles, but also instruments and instrumental techniques. Jazz drummer Art Blakey said, 'When we heard the Caucasians playing their instruments, we took the instruments and went somewhere else... This is our contribution to the world, though they want to ignore it and are always trying to connect it to someone else. It couldn't come from anyone but us.'362 James Stewart reinforces Blakey's claim about the cultural provenance of these transformative practices, suggesting, '[Blacks] had to impose on borrowed instruments an aesthetic convention that we obviously possessed even before we acquired [those instruments].'363 William Schafer suggests New Orleans brass bands were the source of instruments, instrumental techniques, and basic repertoire for early jazz musicians. ${ }^{364}$ However, it was not the fact that early jazz musicians made use of these musical resources that assured their place in posterity, but their idiosyncratic reshaping of the sounds and roles of instruments, instrumental techniques and repertoire. ${ }^{365}$

Olly Wilson illustrates this principle with an analysis of a (1959) Miles Davis recording of 'On Green Dolphin Street'. He concludes by stating that, 'The

\footnotetext{
${ }^{361}$ While these transformations made the music of African Americans desirable to some listeners of European descent, to others such transformations made the music incomprehensible. See Morton Marks, 'Uncovering ritual structures in contemporary America', in Religious movements in contemporary America, ed. Irving Zaretsky and Mark Leone (Princeton, NJ: Princeton University Press, 1974), 60-129.
}

362 Art Blakey, quoted in Ingrid Monson, 'Art Blakey's African Diaspora', in The African Diaspora: A musical perspective, ed. Ingrid Monson (New York: Garland Publishing, 2000), 346. Blakey, born in 1919, was not one of the African Americans who 'took the instruments and went somewhere else.' Here, Blakey uses 'we' for political (and perhaps poetic) resonance. See also Stewart, 'Introduction to the Black Aesthetic', 86.

363 Stewart, 'Introduction to Black Aesthetics in Music', 86.

364 William Schafer, Brass Bands and New Orleans jazz (Baton Rouge: Louisiana State University Press, 1977), 8.

365 Chris Washburne ('The Clave of Jazz: A Caribbean Contribution to the Rhythmic Foundation of an African-American Music', Black Music Research Journal 17/1 [Spring 1997], 65-66) reports that many prominent early jazz musicians - including Kid Ory, Louis Armstrong, Joe 'King' Oliver, Bunk Johnson - received their earliest musical training in brass bands, playing a mixture of music that included transformed European and Euro-American repertoire. 
Miles Davis Quintet's recording of this tune transforms it completely and places it squarely within the modern jazz tradition.' ${ }^{366}$ In this case, music was first appropriated from another genre (a song from a film) and then adapted or transformed to meet the purposes of the musicians involved. Thus transformation - achieved when music is qualitatively changed through the interpretation of the musicians - is central to Wilson's understanding of the jazz tradition. Such transformations not only reveal the 'voice' of the musician(s) performing, but also provide means by which any musical materials (whatever their provenance) may be initiated into the jazz tradition.

It's not just repertoire, instruments and techniques from 'outside of' jazz that jazz musicians transform; adaptation and change are also applied to materials that jazz musicians inherit when they involve themselves in the genre, materials that are already accepted as part of jazz. Albert Murray illustrates this point by suggesting that Duke Ellington's supremacy is not based on his capacity for invention but because his oeuvre 'represents the most comprehensive assimilation, counterstatement and elaboration of most, if not all, of the elements of blues musicianship.'367 Murray goes on to say, 'It was not so much what Charlie Parker did on impulse that made him the formidable soloist and influential revolutionary stylist that he was, it was what he did in response to already existing procedures.'368

Joanne Demmers, in her book Steal This Music, considers 'transformative appropriation' an essential ingredient to musical creativity. ${ }^{369}$ It has been central to the practice of jazz musicians since the birth of the genre, and demonstrably present in each significant stylistic evolution the music has experienced. At times those stylistic shifts have involved the transformation of the accepted materials

\footnotetext{
366 Wilson, 'Black Music as an Art Form', 16.

367 Albert Murray, Stomping the Blues (New York: McGraw-Hill, 1976), 126. 'Blues musicianship' is a somewhat slippery concept, but involves 'stylistic code for representing the most difficult conditions, but also provides a strategy for living with and triumphing over those conditions with dignity, grace, and elegance' (Ibid.) Whatever those codes comprised, Murray champions jazz as the music most comprehensively informed by them, and suggests it is Ellington's transformations of them ('counterstatement and elaboration) that is a signal feature of his art. 
or procedures of jazz, for example the emergence of bebop. Although the song forms and procedures bebop pioneers used were inherited from their jazz forebears, I think 'appropriated' is still the right word: these musicians took those materials 'for their own use', and made something different with them. At other times significant shifts in jazz have involved the introduction of ideas or music from outside of jazz, which have been reinterpreted by jazz musicians. An example is the introduction of clave rhythms into jazz by Mario Bauza and Machito in the 1940s, or the introduction of rock instruments and rhythms to jazz during the 1960s by musicians including Larry Coryell, Gary Burton and Miles Davis. ${ }^{370}$

When this kind of appropriation and transformation occurs, the materials reinterpreted by the musicians are of course altered in some way. But so too is jazz, which in becoming the musical laboratory in which these materials are subject to metamorphosis, is itself in some way changed. The revisions to which inherited or accepted musical materials and procedures are subject, along with the accommodation and transformation of musical incursions from 'outside of' jazz have, together, seen jazz continue to change and evolve.

As Brian Ward suggested, the successive styles of jazz emerged as the music changed to reflect the changing lives and circumstances, consciousness and aspirations of the musicians making it. Initially that group comprised African American musicians in the United States, but over the past century it has grown to include people from astonishingly diverse cultural backgrounds and from all over the world. While the ethnic and cultural bases of those who make jazz has grown, I argue that the appropriation and transformation that characterised early jazz has been consistently significant in the changes that jazz has undergone and remains a vital aspect of the music.

\section{Summary}

This chapter offers a methodological lens through which to view jazz, one that privileges process as primary in understanding the music. Within that frame, the processes I have emphasised are: the development and expression of individual

370 Raul Fernandez, From Afro-Cuban Rhythms to Latin Jazz (Berkeley: University of California Press, 2006), 59-70; Stuart Nicholson, Jazz Rock: A History (New York: Schirmer, 1998). 
voices; improvised interactivity within the jazz ensemble; and the appropriation and transformation of musical materials (both from within jazz and from outside of its borders). These three processes are interdependent; each is implicated in the action of the other two. They are also processes that I (along with the host of scholars I have cited) argue were central to jazz in its earliest forms and have remained vital to jazz even as its surface features have changed over the past century. In Part Two of this thesis I will use this lens to examine the practice of four jazz musicians and those with whom they worked. From these case studies I will propose some of the ways creativity has been enabled in jazz practice, and suggest approaches that are likely to further facilitate creative practice in jazz in years to come. 
PART TWO: CASE STUDIES 


\section{Introduction to Part Two}

Part Two of this thesis comprises three case studies, a conclusion that incorporates a further case study, and an afterword that draws several threads together and, finally, contextualises this work in relation to Aotearoa/New Zealand. Two of the case studies, those examining the work of Ornette Coleman and Miles Davis, operate on two levels. First, I use the lens of creativity to view Coleman and Davis's practice and in doing so confirm ideas that are already common currency about these musicians. In some ways this move validates the methodological lens I have chosen. Scholars who scrutinise the work of these musicians have made a number of conclusions about their practice using approaches that might consider creativity, but rarely with the kind of nuanced definitions of creativity I have laid out in this thesis. Placing an emphasis on such a nuanced view of creativity allows us to understand aspects of the work of these musicians with which we are already familiar, in fresh ways. For example, using Mihaly Csikszentmihalyi's Systems Model to assay the professional trajectory of Ornette Coleman provides us with an explanation of the ways Coleman's music was gradually accepted by the field of jazz, but doesn't really offer any profoundly new insights; it is already commonly understood that his music was at first almost universally rejected and is now generally accepted. Nevertheless, the Systems Model does provide an explanatory paradigm for that gradual acceptance, and perhaps adds nuance to an existing consensus. In this way the theoretical framework adopted for this thesis is confirmed: it can usefully endorse the observations of scholars who have addressed questions about these musicians using different approaches, and offer modest advances on those scholars' work.

However, the lens of creativity is also capable of revealing something different about these musicians, something that is not so apparent using other methodological approaches. In particular, emphasising process ahead of product discounts the significance of the sounding objects musicians produce (and which has largely been the focus of attention of the field). Instead, by thinking about jazz in terms of the creative processes that generally underscore it, it is possible to tell a different story about key actors in the music. In this respect the work of 
this thesis is able to offer a different set of insights to the work of other scholars, and so reveal not only Ornette Coleman and Miles Davis's music and example in new light, but also disclose some generalisable principles that may be applied to other musicians in the jazz idiom as well. It is these principles I emphasis in the closing chapters of this thesis.

The third case study, which examines aspects of Duke Ellington's music, proposes that Keith Negus and Michael Pickering's inclusive definition of creativity is one that is meaningful for jazz because it provides a theoretical framework that makes sense of the routine practice of many jazz musicians as a different, more modest kind of creative practice, to the innovative creative work of musicians such as Davis and Coleman. However, when enacted in a mutually constitutive dialogue with the ensemble, such routine work can sometimes achieve great heights of creative achievement. Nevertheless, for all of the music examined in this chapter, the products of musical acts are considered primarily in light of the processes use to generate them, usefully moving the conversation about jazz away from the 'what' and onto the 'how' of the music.

It is this concern with the 'how' of jazz that permeates both my concluding chapter, which considers Jan Garbarek's music, and my Afterword, which explores the possible meanings such a focus might have in Aotearoa/New Zealand. 


\section{Chapter Three: Ornette Coleman - Play Your Own Thing}

'I'm convinced that style will never dominate ideas.'

Ornette Coleman ${ }^{371}$

Ornette Coleman's music illustrates two key principles adumbrated in Part One. First, Coleman's music provides insights into the ways fields make determinations about the acceptability of practitioners within their ambit. As an illustration of Mihaly Csikszentmihalyi's Systems Model of creativity, Coleman is exemplary, and consideration of reception of his work over time provides clear evidence of the way a field - in this case the field of jazz, comprising journalists and critics, record companies and radio programmers, audiences and other jazz musicians - may sometimes take a little while to catch up with its most innovative practitioners. ${ }^{372}$ However, Coleman's example also reveals to us that the field of jazz is selective in what it valorises, and can neglect to acknowledge appropriately important aspects of the practice of musicians whose work it otherwise embraces.

The second idea related to Coleman's practice I draw attention to is divergent thinking. As Csikszentmihalyi suggests, 'fluency, or the ability to generate a great quantity of ideas; flexibility, or the ability to switch from one perspective to another; and originality in picking unusual associations of ideas' are all capabilities that are conducive to creativity. ${ }^{373}$ The capacity to generate many ideas is widely recognised as a characteristic of Ornette Coleman's work; ${ }^{374}$ his ability to manipulate those ideas in real time, and to move from one

\footnotetext{
371 Ornette Coleman, quoted in 'Ornette Coleman: The Seeker', Magnet Magazine (1 May 2007), <http://www.magnetmagazine.com/2007/01/05/ornette-coleman-the-seeker/> (18 March 2014).

372 Csikszentmihalyi, Creativity, 28.

373 Ibid., 60.

374 Evidence for the variety of approaches Coleman adopts is found in the range of his musical output (duos, trios, various quartets and larger aggregations, chamber music and orchestral works) and in his prolixity as a composer. A summary of these ideas is found in John Litweiler, Ornette Coleman: A Harmolodic Life (New York: William Morrow, 1993); Peter Niklas Wilson, Ornette Coleman: His life and music (Berkeley: Berkeley Hills Books, 1999).
} 
approach to another has attracted less comment but nonetheless is also central to his practice. Both are significant to his creative achievements.

\section{Ornette Coleman and the field of jazz}

Born and raised in Fort Worth, Texas, Ornette Coleman's journey from musical novice to acknowledged jazz master was slow and beset with many obstacles. Like Charlie Parker, perhaps his most significant musical role model, Coleman was initially rejected by musicians and club owners as a neophyte without talent or even a basic grasp of the principles of the jazz music he was attempting to play. ${ }^{375}$

It is probably fair to say that Coleman's grasp of the theoretical principles that underscore mainstream jazz performance when he emerged onto the scene (late 1940s-mid 1950s) was unconventional. Musicologist and composer Gunther Schuller describes Coleman as a musician who was 'spared conventional musical education [...] possessing total immunity to the notational aspect of music.' Schuller didn't regard this as an impediment to Coleman's development however, suggesting that it was 'because Mr. Coleman was not "handicapped" by conventional music education that he has been able to make his unique contribution to contemporary music.'376

Coleman's rejection as an instrumentalist without talent was unfair however: Coleman's executant grasp of the music was sound; by the time he made his first recordings (in 1957) he had been playing saxophone for 15 years, and his study of Charlie Parker's performance style meant that by the mid-fifties he could play in the bebop style with considerable élan. ${ }^{377}$ Martin Williams recalled:

\footnotetext{
375 I am referring to the rejection Coleman experienced as a jazz player in the mid-50s, by which time his more radical ideas were becoming evident. This I contrast to his earlier (provisional) acceptance as a rhythm and blues player, which as far as I can tell was more idiomatically acceptable. Nevertheless, even then Coleman's approach was less than conventional and even as a blues tenor player he was marginalised. For an account of Coleman's development, including his uneven reception in blues contexts, see Litweiler, Ornette Coleman.

376 Gunther Schuller, A Collection off the Compositions of Ornette Coleman (New York: MJQ Music, 1961), 2.

377 Martin Williams, quoted in Shirley Clarke (dir.) Ornette Coleman: Made in America. See James Clay, quoted in Litweiler, Ornette Coleman, 53-54.. For an insight into Coleman's unorthodox theoretical perspective, see Gunther Schuller's account in Litweiler, Ornette Coleman, 93-94.
} 
And suddenly Ornette Coleman up on the bandstand in the Five Spot [...] started to play the blues like Charlie Parker and I have never heard anyone else other than Charlie Parker do that, that way. Charlie Parker has had many followers and he has also had many imitators ... none of them has come near this. Ornette had the attack on the reed right; he was doing it like late Parker too, the more virtuoso period of Parker's short career. It was absolutely uncanny and he went on and on doing it. And I said, "Man, why don't you do this more often; why don't you do this on a record to show people that you really do know what you are doing - those that won't listen to you and learn it that way?" And Ornette said, "Oh, I like to do that every now and then for fun." 378

However, Coleman was not content to duplicate the style of another musician - even at a time when doing so would almost certainly have meant acceptance and possibly an easier road to recognition in the jazz community. 379 'I was playing rhythm and blues. When I heard Charlie Parker, I said, "Wait a minute, [rhythm and blues has] got to go!" Then, all of a sudden, I outgrew [bebop]. Because it all became kind of stylistic, and I'm convinced that style will never dominate ideas.' 380 Moving beyond bebop, Coleman determinedly followed his own ideas, even though it was a convoluted and, in the short term, a much more difficult route.

While Coleman's sound in some respects resembled Parker's, his tone was more varied, his intonation far more idiosyncratic and the harmonic ordering of his work predicated on quite different principles to the essentially functional approach that characterised most bebop. Together, these features meant that when Coleman was trying to establish himself on the jazz scene in Los Angeles during the early 1950s, other musicians did not allow him to sit in at jam sessions and dismissed him as a charlatan. ${ }^{381}$ Years later, and even with a number of albums out and engaged to work at a high profile club in New York, Coleman suffered the slings and arrows of the field.

\footnotetext{
378 Williams in Shirley Clarke [Dir.], Ornette Coleman: Made in America (New Jersey: Milestone Films, 1984).

${ }^{379}$ At around the same time Coleman was making his first in-roads into the jazz community, and when he performed with James Clay who attested to his capacity to play so much like Parker, Cannonball Adderley made a considerable impression in New York by playing very precisely in the style of Parker, shortly after Bird's death. Adderley went on to a very successful career beginning with his membership in the Miles Davis sextet. Cary Ginell, Walk Tall: The Life and Music of Julian 'Cannonball' Adderley (Milwaukee: Hal Leonard, 2013), 10-11.

380 Quoted in 'Ornette Coleman: The Seeker'.

${ }^{381}$ Litweiler, Ornette Coleman, 45-46.
} 
I stayed [at New York jazz club, The Five Spot] for months, but everybody thought that I was out of my mind. They said, "You can't play-there's no way you can play like that." Oh man, it was terrible because nobody encouraged me. I guess they thought I was just being exploited, but I was really getting more and more into it. ${ }^{382}$

Ultimately, Coleman's music has been accepted and he is now widely regarded as a significant figure in jazz and feted for his work the world over. As I see it, two factors were crucial to his acceptance by the field of jazz, and preeminent among these was first, his self-belief - the absolute conviction that the path he was following was the right one - and the intrinsic motivation that attended that attitude. The second factor crucial to Coleman's eventual acceptance was a series of opportunities he was afforded to present his music without dilution, opportunities created for him by a handful of sympathetic musicians, club owners and critics. I will speak to these factors in turn, using the Systems Model to illuminate the process by which the field has slowly come to embrace Coleman.

It is important at this point, however, to flag that the jazz field's embrace of Coleman's music has been provisional. Coleman is celebrated as a recording artist and composer - his best recordings are highly regarded and his compositions are published in Real Books - but the procedures he employed to play his music are often only mentioned coincidentally. When discussion turns to Coleman in jazz histories the sounding objects he produced are discussed, and while the processes he engaged to make this music are usually described, commentators generally stop short of considering the implications of the processes for subsequent mainstream jazz practice. For example, Mark Levine's widely used The Jazz Theory Book claims a jazz solo is 99\% 'stuff that is explainable, analyzable, categorizable, doable'. The other $1 \%$ is magic by Levine's reckoning. ${ }^{383}$ Ornette Coleman's music is accepted as jazz by the field (his music is found in college textbooks, and in the two highest profile anthologies - The Smithsonian Collection of Classic Jazz and Ken Burns: Jazz), and yet is not explained, analysed or revealed to be particularly doable in Levine's book. This book, and Levine's companion volume on jazz piano are excellent; I

\footnotetext{
382 Quoted in 'Ornette Coleman: The Seeker'.

383 Mark Levine, The Jazz Theory Book (Petaluma, CA: Sher Music, 1995), vii.
} 
use them for teaching. However, the approach he adopts does not accommodate the processes Coleman engages in his music making.

Jazz critic Francis Davis, writing 25 years after Coleman's first Five Spot engagement, confirms that this failure genuinely to accommodate Coleman's approach is widespread, writing:

If one listens closely for them, one can hear Colemanesque accents in the most unlikely places: the maundering piano soliloquies of Keith Jarrett and the bickering, simultaneous improvisations of young hard-boppers like Wynton and Branford Marsalis. Yet for all that, Coleman's way has never really supplanted Charlie Parker's as the lingua franca to jazz, as many hoped and others feared it would. ${ }^{384}$

I think Davis's analysis is correct, and I will return to what might be described as the provisional embrace of Coleman's example below (in 'No Copycats').

\section{Self-belief and intrinsic motivation}

Ornette Coleman's example emphasises the self-belief and intrinsic motivation that is often required of practitioners whose work troubles the limits of the domains in which they operate. The brickbats of other musicians and the way he was denied opportunities to perform in Los Angeles during the 1950s was only the beginning of Coleman's troubled negotiations with the field of jazz, but he refused to compromise his musical vision. Although he was at times discouraged by the lack of opportunity to play his music in his own way, and by the indifference (and sometimes outright hostility) of the jazz community, he continued to apply himself to study and practice. His commitment to developing his own musical direction is evident in his refusal to take commercial musical jobs or return to the rhythm and blues styles with which he had earned a living as a younger man. Instead, he took menial jobs to meet his living expenses so that he could continue single-mindedly to develop his own sound and musical approach. 'That's one thing that I escaped,' Coleman claims, 'I didn't ever use what I was doing [musically] to survive. I always wanted to get better in the direction that I was going.' ${ }^{385}$

\footnotetext{
384 Francis Davis, 'Ornette's Permanent Revolution', The Atlantic Monthly 257/3 (September 1985), 99-102.

385 Quoted in 'Ornette Coleman: The Seeker'.
} 
Coleman's decision not to take commercial musical work, and the lengths to which he went and risks he took in order to present his music, are evidence of his considerable intrinsic motivation. In 1962 he rented New York's concert venue Town Hall and presented his music at his own expense, including musicians' fees for the string quartet that performed with him alongside his rhythm section. Coleman also paid for the recording of the music in order to make sure it was disseminated. ${ }^{386}$ He repeated this process a few years later in Britain, where he staged a concert for his trio and a wind quintet, again recording the music for subsequent release. ${ }^{387}$ Howard Mandel wrote, 'Blessedly innerdirected, [Coleman] instituted his own concerts, his own artists' house, his own record label [...] Ornette has allowed nothing to deter him from his quest of self-realization.' ${ }^{388}$ Such intrinsic motivation was crucial to Coleman's eventual acceptance, but motivation alone was not sufficient to ensure the acceptance of his music; musicians also need to be heard.

\section{Having the chance to perform}

The second factor crucial to Coleman's acceptance by the field of jazz was the series of performance and recording opportunities he was granted in the late 1950s. As I suggested in Chapter One, fields are complex, polyvalent agglomerations and consensus about the acceptability of new ideas is sometimes achieved slowly, if at all. At first the only members of the field of jazz to accept Coleman were a handful of fellow musicians who saw in his ideas a fruitful avenue towards renewed musical expression. Their acceptance was key to providing Coleman the opportunity to present his music on its own terms, an important stepping-stone to the wider recognition of his music. The like-minded musicians with whom Coleman collaborated included drummers Ed Blackwell and Billy Higgins, trumpeter Don Cherry and bassist Charlie Haden. ${ }^{389}$ This

\footnotetext{
386 Litweiler, Ornette Coleman, 104. The music from this concert was released as Town Hall Concert, ESPCD 1006, 1962.

387 Ibid. This music was released as The Music of Ornette Coleman, RCA Victor LPM 2982, 1967.

388 Mandel, Miles, Ornette, Cecil, 11-12.

389 Other musicians who worked with Coleman early in his career include saxophonist James Clay, and trumpeter Bobby Bradford. See Litweiler, Ornette Coleman, 49-54.
} 
group served Coleman in several ways. First, they were willing to play his music, thus creating a group context that accommodated the musical freedoms Coleman's music demanded. Charlie Haden explained:

Ornette Coleman and Don Cherry and Billy Higgins and I were lucky enough to have met at the same time as we were feeling the same way about music and that feeling was to play music as if we were hearing it for the first time and creating a new chord structure as we improvised...playing with Ornette was a learning experience, definitely. I had to really listen to everything that he played because he was always modulating from one key to another and I was the only chordal instrument in the band. There was no piano or guitar playing chords and so I had to play chords in my bass lines and learn how to create new chord structures. It was a great band. 390

The opportunity to play with such open-minded and skillful musicians, who shared Coleman's strong intrinsic motivation and were prepared to rehearse without the expectation of a paying gig, was vital to Coleman's development. The group's rehearsals provided opportunity for him to test his ideas and allow the music to develop collectively, an essential ingredient in his approach - essential because Coleman's music engaged processes different from those of other current jazz groups ${ }^{391}$ and rehearsals were necessary for the musicians not only to become adept with them, but also to develop the kind of intersubjectivity that the processes required if they were to be successfully employed. I will explain this in greater detail below (No Copycats). The point I want to emphasise here is that a small part of the field (a few practising jazz musicians) embraced Coleman's ideas in the mid-1950s even though many others in the field (most other musicians, and a large part of the audience for jazz) rejected them at that time.

Acceptance of Coleman's music, granted at first by this tiny cohort of players, began to spread to other musicians, and Coleman's group was afforded the opportunity to perform at the Hillcrest Club in Los Angeles when pianist Paul

\footnotetext{
390 Quoted in 'Charlie Haden: with Ornette Coleman', (no date)

<http://www.charliehadenmusic.com/music/ornette-coleman> (17 March 2014).

391 The only other groups I am aware of that had attempted anything like Coleman's music was pianist Lennie Tristano's sextet, which in 1949 recorded two collectively improvised pieces ('Intuition' and 'Digression') and Charles Mingus's collectively improvised 'Gregarian Chant' (1954). However, these appear to have been experiments. Tristano does not seem to have redeployed this approach for audiences or in the studio. Mingus did employ collective improvising in live contexts but perhaps not as freely as Coleman (See Priestly, Mingus, 59). In this way the collective freedoms instituted as an ongoing modus operandi by Coleman's groups was pioneering.
} 
Bley heard Coleman play. Bley had been working with Haden and Higgins at the Hillcrest, and perceiving in Coleman's music possibilities for new directions in jazz, he fired the vibes player in his ensemble and added Coleman and Don Cherry. ${ }^{392}$ Bley recognised that embracing Coleman's music might alienate many listeners, yet he was prepared to sacrifice a stable residency in order to play with Coleman. As Bley recalled:

When you were driving down Washington Boulevard and you looked at the Hillcrest Club you always knew whether the band was on the bandstand or not. If the street was full of audience in front of the club, the band was playing ... And as soon as the band stopped they would all come back in and drink, talk and shout and be happy. ${ }^{393}$

No one was sympathetic. The only people in the club were the staff. ${ }^{394}$

Bley's intuition about the importance of Coleman's approach eclipsed both his concern about whether or not the audience (and perhaps other musicians, too) would accept the music, and his desire for financial security. He chose to pursue the musical goals Coleman represented ahead of ongoing work at the Hillcrest, and what had been a two-year residency folded within six weeks. Nevertheless, Coleman had received a valuable opportunity to perform his music regularly, important not only for his development but also providing valuable exposure for his ideas. ${ }^{395}$

The gradual dissemination of Coleman's ideas led to further opportunities. Pianist John Lewis, of the Modern Jazz Quartet, was very taken with Coleman's music, and sponsored Coleman to be a participant in the Lennox School of Jazz in 1959. At this event Coleman's music was heard by a large group of established and emerging jazz musicians active on the East Coast. Lewis also urged Nesuhi Ertegun of Atlantic Record - to whom the Modern Jazz quartet were signed - to consider Coleman for the Atlantic roster. ${ }^{396}$ Each of these small

\footnotetext{
392 See Joe Klee, Will Smith, 'Paul Bley', Downbeat 41/1 (17 January 1974), 12-13.

393 Litweiler, Ornette Coleman, 61-62.

394 Norman Meehan, Time Will Tell (Berkeley Hills Books, 2003), 44.

395 Selected performances from the Hillcrest were released as Paul Bley's The Fabulous Paul Bley Quintet. American AM 6120, rec. 1958.

396 Litweiler, Ornette Coleman, 66. Lewis likely became aware of Coleman's music because Percy Heath, bassist with the Modern Jazz Quartet, played on Coleman's second album, Tomorrow is the Question, Contemporary/Original Jazz Classics OJCCD 342-2.
} 
steps constituted a further widening of the exposure of Coleman's music within the broader field of jazz. This in turn led to a gradual embrace of his music which reached something of a tipping point (to use Malcolm Gladwell's expression) with two record companies recording and releasing his music, and an important jazz club residency. ${ }^{397}$ Record company acceptance initially came in the form of Lester Koenig and his Los Angeles-based Contemporary Records. Koenig was at first interested in recording Coleman because he liked the saxophonist's compositions, and believed that Coleman's tunes would prove worthwhile as improvisational vehicles for other artists on his roster. ${ }^{398}$ Although the two albums Coleman made for Contemporary Records sold poorly, ${ }^{399}$ they marked a beginning, and probably gave Nesuhi Ertegun confidence (along with John Lewis's recommendation) to sign Coleman to Atlantic Records. 400

For the Atlantic sessions, Coleman recorded with his choice of rhythm section players, allowing his conception - which depended upon sympathetic collaborators - to be properly aired. 401 The release of the first Atlantic recording, The Shape of Jazz to Come, coincided with a two-week residency at New York jazz club The Five Spot. The Five Spot was a bar in Greenwich Village where many of the finest jazz musicians performed, and so Coleman's engagement for two weeks in November 1959 was something of a coup for an untested musician,

397 Malcolm Gladwell, The Tipping Point: How little things can make a big difference (Boston: Back Bay Books, 2002).

\footnotetext{
398 Some artists on the Contemporary label did record Coleman's tunes, including Art Pepper who recorded 'Tears Inside' on his album Smack Up (Contemporary, 1960).
}

\begin{abstract}
399 Coleman's musical ideas are not fully represented on these two Contemporary albums, almost certainly because he was not working with his own group. While Don Cherry did play on these sessions, Koenig used established rhythm section players to accompany the frontline of Coleman and Cherry. This decision meant that the very democratic principles of Coleman's music were compromised through the lack of suitably equipped rhythm section players. Related to album sales, Coleman told me in 2008 that he had not received a royalty payment for any (!) of the records he had made across his career. This may be because he demanded high advances for his later recordings, but does suggest sales of the early albums were very poor indeed.
\end{abstract}

400 Ertegun had worked for Koenig at Contemporary during the early 1950s so it is possible an ongoing interest in the work of Contemporary on Ertegun's part, or correspondence between the two at least contributed to the Atlantic signing.

${ }^{401}$ For first three albums Coleman recorded for Atlantic, (The Shape of Jazz To Come; Change of the Century; This Is Our Music) he used Don Cherry, Charlie Haden and either Billy Higgins or Ed Blackwell, all musicians intimate with his concept and compositions and able to play in appropriately collaborative ways. 
one newly arrived in New York. Critic Martin Williams is said to have convinced the club's owners to hire Coleman, and the furor that attended the engagement saw the owners extend the booking to ten weeks, until January 1960, and hire Coleman for a further four months during 1960.402

Coleman's music polarised the jazz community (by which I mean the field) and reactions were extreme. Jazz trumpeter Dizzy Gillespie told Time magazine 'I don't know what he's playing but it's not jazz' and drummer Max Roach is reported to have punched Coleman in the mouth at the conclusion of one of the group's sets. John Lewis believed 'He's the only really new thing in jazz' and composer Leonard Bernstein was a regular at the club to hear the music, praising Coleman as 'a visionary'. ${ }^{403}$ Critics were no less divided. Coleman's double quartet album from 1960, Free Jazz, was reviewed twice in Downbeat: Pete Welding described the album as 'a powerful and challenging work of real conviction and honest emotion ... I, for one, have been completely won over' and awarded it five stars (the maximum rating available); John Tynan was less sympathetic, suggesting 'eight nihilists were collected together in one studio at one time and with one common cause: to destroy the music that gave them birth.' Tynan awarded the album 'no stars' (i.e. too poor to rate any sort of recognition). ${ }^{404}$ Clearly Coleman's Five Spot engagement and recordings for Atlantic were not 'road to Damascus' experiences for the field. Nevertheless, while opinion remained divided about Coleman's music, after 1960 he was clearly on the radar and was recognised by enough individuals in the field to be acknowledged as someone to watch, even if the ramifications of his work remained unclear.

While there is little question that Coleman's music was novel - it would have hardly elicited the reactions it did if it were conventional - its eventual

\footnotetext{
402 Litweiler, Ornette Coleman, 78-79. It is worth noting that increased dissemination of Coleman's music and its gradual acceptance also corresponded to his geographical relocations from the margins of jazz (in Texas) to its epicentre (New York, by way of Los Angeles).

403 'Music: Beyond the Cool', Time Magazine (June 27, 1960); I-Huei Go, 'Ornette Coleman', New York Observer (19 December 2005) <http://observer.com/2005/12/ornette-coleman-2/>. (18 March 2014); Litweiler, Ornette Coleman, 78-79.

404 Pete Welding and John Tynan, 'Critical Reception of Free Jazz', in Keeping Time: Readings in Jazz History, ed. Rob Walser (New York: Oxford University Press, 1999), 253-255.
} 
acceptance by the field of jazz has been somewhat provisional, and only some aspects of Coleman's novel music have made their way into mainstream jazz practice. So while Coleman is included in jazz histories and college curricula as an important jazz musician, the fundamental lessons of his music (in terms of creative practice) have not been widely embraced. To explain, I need to backtrack fifteen years to the emergence of the jazz style known as bebop.

As Stanley Tambiah suggests, cultural practices universally tend toward ossification and the ritualisation of forms, and it seems to me that the field of jazz shares this tendency. Prior to Coleman's arrival on the scene, the last significant paradigm shift in jazz - according to the generally accepted narrative - had been with the emergence of bebop. While bebop's arrival has been described as revolutionary, ${ }^{405}$ I think it is arguable that the advances of Charlie Parker and Dizzy Gillespie (and to some extent Thelonious Monk and Kenny Clarke) represent an incremental step forward for the music rather than a stylistic revolution (that is, they demonstrate exploratory rather than transformational creativity, in Margaret Boden's terms). As Scott DeVeaux elegantly explains, the innovations Parker, Gillespie and Monk contributed to jazz were nascent in the musical examples of Coleman Hawkins, Art Tatum and Lester Young. ${ }^{406}$ As such bebop might be seen as the next step, perhaps even an inevitable step, in the evolutionary development of jazz. Bebop in these terms can be viewed almost as a conservative development, because while the musical materials bebop musicians made use of represented an advance on those of their predecessors (greater rhythmic complexity, more frequent embrace of abstracted harmony, more extreme tempi), the fundamental procedures of their music are isomorphous with those that came before. In light of this it is unsurprising that bebop became (and in pedagogical and some critical discussions about jazz, has remained, it seems to me) a metonym for modern jazz. Critic Francis Davis has suggested that bebop represented a kind of

405 Gioia, The History of Jazz, 201-204.

406 Coleman Hawkins's virtuosity and harmonic complexity; Art Tatum's harmonic sophistication and virtuosity; Lester Young's rhythmic subtlety and variety. DeVeaux, Birth of Bebop, 89-92; 84/322, 113. 
apotheosis for jazz, the point at which it had completed the journey from folk origins to become 'codified art music'. 407

Like the bebop musicians who preceded him, Ornette Coleman also proposed new materials improvising musicians might use, such as, for example, an emphasis on modality, a kind of glossolalia for the saxophone, a book of new compositions. In this way he was conventionally creative in terms the field of jazz could accommodate - that is, by extending the basic materials of jazz (in ways that were perceived as challenging) rather than fundamentally challenging the field itself. However, Coleman's example is crucially different from that of the bebop musicians in that his procedures call into question a number of the generative principles that characterised mainstream jazz (including bebop) at that time. ${ }^{408}$

Coleman's concept is primarily a melodic one, and as such he seems content to allow the music to be produced in a kind of top-down manner, with the accompanying musicians composing their own parts. In the liner notes to his first record, The Music of Ornette Coleman: Something Else!!!!, the saxophonist wrote:

I always write the melody line first because several different chords can fit the same melody line. In fact, I would prefer it if musicians would play my tunes with different changes as they take a new chorus so that there'd be all the more variety in the performance. 409

Jazz pianist and commentator Ethan Iverson acutely observed:

Long before [Coleman] came up with the name Harmolodics, his bands huddled around the blast furnace of his melodic genius and were inspired to create the rest of the arrangement. Each member of the group was required to take a lot of

\footnotetext{
407 Davis, 'Ornette's Permanent Revolution', 99-102. Stuart Nicholson explores the implications of the codification of jazz that attended the advent of bebop in Is Jazz Dead? 100-102.
408 Bebop did challenge some of the fundamental values of jazz. These include what appears to be a deliberate move away from vernacular (dance) values towards art music values; new social contexts for the music (the jam session); a greater emphasis on improvisation than had been normal in the swing style jazz that preceded it. These moves were accompanied by greater rhythmic, harmonic and melodic complexity in the surfaces of the music. All of these moves were embraced - more or less - by the evolving field. Coleman's innovations - those which challenge some of the basic generative principles of the music - are of a different order.

409 Ornette Coleman, liner notes to Something Else: The Music of Ornette Coleman (Los Angeles: Contemporary 7551, 1958). 
initiative. The biggest problem with most critical discussion of Ornette is how little consideration is given to his ensemble. 410

In this, Keith Sawyer's claims (and those of Thomas Kuhn, too) that all creativity is collectively achieved are affirmed. However, the point I want to emphasise here is that Coleman's approach invites musicians to abandon fixed harmonic frameworks, conventional intonation, regular metre and accepted formal conventions (head-solos-head for example, or individual improvisers accompanied by the rhythm section as the standard improvisational context of the music). In other words, Coleman's procedures violate many of the conventions of standard jazz practice - practices that are often evaluated in terms of their emergent style features ('Does it swing?') rather than for the creative potential such procedures might offer ('Does this kind of rhythmic freedom offer greater opportunity for expression/musical communication?'). As such (and given Tambiah's proposition that cultural practices tend toward ossification, perhaps particularly in fields seeking cultural legitimation, as jazz was at mid-century) Coleman's approaches - and their musical implications troubled the field of jazz. ${ }^{411}$

An interesting thing has happened here, I think. While, as I have shown, there is little question that Ornette Coleman has been influential (he is discussed in published jazz histories; his compositions appear in Real Books; his albums have been lavishly re-packaged and re-issued), only certain aspects of his musical example have been embraced for inclusion in the mainstream of jazz. The elements that could be embraced are perhaps best illustrated by the music Miles Davis and John Coltrane made during the decade after Coleman's appearance on the scene. Francis Davis writes:

Davis and Coltrane showed which elements of free form the jazz mainstream could absorb (modality, approximate harmonies, saxophone glossolalia, the sixteenth note as a basic unit of measurement, the use of auxiliary percussion and of horns once considered "exotic") and which elements it finally could not (variable pitch, free meter, collective improvisation). Coleman's early biography is replete with stories of musicians packing up their instruments and leaving the

\footnotetext{
410 Ethan Iverson, 'This is our Mystic', Do The Math (19 September, 2010) <http://dothemath.typepad.com/dtm/this-is-our-mystic.html> (17 March 2014).

411 The quest for cultural legitimation amongst jazz musicians and aficionados is the central theme of Paul Lopez's The Rise of a Jazz Art World (Cambridge: Cambridge, 2002). The Introduction (pp. 1-10) offers a useful summary.
} 
bandstand when he tried to sit in. If Coleman now showed up incognito at a jam session presided over by younger followers of Parker, Davis, and Coltrane, chances are he would be given the cold shoulder. Bebop seems to be invincible, though Coleman and other prophets without honor continue to challenge its hegemony. 412

The aspects of Coleman's music that have been accepted and adopted more widely (in mainstream jazz circles) are those that might be described as style features: musical materials that can be used to decorate or shape the surfaces of the music without fundamentally affecting the procedures that underscore its creation. ${ }^{413}$ Not all jazz musicians have been impervious to the more transgressive aspects of Coleman's example, but by and large the very fluid conception evident in Coleman's music is not readily apparent in much of the mainstream jazz playing with which I am familiar. ${ }^{414}$ There are costs both to adopting and failing to adopt Coleman's procedures, which I will discuss below ('No Copycats'), but at this point what I want to emphasise is that Coleman has been accepted by the field of jazz, but only in terms that do not fundamentally complicate the increasingly ritualised practices evident in much mainstream jazz since mid-last century.

Howard Mandel has suggested that Ornette Coleman, like Miles Davis and Cecil Taylor, was not ahead of his time; rather, 'the times - defined by the interests and attentions of the overall social, cultural and commercial milieu have not always kept pace with an era's most significant activists.' 415 While there are traces here and there in mainstream jazz of Coleman's insurrectionary methods (recent music from the Wayne Shorter Quartet, or Tomasz Stanko's

412 Davis, 'Ornette's Permanent Revolution', 102.

${ }^{413}$ There are many musicians who have done the opposite. They have adopted the procedures of Coleman - well, a very roughly drawn version of 'freedom' anyway, which often sounds as though it has been reified as a freedom from constraint, rather than freedom in the service of greater self-expression (some of the European energy players [perhaps Peter Brotzman et al?] spring to mind, which given their context is understandable) - without paying very much attention to Coleman's playing - its debt to the blues and evident traces of bebop. However, few in the field of jazz would describe this music (Brotzman et al.) as being part of the mainstream; many deny it is jazz at all.

414 Coleman's fluid conception is rarely defined or discussed as a genuinely viable path for improvisers in jazz education circles and given fairly short shrift in standard pedagogical texts (Jamey Aebersold, David Baker, Jerry Coker, Hal Crook, Scott Reeves, Mark Levine, Dan Hearle and so forth).

415 Mandel, Miles, Ornette, Cecil, 15. 
young Polish band suggest that Coleman's processual example is perhaps exerting an effect), it is not clear to me that the mainstream field of jazz (as represented by various institutions that support jazz, college curricula, major record labels and many musicians) has yet caught up with Coleman's fundamentally radical music. I will elaborate this idea below, but to do so it is necessary to first explore the second idea that Ornette Coleman's music powerfully illustrates: the centrality of divergent thinking to creative practice.

\section{Divergent Thinking}

As Mihaly Csikszentmihalyi - drawing from Joy Paul Guilford - suggests, divergent thinking involves having many ideas, being able to switch from one perspective or approach to another, and identifying original and fruitful combinations of ideas. ${ }^{416}$

From among the musicians discussed in my case studies Coleman is not alone in displaying divergent thinking: such thinking is evident in Miles Davis's practice, particularly in the late 1960s and early 1970s when he adopted a range of compositional approaches and orchestration strategies; divergent thinking can be found in the wide variety of orchestrational conceits Duke Ellington employed; and it is evident in the remarkable range of contexts in which Jan Garbarek has chosen to perform and record. Many other musicians could equally be presented as exemplars of this kind of thinking, too; this is because such thinking is the normal province of creative musicians and is a key to the kind of groundbreaking creativity celebrated by music histories. To the extent that divergent thinking has shaped the sounding products Coleman has produced, he is not terribly different from other jazz pioneers, although Coleman has demonstrated a considerable richness in the sheer number of strategies and approaches he has employed. ${ }^{417}$

\footnotetext{
416 Csikszentmihalyi, Creativity, 60.
}

417 Coleman's assertion that his approaches are unified under the rubric 'Harmolodics' (and more recently 'Sound Grammar') seem to suggest there might be a kind of overarching unity to his conceptual approach. That may be the case, although the opacity of Coleman's remarks about the system and the divergence of his various approaches might suggest that Harmolodics is a bag of diverse ideas rather than the product of a single thesis? Could it be that Coleman's claims about Harmolodics are a legitimating strategy on his part, perhaps bought on by his discomfiture with accepted theories of music? See Schuller's comments in Litweiler, Ornette Coleman, 93-94. 
However, divergent thinking, when expressed as problem-finding creativity, tells a deeper story about Coleman's creative practice. When married to ideas about what the field of jazz has and has not accepted in Coleman's example (discussed above) it becomes clear why Coleman is such an important exemplar of creative jazz practice. For the sake of completeness, I will briefly outline some of the evidence of the divergent thinking/diversity found in Coleman's music - evidence that reveals Coleman's work to be creative in ways similar to that of other jazz pioneers - and follow this with an examination of problem-finding creativity in Coleman's music.

Paul Bley, who worked with Coleman at the Hillcrest Club in Los Angeles, commented on the variety of approaches Coleman adopted in his music making.

A lot of people made the mistake of thinking that Ornette only played in one way. Every piece that he did suggested a different procedure for playing music. You couldn't use the last pieces' criteria to direct your playing on the next piece. Every tune had a different premise. Some tunes had a B section in a completely different feel or speed - it would have nothing to do with the first section: it was anti-the first section. You would have to maintain that "anti-ness" during the solos. Another tune would have another premise: so we didn't learn tunes, we learned premises. ${ }^{418}$

Bley illustrated the misconception that many people - including musicians - had about the apparently monolingual nature of Coleman's music by commenting on bassist Scott LaFaro's playing with Coleman (as documented on the albums Free Jazz and Ornette on Tenor):

On the early records that Ornette made with Scotty, Scotty thought that all he had to do was to play atonally behind Ornette, and that that would work. That only worked for $10 \%$ or $15 \%$ of Ornette's playing. Ornette has five ways to play, ${ }^{419}$ of which he is liable to play any one at any time, including [atonal] "erasure phrases" [...] Scotty made those records with Ornette and played atonally throughout, which was only suitable for a small part of the music. 420

The wide variety of approaches that Coleman makes use of can be found in his compositions, in his improvisational conceits, in his choice of ensemble and even

\footnotetext{
418 Meehan, Time Will Tell, 45.

419 I elaborate some of Coleman's 'ways to play' below, under 'Coleman's Performance Techniques'.

${ }^{420}$ Meehan, Time Will Tell, 45.
} 
in his choice of instruments. ${ }^{421}$ I will illustrate this diversity by speaking to Coleman's compositional and performance techniques in turn.

\section{Coleman's compositional techniques}

Coleman's first recording sessions from the late 1950s were dominated by pieces that sound very much like a continuation of the ideas first promulgated by bebop musicians and composers of the 1940s. The melodies of these early Coleman compositions could in many cases be accommodated by chord progressions that had formed referents for a number of bebop compositions: 'Angel Voice' works as a 'rhythm changes' tune; 'Forerunner' may be harmonised using an elaboration of the tonic chord by means of turnarounds; and 'Tears Inside' and 'Turnaround' are blues compositions. ${ }^{422}$ However, unlike the bebop composers for whom the chord progressions generally predicated the melodic line ${ }^{423}$ for Coleman the order was reversed: melodies preceded harmony and form. Because of this, tunes possessed mutable harmonic schemes and frequently boasted uneven numbers of measures ('Congeniality' has a 7-bar A section; 'Forerunner' a 9-measure A section) and inconsistent metre ('Rejoicin" is in $4 / 4$ but begins with a measure of 6/4, 'Birdfood' includes a measure of 2/4).

A more significant departure from bebop conventions is found in Coleman's willingness to relax strict, overarching tempo. This plastic approach to tempo is most obvious in his rubato themes, which include 'Lonely Woman', 'Lorraine' and 'Broken Shadows'. An intriguing development that Coleman pioneered was the combination of different tempi or metres, heard clearly in 'Congeniality' where a fairly strict $4 / 4$ alternates with a rubato $3 / 4$ section, or in 'Compassion' where a fast three alternates with a slow swinging 4/4.

Musicologist Ekkehard Jost categorises these kinds of compositions as 'Coleman

\footnotetext{
${ }^{421}$ Comprehensive analyses of Coleman's music have been published by Ekkehard Jost, Free Jazz, (New York: DaCapo, 1974) and Peter Niklas Wilson (Ornette Coleman). Their analyses along with my own observations are presented in the following section.

422 And, as we have seen, Coleman was happy for musicians to vary these chord progressions once the tune was played and improvisations were underway.

423 For example, see Scott DeVeaux's discussion of Dizzy Gillespie’s composition 'Woody 'n You'. Deveaux, The Birth of Bebop, 311-313.
} 
Themes' presumably because in his view such a combination of different metres was one of Coleman's unique contributions to jazz. ${ }^{424}$

A further approach adopted by Coleman is what has been described by Wilson as 'Modular Themes', tunes that build through development of a single melodic cell, on occasion through a series of (sometimes surprising) implied tonal centres. ${ }^{425}$ These compositions can be quite static (for example, "The Legend of Bebop') and may seem naïve (for example 'Latin Genetics') but they can also be surprisingly compelling (for example, 'Peace Warriors', or 'Checkout Time'). A variation on the modular theme approach is found in what have been described (again, by Wilson) as 'Endless Riff' tunes. ${ }^{426}$ These are compositions that comprise a single motif repeated many, many times before resolving with a counter-phrase. Examples include 'Theme from a Symphony' and 'School Work'.

Related to his compositional techniques, Coleman has shown a fondness for the use of parallelism in orchestrating his music. In performances with trumpeter Don Cherry some passages were harmonised in parallel at a perfect fourth, possibly a consequence of the two of them reading from the same nontransposed score rather than a deliberate orchestration choice. Such parallelism is clearly heard in Coleman's music for multiple horns (for example 'All My Life' from Science Fiction ${ }^{427}$ ) and in his orchestral suite Skies of America. Whether such sounds are the product of a deliberate agenda on Coleman's part or the result of a failure to understand conventional musical principles, the net outcome of this approach is music that sounds quite unlike other music in the jazz repertory.

Using all of these approaches, alone and in combination, Coleman has produced a remarkably diverse oeuvre documented on more than 50 albums.

\footnotetext{
424 Jost, Free Jazz, 57.

425 Wilson, Ornette Coleman, 79-81.

426 Ibid., 83.

427 Ornette Coleman. Skies of America (New York: Colombia KC31562, 1972).
} 
Significantly, Coleman's output reveals rather more diversity than that of most celebrated jazz musicians. ${ }^{428}$

\section{Coleman's performance techniques}

In addition to these diverse approaches to composition and orchestration, Coleman has adopted a range of different strategies when improvising. These include what Ekkehard Jost called 'motivic chain associations' - melodic ideas developed sequentially in entirely logical and musical ways, but without regard for tonal centres. ${ }^{429}$ Coleman generally plays modally, but moves with ease to new tonal centres as his melodic line evolves. Movement from one tonal centre to another is sometimes achieved with pivot tones or phrases, and sometimes through transposition of ideas. ${ }^{430}$ There are clear examples of both approaches during Coleman's solo on 'Chronology'.431

A device that appears to have been pioneered by Coleman was the use of erasure phrases, as described by Paul Bley:

An erasure phrase is meant to do nothing except erase from your memory what you have just heard him play. Clean the blackboard, so to speak, before you write the next piece of music. It's there to make you forget, it's not there to tell you anything: it's there to cleanse the palate [...] There are [tonal] centers that [Ornette] goes to and hugs like a folk musician, and he is liable to go from one center to another at any time, and not necessary directly there: he is liable to go to an erasure section before he goes to the next section. 432

These atonal passages can been heard to great effect during Coleman's solo on 'Garden of Souls', where erasure phrases are used to punctuate not only changes in tonal centre but also changes in tempo. ${ }^{433}$

\footnotetext{
428 Charlie Parker, Billie Holiday and Count Basie for example, produced work in a much narrower idiomatic range than Coleman. A few jazz musicians approach the diversity evident in Coleman's catalogue, including Charles Mingus, Miles Davis, perhaps Chick Corea.

429 Jost, Free Jazz, 49-50.

430 Such motivic development was not uncommon amongst jazz improvisers when Coleman emerged, but Coleman's willingness to allow the melodic line to determine the harmonic setting was a radical departure from standard procedures in which the reverse was true: harmonic settings constrained the melodic lines.

431 Ornette Coleman. The Shape of Jazz to Come (New York: Atlantic 1317, 1959). See Jost, Free Jazz, 48-53.

432 Meehan, Time Will Tell, 45.

433 Ornette Coleman, New York is Now (New Jersey: Blue Note 784287 2, 1968).
} 
Such spontaneous tempo changes were not particularly evident in Coleman's performances on his early albums. In bebop (which along with the blues formed Coleman's musical grounding), tempo was strictly regular, and this practice was carried over to Coleman's soloing on those early recordings. However, by the mid-60s he seemed happy for soloists to change tempo as well as tonal centres and other aspects of the formal characteristics of the music being performed. On the basis of the recordings (particularly in the trio with David Izenson and Charles Moffett, and the quartet recordings from 1968) it appears changes were generally directed by the soloist, although there is a bit of push and pull with the rhythm section as well. Coleman's solo on 'Garden of Souls' is exemplary in this regard, and examination of a transcription of this solo (Appendix 1) and audition of the recording reveals the band's supple flexibility with regard to tempi as well as their nimble harmonic conception. ${ }^{434}$

During his improvised solos, Ornette Coleman frequently plays phrases that are melodically coherent and bounded by a single tonality. However, Coleman often moves (apparently effortlessly) between tonal centres, in many cases in ways not easily explained by means of functional harmony. Such spontaneous harmonic mobility makes Coleman's performances sound like movement through a succession of (not necessarily related) tonal centres. Peter Niklas Wilson categorises this phenomenon as successive polymodality. Coleman's orchestral music (heard on Skies of America) and that of Prime Time (Coleman's 'electric' band formed in 1975) features multiple tonal centres played simultaneously (simultaneous polymodality), creating a homogeneous (if rather dissonant) sound. Examples from each can be heard during 'Latin Genetics' (performed by Prime Time ${ }^{435}$ ) and the orchestral passage entitled 'The Good Life'. ${ }^{436}$ More common however is for the ensemble to accommodate the soloist's move from one tonal centre to another. Such changes sometimes occurred around the nominal 'double bar' line points of a composition's form.

\footnotetext{
434 Ornette Coleman, New York is Now (New York: Blue Note, 1968).

435 Ornette Coleman, In All languages (Fort Worth TX: Caravan of Dreams 85008, 1987). Prime Time was Coleman's 'electric' septet, which ran from the mid-1970s through mid-1990s.

${ }^{436}$ Coleman, Skies of America.
} 
Ekkehard Jost explained these phenomena by suggesting that each formal section was like an empty vessel (which he called 'empty forms'), and during each eight or twelve or sixteen-measure section the improviser was free to perform whatever they chose, punctuating the move from one section to another with a modulation as required. An example of a solo by Coleman in which he uses this 'empty form' approach is 'Chronology'. 437

Another aspect of Coleman's performance technique that widens his choices when improvising is his use of microtonality. For Martin Williams,

Intonation is a matter of context and expression to Coleman. "You can play sharp in tune and you can play flat in tune", he has said, and a D in a context representing sadness should not sound like a $D$ in a passage of joy [...] This is not a matter of "good" intonation, and if there were any doubt about that, there are enough key notes and phrases in Coleman's solos on exact pitch to dispel that doubt. 438

Coleman was frequently accused of playing out of tune, and while his lines may not have adhered to the conventions of equal temperament, this was more a matter of conscious choice on Coleman's part rather than an inability to play tempered scales. During the Summer School of Jazz in Lennox (Massachusetts) which Ornette Coleman and Don Cherry attended in 1959, 'Bob Brookmeyer, the trombonist and composer who was on the faculty that summer, became so angry at the two - at one point he screamed "Damn it, tune up!" - that he stormed off and quit the school in protest.' 439 Coleman drew his music from different wells to Bob Brookmeyer and claims his grounding in the blues is the reason he is happy to use non-tempered pitches. He has argued that such an approach has admitted greater emotional expressiveness to his music. ${ }^{440}$ However, it is not an approach that sits well with many conservatory-trained musicians, or even jazz musicians

\footnotetext{
437 Coleman, The Shape of Jazz To Come.

438 Martin Williams, The Jazz Tradition (New York: Oxford University Press, 1993), 240.

${ }^{439}$ Fred Kaplan, 1959: The Year Everything Changed (Hoboken, NJ: John Wiley and Sons, 2009), 206.

440 Robert Palmer, Beauty is a Rare Thing. Ornette Coleman: The Complete Atlantic Recordings. [liner notes] (New York: Atlantic R2 71410, 1993), 45.
} 
who have developed without the benefit of the conservatoire but still adopt conservative attitudes toward playing 'in tune'. ${ }^{441}$

In addition to this wide array of compositional and performance techniques, Coleman has broadened his range of available choices by making use of a variety of instruments, both in his ensemble and through the unusual step of taking up violin and trumpet as well as his usual alto saxophone. Coleman's taste for diverse instrumentation has seen his groups boast: Coleman (on alto and occasionally tenor saxophone), pocket trumpet, bass and drums; Coleman (alto only) with two trumpets, bass clarinet, two bassists, two drummers (for the double quartet on Free Jazz); Coleman (on alto, trumpet and violin) with tenor saxophone, bass and drums; trios of Coleman (on alto, trumpet and violin) with bass and drums; Coleman (on alto, trumpet and violin) with two guitarists, two bassists and two drummers (with Prime Time); and recent groups with Coleman (on alto, trumpet and violin) and two or three bassists and a drummer. There are also numerous other amalgams documented on his recordings, including chamber groups and performances with band and full orchestra.

Taken together, this wide variety of compositional techniques and performance strategies reveals Coleman to be a musician and composer with many ideas - and many more than the recorded output of most jazz musicians suggests is common, some of which (in Coleman's case) were quite unconventional when first mooted ${ }^{442}$ - who is happy to mix and match them in interesting ways. Mihaly Csikszentmihalyi's summary of Joy Paul Guilford's definition of divergent thinking suggested, 'Divergent thinking [...] involves fluency, or the ability to generate a great quantity of ideas; flexibility, or the ability to switch from one perspective to another; and originality in picking unusual associations of ideas.' ${ }^{443}$ These examples reveal the centrality of

\footnotetext{
441 Coleman's is an approach that has been wholeheartedly embraced by others however. John Coltrane studied Coleman's approach and adopted aspects of it. This is clearly evident on Ascension (rec. 1965, which marries ideas from Coleman's Free Jazz and Davis's 'Flamenco Sketches'. See Jost, Free Jazz, 86-88). Albert Ayler adopted approaches that recall some of the timbral devices evident in Coleman's music, as well as his penchant for folk-like melodies.

442 Unconventional, for example, in the use of: simultaneous disparate tempi; motivic chain association; saxophone glossalalia.

${ }^{443}$ Csikszentmihalyi, Creativity, 60.
} 
divergent thinking to Coleman's practice, and the innovations they represent are enough to ensure him a reputation as a musician who has propelled jazz in some new directions. However, these examples are mainly described in terms of the surface features of the music produced, surface features that others (Coltrane and Davis for example, as discussed earlier) have adopted without necessarily embracing the procedures from which many of them emerge. ${ }^{444}$ It is these procedures that I think are central to Coleman's example as a creative musician, and it these procedures I think Howard Mandel refers to in writing that Coleman 'has inspired admirers and followers but no copycats, having established an example of being true to himself that prescribes others do likewise.' ${ }^{445}$

\section{No Copycats}

As I mentioned, while Coleman's recordings are discussed in jazz histories, and explicit mention is made of his musical processes, there appears to be a lag between what is celebrated in this music and what Coleman has actually achieved. This apparent lag is in part because the determinations made by the field of jazz have focused on the style features of Coleman's music (the sounded object rather than the process from which it emerged) and partly because the processes Coleman engages are difficult - elusive ideas that are not only difficult to quantify or reduce to easily-understood principles, but also extremely challenging to execute successfully. While Coleman's processes are acknowledged in discussions about the importance of his music to the evolution of jazz, such acknowledgement has failed in most cases to recognise how potentially prophetic his example is in terms of ongoing creativity in jazz.

Commentators Don Heckman and Gunther Schuller both acknowledge that Coleman's procedures are important, but primarily concern their analyses with the surface features of the music. Peter Niklas Wilson and Ekkehard Jost emphasise Coleman's processes but for my money don't make the point strongly enough that it is the processes themselves that are the foremost factor in

\footnotetext{
${ }^{444}$ Some of the procedures Miles Davis (and Coltrane, too) adopted during the 1960s are related to those Coleman pioneered, and embrace a similar kind of indeterminacy; hence the qualifiers 'mainly' and 'without necessarily' in the preceding sentence.

445 Mandel, Miles, Ornette, Cecil, 12.
} 
Coleman's radical music, rather than the surface features that follow (and on which they focus most of their analyses). David Ake's insightful essay on Coleman's music acknowledges some of the processes Coleman engaged but links the negative reception his music experienced to notions of masculinity. 446 Ake's analysis undoubtedly has bearing on the current discussion, but primarily because the kinds of virtuosity Coleman's musical approaches require are subtler than the sort of bravura values reified in exemplary bebop performances (higher, faster, more complex). The processes central to Coleman's music instead require careful and empathetic listening, and significantly, surrender to the musical directions of the moment rather than conquest of an alreadyunderstood musical problem (a chord progression or tempo, for example).

The point I want to emphasise here is that Coleman's approach, which leaves the formal structures of the music open to change during performance, is a problem-finding approach. ${ }^{447}$ As the musicians manipulate timbre and tempi (and as the accompanying musicians respond to that lead) and improvise not only their melodic/rhythmic lines but also chord progressions and other aspects of formal organisation, there is a rich efflorescence of emerging possibilities, such that the music will never be significantly predictable. This approach to making music embraces the unexpected, and conforms not to a script but rather to a set of procedures. It contrasts with straight ahead post-bop performance practices, where tempo is generally fixed, harmonic patterns are prescribed and improvisational conventions obtain. Improvising a solo in such conventional contexts, where observing the harmony and metre are expected, is a problemsolving exercise. Coleman's problem-finding approach ensures the music produced is never predictable. In line with John Dewey (as quoted by Keith Sawyer), 'The unexpected turn, something which the artist himself does not

\footnotetext{
446 David Ake, 'Re-Masculating Jazz: Ornette Coleman, "Lonely Woman," and the New York Jazz Scene in the Late 1950s', American Music 12/1 (Spring 1998), 25-44.

447 Not all of Coleman's music is open in this regard, as far as I can tell. For example, the formal ordering of the symphonic work Skies of America is probably relatively fixed. This is likely a function of necessity (how does one get an orchestra to improvise with harmony and formal structures in performance?) but may also reflect a desire on Coleman's part to limit this kind of structural freedom on some occasions.
} 
definitely foresee, is a condition of the felicitous quality of a work of art; it saves it from being mechanical. ${ }^{\prime 48}$

It is possible to describe the music that emerges from Coleman's procedures in terms of its style features, and many scholars, as noted above, have done so. ${ }^{449}$ As interesting as the work of these scholars is, the predominant focus on the product of the performances (aspects of Jost and Wilson's analyses exempted) simply endorses the view of the field (that some of Coleman's work is acceptable - for example his compositions - and some of it is outside of the republic of jazz) and to some extent misses the point of the music; the point being achieving communicative value by 'applying your feelings to sound' (as Coleman has succinctly put it) by whatever means available, rather than allowing style to trump ideas. ${ }^{450}$ In the ways that Charles Olsen and William Carlos-Williams' Projective Verse contravened the orthodoxy of received poetic forms, so establishing a new paradigm for modernist poetry, Coleman's procedures violate the formal constraints of mainstream jazz and instead propose a problem-finding approach that is at odds with the problem-solving approach that characterises playing on changes. Such an approach can lead to the 'unexpected turn', and that is certainly the case with Coleman's performances. As Gunther Schuller reports,

There are certain variables in the recorded performances of Mr. Coleman's works with respect to tempos, meters and chord progressions, not only within a given piece, but from performance to performance [...] In Mr. Coleman's world, where freedom and constant variation are the main guiding principles, it is not at all unusual that an improvised phrase, which on its first appearance consists of six bars, turns out to be eight the next time, and perhaps nine still later. The chord progressions (or 'changes') upon which the improvisations are based are often only loosely related to the composition, at other times relate only to part of the written section, and in any case are not always strictly adhered to [...] These structural and harmonic liberties have led some observers to conclude that Mr. Coleman's music is chaotic and formless... ${ }^{451}$

\footnotetext{
${ }^{448}$ John Dewey, quoted in Sawyer, Group Creativity, 106.

449 In addition to those mentioned above, Steven Block has also analysed Coleman's music, using set-theoretical tools: 'Pitch-Class Transformation in Free Jazz', Music Theory Spectrum 12/2 (Autumn 1990), 181-202.

450 Coleman, quoted in Palmer, Beauty is a Rare Thing, 47.

451 Schuller, Compositions of Ornette Coleman, 3-4.
} 
Walter Norris, who played piano with Coleman for his first recording as a leader (Something Else, 1957), was still somewhat bewildered by Coleman's approach when historian Ted Gioia interviewed him in 1990.

We rehearsed two or three times a week for about six months leading up to the recording. A number of times we rehearsed at my house. I would take a paper and pen and make notes about the compositions and about what we were supposed to be doing. But the funny thing was that at every rehearsal Ornette would change what we had done the last time. He would change the structure of the song or where the rubato was. And then when we finally showed up for the record date, he changed everything again. 452

That Norris could play with Coleman so extensively and then describe a fundamental aspect of Coleman's approach as a 'funny thing' is revealing, and I think, emblematic of a kind of myopia the jazz field has indulged with regard to Coleman's music. Conceptually, all Coleman has done is extend the scope of improvisation in his music from the melodies and rhythms of improvised solos (and some features of the accompaniment) to include the compositions' formal features (harmonic progression, sectional durations, tempi and the like). For such an approach to be successful however, a very high level of musicianship and mutual understanding is required of the musicians performing, and the final product of such performances is not readily predictable.

What is important for my argument is that the processes Coleman engaged - problem-finding processes; group creativity in which individuals have freedom concerning means, share common goals and have had the opportunity to develop mutual understanding; processes that require deep listening - are those identified by creativity researchers as being conducive to creative practice. And yet these processes are glossed in most discussions of Coleman's music. Thus the rhetoric of the field around Coleman's music is a rhetoric that (if used to inform musical practice) encourages reproduction of the sounding objects that Coleman has already made (or ones quite like them). This is quite different from deployment of the processes his music advocates, processes that - in reifying the unique ideas of the individuals who engage them - will give rise to music that sounds different from the run of the mill. This (latter approach) is Coleman's example: being true to oneself. As such, and if faithfully embraced, it

452 Walter Norris, quoted in Gioia, The History of Jazz, 314. 
will inspire 'admirers and followers but no copycats.' ${ }^{453}$ Charles Mingus, frequently an antagonist of Coleman's music, ${ }^{454}$ summarised this idea elegantly (whether knowingly or not) when he said 'I'm not saying everybody's going to have to play like Coleman. But they're going to have to stop playing Bird.' ${ }^{455}$ Hearing recent music from Wayne Shorter's quartet or Tomasz Stanko's Polish group ${ }^{456}$ reveals that the procedural lessons of Coleman's music have not fallen entirely on deaf ears amongst musicians associated with the mainstream of jazz. Certainly many musicians have followed Coleman's procedural examples, but by and large the mainstream has not wholeheartedly embraced them. ${ }^{457}$ Perhaps Shorter's example may see the field of jazz begin to change, with the language of Charlie Parker and his descendants being supplanted by the very open procedures of Ornette Coleman, procedures that invite musicians to exercise more freedom, experience more uncertainty, and exhibit more creativity.

453 Mandel, Miles, Ornette, Cecil, 12.

454 Mingus said of Coleman, 'It would be pitiful if he was forced into a jam session and somebody called "Body and Soul." He couldn't make it, man. When we played the Protest Festival some years ago at Newport [1960], we played "All The Things You Are," and Ornette was lost after the first eight bars.' Quoted in John Goodman, Mingus Speaks (Berkeley: University of California Press, 2013), 26-27.

455 Charles Mingus, quoted in Priestly, Mingus, 110.

456 Shorter's recent recordings Footprints Live, Beyond the Sound Barrier and Without A Net, and Stanko's group in live performance (I'm not aware of any live recordings but have had the pleasure of hearing them in concert) and on the studio recording Lontano all reveal groups negotiating collective improvisation contexts that engage almost all (stylistic and structural) aspects of the music being performed.

457 The two notable exceptions are Keith Jarrett and Pat Metheny, although both have been able to 'sweeten' the uncompromised aspects of their music with their deeply lyrical improvising styles. Both have also worked in group-contexts in which other, more conservative values have been strongly in evidence, too. For the most part musicians who have followed Coleman's example have been relegated to sidelines of the mainstream or categorised as something other than 'jazz' - 'free jazz' for example, which some commentators have described as a mistake, or at best as a dead-end. 


\section{Chapter Four: Miles Davis - Alchemist}

'I have always felt that what the group does together is what makes the music happen.'

Miles Davis 458

Jazz trumpeter Miles Davis claimed in his autobiography that he constantly had to change his music, and described that compulsion as being 'like a curse'. ${ }^{459}$ Change does appear to be a constant in a survey of Davis's music, particularly the period that runs from 1950 until 1975 (after which Davis took a five-year sabbatical from performing). I want to draw attention to several aspects of Davis's practice during this period that reveal the ways in which he operated that led to creative music making. First: Davis's appropriation and transformation of ideas and musical materials not normally considered a part of the jazz idiom as ingredients in his music making. Second: Davis's leadership style, and his emphasis on an interactive, largely egalitarian process. Third: as a result of that leadership style, the way Davis's routine practice became a site in which ordinary and exceptional creativity occurred, producing music that was not always successful ${ }^{460}$ but which generally fore-grounded the creative capacities of Davis and his collaborators. While I am continuing to adopt the kind of inclusive definition of creativity proposed by Negus and Pickering, this discussion of Davis's music does dwell on moments of exceptional or markedly innovative creativity. However, as will become clear, such moments occurred in the context of routine practice.

As with my discussion of Ornette Coleman, this examination of Miles Davis's music works on two levels. First, viewing Davis's practice through the lens of creativity usefully confirms received wisdom about Davis's work. That Davis introduced new and influential ideas to jazz is perhaps the most common trope in print about the trumpeter - it is an idea that has been rehearsed in

458 Miles Davis and Quincy Troupe, The Autobiography (New York: Simon and Schuster, 1989), 272.

459 Ibid., 401-402. In March of 1969, Miles Davis told Washington Post journalist Hollie West, 'I have to change. It's like a curse.'

460 Some of the music Davis recorded did not meet his standards and was therefore not approved for release, for example. 
pretty well everything I have read about him. The writers of The Penguin Guide to Jazz go so far as to suggest a jazz history could be written from the 1940s through the present day using only Davis's music as exemplary of the development of the genre. 461

As the examples presented in this chapter will reveal, appropriation and transformation are two of the ways Davis introduced new ideas to jazz, and in this regard he is no different from many composers who have been regarded as innovators. In the ways that Igor Stravinsky made use of Russian folk themes or Olivier Messiaen drew sounds from the natural world and Lennie Tristano looked to Bach to find new materials for their music, so Davis drew lessons from traditions outside of jazz in order to find new ways to play. The lens of creativity (and specifically in relation to Davis, the processes of appropriation and transformation) provides an instructive paradigm for viewing this practice and so makes sense of Davis's musical materials. It is the materials Davis used that have often been the subject of discussion in the discourse about him, and understanding these materials as the results of appropriation and transformation provides a different methodological lens to reinforce, in slightly different terms, an already common consensus. Once again, the lens of creativity is confirmed in that it endorses well-established conclusions while at the same time offering a subtly different intuition with regard to the various means musicians enact to achieve results.

However, as important as appropriation and transformation have been to the innovations Davis introduced to jazz, I propose that the manner and the group contexts in which he engaged these processes offers the most compelling examples of jazz creativity available to us from his work. This is the second point I wish to make, one that I think offers an advance on previous thinking about Davis's music. ${ }^{462}$ In that respect this chapter does similar work to Gary

\footnotetext{
461 Richard Cook and Brian Morton, The Penguin Guide to Recorded Jazz (London: Penguin, 2011), 340 .

462 Although writers acknowledge the importance of Davis's groups, their language consistently emphasises the role Davis played at the head of the ensemble. See Gary Tomlinson, 'Cultural Dialogics and Jazz: A White Historian Signifies', Black Music Research Journal 22 [Supplement Best of BMRJ] (2002), 71-105; John Szwed, So What: The life of Miles Davis (New York: Simon and Schuster, 2002); Ian Carr, Miles Davis: The Definitive Biography (New York: Thunder's Mouth
} 
Tomlinson's essay on Davis, 'Cultural Dialogics and Jazz: A White Historian

Signifies, ' which I consider one of the most significant critical articles on Davis's music with respect to his group practice. ${ }^{463}$ This project differs somewhat from Tomlinson's in that he emphasises dialogue and its utility as a mechanism to enable Signifyin(g) in Davis's practice, whereas I wish to emphasise the role of the entire group as central to enabling creative outcomes. As Keith Sawyer claims, and as Davis's musical example bears out, all creativity is group creativity.

\section{Appropriation and Transformation}

Scholars and jazz commentators widely agree that one of the strategies Davis used to propel his music in fresh directions was by introducing musical ideas or materials from outside of the commonly accepted borders of jazz into his music making. 464 This strategy has characterised jazz for as long as the music has had that name; for example, the majority of recorded jazz has involved interpretation of repertoire that would not in its earlier incarnations be called jazz. Standards, the songs that have formed a core repertoire for many jazz musicians and still populate jazz recordings in the new century, mainly began life as popular songs in musical theatre or film; they became 'jazz' by virtue of the transformations to which jazz musicians subjected them. Davis too followed this practice, playing standards that others had performed before him - for example, Jerome Kern's song 'Yesterdays' (from the 1933 Broadway show Roberta), which had been performed and recorded by many jazz musicians before Davis committed it to disc on the 1952 album Miles Davis, Volume $1{ }^{465}$

Press, 1998); Amari Baraka, 'Miles Davis: One of the great mother fuckers', in A Miles Davis Reader, ed. Bill Kirchener (Washington: Smithsonian, 1997), 63-73.

463 Tomlinson, 'Cultural Dialogics'. Christopher Smith's article exploring similar issues ('A Sense of the Possible: Miles Davis and the Semiotics of Improvised', TDR 39/3 [Autumn, 1995], 41-55) is also relevant to this discussion.

464 See Szwed, So What, 272; Gridley, Jazz Styles, 220; Gioia, The History of Jazz, 334-335;

Tomlinson, 'Cultural Dialogics', 27-29.

465 Miles Davis, Miles Davis Volume 1 (New York: Blue Note BLP 1501, 1952). All subsequent discographical information pertaining to Miles Davis is drawn from the excellent Miles Davis discography at http://www.jazzdisco.org/miles-davis/discography/. (First retrieved $16 \mathrm{March}$ 2014) 'Yesterdays' was recorded by jazz musicians Artie Shaw, Billie Holiday, Art Tatum, Erroll Garner and Bud Powell among others before Davis made this recording. 
Where Davis differed from many other jazz musicians was in his willingness to incorporate ideas from a rather wider range of sources than those that had generally fuelled jazz. This diversity of taste is evident in his first collaboration with composer and orchestrator Gil Evans, for the 1949-1950 nonet recordings that were later assembled as the album Birth of the Cool. ${ }^{466}$ The carefully crafted arrangements performed at these sessions - along with the lack of vibrato in, and fairly 'even' delivery of the music, characterised as it was by subtle dynamic contrasts and measured solos - were an attempt on Davis's part to distance his music from the bebop he had been playing. With this music he sought instead to emulate the example of jazz pianist Claude Thornhill's band from the mid-1940s, a band for which Gil Evans had written. 467

Some writers compared the resulting performances to the so-called 'impressionist' music of fin de siècle European composers. Winthrop Sergeant, music critic for The New Yorker, described the music Davis and Evans (along with other arrangers) released on Birth of the Cool as being what he might expect from an 'impressionist composer with a great sense of aural poetry and a very fastidious feeling for tone color. . . The music sounds more like that of a new Maurice Ravel than it does like jazz ... it is not really jazz.' ${ }^{468}$ Given that this music was made by recognised jazz musicians, playing instruments commonly associated with jazz and featuring improvised solos, Sergeant's comments are revealing; for him at least, the inclusion of musical materials he believed exogenous to jazz excluded Birth of the Cool from the genre of jazz. Using Jason Toynbee's radius of creativity model ${ }^{469}$ to interpret Sergeant's assessment, it is possible to describe the orchestration strategies that gave rise to so-called 'impressionist' sounds as being sufficiently remote on the radius of (jazz)

\footnotetext{
466 Birth of the Cool was compiled as a 12' LP in 1957 by Capitol Records. Gil Evans prepared two of the arrangements, with others written by Gerry Mulligan (6), John Carisi (1), John Lewis (3).

467 Davis and Troupe, The Autobiography, 117.

${ }^{468}$ Gioia, The History of Jazz, 283. (My emphasis)

${ }^{469}$ Toynbee, Making Popular Music, 35-42.
} 
creativity to dislodge the music from the 'jazz' values at the centre of the circle. ${ }^{470}$

Sergeant may have felt uncomfortable calling this music jazz, but a number of the musicians involved with these sessions - in particular Gerry Mulligan, Lee Konitz and John Lewis - were more than happy to go on making use of similar sounds and styles. In doing so, they become principal actors in what became known as cool jazz, a style that enjoyed considerable popularity during the 1950s. In this way the stylistic lessons of Birth of the Cool were thoroughly embraced. The careful arrangements evident on the recordings made by Gerry Mulligan with Chet Baker (or later, with Art Farmer), the thoughtful sometimes restrained - playing of Lee Konitz and Warne Marsh, the contrapuntal surfaces evident in John Lewis's music for the Modern Jazz Quartet, all attest to the lessons of Birth of the Cool. ${ }^{471}$ In this way Davis's advocacy of an approach that embraced materials and performance techniques somewhat distant from jazz, even if initially rejected by some observers, contributed to a change in the domain of jazz. In these terms Davis's work on the Birth of the Cool is creative (it led to new and useful outcomes) in a reasonably conventional manner.

The same principle held when, a decade after the Birth of the Cool recordings, Davis released his fourth collaboration with Gil Evans, Sketches of Spain. ${ }^{472}$ For this album Davis and Evans reinterpreted music by Spanish composers Joaquin Rodrigo and Manuel de Falla as well as Spanish folk music and new pieces composed by Evans in a style (or perhaps mood) resonant with the 'Spanish' qualities of the other pieces. Such Spanish 'borrowing' was not a particularly radical departure - New Orleans jazz pianist and composer Jelly Roll Morton identified 'the Spanish tinge' as a constitutive element of jazz - although

\footnotetext{
470 Stanley Crouch's assessment of this music also framed it as a 'failed attempt to marry jazz to European devices' resulting in music that was 'little more than primers for television writing.' Crouch's judgment appears to be based on his (quite reasonable) appraisal that the music was 'far from idiomatic'. Crouch, 'Play the right thing', 25.

${ }^{471}$ For example, 'Walking Shoes' performed by Mulligan and Baker, or 'What is there to say?' performed by Mulligan and Farmer; Lee Konitz with Warne Marsh (Atlantic, 1955); Modern Jazz Quartet, Third Stream Music (Atlantic, 1957).

472 Miles + 19 and Porgy and Bess were the second and third projects they completed together.
} 
the treatment that Davis and Evans subjected the music too left some commentators cold. ${ }^{473}$

However, the presence of flutes, French horn, harp and bassoon, the delicate textures of the orchestration and the dynamic contours of the music suggest why some commentators considered the album to be 'one of the most successful and astonishing blends of jazz and classical music ever.' ${ }^{474}$ As such it has sometimes been described as Third Stream, a term coined by composer Gunther Schuller to describe a classical-jazz hybrid. ${ }^{475}$ With this album, the blend of 'classical' music elements once again troubled the music's definition as jazz, hence the creation of a new denomination ('third stream') in some quarters to describe the music. ${ }^{476}$ In this case, and unlike Birth of the Cool, acceptance of Davis's music as jazz was less enthusiastic, and while the album is still generally filed under 'Jazz' in CD stores, some commentators prefer to categorise it using different terms.

Davis's eclecticism became increasingly disquieting to some fans and commentators during the second half of the 1960s and early 1970s, and the music he made during this period was to prove controversial. The first signs can be heard on the 1965 album, ESP, and in particular on the Ron Carter composition, 'Eighty-One'. With this piece the straight groove that drummer Tony Williams plays is closer to a boogaloo-type R\&B rhythm than to the swing feels usually associated with jazz. Within a few years, (beginning with Miles in the Sky, and Filles de Kilimanjaro, both released in 1968) such straight-eighth rhythms came to predominate on Davis's recordings, and provide evidence that Davis was drawing explicitly from $R \& B$ and rock music. This conclusion is

\footnotetext{
473 Gioia, The History of Jazz, 6, 206, for the 'Spanish tinge'. Jazz critic Martin Williams then writing for the New York Times thought Sketches of Spain a curiosity, and a failure: Jack Chambers, Milestones: The Music And Times Of Miles Davis (New York: Da Capo Press, 1998), Pt 3, 10. Cook and Morton (in The Penguin Guide to Jazz) considered that the sombre moodiness of the album yielded a soundtrack closer to glorified elevator music than to jazz ( $5^{\text {th }}$ ed., 375$)$.

474 Heike Raphael-Hernandez, Blackening Europe: The African American Presence (Florence, KY: Routledge, 2012), 147.

475 Gunther Schuller, Musings: The musical worlds of Gunther Schuller (New York: Da Capo, 1986), 114.

476 Gunther Schuller describes Sketches of Spain as Third Stream in his notes to the fiftieth anniversary release of the album (CBS Legacy, 2009).
} 
reinforced by Davis's introduction of electric instruments that same year, in particular electric piano and guitar. I will discuss these developments in greater detail below as I turn my attention to Davis's leadership and working practices, but pertinent to this discussion of the catholic approach Davis adopted to making music are the ways the resulting music fitted only uncomfortably into accepted definitions of jazz.

The reception of the rock-influenced music Davis made between 1968 and 1971 reveals how problematic some listeners found the rapprochement between jazz and rock that Davis's music exhibited during this period. John Litweiler was distinctly underwhelmed by In A Silent Way (from 1969) and his commentary suggests that during the album's title track 'the solos are dissipated ... "Shh/Peaceful" is even more precious, with electric pianos tinkling in and out. The impersonality of the guitarist is the finishing touch on a performance with all the enduring, debilitated stimulation of a three-day drunk on white port wine: sickly sweet and effective.'477 Stanley Crouch wrote: 'With Bitches Brew, [1970] Davis was firmly on the path to the sellout. It sold more than any other Davis album, and fully launched jazz rock with its multiple keyboards, electronic guitars, static beats, and clutter. Davis's music became progressively trendy and dismal...'478 Pete Welding suggested that on Live Evil [1971] 'Despite the ferment of electronic and rhythmic energies, there's quite a bit of musical temporizing throughout the four sides of the set', and described the music as evidence of 'the sacrifice of so brilliant a contributor [Davis] on the altar of commercial success.' 479

Setting aside the conflation of commercial success and poor quality that Welding and Crouch seemed determined to make, these writers are clearly discomfited by this music and appear unable to judge it on its own terms, preferring to compare it unfavorably with Davis's earlier (predominantly

\footnotetext{
477 John Litweiler, The Freedom Principle: Jazz After 1958 (New York: Morrow, 1984), 127. 478 Crouch, 'Play the right thing', 34.

479 Pete Welding, 'Miles Davis: Live Evil', in The Miles Davis Reader, ed. Bill Kirchner (Washington: Smithsonian, 1997), 258.
} 
acoustic) music. ${ }^{480}$ Tom Piazza summed up this critical position in blunt terms: 'The jazz world is split on the subject of Davis's later work; plenty of people think it's good, and that's fine with me. But I can't recommend Davis's post 1968 work as jazz.' 481

The problem with this music for these writers might be summed up in those last two words: 'as jazz'. Where Davis mixed in elements from outside of jazz, his work appeared to move commensurably further away from the genre's centre. As with Davis's embrace of 'impressionist' harmony and orchestration on Birth of the Cool and his use of elements of Spanish music and orchestral instruments on Sketches of Spain ${ }^{482}$, this movement toward rock and R\&B styles - and in the early 1970s the introduction of avant garde ideas from European art music (in particular the music of Karlheinz Stockhausen) and continental India (for example the sitar and tambura, which were present on recordings as early as 1969) - resulted in two primary outcomes. First, and presumably a key motivation for Davis, the sound and to some extent the formal qualities of the resulting music changed. In this, Davis was able to progress his musical vision by means of combination creativity, mixing ideas from outside of jazz with musical materials and procedures close to the core values of the genre. Second, and as a result of the sonic and formal changes in the music, critical and public reception of Davis's work changed, and the leaps Davis had made effectively divided the field of jazz. If some of the audience had raised their eyebrows at Filles De Kilimanjaro, with its electric instruments and transformation of motifs from Jimi Hendrix, many were probably completely bewildered by the music found on Jack Johnson and Get Up With It (recorded between 1970 and 1974, released in 1971

\footnotetext{
480 Crouch praises Davis's mid-50s recordings and claims that by the 1980s Davis had 'lost all interest in music of quality' ('Play the right thing', 35); Litweiler suggests 'Miles Davis's music declined in the late 1960s' (The Freedom Principle, 222); and Welding wonders if Live Evil represents 'a relaxation of the standards we have come to expect of the trumpeter' ('Live:Evil', 258).

481 Tom Piazza, The Guide to Classic Recorded Jazz (Iowa City: University of Iowa Press, 1995), 186.

482 Attributable at least as much to Evans as to Davis; but whatever the original animus for this music, the resulting outcomes I point to are the same, I think.
} 
and 1974 respectively). ${ }^{483}$ An acquaintance of Davis's brother Vernon, a woman who claimed to own every Miles Davis record, said of the trumpeter's music of this (1970) period, 'now he done lost us'. ${ }^{484}$

Davis appeared to be unconcerned that, as a result of his combinatorial practice, his music had appeared to move away from the heartland of jazz (which is to say, further out on the radius of creativity). His response to a question about the validity of Sketches of Spain was, 'It's music. And I like it.'485 And his reply to the comments Vernon's acquaintance made was, 'Tell her I don't have time - I can't stay in one place. They got to get on board.'486 Davis's cavalier attitude to style or genre constraints - possibly his antagonism towards such constraints - may have been the result of his ambivalence about the appellation 'jazz' and his preparedness to see his music differently conceived. For example, when Davis performed at the Isle of Wight festival in 1970, the set was filmed. The filmmakers were perplexed by Davis's music; they knew he was a jazz musician but what they heard from the stage didn't fit what they thought jazz sounded like. When they asked Davis what they should call the music, he replied, 'Call it anything.'487

However, Davis's apparently relaxed attitude toward some jazz conventions may also have been a deliberate attempt on his part to distance himself from associations with the idiom. As Gerald Early says:

The major, overarching context that, I think, explains [Davis] better than most is that he came of age when jazz music ceased to be a popular commercial music. Thus, he was faced with the dilemma of trying to make a living, of being something of a personality, in a music that had a dwindling audience and lacked the cultural and artistic presence it once had. He was enormously inventive,

\footnotetext{
${ }^{483}$ Filles de Kilimanjaro features electric piano and bass, and 'Mademoiselle Mabry (Miss Mabry)' is a re-working of Jimi Hendrix's composition 'The Wind Cries Mary'.

${ }^{484}$ Szwed, So What, 303.

485 Quoted in Joe Levy and Steven Van Zandt, '365: Sketches of Spain - Miles Davis', in Rolling Stone's 500 Greatest Albums (London: Turnaround, 2005).

486 Szwed, So What, 303.

${ }^{487}$ Quoted in Murray Lerner (Dir.), Electric Miles: A Different Kind of Blue (London: Eagle Rock Entertainment, 2004).
} 
snappishly opportunistic, yet surprisingly principled in the simple act of making a living in a dying art, that is, dying as an art form with a large audience. 488

Davis's own comments reinforce this conclusion. Clive Davis, president of Columbia Records from 1967-1973, recalled a conversation with Miles Davis during that period: 'If you stop calling me jazz, man, [Miles Davis] said at one point, and just sell me alongside these other people [cross-over bands such as Blood, Sweat and Tears, and Chicago], I'll sell more.'489

It seems to me that Miles Davis's aversion to jazz was to the name, and all that it had come to imply: a genre constrained by style markers and audience expectations, and a niche market to boot. Davis was interested in making music, whatever it was called, and one of the ways in which he was quite principled about it was in his commitment to eclecticism, a willingness to mix and match that had always characterised his work as a leader. For Gary Tomlinson, 'Almost from the beginning, then, Davis's musical achievement was an acutely dialogical one, reveling in the merging of contrasting approaches and sounds, highlighting the awareness of difference...' 490 That eclecticism reached something of an apotheosis in Davis's output between 1968 and 1975, and for many commentators the category of jazz (with attendant, agreed surface features and conventions) no longer obtained.

Whatever his reasons - possibly financial, possibly to do with pressure from his record company, ${ }^{491}$ possibly inline with a progressive conception of music making ('I have to change...') - Davis was determined to continue mixing and matching musical materials from an ever increasing variety of sources, subjecting that borrowing to the musical transformations that had come to characterise his approach to making jazz. As the resulting music moved further

\footnotetext{
488 Gerald Early, 'The Art of the Muscle: Miles Davis as American Knight and American Knave', in Miles Davis and American Culture, ed. Gerald Early (Missouri Historical Society, 2001), 3.

${ }^{489}$ Quoted in Szwed, So What, 302.

490 Tomlinson, 'Cultural Dialogics', 97.

491 Dave Brubeck suggests that Davis may have been required to use Fender electric pianos and basses on his recordings by Columbia, part owners of the Fender Company. Davis refused, according to Brubeck but eventually acquiesced because he was overdrawn on royalties. See Fred Hall, It's About Time: The Dave Brubeck Story (Fayetteville: University of Arkansas Press, 1996), 147.
} 
out on the radius of creativity and further away from some of the agreed stylistic features of jazz (swing feels, strophic forms, the blues, bebop's melodic and harmonic language), the field of jazz became quite divided and the applicability of the word 'jazz' to Davis's music became increasingly contested.

Given the sales of Bitches Brew (released in 1970, and selling 500,000 copies by $1976^{492}$ ) a lot of people clearly loved this music, and there were critics amongst them. Langdon Winner, writing for Rolling Stone said the rhythm section on the album was 'just as natural and just as swinging as anything jazz has ever known' and concludes his review by suggesting: 'The freedom which Miles makes available to his musicians is also there for the listener. If you haven't discovered it yet, all I can say is that Bitches Brew is a marvelous place to start.' 493 Downbeat magazine feted it as 'Jazz Album of the Year' in 1970.

However, given the comments of Litweiler and Crouch above, the field was still divided over Bitches Brew in the 1980s and early 1990s.

The issues some commentators and musicians have with the music Davis made between 1969 and 1975 appear to revolve around surface features, or the materials Davis made use of. For John Litweiler, the atmospheric tendencies of modal jazz and the rhythmic patterns of rock with their apparent gravitational pull on soloists led to music that was largely decorative, and in which 'a coherent musical line becomes dispensable.'494 For Stanley Crouch, 'multiple keyboards, electronic guitars, static beats, and clutter' revealed Davis to be a musician who had 'lost all interest in music of quality.'495 It is curious that (some) commentators rejected these kinds of stylistic incursions from one genre to another, particularly in jazz where such syncretism has always been central to the music. ${ }^{496}$ It is not clear to me why commentators have felt the need to police

\footnotetext{
492 From RIAA figures, cited in Jeremy Smith, Sound, Mediation, and Meaning in Miles Davis's "A Tribute to Jack Johnson" (PhD Dissertation, Duke. UMI, 2008), 283-284.

493 Langdon Winner. 'Miles Davis: Bitches Brew', Rolling Stone (28 May 1970), <http://www.rollingstone.com/music/albumreviews/bitches-brew-19700528> (27 March 2014).

494 Litweiler, The Freedom Principle, 127.

495 Crouch, 'Play the right thing', 34.

${ }^{496}$ As discussed in Chapter Two, under 'Appropriation and transformation.'
} 
the borders of genre in this way, ${ }^{497}$ but I would suggest that such attitudes - if they in fact influence the choices musicians make (and given that critical response can significantly affect record sales, as well as more broadly-defined acceptance by the field, this is entirely possible ${ }^{498}$ ) - potentially foreclose genuinely meaningful opportunities for creativity.

As vital as the materials Davis introduced were to his music making, the more important point I want to make in this chapter relates to the ways these materials were used by Davis and his sidemen. Examination of the processes Davis deployed as a musician and leader in engaging these materials reveals how all of the music he made between 1950 and 1975 can be understood to be the result of processes conducive to creativity.

\section{Being 'In the moment'}

For Miles Davis the music being made, or about to be made, was always more important than music that had already been pre-formed. ${ }^{499}$ This perspective is evident in Davis's ambivalence about his past work. For example, he adopted a somewhat dismissive attitude towards his 1959 recording Kind of Blue, claimed by some commentators to be his masterpiece. ${ }^{500}$ According to Davis scholar Ashley Kahn, this determination not to dwell on past achievements allowed Davis to concentrate on his next performance, his next recording session, his

\footnotetext{
497 Why the borders of jazz might be policed is somewhat beyond the scope of this thesis, but I think Gary Tomlinson's comments about canon formation are instructive in this regard. Tomlinson suggests that the 'move toward the communal solace of a shared, metapersonal canon is a play for the political power of an institution.' The institutionalisation of jazz - if indeed that is one of the objectives of those who seek to circumscribe the music - offers many benefits to those associated with the newly legitimated form, including inclusion in the Lincoln Center program or the academy (i.e. university curriculum). See Lewis, A Power Stronger Than Itself, 441-444; Sarath, Improvisation, Creativity, and Consciousness, 153-154.

498 For example, see Teo Macero's comments about the ways the critical establishment adversely affected jazz musicians in Goodman, Mingus Speaks, 222-224.

499 Davis and Troupe, Miles, 234.

500 Several authors have written books exploring just this album, including Ashley Kahn's Kind of Blue: The Making of Miles Davis's Masterpiece (New York: Da Capo, 2000); Eric Nisenson's The Making of Kind of Blue: Miles Davis and his Masterpiece (New York: St. Martins Press, 2000); and Richard William's The Blue Moment: Miles Davis's Kind of Blue and the Remaking of Modern Music (London: W.W.Norton, 2012).
} 
next career turn. ${ }^{501}$ In this way musical work was not parsed as a noun for Davis (so denoting an oeuvre comprising musical works) but as a verb; music was something one did, and as such consisted of processes. ${ }^{502}$ These processes shaped the performances of Davis's groups. Once delivered however, the products of his work seemed to hold little interest for him; Davis was not a musician who listened to his own recordings to any great extent. 503

Given the diversity of Davis's output, the processes he employed to accomplish his musical work were surprisingly consistent across the period from the 1950s through 1975. As we have seen, Davis made use of appropriation and transformation as a means to secure fresh musical materials to populate his work. However, it is the group processes he used to transform both received and appropriated materials that I focus on in this section. These processes predominantly involved improvised group interactivity enabled by a number of strategies Davis employed as the group's leader. With these approaches Davis ensured that both he and his colleagues remained very much 'in the moment' when performing. As I shall explain, this focus on the here and now was a vital aspect of the culture he cultivated for his bands and effectively created a problem-finding environment in which they could work. Christopher Smith has observed that Davis 'profoundly influenced generations of jazz musicians who played with him [...] It is no coincidence that, in attempting to explain Miles's influence, they uniformly allude, not to issues of technical or compositional approach, but to a way of hearing, responding, and encouraging others to hear and respond.'504 Keith Jarrett, who was a member of Davis's band in 1970/1971, said, 'My greatest tribute to Miles would just be to be aware.'505

\footnotetext{
${ }^{501}$ Ashley Kahn, 'Blue Clues: Kind of Blue', Jazztimes 30 (September 2000), 73.

502 Small, Music of the Common Tongue, 14, 50. Indeed, music as process could be seen to be the norm for all music, with the paradigm shift to the 'work' in the $19^{\text {th }}$ century as an anomaly. See Goehr, The Imaginary Museum of Musical Works.

503 Davis, Troupe, Miles, 234. This is clear evidence of Davis's strong intrinsic motivation, a key characteristic of creative practitioners.

504 Smith, 'A sense of the possible', 52.

${ }^{505}$ Keith Jarrett, quoted in Smith, 'A Sense of the Possible', 41.
} 
This kind of focus, of hearing and responding and being aware, of 'being in the moment', was central to Davis's routine practice with his groups. As well as being routine, such practice also provided the context for moments of exceptional creativity that saw Davis and his sidemen introduce ideas to jazz that were to have lasting effects on the domain. However, Davis's routine studio practice also saw him complete albums that were perfectly fine but that did not particularly advance the domain, and attempt projects and recording sessions that he abandoned or for which he refused to sanction release. ${ }^{506}$ In this regard, Davis's practice is a good example of Negus and Pickering's proposition that exceptional creativity only occurs from a context of sustained routine practice. ${ }^{507}$

To illustrate these two ideas (Davis's routine practice required in-themoment group interactivity from all participants; and such routine practice was the site not only for musical creativity that ranged from modest to exceptional, but also for music-making that could be said to have failed) I'll cherry-pick examples of Davis's recordings from the 1950s to the 1970s and describe the circumstances and processes of those recordings. ${ }^{508}$ My purpose in doing so is to illustrate that to achieve creative work often requires improvised group action, action that necessarily embraces uncertainty, risk and frequent failure. This stands in contrast to the commonly held view that creativity is the work of the individual, a view reinforced by great man narratives and the use of words like 'genius' and 'innovator'.

\footnotetext{
506 For example, the 1969 sessions which included percussionist Airto as a member of a large group. See Szwed, So What, 302. Teo Macero said: 'Columbia put a lot material from the vaults on the Bitches Brew boxed set [released in 1998]. That material had not been released for a reason: it was no good. Miles would never have agreed to the way the company is re-issuing his material.' Quoted in Paul Tingen, 'The Making of In A Silent Way \& Bitches Brew', Mojo 94 (September 2001), 46.

507 Negus and Pickering, Creativity, Communication and Cultural Value, 203.

508 While this is certainly quite a long period of time, during which Davis traversed a very diverse range of styles, the sample is valid and representative because Davis's routine practice was consistent across the entire period. I think it is fair to say that there were peaks and troughs in the quality of Davis's creative work during this period, attributable to a variety of factors (Davis's health for example, or the calibre and disposition of the sidemen he was using), but my sense is that Davis consistently sought this kind of collaborative practice.
} 


\section{Davis's group practice}

In June 1967 when Miles Davis entered the studio with his quintet, among the tunes the group recorded was saxophonist Wayne Shorter's composition 'Nefertiti.' This piece itself had a very improvised genesis, and Shorter recalled that it seemed to compose itself in a matter of minutes. ${ }^{509}$ Shorter observed that the piece had a kind of completeness that was unusual, and that translated to the recording of the tune: 510

When we recorded [Nefertiti], without anybody saying anything, nobody took a solo. We just kept playing the melody over and over again. We let it become like an organism. After we recorded it, we talked about it becoming an organism and let it have its own direction. Miles Davis said there was nothing else for him to play. He said this song was like a song and a solo all at once - an improvisation and established melody all at once. He was saying that if he played anything else, it would disturb it. 511

On the recording, the composition becomes a showcase for the rhythm section, whose accompaniment steadily evolves over the course of the performance. While the front line of saxophone and trumpet repeat the melody (for 13 iterations of the 16 measure form ${ }^{512}$ ) pianist Herbie Hancock, bassist Ron Carter and particularly drummer Tony Williams increase and decrease the density and the abstraction of their playing. Witness the more animated accompaniment offered by Hancock leading into the 'second eight' (measures 9-16 of the form) of the $3^{\text {rd }}$ chorus and the way it seems to inject a slightly dancing quality, a quality subtly picked up by Williams over the succeeding measures; or the way Davis and Shorter extend the A-flat in measure 9 of the $5^{\text {th }}$ chorus (a kind of delivery on the promise of the very legato phrasing of the preceding measures) that leads Hancock to lay out and Williams to reduce the dynamic to create a small valley in the music before playing a strong fill into the new chord half way through the $12^{\text {th }}$ measure, a chord the whole band hits with renewed intensity;

${ }^{509}$ Quoted in Ronald Schiff, Wayne Shorter: Artist Transcriptions (Miami: Warner Brothers, 2000), 61 .

510 Miles Davis, Nefertiti (New York: Colombia, 1967).

511 Quoted in Schiff, Wayne Shorter, 61.

512 Shorter's saxophone plays the first iteration of the melody alone, and is joined mid-way through the second head by Davis's trumpet. Both horns lay out for the $12^{\text {th }}$ iteration (6:32-7:08 min) and return for the $13^{\text {th }}$ and final statement of the melody. 
or the diminuendo through the second half of the $8^{\text {th }}$ chorus which creates a moment of calm before the storm of Williams's caffeinated interjections and clatter through the $9^{\text {th }}$ and $10^{\text {th }}$, and especially the $11^{\text {th }}$ choruses. Exquisite.

This role reversal (the front line accompanying as the rhythm section improvise, exploring the implications of the composition's form and harmony) was dramatically at odds with normal procedures in a small group jazz context, which tend to emphasise the improvising prowess of the front-line rather than the musical environments created by the rhythm section. The possibilities thrown up by this approach were not lost on Davis, who reused it for studio recordings including 'Sanctuary' (August 1969, another Wayne Shorter composition) and 'Great Expectations' (November 1969, credited to Davis and Joe Zawinul). The duration of 'Great Expectations' (as released, at over 27 minutes) suggests that Davis was happy for the repetitive melody to provide a hypnotic anchor that would allow the textural improvisation of the accompanying musicians to be fore-grounded.

In the case of the 'Nefertiti' recording, the decision not to move from theme statement to improvised solos by the front line was one taken in the moment, by the collective, and the implications of that consensual decision (static melody; improvised accompaniment forming the points of evolving interest across the performance) were worked out on the fly. A number of key ideas are illustrated by this occurrence. First, Davis employed a leadership style that both accommodated and encouraged creative action on the part of his sidemen. Second, and as a result of Davis's leadership style, a kind of group genius (to use Keith Sawyer's phrase ${ }^{513}$ ) operates to enable this surprising outcome. This outcome is an emergent of the group's performance rather than the product of a decision taken by a single actor; innovation is the result of unpremeditated, improvised group action. Might an individual musician have come up with this performance idea (role reversal of the front and back lines)? It's possible, but if this novel approach were an idea introduced as a kind of intellectual possibility ('I know, we could try this...') it is not clear that the musicians in the ensemble would have participated quite as actively in the

\footnotetext{
513 Sawyer, Group Genius, ix.
} 
process of exploring and performing the idea as they obviously do on this recording, where the idea belongs to all of them: the sense of quest, of adventure, of making it up as they go along, is palpable, and the result was a new approach for jazz (i.e. rhythm section and front line roles reversed). The various strategies Davis made use of as a leader to enable this kind of group action and admit this kind of focused participation from his sidemen can instructively inform our understanding of his effectiveness as a creative musician.

\section{Davis's leadership styles}

A key aspect of Davis's leadership style in terms of enabling creative work among the musicians with whom he worked was his adoption of a role as an equal participant in the group. This practice is consistent with Keith Sawyer's claim, 'leaders of innovative groups are active participants in the work; they function more like peers than a boss. ${ }^{514}$ Davis was after all performing as a member of the group, a group in which all individual members enjoyed considerable freedom.

However, the primary strategy Davis engaged in achieving the kind of group flow evident in this example (and many others, too), was by staying out of the way, by 'leading from among', and often in a manner that was frankly ambiguous. Pianist Chick Corea recalled, 'With Miles, there was never any sitting down and discussing music: 'Hey, I'd like you to play a little more of this or that.' No instructions, no analytical conversation. There were grunts, glances, smiles, and no smiles. Miles communicated but not on a logical or analytical level. ${ }^{515} \mathrm{~A}$ number of Davis's sidemen have reported that during recording sessions, astonishingly given the expense of such exercises, an absence of clear directives from Davis meant they did not know what was going on. Percussionist Airto said of his first session with Davis, 'I couldn't get into the music. It was new music to me and I didn't really understand.'516 Of the sessions that yielded the album In $A$ Silent Way, Herbie Hancock reported:

\footnotetext{
${ }^{514}$ Sawyer, Group Genius, 34.

515 Quoted in Len Lyons, The Great Jazz Pianists: Speaking of their Lives and Music (New York: William Morrow, 1983), 261.

516 Quoted in Szwed, So What, 302.
} 
After we finished we walked out of the studio, and while we were standing in the hallway [guitarist] John McLaughlin came over and whispered to me, "Can I ask you a question?" I answered, "Sure". He then said, "Herbie, I can't tell... was that any good what we did? I mean, what did we do? I can't tell what's going on!" So I told him, "John, welcome to a Miles Davis session. Your guess is as good as mine. I have no idea, but somehow when the records come out, they end up sounding good." Miles had a way of seeing straight through things and knowing that over time people would figure out what was really happening. ${ }^{517}$

In the recording studio (and in live performances, too) Davis avoided overprescribing the music by leaving his sidemen and women to their own devices. In this way the musicians in Davis's band became equal partners in the creation of the music, because the contribution asked of them was their contribution, improvised in the moment. As a result, there was no room for complacency; Davis might have been the leader but the musicians knew that what the audience ultimately heard was as much a result of their choices as any decisions made by Davis. Bassist Dave Holland reported, 'Miles always gave the minimum amount of instructions. Usually he'd let you try and find something that you thought worked, and if it did, then that would be the end of it. His approach was that if he needed to tell someone what to do, he had the wrong musician.'518

In this, Davis's leadership strategies are a precise match with Teresa Amabile's observations concerning strategies for stimulating creative action within groups: 'the key to creativity is giving people autonomy concerning the means - that is, concerning the process - but not necessarily the ends.'519 Holland's remarks also underscore another aspect of Davis's gifts as a leader: the capacity to select the right personnel in order to create a group whose work was likely to be creative, and then keeping those groups together long enough to optimise the collaboration. Davis's success in forming groups that achieved creative work involved selecting performers with different skills and

\footnotetext{
517 Tingen, 'The Making of In A Silent Way \& Bitches Brew', 48.

518 Paul Tingen, Miles Beyond: Electric Explorations of Miles Davis, 1967-1991 (London: Billboard Books, 2001).

${ }^{519}$ Amabile, 'How To Kill Creativity', 86. The 'ends' in the examples I am discussing from the recording sessions Davis conducted, were determined by Davis and producer Teo Macero. In live performances, Davis took an active (if sometimes ambiguous) role in shaping performances, thus determining the 'ends' (although in this his leadership style was quite democratic). See Smith, 'A Sense of the possible', 44-51.
} 
dispositions, 'identifying group combinations that are more likely to achieve group flow.'520

Davis's career is notable for the work he achieved in combination with particular individuals and groups. Commentators talk about the 'first' and 'second great quintets', the 'lost quintet', the chemistry Davis achieved with the sextet that recorded Kind of Blue, and Davis's partnerships with orchestrator and composer Gil Evans, producer Teo Macero, and bassist and producer Marcus Miller. ${ }^{521}$ Each of these collaborations was characterised by a combination of individual actors with distinct skill sets, and all of them lasted long enough for a measure of mutual understanding to be established between Davis and his associate(s). As a result, the emergent performances produced were shaped by the simpatico understanding Davis and his associates achieved, and the best of the work that emerged from these collaborations is considered significant in the trumpeter's career..$^{522}$

Jazz scholar Christopher Smith described such coalescences as evidence of 'Miles Davis's particular genius' and considered that it 'was centered in an ability to construct and manipulate improvisational possibilities, selecting and combining compositions, players, musical styles, and other performances parameters. ${ }^{\prime 523}$ Davis's capacity for finding an optimal combination of musicians is clearly evident with his first great quintet (1955-1956), which jazz commentator Gary Giddens described this way:

Miles Davis shares with Ellington the genius for tapping precisely the talents of his cohorts; in [pianist Red] Garland he found a musician whose primary attributes were vigor, clarity, and simplicity - just the combination to negotiate (along with bassist Paul Chambers) between the turbulence of Philly Joe Jones's drums and the impassioned front line of Davis and John Coltrane. 524

\footnotetext{
${ }^{520}$ Hennessy and Amabile, 'The conditions of creativity', 21. See also Sawyer, Group Creativity, 82.

521 Mandel, Miles, Ornette, Cecil, 35.

522 Richard Cook, It's About That Time: Miles Davis on and off record (London: Oxford, 2007).

523 Smith, 'A Sense of the Possible', 41.

524 Gary Giddens, 'Red Garland's Texas Cocktail', The Village Voice (3 April 1978), 49.
} 
Some commentators dismissed Garland as 'a cocktail pianist'525 - a pejorative expression in jazz circles - but Davis heard qualities in Garland's playing that complemented the other musicians in his group. By establishing a productive mix of skills and dispositions, Davis created an ensemble feted as one of the great small groups of jazz. ${ }^{526}$

An important value in enabling mutual understanding in groups - like that evident in the work of the first great quintet and which manifests as empathetic musical behaviours - is allowing time for the actors to learn to work together. Keith Sawyer identifies the longevity of groups as a factor in their creativity; groups need enough time together to establish rapport if group flow is to occur. ${ }^{527}$ By establishing a history together, groups can develop a common language and a set of unspoken, mutual understandings or tacit knowledge, described by psychologists as intersubjectivity. ${ }^{528}$ Sawyer contends that in improvising situations 'group flow happens only when all the players have mastered a body of tacit knowledge.' Groups can remain together for long periods of time, but this may eventually prove detrimental to the creativity of the group. 'After two or three years, members of groups can become too familiar with each other and their effectiveness starts to decrease. ${ }^{529}$ In these instances groups often demonstrate a declining capacity to achieve problem-finding creativity, but may become very adept at problem-solving creativity - where iterative processes predominate..$^{530}$

\footnotetext{
525 Giddens, 'Red Garland's Texas Cocktail', 50.

526 Ian Carr, in The Rough Guide to Jazz (London: Rough Guides, 2004), 198.

527 Sawyer, Group Genius, 51-53.

528 Sawyer, Group Creativity, 9.

529 Sawyer, Group Genius, 51.
}

530 Perhaps an example of this is the Modern Jazz Quartet whose career initially ran from 1952 through 1974 but whose albums became more or less indistinguishable from one to the next. Their long string of albums (more than forty) employing similar strategies and repertory were made distinct largely by means of a series of guest artists and collaborators. Brian Priestly reported on a concert at which vibraphone player Milt Jackson performed with Charles Mingus in 1974, describing Jackson as 'newly released from the bondage of the Modern Jazz Quartet.' Priestly, Mingus, 205. 
For problem-finding creativity - the kind of work I am drawing attention to in this discussion of Miles Davis - a middle ground appears to have been tremendously fruitful for Davis's purposes: enough time together for the musicians to get a feel for one another without becoming complacent. These time periods were generally between a few months (if the group was working regularly) and three or four years. Briefer associations are unlikely to enable the kind of mutual musical understanding Davis sought (although there are different benefits from brief encounters), and longer associations can lead to stasis. Miles Davis was adept at managing this balance, and his quartet of the mid-1960s is an excellent example of his resourcefulness in this space. Settling on a lineup of Wayne Shorter, Herbie Hancock, Ron Carter and Tony Williams, the trumpeter was able to keep this group together for about four years, recording a number of acclaimed studio and live albums.

First performing together as a quintet in the fall of 1964, the group's debut studio album (recorded January 1965) evidenced such remarkable musical empathy that Davis entitled the record E.S.P (for 'extra-sensory perception', after the Wayne Shorter composition included on the album). A further year together saw their mutual understanding - or tacit knowledge of one another and the group's procedures - grow to such an extent that their recordings from Chicago's Plugged Nickel (December 1965) have been described as the 'Rosetta Stone of modern jazz' by the writers of Penguin Guide to Jazz. 531 This high praise is for the way group redrew their performances from set to set, playing the same repertoire in sometimes strikingly different ways as they explored the available possibilities for the interpretation of standard forms. It was this process that musicologist Henry Martin described as 'total improvisation' with the group 'rework[ing] all the elements of the original material.' Martin concluded that this group had taken 'jazz about as far as it is possible to go in live performance while maintaining strophic form.' 532 Of this apparent terminus point, Davis himself recalled:

\footnotetext{
531 Cook and Morton, The Penguin Guide, 346.

532 Henry Martin, 'The Nature of Re-composition: Miles Davis and 'Stella By Starlight”, Annual Review of Jazz Studies 9 (1997-1998), 81.
} 
I learned a lot from Herbie, Tony, Wayne, and Ron ... now I was starting to think about other ways I could approach the music I wanted to play, because I could feel myself starting to want to change but I didn't really know yet what this change was all about. I knew it had something to do with the guitar voice... 533

When Davis felt this need to advance his music in new directions in the late 1960s, he reconstituted his group. Perhaps aware at some level that if a group needs to find and define a new problem, too much shared information becomes a problem,'534 Davis stimulated change and growth by introducing electric instruments (notably bass and electric piano and for some sessions, electric guitar ${ }^{535}$ ), by enlisting two new members, and by introducing a different approach in the recording studio. With these changes he forced his personnel into finding new ways to play together. This process reached something of an apotheosis in 1969 by which time instead of a single (acoustic) piano player, there were two or three electric keyboards on each track, as well as guitar; strophic forms had been replaced in some compositions with a variety of sectional forms; and recording sessions comprised not of a series of complete performances, but rather a number of fragments that were later assembled into complete tracks in the editing room. Hints of what was to come are found on Miles In the Sky (recorded and released in 1968, with electric guitar added for one track, and electric piano and electric bass replacing the acoustic instruments on a further track) although the revolution really got underway with Filles De Killimanjaro (also recorded and released in 1968, and which included electric piano and electric bass) and which Davis, clearly aware that his music was taking a new turning, had Columbia Records release under the rubric 'Directions in Music by Miles Davis.' In A Silent Way (February 1969) captures Davis's metamorphoses at mid-point, with melody largely taking a back seat to texture. For those sessions Wayne Shorter replaced his tenor saxophone with a soprano sax (presumably to cut through the mid-register bustle of all those electric

\footnotetext{
533 Davis and Troupe, Miles, 288.

534 Sawyer, Group Genius, 53.

535 Between 1967 and 1969 electric instruments were introduced and personnel changed notably. Together, these changes disrupted the routine procedures of the group and heralded an altogether new sound for Davis's recordings. For a history of these developments, see Paul Tingen, Miles Beyond.
} 
keyboards and guitar) and taken together - a couple of tinkling electric pianos along with slightly dark but sonorous chords on organ; McLaughlin's languorous guitar; Tony Williams largely restricting himself to a cross-stick groove (except for the glorious and all too brief passage at 13:10 during 'In A Silent Way / It's About That Time' when, during Davis's second trumpet solo and after a flurry of syncopated sixteenth notes from the trumpeter, Williams suddenly leaps to the cymbals and throws in some agitated snare chatter to boot: a musical moment that splits clouds and ripens corn) - the overall effect is beautiful, if somewhat funereal. Davis's process however, left some of the musicians bewildered. As John McLaughlin reportedly said after the sessions, 'I mean, what did we do? I can't tell what's going on.'536 McLaughlin was possibly referring to Davis's apparently cryptic instructions, which for the track 'In A Silent Way' included the directive to, 'Play it like you don't know how to play the guitar.'537 McLaughlin was probably also commenting on Davis's approach of recording fragments rather than complete performances, a recently acquired technique for Davis (one that he began using in December 1967 for 'Circle in the Round'538) that came to predominate during Davis's next studio foray.

That next foray occurred six months later when Davis returned to the studio for the Bitches Brew sessions. For these August 1969 recordings a second bassist was added who was unfamiliar with the music, along with a second drummer and two percussionists, ensuring that both bassist Dave Holland and newly incumbent drummer Jack DeJohnette - who had joined the group the previous month - would need to think and play differently. Davis also varied his standard front line of trumpet and saxophone, adding bass clarinet to the group as well. Further, after a single rehearsal Davis had the group play short segments with only vague guidelines. Dave Holland, then a member of Davis's live band recalled:

536 Tingen, 'The Making of In A Silent Way \& Bitches Brew', 48.

537 McLaughlin quoted in Jim Fusilli, 'John McLaughlin: From Miles Davis Protégé to 'Old Punk', Wall Street Journal (26 March 2014),

$<$ http://online.wsj.com/news/articles/SB10001424052702303779504579463164133136046? mg=reno64wsj\&url=http\%3A\%2F\%2Fonline.wsj.com\%2Farticle\%2FSB100014240527023037 79504579463164133136046.html> (31 March, 2014).

538 Tingen, Miles Beyond, 42-43. 
If you'd asked me at the session what was going on, I would have told you that I didn't have a clue. We were all trying to figure out what was going on. The idea of using two basses and two drummers was very interesting. The role division between [bassist] Harvey [Brooks] and me depended on the piece, but as I remember it, Harvey was taking responsibility for laying down the main line on the electric bass, and I had a freer part embellishing things on the acoustic bass. ${ }^{539}$

As Holland has suggested, Davis preferred not to give the musicians specific directions but rather let them work out the implications of the music themselves, improvising solutions in the studio. Here Davis's concept is very clear: he and the musicians together worked out the music in an improvised setting, where individual actors were able to exercise considerable autonomy in the creation of their parts.

Davis was acutely aware of the centrality of this process to the music, and had a clear understanding of what he was doing. 'What we did on Bitches Brew you couldn't ever write down for an orchestra to play. That's why I didn't write it all out, not because I didn't know what I wanted; [but because] I knew what I wanted would come out of a process and not some prearranged shit. This session was about improvisation... 540 The Bitches Brew sessions mainly comprised recording fragments rather than complete performances, and this process was very much in the moment. Davis recalled:

So I would direct, like a conductor, once we started to play, and I would either write down some music for somebody or I would tell him to play different things I was hearing, as the music was growing, coming together. It was loose and tight at the same time. It was casual but alert, everybody was alert to different possibilities that were coming up in the music. While the music was developing I would hear something that I thought could be extended or cut back. So that recording was a development of the creative process, a living composition. It was like a fugue, or motif, that we all bounced off of. After it had developed to a certain point, I would tell a certain musician to come in and play something else, like Bennie Maupin on bass clarinet [...] Sometimes, instead of just letting the tape run, I would tell Teo to back it up so I could hear what we had done. If I wanted something else in a certain spot, I would just bring the musician in, and we would just do it. 541

This somewhat unusual approach (and one that was probably completely new to the musicians who were working with Davis for the first time) coupled with the

\footnotetext{
${ }^{539}$ Dave Holland, quoted in Tingen, 'The Making of In A Silent Way \& Bitches Brew', 47.

${ }^{540}$ Davis and Troup, Miles, 300.

${ }^{541}$ Ibid., 299-300.
} 
unconventional way Davis had conceived the harmonic arrangement of some of the music, left many of the musicians who contributed to the sessions bewildered. ${ }^{542}$ The results however were strikingly innovative, so much so that this album (along with In A Silent Way which preceded it) divided the field of jazz to the point where a new sub-genre was mooted: jazz-fusion. ${ }^{543}$

There are two key points that I want to draw out of this discussion of the Bitches Brew sessions. First, Davis used a core of musicians who were familiar with one another and had established considerable shared tacit knowledge. ${ }^{544}$ Second, Davis made choices that unsettled those players, primarily in terms of his procedures. ${ }^{545}$

These unsettling choices included introducing a) new players into the mix, including Bennie Maupin on bass clarinet, Harvey Brooks on bass, Lenny White on drums, Don Alias and James Riley (aka Juma Santos) on percussion, organist Larry Young on some tracks; and b) several (somewhat familiar) additional players including a second and sometimes third keyboardist, and a guitarist. ${ }^{546}$ Together, these personnel changes both disrupted the routine procedures of the established group and changed the sound of the overall ensemble (and of course these two factors had implications for one another). Another strategy Davis employed which forced the musicians to think and play differently was to record fragments instead of complete performances. While some of the musicians - those who had been present on sessions earlier in the year that had yielded In A Silent Way - had experienced this approach before, it

\footnotetext{
542 For a discussion of the somewhat unorthodox writing approach Davis adopted for In A Silent Way and for the Bitches Brew sessions, see Davis and Troupe, The Autobiography, 299.

543 Nicholson, Jazz Rock, xiii-xiv.

544 Wayne Shorter, Herbie Hancock, Chick Corea and Dave Holland. Jack DeJohnette might be reasonably included in this group, although he was a very recent addition to the band.

545 The material Davis made use of during these sessions and that characterised the album that was released was unsettling for some listeners and commentators, but for the musicians the material was more a surprising emergent from the challenging processes Davis deployed than particularly unsettling in and of itself. Nevertheless, the new sounds the musicians heard as they recorded would have prompted them to play differently, to respond in appropriate (and likely) fresh ways to what was happening around them.

546 Joe Zawinul and John McLaughlin; both had some familiarity with Davis's music and procedures.
} 
was a still a very new way of working, and as such required the musicians to be very aware, 'in-the-moment', and to play in different ways. A third strategy Davis made use of to focus his musicians on the task at hand was making improvisation the principal modus operandi of the sessions. While Davis gave directions and made suggestions, to a large extent the musicians had to improvise their parts, working out the implications of the music and their responses to it as they went along.

The final strategy Davis made use of both to unsettle and focus his musicians was rather less conventional: any complacency his musicians might have felt was further disrupted by an argument between Davis and producer Teo Macero immediately before recording began. Macero recounted the occasion:

I think Bitches Brew came out of a bitter battle that Miles and I had in the studio... he and I almost had a fistfight in the studio. [Eventually] I told him, I says, "Take you and your fucking trumpet" (these were my exact words) "and your fucking musicians, and get outa here! I want you out of this building! Get your ass outa here!" ... And he was, like, coming at me, and I said, "You sonofabitch, I'm coming over there!" And they were hauling him back ... There were several people sitting around and everybody was dumbfounded... I says, "Well, take your goddam trumpet and go!" And he took his trumpet, and as he started to go out of the door he made a left turn. He went into the studio, took out his trumpet, and I said "Put the machines on." 547

Davis's biographer Ian Carr speculated that this confrontation was largely enacted as a strategy to get 'the adrenaline flowing' among the musicians on the session but presciently observes that the effect of 'doing the unexpected and the outrageous, which shocks everyone else and oneself" has the effect of 'dislocating habitual thought patterns and releasing a lot of creative energy.'548

Taken together - the addition of extra (and some new) players to the ensemble and the resultant expanded and novel timbres those additions produced; a revised modus operandi (recording largely improvised fragments for later assembly into complete pieces); the strained social setting of the studio for the recordings - these factors almost certainly contributed to the success of the sessions and provided material for one of Davis's most storied and innovative

\footnotetext{
547 Quoted in Carr, The Definitive Biography, 257-258.

548 Ibid., 259.
} 
albums. The results were a surprise even to some of the musicians involved. ${ }^{549}$

Pianist and composer Joe Zawinul recalled:

After the Bitches Brew sessions Miles took me home in a limousine, and I didn't say anything. He asked, "Why don't you say anything?" and I said, "Because I didn't like what we just recorded." We had played a lot of stuff that was OK, but I was not impressed. Several months later I walked into the CBS offices, and through some closed doors I heard some enormous, fantastic music. I asked "Wow, what is that?" and a secretary replied, "Well, Mr. Zawinul, that's you playing with Miles on Bitches Brew!"550

\section{Where great art and music happens}

The final point I want to draw from these examples is that Davis's routine practice was an open, experimental practice; he was determined to explore music both in the studio and in performance. He told his sideman 'I pay you to practice on the bandstand', wanting his fellow musicians to be engaged constantly in the kind of musical exploration that had characterised his career. ${ }^{551}$ Had Davis been seeking note-perfect performances of idiomatically stable music this would have been a risky strategy, but his desire was that his music grow and change; I think Davis wanted to be surprised by the music he and his collaborators produced. Davis's desire for change and progress in his music appears to have been a consistent motivator across his career. Describing his sextet in the late 1950s Davis recalled:

I wanted the music this new group would play to be freer, more modal, more African or Eastern, and less Western. I wanted them to go beyond themselves. See, if you put a musician in a place where he has to do something different from what he does all the time, then he can do that - but he's got to think differently in order to do it. He has to use his imagination, be more creative, more

\footnotetext{
549 Teo Macero's role was critical in this regard, as revealed in Paul Tingen's account of the postproduction of Bitches Brew (Miles Beyond, 62-75). The extent of Macero's 're-composition' of the raw materials (which in some cases lead to tracks that are assemblages rather than records of live performances) poses questions about how such after-the-fact manipulation affects the inthe-moment-ness generated during the sessions. There's probably another thesis buried in these issues, but my sense is that Macero did an astonishingly good job of piecing the tracks together, but had the good fortune to be working with excellent raw material that possessed the kind of spark and sense of adventure Davis sought from his collaborators. That the tracks feel so much of-a-piece is testimony to the focus Davis was able to generate in the studio - leading to very consistent feels, tempi and musical intensity from his collaborators - and Macero's brilliant assembly of the parts to create such coherent wholes (to my ear). A miracle, really.

${ }^{550}$ Joe Zawinul quoted in Tingen, 'The Making of In A Silent Way \& Bitches Brew', 47.

${ }^{551}$ Herbie Hancock, quoted in Mike Ragogna, Tribute To Miles: A Conversation With Herbie Hancock. (24 June 2011) <http://www.huffingtonpost.com/mike-ragogna/tribute-to-miles-aconver_b_883658.html> (26 March 2014).
} 
innovative; he's got to take more risks. He's got to play above what he knows far above it - and what that might lead to might take him above the place where he's been playing all along, to the new place where he finds himself right now and to the next place he's going and even above that! So then he'll be freer, will expect things differently, will anticipate and know something different is coming down. I've always told the musicians in my band to play what they know and then play above that. Because then anything can happen, and that's where great art and music happens. ${ }^{552}$

By making it clear to his fellow-musicians that such exploratory, improvisational playing was expected, and by creating performance and recording contexts and conditions that enabled such exploration, Davis was able to routinely keep his groups in a state of readiness to follow new musical possibilities when they arose. That such an approach was routine is amply illustrated by drummer Jimmy Cobb's comments about the sessions for Davis's most celebrated album, Kind of Blue. 'The call I got from Miles for that record was just like any other record. He'd say we've got a date, where it is and what time it is...' 553

Not all of Davis's groups were equally adept at such adventurous playing; while his sextet of 1959 achieved considerable heights of musical exploration (as documented on Kind of Blue) his quintet of 1961 produced immaculate post-bop jazz but without introducing anything particularly innovative to the idiom. ${ }^{554}$ However, by selecting personnel capable of this kind of musical adventurousness and regularly performing or recording with them in contexts that allowed them to follow their impulses, to exercise their musical curiosity, Davis's routine practice became a site in which moments of unusual and sometimes strikingly innovative creative work was accomplished.

As even Davis acknowledged, such a process involved risk, and there were many failed experiments across Davis's career. Even when Davis collaborated with some of the finest musicians the results sometimes left much to be desired. The 1962 collaboration between Davis and Gil Evans that eventually yielded the album Quiet Nights was a fallow experience for the trumpeter, and he recalled, 'The last thing Gil and I did on Quiet Nights ... just

\footnotetext{
552 Davis and Troupe, Miles, 220.

553 Jimmy Cobb, in Kahn, Kind Of Blue, 95.

554 Judging by Davis's comments about this group and this time, he was perhaps as culpable as his colleagues in the matter of musical exploration. See Davis and Troup, The Autobiography, 252-253.
} 
wasn't happening. It seemed like we had spent all our energy for nothing and so we just let it go.'555 Although Quiet Nights was released (much to Davis's ire ${ }^{556}$ ), more often such failures were consigned to the storage vaults at Columbia. Brazilian percussionist Airto's first session with Davis included a large cast of musicians including Khalil Balakrishna on sitar and Bihari Sharma on tamboura. Airto recalled, 'There was nothing to play because everyone was playing so much. Two hours into it, Miles cried out, "Stop, Teo, stop! This sounds like shit! I'm going home, Cancel it!" and he left.' 557 The music from these sessions has not been released.

Such failures are not a reflection of a lack of skill or capability; they are simply an inevitable consequence of the risk taking involved in courting the unknown. Keith Sawyer writes, 'Research shows us over and over again that the twin sibling of innovation is frequent failure. There's no creativity without failure, and there's no group flow without the risk of failure. Since group flow is often what produces the most significant innovations, these two common research findings go hand in hand.' 558 As we have seen, Miles Davis constantly sought to achieve a kind of group flow with his ensembles, and desired progress and innovation in the music they produced together. Perhaps the most surprising aspect of his work in this regard is not that he failed, but the high ratio of success to failure evident in his recorded output.

\section{Summary}

The examples from Miles Davis's catalogue I have discussed in this chapter offer a number of lessons about creativity in jazz. The three principles I emphasise in particular can be divided into two categories. The first of these categories relates to musical materials and yields the first principle: Davis's appropriation of materials not normally found in jazz and their transformation to serve the needs

\footnotetext{
555 Davis and Troupe, Miles, 259.

556 Davis was so enraged at Macero's decision to release the music he refused to work with the producer for a number of years after these sessions. Cook, It's About That Time, 141.

557 Szwed, So What, 302.

558 Sawyer, Group Genius, 55.
} 
of his (and his collaborators) musical imaginations. In this Davis's work is exemplary of domain-changing creative action that makes use of Margaret Bowden's combination creativity. By means of such borrowing (and juxtaposition) Davis introduced new material (and ultimately, new styles) to the jazz idiom.

The second category of creativity evident in Davis's work is related to the processes he engaged in transforming these appropriated (and received) materials. The two principles I draw attention to in this regard are found in: first, Davis's leadership style, which encouraged all members of the ensemble to contribute their own ideas in improvisational settings. This understanding also displaces the role of the individual as 'creator' and instead points towards Davis as a leader who facilitated creative processes, processes enacted not by individuals but by groups. Given the efforts of the field of jazz to achieve cultural legitimation (beginning as early as the 1920s, with Paul Whiteman ${ }^{559}$ ) it is perhaps unsurprising that the discourse around jazz was forced into a rhetoric that sought to explain the music in terms of the 'great man' tradition prevalent in discussions of western art music, the culturally validated music par excellence of the time. Conformity to this model necessarily required identifying and valorising the 'great men' of jazz, which is still the dominant narrative structure of most jazz histories. Few would dispute that Davis was great: however, what made him most great (the collaborative processes he facilitated) is not generally acknowledged because it does not fit aspects of the 'genius' paradigm common in discussions of western art music.

The second principle that is important here is Davis's use of a regular practice comprising interactive, improvised strategies. This practice established a context in which routine creativity could occur, which as well as admitting the possibility of failure, also left the way open for occasional moments of exceptional creativity.

There are two further issues that emerge from this discussion of Miles Davis's musical processes. The first is around the respective roles played by musical materials, musical (or genre) conventions, and creative processes in the

559 Porter, What is this thing called Jazz?, 11. 
categorisation and valuation of Davis's music. The second concerns the degree to which the processes I have outlined here are unique to Davis's music. I will speak to each in turn.

Numerous writers have expressed disappointment with some of Davis's musical choices, particularly with regard to the styles he embraced. For some of them, particular stylistic incursions implied that Davis's music ceased to be classifiable as jazz: Winthrop Sergeant's comments about Birth of the Cool, or Tom Piazza's position on the music Davis made after 1968, for example. These commentators do not appear to regard these incursions as leading to music of poor quality; they simply suggest that the music may no longer be categorised as jazz. Other commentators are less forgiving. John Litweiler and Stanley Crouch dismiss Davis's embrace of surprising stylistic values on In A Silent Way as leading to inferior music. Crouch goes so far as to describe Davis's music of that period (c. 1970) as being tantamount to a fall of biblical proportions. ${ }^{560}$ Davis certainly did change the style(s) of his music between about 1967 and 1972 (incorporating gestures from rock, and rhythm and blues, for example), and adopted a number of different conventions (a move away from circular forms to open, sectional forms; a wider embrace of modal approaches to replace chord progressions and functional harmony; the kind of role reversal between front line and rhythm section evident in 'Nefertiti', and so forth). However, the processes Davis engaged (interactive, collaborative music making that utilised improvisation as a primary generative strategy) remained more or less consistent during this period (and, I have argued, across much of his career to 1975): processes conducive to creativity. Davis's music from 1967 through 1972 does sound different - and perhaps, depending upon one's definition, it isn't jazz - but it is music in which he proposed new ideas and introduced new sounds in a manner distinctive to the jazz tradition; ideas and sounds that others have subsequently mined for successful music making.

If this is the case, then perhaps useful measures of musical quality are the outcomes of the performance being considered: does it sound good (subjective, to be sure, but if music involves communication then such subjectivity is

560 Crouch, 'Play the right thing', 34. 
inevitable); and does it suggest fruitful avenues for musical inquiry going forward? Using this frame I think its fair to say Davis's music is pretty successful. This of course is only one way to measure Davis's work. A different kind of critical conversation might consider how well a particular performance conforms to style markers or conventions of a particular genre. However, while such discussion may have value if categorisation is important, unless one's goal is a kind of stylistic perfection (which seems a rather sterile objective) it is not clear to me what the purpose of such an assessment might be. By this second rubric - fidelity to genre codes - Davis's music is considerably less successful. However, such fidelity does not appear to be a quality Davis was ever very interested in. ${ }^{561}$

In terms of the second question that emerges from my discussion of Davis - the uniqueness of his approach - I don't think he was particularly unusual in adopting the processes he engaged with his groups; these processes are evident in the leadership strategies of all the musicians discussed in the case studies in this thesis, all of whom could reasonably be described as creative musicians. I do think the evidence suggests Davis was particularly adept in making use of these strategies, and quite consistent in applying them. I also sense that Davis and Coleman and Charles Mingus and others who make such extensive use of these approaches are not in the majority in the jazz world.

Leaders who adopt these collaborative, improvisational strategies are at one end of a continuum, where freedom, uncertainty and risk are common currency. In the middle of such a continuum might be bandleaders including Art Blakey or Dave Brubeck, who exercised various degrees of control over their ensembles but also admitted quite a bit of freedom into their group practice. At the other end of the spectrum from Davis et. al. are leaders whose ensembles perform with considerable consistency but with little or no scope for acts of individual agency on the part of band members and with no possibility for the emergence of surprising, collectively improvised music. Davis and his sidemen are firmly in the camp that courts uncertainty and risk, perhaps understanding

\footnotetext{
${ }^{561}$ It is not clear to me that any of the 'greats' of jazz have been terribly concerned with fidelity to
} genre codes. 
that collectivity and improvisation are necessary companions in the adventure of making music that reflects the moment of its creation.

\section{A comparison}

As a kind of afterword to this discussion of Miles Davis, I'll briefly draw a comparison between Davis's practice and that of one of his celebrated sidemen, pianist Bill Evans. I'm doing so to highlight the importance of the kind of experimental, open and improvisational collaborative practice that Davis engaged, compared with the more conservative, less dialogic practice that characterised much of Evans's career. This comparison illustrates the utility of the improvised collaborative practice that was Davis's modus operandi, a practice that saw Davis's music evolve significantly across his career.

Evans worked with Miles Davis for less than a year, but their collaboration was significantly responsible for the album widely regarded as Davis's masterpiece, Kind of Blue. Davis and Evans met before the recording sessions to sketch out many of the ideas found on the album. ${ }^{562}$ The conspicuous use of modes (or particular scales) on the resulting album is unsurprising given Davis's interest in modes as an organisational device (for example, in 'Milestones' from the album Milestones [1958]) and Evans's earlier work with composer George Russell, the musician generally credited with the introduction of so-called modal practices to jazz. ${ }^{563}$ Evans plays beautifully on Kind of Blue, and engages in the same kind of spontaneous improvisational play as his band mates; together these musicians make a great deal of music from the barest of sketches. Davis claimed: 'I didn't write out the music for Kind of Blue, but brought in sketches for what everybody was supposed to play because I wanted a lot of spontaneity in the playing [...] Everything was a first take, which

\footnotetext{
562 Kahn, The Making of Kind of Blue, 98. Davis denies that Evans was a co-composer of the music on the album. Davis, Troup, Miles, 234.

563 Evans recorded as a featured soloist with Russell on four albums between 1956 and 1960. Russell is widely regarded to be the theorist who initiated the use of modes in jazz, which he documented in his 1953 book, The Lydian chromatic concept of tonal organization (Brookline, Massachusetts: Concept Publishing Company, 2008 [revised and re-printed]). For a discussion of Evans's input into Kind of Blue, see Kahn, The Making of Kind of Blue, 98, 134. Davis was also an intimate of George Russell, and Russell's work was to some extent the result of a remark made by Davis. See Duncan Heining, George Russell: The Story of an American Composer (Lanham, MA: Scarecrow Press, 2009), x.
} 
indicates the level everyone was playing on.'564 Jimmy Cobb, the drummer on the sessions, agreed: 'To see how good those guys are, what they could do with just a little, that they could make it sound like that - you know, that's the thing.'565

When Kind of Blue was recorded (March and April, 1959), Evans had already left Davis's performing group, and by the end of the year was leading his own trio with bassist Scott LaFaro and drummer Paul Motian. That trio made four albums together, and their 1961 club recordings are considered a high watermark in interactive small group jazz playing. The writers of The Penguin Guide to Jazz claim this trio 'loosened the common practices of the bop style rhythm section which had become standard during the 1940s and ' 50 s ... thereby emancipating the piano, bass and drum roles.' Bassist Scott LaFaro has been described as a musician who was 'an interactive, counterpunctive, melodic contributor throughout the music.'566 While the innovations of this group have possibly been overstated, ${ }^{567}$ their 1959 recording of 'Autumn Leaves' is strikingly interactive for the time, and reveals all three musicians as equal partners in a musical dialogue that still sounds as fresh as paint more than 50 years after it was committed to tape. ${ }^{568}$ That fans and musicians still listen to these recordings and that scholars are still discussing them is testimony to the lasting impact of this music. What strikes me as germane to this thesis is that the very open improvisational approach adopted by Evans with LaFaro and Motian on this 1959 recording of 'Autumn Leaves' - for which all the group members forego stating regular time in their playing - is not, to my knowledge, an approach Evans was to attempt again. Further, the kind of freedom adopted by

\footnotetext{
564 Davis and Troupe, Miles, 234. This practice was used again for the Bitches Brew sessions, 299.

565 Jimmy Cobb, quoted in Rob Trucks, 'Chatting with Jimmy Cobb, Kind of Blue's Last Surviving Player', The Village Voice (8 October 2008) < http://www.villagevoice.com/2008-1008/music/chatting-with-jimmy-cobb-kind-of-blue-s-last-surviving-player/> (28 March 2014).
}

566 Cook and Morton, Penguin Guide to Jazz, 419; Eddie Gomez quoted in Helene LaFaroFernandez, Jade Visions: The life and Music of Scott LaFaro (Denton, TX: University of North Texas Press, 2009), 164.

567 See Rowan Clark's unpublished Master's thesis, An analysis of Scott LaFaro's bass playing as part of the Bill Evans Trio 1959-1961 (New Zealand School of Music: Victoria University of Wellington/Massey University, 2014).

568 See Robert Hodson, Interaction, Improvisation and Interplay in Jazz (New York: Routledge, 2007), for an extensive discussion of this performance, 119-144. 
LaFaro, when emulated and extended by bassist Gary Peacock as a member of the group (and captured on a single recording session from late 1963), was an approach that Evans was uncomfortable with. Evans said of Peacock, 'He fit right into what we were doing, and yet when his solo time came he went into complete [harmonic and rhythmic] abstraction, and it didn't really fit.'569 After Peacock's brief tenure with the group Evans reunited with bassist Chuck Israels, a player who respected the conventions of standard post-bop playing.

The conservative repertoire of Evans's trios both in terms of content (his band book evolved only slowly over the next twenty years, judging by the recordings he made) and nature (largely standards and newer material that adhered to the kinds of harmonic games that standards and show tunes generally followed), along with an almost reactionary attitude to harmony, saw his music manifest a centripetal tendency towards genre values that might be characterised as the heartland of jazz style: music that swings in conventional ways; makes use of harmonic approaches codified by swing and bebop musicians; includes the blues and ballads, and makes use of the 'Spanish tinge'. ${ }^{570}$ While these aspects made his music easy to identify as jazz, it also resulted in a kind of stasis. In 1980 Evans acknowledged the stasis his music experienced (something that seems to have begun after Scott LaFaro's death in 1961), alluding to a kind of impasse:

I had become rather rigid. I had gotten into a frame of mind where there wasn't really a chance for the music to be alive and growing as much. I had arrived at a refinement of what we were doing, to the point where it just wasn't as natural. [...] The music wasn't growing. We were being very resourceful and being on a very high professional level and so forth, but it didn't have that inner thing. 571

That 'inner thing' is what is missing for me from most of Evans's recordings, although I hear hints of it in his final sessions, live club dates captured just a few weeks before his death in September 1980. For those recordings Evans was

569 Bill Evans. Trio 64 (New York: Verve 8578, 1964). While Peacock's playing might be surprising in places, 'complete abstraction' seems quite an overstatement. Compared with his playing with Albert Ayler six months later, the music Peacock made with Evans seems very tame.

570 I'm using Stanley Crouch's style parameters for mainstream jazz. Crouch, Considering Genius, 210. For Evans's fairly conservative approach to harmony, see Jim Aitkin, 'Bill Evans: The Essence of Jazz Piano', Contemporary Keyboard (June, 1980), 50.

571 Ibid. 
working with bassist Marc Johnson and drummer Joe LaBarbera, and the group sounds like they are really exploring the music, listening intently to one another and taking chances that unsettle the standard practices that had characterised Evans's music for the previous twenty years - for example, the fluid tempi heard during 'The Days of Wine and Roses.'572

For most of the intervening 20 years however, Evans' recordings strike me as evidence of what Jason Toynbee describes as work that strives to implement or express a stylistic norm completely: 'This is a centripetal tendency where what is at stake is crystallisation of a style. ${ }^{\prime 573}$ Music writer Jim Aikin, who interviewed Evans in the year before his death, described the pianist as a musician who had drilled down to 'the essence of jazz piano,' and while this was one of Evans's virtues, it was probably also an impediment to his progress as a creative musician. This was the view taken by composer George Russell who worked with Evans during the 1950s. Russell said that Evans had been a progressive musician until about 1960, but after that point Russell felt that Evans became trapped. ${ }^{574}$ While I would agree that aspects of Evans's music were creative during this period (1961-1979) - in particular from the viewpoint of an inclusive definition of creativity - the kind of innovation evident in Miles Davis's music during the same period is largely absent from the recordings we have of Evans.

It seems to me a key difference between Evans and Davis is that while Davis deliberately cultivated an exploratory practice that invited his collaborators to contribute their ideas to a collectively forged music, Evans preferred to operate within the established forms of the music, making use of conventional approaches and repertoire and engaging musicians comfortable with the conservative performance practices he appears to have preferred. ${ }^{575}$ In

\footnotetext{
572 Bill Evans, Consecration (New York: Milestone 8MCD 4436-2, 2002), Disc 2.

573 Toynbee, 'Music, Culture, and Creativity', 105.

574 George Russell, paraphrased from a lecture for a paper addressing Bill Evans's music at New England Conservatory, 2000.

575 Which is not to say they were somehow shallow or monochromatic musicians. In bassist Eddie Gomez or drummer Jack DeJohnette for example, Evans had sidemen with unique sounds and approaches. They were, nevertheless, approaches that dovetailed elegantly with Evan's very straight-ahead procedures.
} 
Gary Peacock, Evans had a collaborator who could potentially have pushed his music into new directions; Evans it seems, was uncomfortable with this prospect, and their collaboration was short-lived. ${ }^{576}$ In this quite fundamental way he differed from Davis. Herbie Hancock said of Miles Davis:

He was the best teacher in the world because he encouraged us to find the answers by ourselves. That's why he never told us, specifically, what to play. It would always be some type of suggestion that would leave you hunting for what he meant. So, you'd wind up finding a solution that was your response to that. So, each time, it was a quest. 577

I think in this respect, Davis was not only a teacher, but also a student, willing to learn from his sidemen and incorporate their ideas into what he was doing.

Davis's openness - both to new ideas and to the input of his sidemen ensured that his ongoing practice was a problem-finding practice, and it is this quality that is central to his evolution as a musician. It is a quality that ensured ongoing creativity was present in his work and which saw his music change repeatedly across his performing and recording career. Perhaps most importantly for my purposes, the creativity evident in the music we attribute to Miles Davis is in fact the result of his group working together. As Davis suggests in the epigraph to this chapter, it is this kind of communitarian approach that makes the music happen.

\footnotetext{
576 Peacock was involved in radically ground-breaking music during the years shortly after leaving Evans's group, including Albert Ayler's Spiritual Unity (New York: ESP 1002), Tony Williams's Life Time (New York: Blue Note, BST 84180) and Paul Bley's Turning Point (New York: IAI 37.38.41) - all 1964.

577 Ragogna. Tribute To Miles. (My emphasis)
} 


\section{Chapter Five: Duke Ellington - Playing The Band}

Duke Ellington is regarded in both the popular and scholarly literature as a bandleader and composer who contributed significantly to jazz. The width of his band book alone - close to 1,700 compositions - is evidence of his industry, and the continued reverence many of those pieces enjoy - elevated as they are to the status of standards - is testimony to the ongoing utility of his music. ${ }^{578}$ Ellington was more than just busy and capable, however. With his music he also contributed a number of significant innovations to jazz. These include the introduction of wordless vocals (known as 'vocalise', where the vocalist functions as an instrument incorporated into the group rather than simply as a melodic delivery mechanism for text, and as distinct from scatting, which is improvised); a wide variety of innovative orchestration approaches; and expansion of the formal possibilities available to jazz musicians beyond the somewhat limited structures musicians initially appropriated from dance music. 579

I will explore two ideas in this discussion of Duke Ellington and his group, the first of which relates to his groundbreaking work as a composer and bandleader. Ellington, like Ornette Coleman and Miles Davis, employed collective means to achieve his innovative work. Gabriel Solis claims Ellington's collaborative practice 'had everything to do with getting his band to bring their distinctive voices into the closest possible interaction in the moment of performance. 580 The focus in the preceding case studies has been on how performances have been shaped by the collective and Ellington's music, like that of Davis and Coleman, reveals such collectivity to be a characteristic of his band's performances. However, his example also complicates notions of composition as the province of sole agents to whom the music is usually attributed. Ellington

\footnotetext{
578 Teachout, Duke, 1.

579 Gridley, Jazz Styles, 121-123; Mark Tucker, The Duke Ellington Reader (London: Oxford, 1993), 171; Teachout, Duke, 63-64.

580 Solis, 'A unique chunk of jazz reality', 337. Solis is specifically referring to Thelonious Monk in this passage, but states that Ellington and Charles Mingus adopted identical processes.
} 
offers a different paradigm for explaining how composers achieve original, creative work.

The second idea this case study explores is creative practice in Ellington's group that did not introduce innovations to jazz. In defining creative practice creative music making in this case - in this way I specifically draw from Keith Negus and Michael Pickering's inclusive definition of creativity, where creative action may be 'a task executed with considerable skill, a problem solved with imagination and panache, an act performed with grace, vivacity or élan, or even an interpretation of a particular artifact such as a song [...] which is judged to be particularly insightful, or at least ingenious. ${ }^{581}$ As these writers go on to suggest, an inclusive definition of creativity - inclusive because it is sufficiently open to accommodate a very wide range of practice - admits creativity comprising communication of experience. Such a definition acknowledges the exquisite artistry of jazz musicians whose work, as good as it might be, did not propel the domain of jazz in new directions. As I suggest, the performances of saxophonist and clarinet player Russell Procope (1908-1981) and tenor saxophonist Paul Gonsalves (1920-1974) illustrate such inclusively-defined creativity.

\section{Ellington/Auteur?}

As great a composer as Ellington was (and he was a great composer), perhaps his greatest virtuosity was his capacity to lead his group, eliciting from them not only many fine performances but also the raw materials that he was to craft into what came to be called the 'Ellington Effect'. This idea is widely accepted, and most writers acknowledge that the unique sound of Ellington's bands was the result of the unusual blend that such a disparate group of idiosyncratic musicians created when they played together. 582 Trumpeter Rex Stewart's description of how Ellington could assemble sounds in a kind of aural collage is a wonderful account of Ellington's process in achieving this musical alchemy.

\footnotetext{
${ }^{581}$ Negus and Pickering, 'Creativity and musical experience', 181.

582 “"There's no such thing as a replacement in my band," he said in 1951. "A new musician means for us a new sound and the creation of new music, which he, and he alone, can properly express." That was the keystone of the Ellington Effect. He craved new sounds...' Teachout, Duke, 255.
} 
I recall one occasion when he'd jotted some notes for the saxophones (Toby Hardwick, Harry Carney, Ben Webster, and Barney Bigard) and each was given a part, but there was nothing for Johnny Hodges. Duke had the saxes run the sequence down twice, while Johnny sat nonchalantly smoking. Then, Duke called to Hodges, "Hey, Rabbit, give me a long slow glissando against that progression. Yeah! That's it!" Next he said to Cootie Williams, "Hey, Coots, you come in on the second bar, in a subtle manner growling softly like a hungry little lion cub that wants his dinner but can't find his mother. Try that, OK?" Following that, he'd say, "Deacon," (how Lawrence Brown hated that nickname) "you are cast in the role of the sun beating down on the scene. What kind of sound do you feel that could be? You don't know? Well, try a high B-flat in a felt hat, play it legato and sustain it for eight bars. Come on, let's all hit this together," and that's the way things went, sometimes. 583

One particularly arresting example of Ellington's sound assemblage is the 1940 recording 'Ko-Ko', widely touted as a defining work for the composer: for Ellington biographer Terry Teachout 'the greatest of Ellington's three-minute masterpieces' and except for the trombone and bass solos 'the composer's show all the way. ${ }^{584}$ But it can hardly be attributed solely to Ellington; it is the product of the group, and a product in which the total exceeds the sum of the parts. Harry Carney's growling buzz-saw baritone to get things going in counterpoint with harmonised and (it has to be said, pretty) ragged brass; the respective lines of the (utterly different) trombonists Juan Tizol and 'Tricky Sam' Nanton; then Ellington's caffeinated, abstract and strangely baroque piano spot. And check out the way the band - full ensemble playing hell for leather in a slightly crazed antiphony - builds to the climax at 1:48 minutes only to stop (!) and allow Jimmy Blanton to play his very grounded bass line a cappella. It is an exceedingly strange potpourri of sounds and approaches, which Ellington directed to be sure, but which could not have happened without this particular group of actors. Just as it takes all the colours to make the rainbow, so all of the voices in the Ellington ensemble are required to achieve this marvel of sonic collage.

While in these accounts Ellington is the principal chef, combining ingredients to create the final musical confection, some of the novel orchestration strategies attributed to Ellington emerged from ideas stumbled upon by his collaborators. The innovation of vocalise for example, debuted on

\footnotetext{
${ }^{583}$ Rex Stewart, Jazz Masters of the Thirties (New York: Da Capo, 1980), 98.

${ }^{584}$ Teachout, Duke, 208.
} 
'Creole Love Call' (recorded 1927), is in the first instance attributable to singer Adelaide Hall.

Hall [...] was sharing the stage with [Ellington's 1920's group] the Washingtonians when she heard them playing 'Creole Love Call' as she stood in the wings. She started humming along with the band, and as soon as Ellington heard her, he left the piano and went backstage. "Adelaide, that's what I've been looking for!" he said, then bought her out to sing the number with the band. They recorded it a few days later. 585

In instances like this, Ellington was a collector of sounds and ideas. The sidemen he most valued possessed unique voices on their instruments and in many cases are instantly recognisable: Bubber Miley's trumpet growls, Johnny Hodges' legato glissandi on alto saxophone, Joe 'Tricky Sam' Nanton's voice-like trombone, or from a little later, Ben Webster's big-toned, occasionally growling tunefulness; or Paul Gonsalves's voluble, slippery tenor. Ellington did not create these sounds - that credit belongs to those individual musicians - but Ellington did have a vision for how they could be put together to create a unique and compelling whole. Nevertheless it was a vision that invited, and indeed required, the active participation of his collaborators. As Metronome reported:

The men take up their instruments and the arrangement is started. Ellington takes the men by sections, first the reeds, then the trumpets, then the trombones, and gives each man his notes for four bars. The men play them singly, then as a section, with remarkable rapidity. Any necessary changes are made section by section; the men make suggestions and from time to time Ellington turns to the piano to trace out an idea. 586

My point here is that collaboration was essential to the Ellington sound. While Ellington often received most of the credit for the outcomes (and along with publisher Irving Mills, most of the royalty cheques, too), his orchestral/timbral accomplishment required this kind of interdependence. In this way Ellington's creativity - like that of Ornette Coleman and Miles Davis - was in fact the result of the work of his group. While this is a well-understood aspect of Ellington's art as an orchestrator and bandleader, I wonder if sufficient attention is given to the very collective nature of Ellington's creative practice (or that of Coleman or Davis for that matter) in the discourses around jazz? Perhaps this is because Ellington is celebrated primarily as a jazz composer? And yet as a composer - and this is

585 Teachout, Duke, 66.

586 H. Overstreet, 'Touching Tomorrow's Frontiers is Duke Ellington's Music', in Tucker, Duke Ellington Reader, 100. 
perhaps less well understood - Ellington also adopted a very collaborative approach.

Ellington was fond of appropriating small fragments of music his sidemen wrote or liked to play, transforming them into complete songs that became a part of the band book. When that occurred, even if creative agency was still attributed to Ellington as 'the composer' (as it generally was), the work of composition had shifted from the singular to the plural, and responsibility for creation (in fact, even if not on the royalty statements) had moved from the individual actor to the collective. A significant number of Ellington's celebrated pieces owe their genesis to such collaborative processes, and his sidemen were central to his composing, providing the melodies for substantial parts of many of his most famous popular recordings. 'We gave every man in the band the opportunity to write', Irving Mills, Ellington's manager claimed, 'They came in with ideas, and Duke helped develop it and give it a style.'587

There are many, many examples of this practice to be found in Ellington's catalogue. Trumpeter Bubber Miley composed the main melodic strain of 'East Saint Louis Toodle-Oo'. 'Black and Tan Fantasy' also makes use of a melodic line attributed to Miley, but was one that he in fact appropriated from the sacred song 'The Holy City', composed by Stephen Andrews in the nineteenth century. ${ }^{588}$ The clarinet solo on 'Creole Love Call' was introduced to the band by Ruby Jackson, a line that, as he neglected to mention to Ellington, he had stolen from cornet player Joe 'King' Oliver. ${ }^{589}$

Trombonist Lawrence Brown and saxophonist Otto Hardwick composed the melody for 'Sophisticated Lady' between them, and Hardwick alone dreamed up the central melody of 'In A Sentimental Mood'. Johnny Hodges was responsible for the main melodies of 'Never No Lament' (which later became 'Don't Get Around Much Anymore') and 'I'm beginning To See The Light'. The eight-note motif that is the principal theme of the A section of 'Concerto for

587 Teachout, Duke, 61.

588 For an account of Ellington's use of musical materials from spirituals, see David Metzer, 'Shadow Play: The Spiritual in Duke Ellington's "Black and Tan Fantasy",' Black Music Research Journal 17/2 (Autumn 1997), 137-158.

589 Teachout, Duke, 61, 62-63,66-67. 
Cootie' (later finessed into the song 'Do Nothing 'Til You Hear From Me') was a lick that trumpeter Cootie Williams often played as a warm-up exercise. It was for this reason that Lawrence Brown told Ellington 'I don't consider you a composer. You are a compiler.'590

Terry Teachout writes:

It is impossible to write truly popular songs without also being able to write truly memorable tunes, and so it stands to reason that the charges of plagiarism that were to be leveled against Ellington in the years to come would center not on his instrumentals but his hit songs, nearly all of which were collaborations with band members who did not always receive credit - or royalties - when the songs were recorded and published. ${ }^{591}$

This is not to deny Ellington's capabilities. As Teachout goes on to explain 'It was what Ellington did with the tunes he poached that bought them to lasting life.'592 Billy Strayhorn, Ellington's amanuensis, was similarly sympathetic:

So this guy says you and he wrote it, but he thinks he wrote it. He thinks you just put it down on paper. But what you did was put it down on paper, harmonized it, straightened out the bad phrases, and added things to it, so you could hear the finished product. Now, really, who wrote it? [...] But the proof is that these people don't go somewhere else and write beautiful music. You don't hear anything else from them. You do from Ellington. ${ }^{593}$

Songwriter Ervin Drake once described Ellington's group as something akin to a 'musical kibbutz' where collaboration - even in composition, which has ordinarily been thought the province of Ellington or Billy Strayhorn in the context of the Ellington orchestra - was routine. ${ }^{594}$ As such, Ellington was not the sole author of much of the music attributed to him. He certainly possessed the perspicacity to identify good ideas, and the craft necessary to turn unpolished stones into the gems that some of his compositions were to become. My point here is that the process engaged to achieve that work was

\footnotetext{
590 Teachout, Duke, 114-115; 152; 254; For the Cootie Williams story, Leonard Feather, quoted in Terry Carter, A Duke Named Ellington (Los Angeles: Council for Positive Images, Inc., 1988).

591 Ibid., 112-113. As Teachout explains, Ellington often purchased tunes outright from his sidemen.

592 Ibid., 211.

593 Ibid., 115.

594 Irvin Drake, who penned the words for the song 'Perdido's, composed by Juan Tizol for the Ellington Band, quoted in 'Duke Ellington records his first big hit: "Mood Indigo",'

<http://www.history.com/this-day-in-history/duke-ellington-records-his-first-big-hitquotmood-indigoquot> (6 May 2014).
} 
collaborative, and without his sidemen Ellington could not have gone on to be acknowledged as one of the great composers of jazz.

I think the mental image most of us have of a composer is of the lone genius scratching away at a score in the night while communing with some muse. ${ }^{595}$ Ellington's example (like that of Miles Davis in the previous chapter, although in different circumstances) not only torpedoes that notion as the primary (or even only) model, but also returns us to the understanding that jazz creativity - even for an activity as apparently individual as composition - is most often (and perhaps is necessarily) a collective phenomenon.

\section{Ellington's Sidemen: Saying Something}

As has become clear from the musicians discussed thus far in this thesis, innovation in jazz is often a collective achievement. And yet so much of the rhetoric about the music is related to the roles of individuals - jazz is, after all (or so we have been told ${ }^{596}$ ) a soloist's art, a musical form and a creative practice predicated on the achievements of great improvisers (i.e. individuals). It is to improvisers in the context of Ellington's band that I now turn, but not to claim for them some kind of individual glory, or to repudiate the notion that jazz needs 'great' soloists. Rather, my purpose here is to propose a different prism through which to view jazz soloists, a prism less concerned with lionisation associated with creativity parsed as innovation, and more concerned with creativity as communicative act. Creativity defined in this way (and which is elaborated in Chapter One, under 'Creativity as the communication of experience') places emphasis on individual agency. Such a prism also offers a new perspective on the apparent contradiction between a view of jazz that valorises the collective, and the perception that jazz is about exceptional individuals. As the examples

\footnotetext{
595 Whether or not this image applies to 'jazz composers' is an interesting question. From my reading it seems to me that the Romantic idea of 'composer as solitary genius' does seem to be at least partially embraced in discussions about jazz. The widely celebrated jazz composers (perhaps Ellington, Jelly Roll Morton, Stan Kenton, Thelonious Monk, Charles Mingus, and more recently Carla Bley, Kenny Wheeler) are generally referred to individually (when discussed in terms of their compositional practice) rather than attached to specific collaborating musicians. Although Jelly Roll Morton is regarded as the first 'jazz composer' (Gioia, History of Jazz, 40-42) probably Ellington is responsible for the legitimation of the term. See Ken Rattenbury, Duke Ellington, Jazz Composer (New Haven: Yale, 1993).

596 Martin Williams, quoted in Jazz: The First 100 Years, 50; Dyer, But Beautiful, 198.
} 
examined will show, great jazz occurs when unique individuals (who do not need to be virtuosi or ground-breaking conceptual innovators, but who do have something to say) operate in a collective context that supports their acts.

As I see it, two clear insights become available when we adopt a perspective that accepts creativity as the communication of experience. First, when individual musicians (which is to say, musicians with a unique voice) are able to communicate effectively to their audience through their music they experience the pleasure, satisfaction and sense of freedom that accompanies the exercise of individual agency (or expression of free will). This can be (and often is) a two-way street. Audiences, in hearing such expressive music, may experience some kind of response to that music, a response that 'enables participation in the work, and activates some connection between what is performed and what is lived.'597 I think this is why many people listen to music: because it gets us where we live.

Second, when the work of a musician in the context of an ensemble achieves such a communicative threshold ('communicates experience' in Negus and Pickering's parlance), the possibility for musical dialogue within the group is enhanced: the musicians are not simply playing a part, they are playing their part, and are doing so with other musicians who are also making individual contributions. When such musical dialogue occurs a kind of synergy becomes possible, one that can lead to (sometimes remarkable) collective creative achievements led by soloists but fuelled by their band-mates. It is a little like the difference between reading a script with friends, and having a free-flowing conversation with friends. With the latter, there will almost always be a deeper, more personal engagement: the participants say their own thing in their own way and all have the opportunity to communicate something. I will speak to these two ideas in turn, using Russell Procope to illustrate the first, and Paul Gonsalves' performance at the Newport Jazz Festival in 1956 as an example of the second.

Negus and Pickering's inclusive definition of creativity - which is concerned with creativity as a communicative act - encompasses not only

${ }^{597}$ Negus and Pickering, 'Creativity and musical experience', 189. 
exceptional creative products (or 'greatness' in the way we might apply it to John Coltrane, say, or in line with a common rule of thumb for creativity: 'new and useful'), but also includes routine cultural practices where much more subtle modification, adjustment and updating takes place. 'What happens in such cases is modification and variation, leading to degrees of newness in relation to what is established and already in social circulation.'598 This kind of newness, even if modest, is a result of individuals applying their own ideas to the work they are doing; of making changes to the ways they (or others) might have executed such tasks before.

As the work of Lawrence Gushee and Howard Brosfky reveal with regard to the improvising of Lester Young and Miles Davis - two musicians acknowledged as 'great' in discourses around jazz - improvised solos often contain little that is particularly new or that might be described as strikingly innovative in terms of rhythmic, melodic or harmonic vocabulary, overall architectural organisation, or timbral variety. ${ }^{599}$ What solos performed by experienced improvising jazz musicians do generally reveal are the musical fingerprints of the musician performing: a unique sound, a particular approach to melody and phrasing, preference for certain idioms (particular aspects of the blues for example, or perhaps an inclination toward pentatonic pitch sets) and so forth. These qualities often define - or at least represent - the individual voice or sound of that musician. It seems to me that while improvised performances may very occasionally offer new ideas to the field of jazz - Louis Armstrong's scat solo on 'Heebie Jeebies', perhaps - it is much more common for improvised performances to allow musicians opportunity to express themselves, and so communicate what is distinctive or unique about them. I would argue such selfexpression, which allows musicians to stamp their personality onto the music being performed, is at least as important as domain-changing creativity because such individual playing (an indispensable quality for jazz, as outlined in Chapter

\footnotetext{
${ }^{598}$ Negus and Pickering, Creativity, Communication and Cultural Value, 14. (My emphasis) ${ }^{599}$ Gushee, 'Lester Young's "Shoeshine Boy"', 151-69; Brofsky, 'Miles Davis and My Funny Valentine'. I would add that this kind of normative flow is part of a continuum that also includes those moments when innovation occurs, when the degree of variation is greater and the results are considered groundbreaking. The processes engaged are often similar.
} 
Two) affirms and reifies the value of that individual. ${ }^{600}$ This kind of personal creativity - where what is accomplished may not alter the domain but does effectively communicate the experience (which is to say, the musical persona) of the performer is demonstrated in Russell Procope's performances of 'Mood Indigo' with the Ellington band.

'Mood Indigo', one of Ellington's most enduring compositions (featured in his band book from 1930 until the end of his life), possessed a memorable solo line for clarinet, originally contributed to the composition by Barney Bigard.601 After Bigard moved across to baritone saxophone, Ellington needed another soloist to cover the part. Ellington had a very acute understanding of the capacities of his sideman, writing parts specifically for them and assigning them tasks that matched their skills and proclivities. Russell Procope was not a great soloist in the manner of Johnny Hodges, but he was a solid player. Terry Teachout suggests Procope was (along with clarinetist and alto saxophonist Jimmy Hamilton) one of 'a pair of well-behaved professionals whom Ellington could count on to do their jobs without fuss.' ${ }^{602}$ Ellington himself offered only the faintest praise for Procope in his autobiography Music is my Mistress: 'What is more, he became a conscientious, all-round musician, one always to be depended on', 603 hardly unreserved praise for a jazz musician. Nevertheless, Ellington recognised that the kind of dependability Procope offered was ideal for 'Mood Indigo', and so he assigned the solo on the piece to the clarinetist. It was a

600 After Greg Tate, in Miles, Ornette, Cecil, xi.

${ }^{601}$ Although Ellington claimed, 'Well, I wrote that in fifteen minutes while I was waiting for my mother to finish cooking dinner,' the composition has a rather more storied provenance.

(Ellington, quoted by the History Channel, 'This Day in History' (no date), http://www.history.com/this-day-in-history/duke-ellington-records-his-first-big-hitquotmood-indigoquot> (17February 2014).) In 1930 New Orleans jazz musician Lorenzo Tio Jr., who had been one of (saxophonist and clarinetist) Barney Bigard's teachers, shared a melody with Bigard called 'Dreamy Blues,' which had served as a theme song for Tio's group in the Crescent City. In his autobiography, Bigard recorded, 'I asked him if I could borrow it. I took it home and kept fooling around with it [...] and got something together that was mostly my own but partly Tio's.' (Barney Bigard, With Louis and Duke: The autobiography of a Jazz Clarinetist (New York: Oxford, 1986), 64.) It was this melodic line that Ellington appropriated for the clarinet solo in 'Mood Indigo,' building the rest of the composition around the kernel provided by Bigard. This melody, coupled with the innovative orchestration Ellington scored for the line, has made it one of the tunes synonymous with his group.

602 Teachout, Duke, 255.

603 Duke Ellington, Music is my Mistress, (New York: Doubleday, 1973), 222. 
melody Procope was to perform many hundreds, perhaps thousands of times over the following 28 years.

Even though someone else composed the notes that comprised this solo, Procope never grew tired of playing the line. He said:

I think we played [Mood Indigo] every night for the twenty-eight years I was with him [...] and I just loved it. People have asked me, 'Why, wouldn't you get tired of playing it?' No - I never got tired, because every time I played it, it was like the first time. I would find out, y'know, maybe I held this note a little long, or maybe I'd cut this one off a little. But tomorrow night I would twist it around this way, that way, what have you. It was mine to play with, because when Duke sent you out to the mic to play you were on your own. You did your thing when you walked out to the mic.604

Given the importance of 'Mood Indigo' in Ellington's band book, it is unsurprising that there are numerous recorded versions of Procope performing this solo. Careful audition of four versions of 'Mood Indigo' recorded over a twenty-year period reveals both how faithful Procope was to the melodic contour of this solo, and also the many ways he was able to introduce variation and nuance to his performances. The four versions I've studied (from 1951, Masterpieces by Ellington; 1958, The Private Collection, Vol. 6: Dance Dates, California, 1958; 1962, Della Reece with Duke Ellington and his Orchestra; and 1970-72, Duke Ellington: New York, New York) are largely similar, but nevertheless differ in memorable ways as Procope lingers over a note here, embellishes a passage there, adjusts his volume or alters his phrasing. Transcriptions of each of these solos are found in Appendix 1.

The two earlier versions possess identical tempi, although the bluesy quality of the 1951 recording - perhaps exemplified by the phrase Procope plays in the third and fourth measures (and repeats to conclude the solo) - is replaced with an emphasis on virtuosic flourishes in the 1958 recording. That virtuosity is even more pronounced in the slightly brighter 1962 recording, and on this take, Procope explores some very melodic elaborations of the line during the $9^{\text {th }}$ to $12^{\text {th }}$ measures. By 1972, Procope sounds an older and perhaps wiser musician. The tempo has crept up still further, but his still-evident virtuosity is displayed less in flourishes than in a kind of melodic questioning. His variations to the line

${ }^{604}$ Carter, A Duke Named Ellington. 
seem to ask questions of the melody and its attendant harmony and come to a strangely inconclusive end, as he finishes the solo by tracing an alteration to Bigard's original melody that unsettles the cadential quality of the underlying chords and leaves the listener hanging.

All four versions are redolent to a lesser or greater extent - it seems to me - of Sidney Bechet's example. Echoes of Bechet are especially noticeable in the vibrato Procope uses in the measures 9-12 of the 1951 version; in the gorgeous shake he adds to the forcefully played G-natural in measure 10 of the 1958 version; in the scoop into the D-flat during measure 12 of the 1962 recording; and throughout the 1972 version, where Procope's sound - which seems to possess more mid-register resonance (perhaps just the recording?) and the vibrato he uses brings Bechet's playing to mind.

Frank Zappa described attention to this kind of musical nuance as 'putting the eyebrows on the music.' ${ }^{605}$ But whatever it is called, for my money it is these personal, interpretive values that bring performances to life, that satisfy careful listeners and are one of the ways music effectively communicates something of a performer to their audience. What performances such as these communicate is difficult to quantify, but I think it these values that are so alluring in music. As Mike Nock has said:

No one really cares if you are the greatest or the cleverest or the hippest; generally, the punters want to get something, and they may not even know what it is. I like to give people an experience that may prove in some way uplifting, a "positive something". I want it to have an effect in the world - music is an emotional communication and to me that's the most important thing. 606

Russell Procope may not have gone down in the annals of jazz as a soloist who changed jazz, but for attentive listeners he is remembered as someone who achieved a kind of emotional communication, as someone who made a contribution. That creative contribution was perhaps the 'Russell-Procope-ness' that he offered to Ellington's band and that is in evidence on these recordings of 'Mood Indigo'. In this admittedly modest way he was able to add nuance and expression to performances of a part composed by some one else, and achieve communicative value by stamping the music with his musical personality.

605 Frank Zappa, The Real Frank Zappa Book (New York: Touchstone, 1990), 164.

${ }^{606}$ Quoted in Meehan, Serious Fun, 183. 
Procope's contribution occurred in the collective context of the Ellington band, a context that highlights the accommodation we need to reach if we are to understand jazz as both the work of individuals and ensembles. In creating a context in which his musicians - musicians with individual sounds and unique approaches - could shine, Ellington provided a forum in which almost all of his sidemen did their finest work. That work is more than a few iconic performances captured on disc however; those particularly memorable performances are like postcards from along the way, and would not have been possible (or possible in quite the same ways) without the years of toil, and the steady refinement and development that their individual and collective music making experienced as a result of the ongoing work with Ellington (as is evident in Procope's performances on 'Mood Indigo'). What I am pointing to is the mutuality of this relationship, the interdependence of leaders and sidemen, and the importance of an ongoing context for the development of all of the actors. Ellington needed these musicians to create his music; and they needed an opportunity to play, and other musicians with whom to work in order to develop their musical identities.

The interdependence between a creative group dynamic and the possibility of developing an individual musical identity contributes to what has been described as the democratic nature of jazz: for Wynton Marsalis, "how the power of the individual can be used in combination with other individuals [...] the one and the many [...] that's what jazz is.' ${ }^{607}$ Here is a key paradox of jazz: the individual serves the needs of the ensemble - is subservient to the ensemble while at the same time the ensemble provides the individual with a place to stand, and a context which both fosters and celebrates what is distinctive about them as an individual. ${ }^{608}$ Their uniqueness may not be akin to the historically significant work of a Charlie Parker, for example (and almost never is), but

607 Wynton Marsalis, 'Jazz as a model of democratic action', < http://www.discovery.com/tvshows/curiosity/topics/wynton-marsalis-jazz-as-a-model-of-democratic-action.htm > (6 May 2014). See also Crouch, Considering Genius, 173-178.

\footnotetext{
608 Marsalis expresses this idea beautifully in the 'Jazz as a model of democratic action' interview: 'You have something about you that's creative, that is special, that only you have. Jazz informs you not to be discouraged even if people tease you about your sound and to express your individually through your horn because it sounds like you; and, it requires honesty and a truthfulness about who you are. Let me hear that come through your horn. Every note you play, let me hear that because that's the only thing you have that's worth playing. I want to know, I want to feel you.' Ibid.
} 
remains valuable because such a unique voice can be embraced and celebrated in a musical practice that encourages all to speak with their own voices. ${ }^{609}$ The key thing here is that the kind of individual creativity I'm emphasising is enabled by, and in turn fuels their collective contexts.

The second example of inclusively defined creative practice from Ellington's catalogue I wish to draw attention to and that illustrates this dialectic (individual action and collective contexts), is drawn from one of the most celebrated events in the bandleader's career. In 1956 Ellington's reputation was at something of a nadir. However, the return of saxophonist Johnny Hodges long one of Ellington's most important soloists and absent for four years during the early 1950s - and an invitation for the band to perform at the Newport Jazz Festival seemed to augur well for the group's fortunes. Ellington and Billy Strayhorn prepared some new music for the event after their Columbia Records producer George Avakian had convinced an ambivalent festival director to confirm Ellington's booking by offering a generous fee to the festival organisation in exchange for rights to record a new Ellington suite during their set. ${ }^{610}$ Unfortunately, the band was not able to rehearse the new music until the day of the event. And as it happened, George Avakian described the rehearsal, from which several key payers were absent, as a 'kind of disaster.'611

A lacklustre performance of the new suite and an indifferent response from the audience - one report said people were beginning to leave - forced Ellington to change the energy. ${ }^{612} \mathrm{He}$ did so by stomping off 'Diminuendo and Crescendo in Blue', a composition in three parts that had been in the band book since 1937 and which boasted a long interlude featuring Paul Gonsalves soloing on a blues. The audience response to Gonsalves was almost immediate, and overwhelmingly positive. To growing excitement in the crowd, Gonsalves played a 27-chorus (more than six-minute) solo that was followed by the piece's

\footnotetext{
${ }^{609}$ After Lewis, A Power Stronger Than Itself, xii.

${ }^{610}$ For Ellington, to write music that utilised longer forms that the three-minute miniatures for which he is primarily remembered was a persistent aspiration. (See Teachout, Duke, 5-10, 122124, 242-243; John Howland, Ellington Uptown [Ann Arbor: University of Michigan Press, 2009]).

611 Teachout, Duke, 286-287.

${ }^{612}$ Ken Burns Jazz, 'Episode 9: The Adventure'.
} 
volcanic final section. Seeing the frenzied crowd and fearing a riot, festival director George Wein tried to stop the concert. Ellington would have none of it and stayed on stage first to calm and then to re-ignite the audience. ${ }^{613}$

Ellington was to say later in life that 'I was born in 1956 at the Newport Festival.'614 Certainly the media response to the event and the subsequent reanimation of Ellington's fortunes marked the performance as a turning point. That media response included statements describing proceedings as a 'magnificent frenzy' and Paul Gonsalves' solo, 'as honest old-time rhythm-andblues - a bomb that blew the crowd to its feet, to rushing crazily at the bandstand'.615 For many, it was Gonsalves' solo that sparked such a memorable response from the audience; it is this now-legendary solo that I wish to scrutinise.

Gonsalves' solo, as heard on recordings, is adequate. In bald terms, while Gonsalves plays some very tasty ideas (I like the A-Lydian idea he starts with, played a tritone away from the Eb dominant chord sounded in the rhythm section, and that recurs in the second chorus; the wide shake on the F natural that concludes the line in measure 7 of the $6^{\text {th }}$ chorus [5:08 min]; the terrific blues phrase and subsequent line he uses to close out the $12^{\text {th }}$ chorus and open the following chorus [6:36-6:41 min]; the 'outside' line in the third and fourth measures of the $20^{\text {th }}$ choruses is certainly ear-catching [8:22 min]; probably my favourite chorus would have to be the $21^{\text {st }}$, where - for me anyway - Gonsalves really gets down and plays some blues [8:32-8:40]), for the most part this is a conservative, melodically repetitive performance. What is perhaps most remarkable about it is the growing crowd noise and attendant excitement that noise generates as the solo progresses. Gonsalves sounds like himself astringent on the high notes and buttery on the mid-register legato phrases, with plenty of lines that snake along underwater without coming up for too much air - and while the energy of the performance is excellent, what he actually plays is

613 John Fass Morton's account of the performance is wonderful, evocatively capturing the occasion and illuminating Ellington's masterful handling of the situation. Backstory in Blue: Ellington at Newport '56 (New Brunswick NJ: Rutger's University Press, 2008), 115-197.

614 Derek Jewell, Duke: A Portrait of Duke Ellington (London: Elm Tree, 1977), 87.

615 Whitney Balliett, quoted in Teachout, Duke, 290. 
somewhat unremarkable. Teachout suggests 'Heard in cold blood, Gonsalves's solo sounds banal and repetitious.' ${ }^{616}$ Nat Hentoff, reviewing the music for Downbeat lamented 'I'm afraid the music that caused the conflagration doesn't wholly hold up.'617 Well, hold up to what, exactly?

Perhaps Hentoff is referring to the quality of the playing (the ensemble is patchy in places, and the performance is pretty muffled in some spots - it was not particularly well-recorded) or the absence of innovative content or new ideas? Gonsalves's solo may not have shifted the harmonic, rhythmic or melodic frontiers of jazz music in any way, but clearly the audience members were excited by what they heard. And the band seems to have risen to the occasion, responding to the audience's growing excitement to form a virtuous circle that further energised both them and the crowd. However, it is difficult to divine exactly what it was that communicated so movingly to those in attendance. I think there is a clue embedded in the remark saxophonist Paul Desmond made to Gonsalves after the event: 'What you and the band played was the most honest statement of the night.'618 What Gonsalves played may have been routine, but it communicated something - which I think is what Desmond meant by 'honest' - to those in attendance, and thrilled them to such a degree that the festival director feared a riot. (Were it always thus...) The solo is not innovative, and in fact differs little from the kind of idiomatic blues playing Gonsalves offers on other recorded versions of this piece, ${ }^{619}$ but it did communicate some sort of experience, and as such may be classed as creative. This is not the creativity that leads to paradigm shifts, but rather the kind that emerges when performance of 'a particular artifact such as a song [...] is judged to be particularly insightful, or

\footnotetext{
616 Teachout, Duke, 289.

617 Nat Hentoff, quoted in Morton, Backstory in Blue, 209.

618 Desmond, quoted in Stanley Dance, The World of Duke Ellington (New York: Da Capo, 2000), 173.

${ }^{619}$ For example, the live versions (both from the late fifties, I guess) here: 'Duke Ellington (Paul Gonsalves) Crescendo+Dimuendo in Blue' <https://www.youtube.com/watch?v=GkElnIiE4U4\&list=RD5vnrNWyvI-U> (8 May 2014); 'Diminuendo and Crescendo in Blue - Part 2' <https://www.youtube.com/watch?v=EQYIWD97fmM\&list=RD5vnrNWyvI-U> (8 May 2014).
} 
at least ingenious.' 620 The ingenuity on display here, I believe, is the unique voice Paul Gonsalves revealed during his solo: not necessarily pioneering, but uniquely his.

Focusing on Gonsalves as soloist, as I do above, sketches out one side of the 'ensemble versus individual' dialectic I am negotiating. The other side of the paradox is illustrated by the collective context of Gonsalves' performance. A considerable part of the appeal of this performance lies in that context: in particular, the exceptional groove the rhythm section was able to generate under Gonsalves, thus energising the performance. In Music Is My Mistress, Duke Ellington attributed the success 'Diminuendo and Crescendo in Blue' at Newport not only to Gonsalves, but also to the rhythm section playing with him: 'Paul Gonsalves, [bassist] Jimmy Woode and [drummer] Sam Woodyard lifted that stone cold audience up to a fiery, frenzied, screeching, dancing climax that was never to be forgotten.' ${ }^{621}$ Clarinetist Jimmy Hamilton's remarks are revealing and offer additional nuance.

You know, one of the secrets of that thing is that many people missed the point. They only heard Paul Gonsalves playing. They didn't realize what egged the thing on was us giving him a good rhythm from behind, with our feet and our hands - which really built the thing. But you never knew that; all you knew was Paul, Paul, Paul, Paul, the whole time. It [was] just one of those moments when you strike something and you drive, y'know?622

And in fact the band had additional help; Gonsalves was 'whipped into a mounting frenzy by Sam Woodyard's popping backbeats and the unseen backstage presence of Jo Jones, who had played drums for Teddy Wilson earlier in the evening and now egged on Gonsalves by shouting words of encouragement and slapping a roll-up copy of The Christian Science Monitor against the lip of the stage.' ${ }^{\prime 23}$ George Avakian, standing in the wings later recalled 'I'd never heard a rhythm section like that. I'd never heard the Ellington band wailing that way.' 624

\footnotetext{
${ }^{620}$ Negus and Pickering, 'Creativity and musical experience', 181.

621 Ellington, Music Is My Mistress, 227.

622 Jimmy Hamilton, in Carter, A Duke Named Ellington.

623 Teachout, Duke, 288-289.

624 Morton, Backstory in Blue, 190.
} 
My point here is that although honour is due Paul Gonsalves for the unique voice he projected when he soloed, even such individual moments in jazz depend upon the toil and support of others. In this way, soloists achieve their greatest heights only in collaboration with the ensemble. ${ }^{625}$ At the same time, the group as a whole can be energised by their soloing colleagues; and leaders Ellington in this case - can use the skills and reputations of such soloists to both promote the ensemble in the marketplace, and exercise agency as leaders in seeking new ways to explore and exploit the synergies that exist between their soloists and ensembles. Yet the rhetoric around this particular performance, as Jimmy Hamilton attests, has been 'Paul, Paul, Paul, Paul', (or perhaps 'Ellington, Ellington, Ellington, Ellington'). ${ }^{626}$ In a strange way this discourse mirrors the creative language of the western classical tradition, which primarily articulates the achievements of individuals (i.e. composers, or occasionally soloists), and not the collective: ${ }^{627}$ strange because the two traditions engage such utterly different processes. ${ }^{628} \mathrm{In}$ jazz contexts both the soloist and the ensemble contribute significantly to the final performance, and it is the dynamic dialogue between all parties that yields the results. It was such a dialogue that Ellington, Woodyard, Woode, Gonsalves and the members of the Ellington band were able to spark at Newport. As trombonist John Sanders recalled: 'We have our little solo parts, the reeds, the brass - the trombones, the trumpets - but we are an orchestra. And I think that night, at that point, there was a oneness between

625 In solo jazz performances (which lie beyond the scope of my discussion), different values obtain. Nevertheless, even the finest solo performers acknowledge the collective aspects of their work. Pianist Keith Jarrett's remarks are instructive in this regard. See Ian Carr, Keith Jarrett: The man and his music (New York: Da Capo, 1991), 65-66.

${ }^{626}$ Another reading of this anecdote is as capitulation to reactionary audience tastes; Ellington falling back on well-known dance tunes to placate an audience unreceptive to his newer, perhaps more ambitious work.

627 For example, Scott Burnham's discussion of Beethoven's 'heroic' style, which in projecting a sense of self, destiny and freedom has come to shape compositional, critical and analytical values - values that emphasise the individual ahead of the collective. Beethoven: Hero (Princeton: Princeton University Press, 2000).

628 Of course this fundamental difference does not stop commentators insisting upon measuring the one (jazz) against the standards of the other (classical). A particularly egregious example (from the perspective I am adopting in this thesis) was penned by English commentator Spike Hughes who considered 'Creole Rhapsody' (1931) 'The first classic of modern dance music. The individual player is, for the first time, completely subservient to the personality of the composer'. Teachout, Duke, 123. 
everyone, and we bought it to a climax. It was a peak moment.'629 It was a moment of dialogue, of communication, that - sometime after midnight - bought thousands of tired jazz fans to their feet and re-launched Duke Ellington's flagging career. And it did so because Ellington and his musicians were able to enact a marvel of social organisation that accommodated both the group, and the singular voices that comprised it, not necessarily saying something new, but saying something unique, and saying it together.

\section{Conclusion}

Duke Ellington and his soloists offer several lessons that fill out the picture of jazz creativity I am drawing in this thesis. As just discussed, Ellington's soloists are not generally acknowledged as pioneers in jazz and, as good as they were, it is not clear that any of them changed how jazz has been played in any fundamental way. Nevertheless, their performances assumed considerable meaning for the band's audiences and as such communicated to those audiences, achieving the kind of work that Negus and Pickering value as creative. What those musicians communicated is difficult to quantify, but playing gave them the opportunity to express something, and in expressing something to stamp themselves - their musical persona - onto the music they were performing. In this way jazz performance offers musicians an opportunity to showcase what it is that is distinctive about themselves as individuals, to shape the music and so exercise agency in the world. From a humanist perspective such enfranchisement is perhaps the most important opportunity that jazz offers performers.

I do not wish to diminish this aspect of creative jazz performance, but it is also useful to assay the music such acts produce. In this regard and as discussed at the beginning of the chapter, the rich mosaic of sounds and ideas Ellington's music possesses - reflecting the kaleidoscopic range of musical personalities in his band - is the cornerstone of his reputation as one of the most celebrated jazz composers and bandleaders in jazz. By enabling this rich counterpoint of voices

${ }^{629}$ Quoted in Morton, Backstory in Blue, 188. 
Ellington was able, with the cooperation of his collaborators, to forge unity from diversity.

Even for Ellington's star soloists, a key wellspring of creativity in their jazz practice remains the ensemble; without the group, the soloist is denied a context in which to express his or herself through their music. The ensemble was also central to the aspects of Duke Ellington's work for which he is best remembered. It has been widely remarked that Ellington's band was his instrument. It is entirely possible that without such a group of individual and dedicated musicians Ellington would not be celebrated as a pioneering orchestrator, a cornerstone of his reputation. Ellington's collective compositional practice has been less widely discussed, but the essential contributions his sidemen made to his composing - an activity generally thought of as solitary - reveals the central planks of his reputation (composer, orchestrator, bandleader) depend upon the collaboration of others. Terry Teachout observes:

None of Ellington's contemporaries tried to sound like him. They played his songs and sang his praises, but that was as far as it went. Not only did they steer clear of literal imitation - which would have been impossible in any case - but they hardly ever tried to emulate his unique method of writing big band music conceived for performance by specific players with highly individual timbres. ${ }^{630}$

In this respect, it seems to me that Ellington's contemporaries (and their successors) were so dazzled by the products of his work (performances, recordings, songs and larger-scale compositions) that they failed to understand the significance of his processes. Viewing Ellington through the prism of his processes reveals them to be those consistent with principles identified as conducive to creativity: shared group goals; group improvisatory practice and the careful listening that attends it; a non-judgmental environment along with considerable freedom for the individuals involved; 631 a regular practice that allowed participants time to become adept at - and indeed to develop in their

630 Teachout, Duke, 213.

631 The non-judgmental aspects of Ellington's leadership are evident in his very relaxed approach to band discipline; the Ellington outfit was a notoriously ill-disciplined group that usually started late (in performance and in the studio), and usually without a full complement of musicians. Drug and alcohol abuse exacerbated this circumstance. It is remarkable the group achieved what it did given the personalities and behaviours involved. For example, see Teachout, Duke, 277. 
own approaches to - their assigned roles; stable personnel, also allowing the group time to establish different kinds of intersubjectivity; and a leader who identified combinations of players who were diversely gifted yet complemented one another.

In light of this, it is possible that Ellington's actions as a leader - a leader who enabled the kind of democratic, mutually constitutive relationships that made his band the celebrated unit it is - were his most significant creative acts. Ellington's recordings and scores are acclaimed, and rightly so, but I suggest his leadership style is his greatest legacy. Ellington's democratic musical context democratic because it encouraged all musicians to speak with their own voices reveals that individual workaday musicians can have the opportunity to have a profound impact on jazz without necessarily being ground-breaking innovators themselves. That almost none of Ellington's sidemen are now feted as having shifted the field of jazz, or even enjoyed successful careers independent of Ellington, reinforces this idea. Ben Webster, Louis Belson and Clark Terry managed to establish reputations as musicians and leaders independent of Ellington, but they are in the minority. Johnny Hodges, perhaps the most likely candidate of all of Ellington's collaborators, tried briefly to lead his own group (with acceptable results) before returning to Ellington's fold. Paul Gonsalves lead a few recording sessions, but remained a member of Ellington's outfit for the rest of his life. Billy Strayhorn, Cat Anderson, Harry Carney, Jimmy Hamilton, Juan Tizol, Sonny Greer, Ray Nance, Barney Bigard, Cootie Williams, Bubber Miley, Joe 'Tricky Sam' Nanton: all are remembered as fine, individual musicians. And all for the role they played in the Duke Ellington Orchestra. ${ }^{632}$

As Teachout suggests, very few subsequent leaders of mainstream large jazz ensembles have adopted Ellington's methods. Ellington is championed as a jazz composer, and innovator, but the egalitarian aspects of his large group practice have not been widely embraced. Band leaders and jazz composers have certainly prepared music that showcases the talents of their unique soloists (for

\footnotetext{
632 Bigard and Williams enjoyed reasonably high profile gigs with Louis Armstrong and Benny Goodman respectively, but it seems to me they are primarily remembered for their roles with Ellington. As it was, Williams (who left the band in 1940) returned in 1962 and remained until after Ellington's death.
} 
example, Benny Goodman's showcasing of Gene Krupa; Krupa's habit [once he had a band of his own] of placing the spotlight on Roy Eldridge; the way Fletcher Henderson prepared music that drew attention to Coleman Hawkins), or been celebrated for the unique combinations of players in their groups (Count Basie's 'All American Rhythm Section' for example), but almost none have allowed their ensembles as much licence in the music's actual creation as did Ellington.

Ellington was a leader utterly dependent upon the unique qualities of the specific musicians with whom he surrounded himself. Those musicians were dependent upon Ellington not only for their livelihoods, but also because he offered them a place to stand as unique musicians with something to contribute. As a postlude to this chapter, I offer a discussion of the musician who perhaps took this aspect of Ellington's practice most to heart, and whose music not only reveals evidence of Ellington's example, but also advances it in some dimensions.

\section{Postlude: Charles Mingus}

Bassist Charles Mingus was briefly a member of Ellington's working band, but the lessons he gleaned from Ellington - even before they played together in 1953 - were central to his working methods. Among the practices Mingus adopted in line with Ellington's example were an inclusive approach to composing, one that invited ideas from other band members. Britt Woodman recalled that the cooperative group 'The Stars of Swing', which included Mingus and performed from late 1945 through 1946, employed this working method in an embryonic form.

Each musician in it was leader conscious but at the same time maintained his feeling of individuality as a sideman. As a result, each idea that a musician put forward was treated with respect by the others and made use of. Charles Mingus, for instance, revealed power and an unusual concept as a jazz composer which the others encouraged him to develop [...] Often [he] would introduce a composition requiring a different approach to jazz playing.633

In 1955, by which point Mingus had been leading groups for a decade (his first recordings as a leader were made in 1945634), Mingus adopted Ellington's

633 Quoted in Priestly, Mingus, 29-30.

634 This date and subsequent recording details are drawn from the discographies included in Priestly's Mingus, 248-282; and from 'Charles Mingus Discography' (2001-2014), < http://www.jazzdisco.org/charles-mingus/discography/> (8 May 2014). 
example of teaching new compositions to his sidemen aurally, inviting the kind of indeterminacy that attended such a procedure.

Mingus was beginning to feel that the new material could be learned more thoroughly if the performers not only did not read any written music on stage, but memorized it from the start by ear alone. Not all of the many musicians who worked with Mingus in the next few years had the patience for this method, but few have disputed its efficacy in freeing (or forcing) them to interpret arranged passages in a more musical, and more personal way, rather than merely reproducing something fixed. [...] Mingus had become the first 'jazz composer' (as opposed to a tune writer such as Monk) whose pieces were not written down, and the first since Ellington whose definitive works were to any extent 'co-composed' by his sidemen. 635

The licence musicians were afforded by Mingus's compositional practice was not limited to the ways lines were phrased; it also included which notes were selected. Trombonist Jimmy Knepper recalled that when Mingus taught his musicians new music aurally from the piano, 'He would sometimes fake the fast runs and aim for the high notes, and you'd try to figure out what he was playing in between. He didn't want anybody to write out his parts. He wanted you to play like you just thought of it yourself, even if it wasn't exactly what he wrote.' 636

Such procedures are risky, and to ensure they yielded satisfactory results Mingus - like Ellington - was assiduous in seeking the right personnel (and mix of personnel) for his groups. His overbearing manner and draconian approach to some aspects of band leadership meant he had trouble keeping his groups together, but he was certainly motivated by a determination to have a mix of personnel who could complement one another in ways that enhanced the music. Dannie Richmond recalled that Mingus was always 'trying to find the right ingredients musically as he sought to populate his groups.' ${ }^{\prime 637}$ Such musicians needed to possess an individual sound or approach, and be able to respond in the moment to the music as it emerged. ${ }^{638}$

\footnotetext{
635 Priestly, Mingus, 66.

${ }^{636}$ Ibid., 77.

637 Ibid.

638 Ibid., 68; 85; 100.
} 
On the occasions when Mingus was able to assemble groups capable of playing his music in their own way, and in-the-moment, he was able to extend the example of Ellington. This advance on Ellington can be found in the way formal divisions were determined in Mingus's music. While Ellington's compositions reveal considerable formal variety and plenty of flexibility, as ensemble leader Ellington did make the determinations about what happened when, and for how long. ${ }^{639}$ Mingus, however, appeared happy for the duration of formal sections in some of his compositions to be determined collectively by the group as they were performed. On the 1956 recording 'Pithecanthropus Erectus', Mingus's use of 'extended form' (to use Mingus biographer Brian Priestly's term) meant that some sections of the composition were 'of indeterminate length, variable according to both the inspiration of the soloist and the rhythm section's decision to cue the next section.' 640 This approach can be heard earlier, on the 1954 recording of 'Eulogy for Rudy Williams' (which also made use of the same turnaround that provides the harmonic referent for the opening measures of 'Pithecanthropus Erectus'). ${ }^{641}$

By 1959 this collective approach to determining form had evolved to the point where Mingus's compositional approach involved 'dictating lines for each player, and leaving structure and orchestration to emerge spontaneously.' ${ }^{642}$ In this way Mingus surrendered overall control of the formal organisation of the composition to the group, allowing the ensemble to determine collectively the final shape of musical performances. As a result, the shape of compositions changed and evolved over the course of weeks and months of performances.

\footnotetext{
${ }^{639}$ Terry Teachout suggests, 'Ellington treated the sections of his compositions as if they were separate pieces in a mosaic that could be re-arranged at will [...] Later on he would bring unfinished, seemingly fragmentary bits of music into the studio, and then shift them around on the spot until he arrived at a sequence that satisfied him.' Teachout, Duke, 64.

${ }^{640}$ Priestly, Mingus, 69.

${ }^{641}$ Pianist Bill Evans, recording with Mingus in 1957 for the album East Coasting, followed Mingus's direction to extend the form by repeating the final measure of the tune 'Celia.' Evans was therefore performing on forms of in-determinant length before his work with Miles Davis on 'Flamenco Sketches' (1959, Kind of Blue). Given the close collaboration between Davis and Evans in the gestation of that album, it's possible that Davis's use of this device - one counted as a significant part of the revolutionary nature of Kind of Blue - was in fact one the trumpeter adopted third hand, from Mingus by way of Evans.

642 Priestly, Mingus, 100.
} 
Drummer Dannie Richmond recalled that aspects of 'Fables of Faubus' (including the vocal exchange between Richmond and Mingus) emerged spontaneously in performances. 'At that time', Richmond recalled, 'Mingus and I had a thing where if something of importance happened on the bandstand, we'd leave it in.' ${ }^{643}$ For example, it was with this (originally improvised) dialogue that the tune was recorded for Candid in 1960.644

Perhaps the most extreme form this kind of social authorship (to use Jason Toynbee's term ${ }^{645}$ ) took was on those compositions that emerged more or less entirely by means of collective improvisation on stage. One of Mingus's bestknown compositions, 'Better Git It In Your Soul', was generated in this way. Mingus recalled, 'We used to improvise with each other in the group. Jimmy Knepper and I would play it for a minute and play it [again] in the next set. 'Better Git It' was written on the bandstand. Not quickly, but over a period of time.'646 A similar approach led to what is probably Mingus's most celebrated ballad. Jazz arranger and pianist Sy Johnson recalled:

They were playing a very slow, minor blues, and, in the middle of the tune, a man came in and whispered to Charles that Lester Young had died. And his response was, immediately, to begin fashioning what became 'Goodbye Porkpie Hat' and, by the time they were finished, the germ of it was there. 647

Although Mingus is credited with this composition (as Ellington is for 'Sophisticated Lady'648), 'Goodbye Porkpie Hat' could not have been completed without the animating input of Mingus's sidemen.

643 Quoted in Priestly, Mingus, 87.

644 The four versions of this composition I auditioned possessed quite similar formal structures, although the tempos were markedly different, and the details at some points varied noticeably. In particular, the version on Mingus: Ah Um omits the vocals, although this was probably a result of Columbia Records discomfiture with the politically inflammatory lyrics rather than a spontaneously determined formal decision (See Priestly, Mingus, 119). The reasonably stable nature of the form in these different versions of 'Fables of Faubus' may be because once a piece had been in the band book long enough, it settled into a reasonably regular form. It would certainly be interesting to hear early versions of the tune in live settings.

645 Toynbee, Making Popular Music, 35-42.

646 Quoted in Priestly, Mingus, 87.

647 Ibid., 103.

648 Teachout, Duke, 114. Ellington's collaborators on this tune did not receive any compositional credit. 
Mingus performed Ellington's tunes, and like so many other jazz musicians sang his praises. However, unlike most other leaders in jazz, he also adopted the more radical, communitarian procedures Ellington modeled. In particular, he welcomed the contributions of his sidemen not only into performances of his music (which is quite normal in jazz contexts), but also into the arrangement and composition of that music (which was quite unusual). In this way both Ellington and Mingus conform to the principles of group creativity delineated by Keith Sawyer: both leaders offered their sidemen considerable freedom in the interpretation (and indeed creation) of their parts; both leaders selected a mix of personnel who complemented one another and the objectives of the group; both leaders created working opportunities that kept players in the group long enough for mutual understanding to develop within the group, and so further fuel their collaborative work. In addition, Mingus also required deep listening and in-the-moment playing from his men, and in this way was able to extend upon Ellington's example of collectively forged music in the jazz ensemble. This is principally evident in the manner in which Mingus's group collectively determined compositional forms in the course of performance.

Subsequently, other groups have adopted the kind of egalitarian practices that characterise both Ellington and Mingus's work. These include the large groups led by Butch Morris, Sam Rivers and the late work of Gil Evans. It is abundantly evident in the music of Sun Ra, whose practice possibly even advanced on the example of Mingus. ${ }^{649}$ Maria Schneider has incorporated aspects of Ellington's practice into her large ensemble music, although not (as far as I know) the social authorship properties of his work. However, none of these groups have produced music as influential as that of Ellington or Mingus. It seems to me that Ellington and Mingus had the capacity to find a balance between a leadership style that controlled the actions of their sidemen, and a leadership style that liberated sidemen to create music in their own way. ${ }^{650}$

${ }^{649}$ Perhaps The Magic City or Atlantis or The ESP recordings (The Heliocentric World of Sun Ra, Vol. 1 \& 2) if those were to be conceived as unified suites? See Jost's discussion in Free Jazz, 187 190.

650 This balance is a difficult one to manage. Ellington's remarkable forbearance of his sidemen's foibles meant that while his band frustrated him in the extreme at times, he was able to keep them corralled. Mingus was a much less charitable man and his intolerance of anything that fell 
Coupled with a willingness to embrace melody (wherever it came from), they were able to forge jazz music that was democratic not only in its delivery (which is more or less a characteristic of most jazz), but in its creation as well. It is this balance that invited a range of creativities into their work and has seen it abide as music of lasting significance. 


\section{Chapter Six: Jan Garbarek - Future Jazz}

'It was absolutely necessary for me to play the music my own way.'

Jan Garbarek 651

This thesis has suggested that a detailed exploration of creative processes rather than stylistic concerns - offers a different perspective on jazz practice. In this chapter I draw together the various threads I have woven through my case studies to propose some possible implications such a perspective might have for current and future jazz. To do so I suggest that Norwegian saxophonist Jan Garbarek's approaches to music making offer an example that is fertile for creativity, and perhaps indicative of a rich avenue for jazz creativity in the years to come. In order to make this argument I draw attention to Garbarek's fidelity to the three processes I have promoted as being central to jazz creativity over the past century: formation of an individual voice; improvised interactive ensemble playing; and the transformation and appropriation of musical materials outside of the accepted jazz tradition, as well as received materials from within the republic of jazz.

Because Garbarek's music draws from such a broad sweep of traditions including Scandinavian folk forms, jazz, traditional musics from around the globe and western art music - the syncretism of his approach is material in consideration of both the formation of his individual voice as a musician and the ways improvised interactivity is fostered and pursued within his ensembles. For this reason I will begin my examination of his music by speaking to the syncretic aspects of his practice and then turn my attention to his unique musical voice and the improvised ensemble strategies that have characterised much of his music making.

\section{Appropriation and transformation in Garbarek's practice}

Jazz musicians in Scandinavia and Finland have developed a unique take on jazz. One of the distinguishing characteristics of their music has been their level of

${ }^{651}$ Michael Tucker, Jan Garbarek: Deep Song, (Hull: University of Hull Press, 1998), 203. 
committed engagement with the folk traditions of their region. This practice has quite a long history in Scandinavia and Finland but perhaps first became widely known through the work of North American jazz saxophonist Stan Getz, who made his home in Scandinavia for a time. In 1951 while living in Sweden Getz recorded 'Ack Varmeland Du Skona' - a song accepted as part of the Swedish folksong tradition, a strong tradition that has been essayed since the first decade of the $19^{\text {th }}$ century. ${ }^{652}$

The approach Getz took with the song was to appropriate the traditional melody and modify the harmony so that it assumed a more or less conventional form for jazz performance and improvisation. Other musicians soon followed this lead, or perhaps became better known for this extant practice as a result of Getz having placed it in the public ear. Swedish pianist Jan Johansson is one of the most celebrated and widely known Scandinavian musicians to work in this space. Johansson performed with Getz in the 50s, abandoning his university studies to become a jazz musician. His album Jazz pa Svenska (recorded in 1964) sold more than 250 thousand copies - the best selling jazz album to be made in Sweden. ${ }^{653}$ For this album he followed Getz's lead of adapting regional folk material. However, the plainer harmony in use and unadorned context of the performances (only piano and bass) places Johansson's recordings closer in sound to their Danish folk sources than the music Getz made in a similar vein. Swedish and Finnish musicians have been internationally recognised for this kind of work, but it has also developed strongly in Norway, especially since the 1970s and perhaps in part as a result of the widespread acclaim Jan Garbarek has enjoyed for his work in this area. ${ }^{654}$

Appropriating folk sources to make new music is a familiar strategy to European musicians; in western art music traditions this practice has been referred to as nationalism - because the composers who have employed it have

652 Swedish folk music collection began formally with the establishment of Götiska Förbundet (The Gothic Society) in 1811. The journal of the society, Iduna, published scores from 1813.

${ }^{653}$ Heptagon Records (no date), <http://www.heptagon.se > (15 May 2014).

654 Swedish musicians Lennart Aberg and Bobo Stenson and their group Rena Rama have explored this terrain. Finns including Edward Vesala and Juhani Aaltonen have drawn from folk sources. Recently Norwegian saxophonist Trygve Seim - who has been significantly influenced by Garbarek - has worked in this vein. 
made use of musical materials that are indigenous to particular national or ethnic groups. An early adopter of this practice was Frederich Chopin. Others include Mikhail Glinka, Bedřich Smetana and Antonín Dvořák.

There is an extensive literature addressing nationalism in nineteenthcentury music, much of which is not particularly germane to the discussion of folk appropriations in jazz music in the twentieth and twenty-first centuries. ${ }^{655}$ However, and usefully for my purposes, Michael Murphy suggests that the techniques and processes of nationalistic music differ from country to country and in fact from composer to composer. ${ }^{656}$ This constructive basis offers a foundation from which to proceed in a discussion providing background to Jan Garbarek's music.

In the twentieth century Hungarian composer Béla Bartók is well known for his work in transforming folk materials into art music. Bartók is a useful source in this context because he theorised his work in interesting ways. This usefulness is not reflective of any deep-seated correlation between his work and that of Garbarek. However, in Bartók and Garbarek we find two musicians whose creative practice was fueled by musical materials drawn from the folk traditions they encountered. Both made these kinds of appropriations without apparently considering the thorny issues around such appropriation or (in Garbarek's case) the complex discourses that attend the phenomenon. It may be that Bartók and Garbarek were thinking about this practice in similar ways, and in this there are similarities in their creative achievements.

In his essays Bartók identifies three strategies composers may employ to transmute so-called peasant music into what he termed modern music: 657

\footnotetext{
${ }^{655}$ For example, musicologist Carl Dahlhaus is critical of the term 'nationalistic music' being attached only to music that draws on folk sources; he argues that all late nineteenth-century European art music is nationalistic in some ways. (See "Nationalism in Music" in Carl Dahlhaus, Between Romanticism and Modernism: Four Studies in the Music of the Later Nineteenth Century (Berkeley: University of California Press, 1980), 79-102.) While that may be the case, my concern is not with the categorisation of nineteenth-century European art music but rather is focused on understanding folk appropriations by jazz musicians. In this light Dahlhaus's argument is not especially relevant to my purposes.

656 Michael Murphy, 'Introduction', in Harry White and Michael Murphy (eds.), Musical Constructions of Nationalism: Essays on the History and Ideology of European Musical Culture, 1800-1945 (Cork, Ireland: Cork University Press, 2001), 12-13.

657 Béla Bartók, 'The influence of peasant music on modern music' in Béla Bartók Essays, ed. Benjamin Sichoff (Lincoln: University of Nebraska Press, 1976), 340-344.
} 
1. A peasant melody provides raw material for a new composition:

a. Original melody used without alteration, with the addition of a harmonised or re-harmonised background; an introduction or coda may in some cases be added.

b. Original melody serves as a seed around which the musical edifice is built - although the musical qualities of the setting are derived from qualities evident in the melody.

2. The composer doesn't make use of original peasant melodies but composes new melodies that imitate peasant melodies. In Bartók's view there was no real difference between this and the first method, perhaps because both are primarily concerned with pitches and tonal forms. 658

3. The composer doesn't use or imitate peasant melodies, but rather allows 'the atmosphere' of peasant music to characterise their composing. In these cases, the composer has 'become completely absorbed in the peasant idiom'.

Musicologist Richard Taruskin suggests the third category - because it imposes the fewest limits - is also the site for greatest creativity. Taruskin identifies practice that corresponds to Bartók's third category in the work of Russian composer Igor Stravinsky and describes it as neo-nationalism - an 'adoption from folklore not of thematic material but of style characteristics, abstractly conceived.' 659

Bartók composed both nationalistic and neo-nationalistic music (to use Taruskin's expression). In doing so the country he invoked was not the real Hungary - the domain that lies between Bulgaria and Turkey - but rather

\footnotetext{
658 Bartók, 'The influence of peasant music on modern music', 342.

659 Richard Taruskin, Music in the Early Twentieth Century: The Oxford History of Western Music, Volume 4 (Oxford: Oxford University Press, 2010), 378.
} 
Bartók's imagined Hungary, evoked using a combination of raw musical materials drawn from the countryside of the Austro-Hungarian empire, combined with Bartók's modern musical technique, derived from his schooling in the Germanic tradition. ${ }^{660}$ For Taruskin, Bartók's imagined Hungary was different from the imagined Hungary of his predecessors. ${ }^{661}$ Those predecessors include composers Mihály Mosonyi, Franz Erkel and Franz Liszt, and the folk or 'peasant' materials they appropriated were drawn almost exclusively from the Magyar or gypsy traditions of Hungary. Mosonyi, Erkel and Liszt's nationalistic music was described as being in the Magyar nota style, but the imagined Hungary that music evoked was a very circumscribed one - one delimited by the culture of the Magyars. ${ }^{662}$

In contrast, Bartók's music - at least that of his own 'imagined Hungary' drew on a wider range of ethnic sources, although still sources found within the political borders of the Austro-Hungarian empire. As well as the style of the Magyars - the so-called 'Gypsy style' - Bartók also studied and assimilated into his creative work the music of the people of 'greater Hungary': Romanians, Slovaks, Bulgars, Croats and Serbs, all of which were found within the state.

There are two points I will make that link Jan Garbarek's work to that of Béla Bartók. The second point pertains to the extremely catholic nature of Garbarek's musical borrowing. First, however, I will speak to the ways Garbarek's musical practice traverses the approaches Bartók delineates in his discussion of how folk traditions have been employed by composers. In fact all three of Bartók's categories are present in Garbarek's recorded music.

\section{Traditional melodies re-arranged:}

On his 1975 album Dansere, Garbarek included the composition 'Lokk', a traditional Norwegian cattle call attributed to Thorvald Tronsgård (although it is

\footnotetext{
660 Bartók also travelled more widely to collect musical materials including to Algeria and Scotland.

661 Taruskin, Music in the Early Twentieth Century, Vol. 4, 374-375.

662 Ibid., 367-369.
} 
not clear if Tronsgård composed the piece). For the recording (and presumably in live performance) Garbarek played the song's melody couched in a jazz-like setting with a repeated strophic form that provides a clear harmonic basis. ${ }^{663}$ Where most jazz performances make use of a regular pulse, Garbarek and his group retain the rubato performance style that characterises performance of calling songs (Lokk is also the generic term for a song used to call farm animals in Norway) in their original settings. ${ }^{664}$ In this way aspects of both Norwegian folk and jazz practices are evident. Garbarek has said:

I haven't got any special grounding in folk music; I play the old melodies in a quite untypical way. The purists may have their doubts, but it was absolutely necessary for me to play the music my own way. If I'd wanted to play the material in the traditional way, I would have had to practice forever, without necessarily ever managing it, even after twenty years. 665

The 'quite untypical way' Garbarek refers to is probably partly attributable to the rhythmic phrasing he applies to the melodic lines - which draw lessons from jazz - but almost certainly also refers to the provision of a harmonic background and the instrumentation employed. Further, the way Garbarek opens up of pieces to accommodate improvisation - pianist Bobo Stenson plays an improvised solo on the recording of 'Lokk' for example - is a characteristic of jazz rather than the traditional settings in which such music was played.

Similar transformations are evident on the recording Garbarek made with Norwegian folk singer Agnes Buen Garnås. Their collaborative album Rosenfole (1989) showcases Garnås performing ancient songs from Norway, with backgrounds and improvised melodic obligati provided by the saxophonist, who doubles on keyboards and percussion. The results, with regularised tempi, repetitive rhythmic parts (performed on percussion instruments), explicit and shifting harmonies and improvised solos, manage a rapprochement amongst

\footnotetext{
${ }^{663}$ In the absence of a recording of the original I don't know if Garbarek has modified the original melody. However, the CD liner notes to Dansere suggest Garbarek arranged the music. In other instances where Garbarek is credited as arranger (for example, 'Pygmy Lullaby' on Visible World, ECM1585, 1996) the melodies appear to be quite faithfully reproduced, but with alterations applied to the harmony and formal organisation.
}

${ }^{664}$ A Norwegian song, also called 'Lokk', but performed by Kari Rueslåtten in a more traditional manner can be auditioned on: Storm, Nordavind (Norway: Moonfog Productions, 1995). Other examples I auditioned also reflect this rubato delivery.

665 Tucker, Jan Garbarek, 203. 
medieval song and contemporary jazz practice while creating music that offers an advance both: I know of no other music that sounds quite like this album.

\section{New music that imitates the characteristics of peasant music:}

For his 1981 album Eventyr Garbarek consciously composed new music modeled on traditional Norwegian music. In preparing for these recording sessions Garbarek spent time listening to a range of Norwegian folk music archived in the Det Norske Studentersamfund collection, in Oslo. Judging by Garbarek's comments about these recordings, it appears that he was seeking to understand the generalisable musical features of Norwegian folk music in order that they inform his own writing. He observed: 'I haven't spent that much time researching the old Norwegian melodies [...but] there is something special about them - they are not so Europeanised as Danish material, for example. There's a strong Balkan flavor, lots of scales with minor thirds; you find similarities to the Greek modes, particularly the Lydian.'666

It seems to me that in drawing from this traditional Norwegian music, Garbarek not only found melodic raw material, but also gained a sense of the music's essential ordering. To my ear, aspects of this music are reproduced in Garbarek's subsequent compositions. The sombre, rubato musing of 'Soria Maria' (named for a Norwegian fairy tale castle, and which recalls Norwegian laments such as 'Tre bånsullår frå Lom'); the playful children's song 'Lillekort' (reminiscent of jaunty Norwegian melodies for children such as 'Pål Sine Honer', or the folk theme 'Syndebukken'); the legato, melancholy lines of 'Once Upon A Time' that play out over the up-tempo rhythm section parts (making use of a compositional strategy evident in Norwegian songs such as 'Danse, ikke grate na' ${ }^{667}$ capture some of the shades Garbarek was able to mine from the traditional music of his homeland. This is not traditional Norwegian folk music -

\footnotetext{
666 Tucker, Jan Garbarek, 203. Given the political historical relationship between Norway and Denmark, the view Garbarek expresses here might be somewhat coloured by that context.

667 'Danse, ikke grate na', 'Pål Sine Honer' and 'Syndebukken' can be heard on Lief Sorbye's Folk Music from Norway (Oslo: Arc Discs, 1998). 'Tre bånsullår frå Lom' is found on Brimi, Has \& Barthelemy, mary \& Faukstad, Jon, Norwegian Folk Music (Oslo: JPS Records, 2009).
} 
the music gains additional nuance from the textural and harmonic commentary of North American jazz guitarist John Abercrombie, and the pliant, animating percussion and gravelly vocalising of Brazilian percussionist Nana Vasconcelos but nevertheless, something of the music's Norwegian provenance remains.

\section{The atmosphere of peasant music characterises the new music:}

Richard Taruskin suggests that neo-nationalistic musical practice - which makes use of abstractly conceived style characteristics and so captures 'the atmosphere' rather than the stylistic details of the folk musics from which it derives - offers composers the greatest scope for creativity. The music that emerges from such processes is also perhaps the most difficult to link explicitly to the ethnic or folk sources from which it is thought to have arisen. In part this is because of the abstraction to which the styles have been subjected, but also because 'atmosphere' is difficult to pin down in any objective way. In light of this, characterising music as belonging to this, Bartók's third, category is a somewhat subjective exercise. I think however, it is reasonable to describe much of the music on Jan Garbarek's 1976 album Dis as belonging to this category.

Garbarek's playing on Dis - on flute as well as tenor and soprano saxophones - is generally quite diatonic, although the scales to which the lines demonstrate their fidelity are not all related to the Ionian mode. This diatonicism is perhaps attributable the folk ideas he mined for this record. For Michael Tucker, 'the six pieces conjured a primal, shape-shifting world strongly redolent of Nordic landscape and myth,' music marking Garbarek as 'a musician of the North.'668 The most striking aspect of this music with regard to atmosphere is the soundscape created through the use of wind (or Aeolian) harp, and which provides a sonic bed for Garbarek's (and guitarist Ralph Towner's) playing (heard to good effect on 'Vandrere', and on the title track). This sonic bed enhances a kind of spacious, oceanic quality in the music and also seems to amplify the isolation of the saxophone and guitar - placing them as solitary actors (even when playing together, they seem somehow alone) in a

668 Tucker, Jan Garbarek, 171-172. 
wide-open acoustic field. The expression 'The Idea of North' has been attached to music recorded for ECM, the record label for whom Garbarek has primarily recorded (including this album); 'The Idea of North' is the subject of an essay in the lavish 2007 book Horizons Touched that surveys the trajectory of ECM records to that point. For me, and for reviewers as well, the music on Dis seems to reify that notion, presenting as it does apparently solitary characters in an otherwise barren expanse. ${ }^{669}$ Reviewer Tryan Grillo for example, suggests the wind harp 'anchors the album into place' - perhaps in a somewhat literal manner given the wind harp was captured in a field recording - as does the sombre brass ensemble, which adds colour during 'Skygger'.

Slotting examples of Garbarek's music into Bartók's three compositional categories usefully reveals different facets of the saxophonist's practice. However, in some ways it seems a little false to try to characterise these performances as belonging exclusively to one discrete category or another. Instead, and to my ear, each of these performances might belong at different points along a continuum; a continuum that begins with simple adaptation of extant folk music, and ends at a point where only abstracted style features of such music remain, although with sufficient recognisable features to still be linked to those traditional sources. Such a continuum might be useful when considering the music Garbarek made with Tunisian oud player Anouar Brahem and Pakistani percussionist Ustad Shaukat Hussain on the album Madar.

Madar offers a fascinating fusion of Arabic classical music, jazz, and extant melodic and rhythmic practices associated with traditional music from Scandinavia, from South Asia, and perhaps from North Africa as well. For example, Brahem's fleet ground figure, played at what seems an impossibly fast tempo sounds in striking contrast to Garbarek's dark tenor ruminations on

669 For Tryan Grillo, 'We are never just listeners, but wayfarers in its deeply internal landscape, where space is no longer a viable marker of location...'

<http://ecmreviews.com/2010/12/17/dis/> (14 May 2014); Cook and Morton's Penguin Guide to Jazz identify this album as belonging in an core jazz collection (p. 475). Such solitariness is one of the themes of pianist and composer Glenn Gould's fascinating radio documentary contemplating his native Canada's northern clines: The Idea of North. The opening minutes of the show feature a montage of voices that convey this very effect - of actors in an open space whose talk occurs concurrently yet independently, as if isolated from one another despite their proximity. Glenn Gould, 'The Idea of North', Canadian Broadcasting Company,

<http://www.cbc.ca/player/Radio/More+Shows/Glenn+Gould++ The+CBC+Legacy/Audio/1960s/ID/2110447480/> (14 May 2014). 
'Ramy.' On 'Qaws' - where Garbarek offers a sweetly diatonic melody so resonant of the folk lines he has appropriated from his homeland elsewhere on the album (on 'Sull Lull' and 'Joron') - the addition of Hussain's tabla introduces what might be a South Asian rhythm grounding that frees the saxophonist to improvise in a vein of a piece with the composition's melody, and has Brahem improvising in a style informed by the Arabic music he more commonly plays. 670

At first brush, this music - possessing as it does qualities drawn from Scandinavian, North African and South Asian musical traditions - might belong in Bartók's second category: it sounds like new music composed in the style of extant traditional music. But (and with due respect to Carl Dahlhaus) given what sound like generalisable and somewhat abstracted characteristics of the three quite distinct musical traditions that are invoked here - and in light of the surprising combination enacted - it may be more reasonable to locate this music in Bartók's third category. Even as this performance does not sit comfortably in any one place in Bartók's taxonomy, so the entire album seems to traverse different points between these discrete categories, tracing the kind of continuum I am suggesting might be a fruitful metaphor to describe Garbarek's practice generally. ${ }^{671}$

The kind of inclusive musical world found on recordings like Madar lead us elegantly to the second parallel I want to draw between Bartók's work and that of Jan Garbarek: the extremely broad musical palette Garbarek draws from in his music making. Garbarek demonstrates a remarkably catholic taste in the

\footnotetext{
670 For example, perhaps Brahem's performance approaches are drawn from the Arab classical music he played with the Musical Ensemble of the City of Tunis in the 1980s (such as 'Rabeb' or 'Andalousiat'). The tabla rhythms Hussain uses on this track emphasise a fast ' 6 ' - not unusual in Hindustani classical music - although the accents are different from those in common Dadra configurations.

${ }^{671}$ It seems to me that Garbarek has followed Bartók's example with regard to that composer's use of traditional materials. Bartók's three categories could be read as an invitation to composers to appropriate music from the folk traditions around them. In Bartók's case this included a wide range of cultural sources present in his home state, but also from farther afield. Garbarek has extended this practice still further (following Don Cherry's example - see below) by inviting music from all parts of the world into his music making, including cultures with which he is basically unfamiliar (see his comment below about the Pakistani musicians with whom he recorded in 1990 on Ragas and Sagas [ECM]).
} 
music he incorporates into his practice. ${ }^{672}$ In this regard, Garbarek's music differs somewhat from current jazz orthodoxy.

The great example to Garbarek with respect to this musical border crossing was jazz trumpeter Don Cherry, and I think it's Cherry's vision that Garbarek has adopted and developed. Cherry came to international attention as a jazz trumpet player working with Ornette Coleman in 1959 and 1960. After ending that association, Cherry's music evolved beyond Coleman's harmolodic approach to embrace the music of all the cultures he encountered. He has been described variously as a 'no-borders spirit making no-borders music', and 'a planetary griot producing a grassroots poly-cultural mash-up'. ${ }^{673}$ Cherry travelled the world integrating aspects of Indian, African, native-American, Far Eastern and European instrumentation, scales and rhythm into his music. Michael Tucker claims 'Cherry was always open to new musical experiences and always keen to synthesise aspects of those experiences, in light of his belief that the 'capacity for unity is one of the prime elements that jazz music has always had.' 674

Living in Scandinavia in the late 1960s Cherry was to have a significant impact on the musical thinking of the young musicians he came into contact with, including Jan Garbarek, who said:

It was Don who first got us interested in our own folk music, who made us realise how much there was to check out in our own backyard. We were to make a radio broadcast once, and Don asked us if we couldn't perhaps play a Norwegian folk tune. That wasn't exactly what we young Norwegian jazzers were into at the time. But we came to change. 675

Now we knew quite a lot of the folk musicians, and would hang out with them in the clubs in Oslo, but the idea of playing together hadn't arisen. At Don's insistence, one was contacted, a lady singer, and she came to the radio studio.

\footnotetext{
${ }^{672}$ Such syncretism, in drawing from so diverse a range of cultural sources, can also be read as an acceptance of those cultures and the people who inhabit them. This is the liberal, utopian aspect of Bartók's music Taruskin identifies, and that I believe is to be found in the music of Garbarek. Garbarek's willingness to treat all musical cultures he encounters as equally valuable saw him win the Paul Robeson prize in 1992. The committee awarding the prize suggested that the border-crossing nature of Garbarek's work had encouraged contact between cultures and thus helped combat racism. See Tucker, Jan Garbarek, 254.

${ }^{673}$ Brian Morton, 'The Primer: Don Cherry', Wire 353 (July 2013), 40.

674 Tucker, Jan Garbarek, 118.

675 Ibid., 119.
} 
Nothing at all was prepared beforehand, Don just organized everything in the moment, very smoothly and easily, and we played - and the combination of folk music and improvising sounded so right to me. I think from that moment on, the idea of having folk music aspects or folk musicians involved in this music was always there in my mind. ${ }^{676}$

Garbarek, in following Don Cherry's pluralistic lead, is making music that sounds somewhat different from much mainstream jazz, but nevertheless remains faithful to a process that valorises appropriation and transformation, a process that has characterised jazz from its earliest manifestations. I will turn now to the other two processes I have drawn attention to in this thesis and discuss their presence and significance to Garbarek's work.

\section{Individual Voice}

It is widely acknowledged that Garbarek has an individual voice. There are two aspects of Garbarek's voice - his musical persona, if you will - that I wish to draw attention to: his distinctive sound; and the aesthetic agency (to use Ingrid Monson's expression) he has engaged in developing a unique approach to playing and improvising.

In terms of the sound Garbarek produces, the BBC described his playing as possessing 'one of the most distinctive and immediately recognisable tones in jazz.' 677 It is a sound that emerged from his early infatuation with John Coltrane's music, and that was subsequently informed by his close study of Archie Shepp, Albert Ayler, Coleman Hawkins and Lester Young. Michael Tucker has suggested that, 'In terms of the jazz tradition [...] Garbarek has been able to synthesise the 'hot' approach of Hawkins with the 'cool' approach of Young. Certainly, Garbarek is a musician whose sensitivity to the inter-relation of sound and phrasing has led to a remarkable range of fresh inflections and development of the saxophone's potential as an expressive instrument.' ${ }^{678}$ That range of inflection

\footnotetext{
676 Paul Griffiths and Steve Lake, Horizons Touched (London: Granta, 2007), 22. In the hands of some musicians a strategy like Garbarek's, of adopting local folk sources, might be seen as a reactionary move. When asked about this, Garbarek suggested that appropriation of these musical resources in contemporary Norway was in fact a radical move. (See Solothurmann, quoted in Tucker, Jan Garbarek, 203)

$677<$ http://www.bbc.co.uk/radio3/jazz/profiles/jan_garbarek.shtml> Retrieved July 25, 2013.

678 Tucker, Jan Garbarek, 62.
} 
can be heard to good effect on Garbarek's 1977 recording as a member of the Keith Jarrett quartet, My Song. On 'The Journey Home' his tenor sound and phrasing ranges from: the muscular opening rubato statement, reminiscent of John Coltrane's sound with a dark tone that emphasises the lower register, coloured by a light and controlled vibrato; to the more plangent, slightly nasal sound he makes use of as he plays the composition's main theme in unison with Jarrett's piano and with a kind of jaunty phrasing that emphasises the dance-like qualities of this passage; through the more pensive playing of the third theme, an out-of-time waltz that succeeds the reprise of the main theme with the same plangent quality as the playing in the main theme but with more hesitancy and an inquiring quality; through the reflective, soft (and sub-toned in places) and tender playing of the dénouement. For jazz trumpeter and commentator Ian Carr, Garbarek's playing with the Jarrett group revealed his 'extraordinary tonal qualities - the subtlety and variety of inflexions, timbres and ways of articulating notes.' Together, these 'give his playing a most affecting eloquence.'679

Across his career, Garbarek's sound has traveled wider pathways than those traversed with Jarrett's group. Witness the powerful glossolalia in evidence on 'Beast of Kommodo' (Afric Pepperbird, 1970), testimony to the saxophonist's interest in late Coltrane (circa. 1965) and the music of Albert Ayler. Or, at another extreme, the almost impossibly tender obligati he adds (on soprano saxophone) to 'We Are Stars' (from Rites, 1998). To be sure, Garbarek has tended to the more ruminative end of this spectrum in his mature work, but having mastered such a range of sounds on his instrument he has cherry picked a handful of signature sonic devices - including the muscularity of sound he developed as a result of his Ayler studies, if not the abandoned dissonance of Ayler's music - that make his music immediately recognisable to knowledgeable listeners.

In terms of performance strategies, Garbarek has applied his evolving personal sound to a number of idiomatic traditions, thus exercising aesthetic agency in developing a distinctive individual approach. The most prominent of these idioms evident in Garbarek's aesthetic is jazz, which has offered his music

${ }^{679}$ Carr, Keith Jarrett, 77. 
an emphasis on improvisation, rhythmic pliancy and a range of vocally oriented sounds. Perhaps the second most important resource for Garbarek has been Scandinavian folk sources, which have contributed an emphasis on melody, clarity and space to Garbarek's music. In addition however, he has drawn ideas from continental Indian music (the snaking melismatic lines of 'All India Radio' on Dansere), Eastern European music (Greek composer Eleni Karaindrou felt she heard a strong Balkan quality in Garbarek's playing; for Karaindrou, his performance style 'brings the 'Greekness' from my Soul'680), early church music (perhaps the hymn-like cadences of Aftenland or his meditative work with the Hilliard Ensemble), aspects of Western art music (his collaborative work with Georgian composer Giya Kancheli, for example) and rock (as heard in his performances on Terje Rypdal's Bleak House ${ }^{681}$ ). It seems to me that Garbarek's procedures involve adopting methods and contexts from outside the jazz tradition and finding ways to adapt his performance and improvisational approaches to those contexts. Such appropriation, adaptation and eventual transformation (the final music is always somewhat different from the any of its constituent parts) can be heard to good effect on Madar. In this, and many similar instances, Garbarek has created new music (or new knowledge) by synthesising material from different sources and with collaborators from different traditions.

There are two consequences that emerge from these kinds of combinations. First, Garbarek subtly affects the traditions into which he injects his sound and playing (even if only in the context of that performance or recording). Second, Garbarek's own procedures and approach are affected by exposure to and participation in those traditions. That is to say, his individual voice is, in part, an emergent quality of these inter-traditional combinations. Just as Garbarek's practice ranges across a broad spectrum of activity, so it also includes a range of creativities. He has been justly feted as a groundbreaking musician, and the innovative music found on albums such as Madar or Ragas and

\footnotetext{
${ }^{680}$ Karaindrou, quoted in an ECM press release. Jan Garbarek (no date), <http://www.worldmix.nu/2007/documents/garbarek_bio.pdf> (15 May 2014).

681 Terje Rypdal, Bleak House, (Oslo: Polydor, 1968).
} 
Sagas provide evidence of combination creativity that meets the criteria for exclusively-defined creativity - it is novel, and it is useful (in all kinds of ways: it sounds good; it suggests fertile avenues for further inquiry; it has sold reasonably well; it has enjoyed positive critical reception).

Not all of Garbarek's music is groundbreaking however, but in almost all cases (that I have encountered) has managed to create a basis from which he has projected his quite identifiable musical voice into the world. An album such as 1975's Dansere does not, to my ear, cover any particularly new ground relative to is predecessor Witchi-Tai-To (1973) but nevertheless contains affecting music that is performed with considerable conviction. Or take Garbarek's tenor sound, perhaps the most noted aspect of his music making during the 1970s (and beyond?). This sound strikes me as largely emulative of John Coltrane (circa 1964) with a dash of Albert Ayler and soupçon of Archie Shepp thrown in for good measure. Perhaps this is a modest form of combination creativity and as such offers something new to the world? I would be more inclined to characterise it as personal creativity that, while not all that original, still achieves the communicative threshold that might place it firmly within the parameters of Negus and Pickering's inclusive definition of creativity. In these ways the products of Garbarek's work meet the twinned criteria for creativity exclusive and inclusive - as adopted in this thesis.

\section{Improvised interactivity}

The third vital area in which Garbarek demonstrates fidelity to the procedures that have animated jazz across its history is in his adoption of an open, collaborative, improvisational approach to music making. This approach is particularly evident in the inter-traditional contexts in which Garbarek has worked, and where he has been happy to operate as an equal partner with his collaborators. His recordings with classical organist Kjell Johnsen; with Brazilian guitarist, pianist and composer Egberto Gismonti; with Qawwali vocalist Ustad Fateh Ali Khan; with Norwegian folk singer Agnes Buen Garnås, and numerous others are all co-credited. Garbarek's approach in these circumstances exemplifies music making as collaboration among equals; it's not a leader imposing his artistic vision on those with whom he is working. Even Keith Jarrett 
- a musician not noted for his humility - said of the group he operated with Garbarek during the 1970s, 'I'm working with a quartet, but it's not mine. It's a special event ... it's billed as Belonging - my name, Belonging, and everybody else's name ... it's not the Keith Jarrett Quartet.'682

The very collaborative nature of Garbarek's work in recent decades has been widely noted by commentators. The music he made with Tunisian oud player Anouar Brahem and French-African drummer Manu Katche was described by jazz writer Josef Woodard in this way: 'The distinctive ethnic imprints of the players weave together without forcing the cross-cultural issue or diluting the integrity of the parts [...] Garbarek's work, especially of late [circa 1993], is tantamount to an argument for universality. Here, Norway and the Middle East sound like neighbours with a common cause.' ${ }^{683}$ Magico - the trio that Garbarek formed with jazz bassist Charlie Haden and Brazilian guitarist Egberto Gismonti - operated according to similar imperatives, and Garbarek's biographer Michael Tucker associates that egalitarian collaboration with the group's creativity: 'The point of the [...] trio was not to play American, Norwegian or Brazilian music in the hope of demonstrating each musician's ability to play the music of the others' countries with full historical "authenticity", as it were. The point was to make creative music.'684 The album Ragas and Sagas, which Garbarek recorded in 1992 with Ustad Fateh Ali Khan and a group of Pakistani musicians, is a perfect example of this kind of leaderless collaboration. Garbarek said, 'The other musicians didn't have any English or Norwegian, and I didn't know any Urdu. We were only able to play together and things went fine.' 685

682 Quoted in Carr, Keith Jarrett, 88.

${ }^{683}$ Woodard, quoted in Tucker, Jan Garbarek, 238. This was a touring group in the early 1990s that did not record as a trio.

684 Ibid., 242.

685 Ibid., 256. The kinds of trans-traditional work Garbarek has engaged might place his music in a 'World Music' (or perhaps more accurately 'World Beat') category. The kind of border crossing evident in this sort of collaborative (or appropriative, in some cases and depending upon the view one adopts) work has been the subject of intense critical debate at least since the 1980s. There appears to be a complex nest of issues embedded in this debate, and plenty of contradiction. As Steven Feld observes: 'When James Brown breaks down complex African polyrythms and incorporates them into dense funk/soul dance tracks, we don't speak of a powerful Afro-American star moving in on African musical turf. Ten years later, when Fela 
Garbarek sees playing together as the means to creating dialogue. He said: 'I always thought, the important thing is for me to play with a musician, no matter where he comes from. If I feel in some way connected to his playing, then we can have a dialogue.' ${ }^{686}$ It is this open musical dialogue - a dialogue that in almost all cases requires improvisation - that has been a cornerstone of Garbarek's creative practice. ${ }^{687}$ Such improvisational dialogue has ranged from qualified to unconditional. An example of a qualified dialogue can be found in his work with composer Giya Kancheli, on the composition 'Night Prayers'. In some ways an outgrowth of Garbarek's performances with the Hilliard Ensemble (who sing medieval music while Garbarek improvises lines around and through their songs) on the 1994 album Officium, 'Night Prayers' finds a middle ground between a composed concerto and the improvisational practice that is Garbarek's home turf.

Initially reluctant to write parts for a player he recognised as one 'who creates something of his own and does it very exactly and very subtly,' Kancheli eventually arrived at a detailed score for soprano saxophone that incorporates a 'window' in which Garbarek can improvise. 'Night Prayers' [...] thus stands as a departure for both composer and player. Garbarek, whose role on Officium had been improvisational, is confronted with notated contemporary music while

Anikulapo Kuti seizes the essence of the James Brown scratch guitar technique and makes it the centerpiece of his Afro-Beat, we don't speak of a powerful African star moving in on AfroAmerican turf. The economic stakes in this traffic are small, and the circulation has the revitalization dynamic, of roots. But when the Talking Heads move in on both James Brown and Fela Anikulapo Kuti and use scratch, funk, Afro-Beat and jùjú rhythm as the basic grooves for Remain In Light, something else happens. The economic stakes - however much attention is drawn to the originators as a result - are indeed different, the gap between the lion's share and the originator's share enlarged, and the discourse of race and rip-offs immediate and heated.' ('From Schizophonia to Schisomogenesis: The Discourses and Practices of World Music and World Beat', in The Traffic in Culture: Refiguring Art and Anthropology, ed. George Marcus, Fred Meyers [Berkeley: University of California, 1995], 106-107) What are we talking about here? Is money what is really at issue? Or the commodification of otherness? (Ibid., 122). While these issues are important, they seem tangential to the specific questions I am raising for Garbarek. I do find Homi Babba's assertion that it is in the interstices between groups, their cultural materials, and their cultural practices, that cultural expression finally emerges (The Location of Culture [New York: Routledge, 1994], 3-5). This strikes me as a fruitful place to begin considering trans-cultural combination creativity.

686 Griffiths and Lake, Horizons Touched, 52.

687 And it is this basic perspective that suggests the potential of his approach for trans-cultural combination creativity, rather than one of appropriation and assimilation. In terms of the discourses of jazz, Garbarek has claimed that the only element of jazz that he has retained in his music is improvisation. This would certainly appear to be the case with the music he performs with the Hilliard Ensemble. See Tucker, Jan Garbarek, 278. 
Kancheli permits the soloist considerably more leeway than is the norm in his pieces. 688

In this case a two-way musical dialogue was one enacted between Kancheli and Garbarek in the preparation of the score. In performance the dialogue is limited but accommodated improvisation; the orchestral musicians remained faithful to their parts while Garbarek improvised soliloquies in response to those parts.

In more straight-ahead jazz contexts (the quartet with Bobo Stenson, Palle Danielsson and Jon Christensen or the music he made with Keith Jarrett) improvisational dialogue has been more complete, and is found not only in solos but also extends to arrangements and formal organisation of the music. The first recording of Jarrett's so-called European quartet, Belonging, ${ }^{689}$ was completed in a single session that was - for Jarrett's biographer Ian Carr - 'effortlessly inspired, largely because of the tremendous rapport' within the group. In concert performances by this quartet the music was different from night to night, 'not merely a rehash of the recorded music, but something fresh growing out of it'. It was music that offered 'new ways of combining freedom with coherence, fresh relationships between composition and improvisation.' 690

In the inter-traditional groups with which Garbarek has worked, collaboratively determined improvisational approaches have been essential and play a constitutive role. Although in some cases there has been music prepared before sessions (for example, in the Magico group, the music was composed by each of the three principals), generally the music recorded emerges as a result of improvisation amongst the musicians working from sketches. ${ }^{691} \mathrm{~A}$ key to the success of such improvisational approaches has been openness, connection and dialogue.

Garbarek's collaborative practice is one that has seen him not only introduce new sounds to the world - there is nothing else in the catalogue that sounds quite like Rosenfole or Aftenland, like In Praise of Dreams or his

\footnotetext{
688 ECM press release, Jan Garbarek. (no date)

<http://www.worldmix.nu/2007/documents/garbarek_bio.pdf> (15 May 2014).

${ }^{689}$ Keith Jarrett. Belonging (Muinch: ECM, 1974).

690 Carr, Keith Jarrett, 76-78.

${ }^{691}$ For example, much of the music on Madar. See Tucker, Jan Garbarek, 238.
} 
collaborations with Keith Jarrett - but also achieve a level of communication with his fellow musicians and with his audiences that has made his music a popular draw all over the world.

\section{Jan Garbarek and Future Jazz}

For the purposes of this thesis I have invoked two definitions of creativity: an exclusive definition that emphasises products that are both novel, and useful or appropriate; and an inclusive definition that places emphasis on communication, or what Negus and Pickering describe as 'communication of experience.' Jazz trumpet player and scholar Ed Sarath recently proposed a definition that appears to accommodate aspects of both of these positions. For Sarath, creativity is 'inventiveness, interaction, the ability to synthesise new forms of knowledge from diverse sources, and the emergence of an individual voice or style within a discipline.'692 This definition is a remarkably elegant fit with Garbarek's musical practice, and with the jazz procedures I have emphasised throughout this thesis more generally.

Even though Garbarek is not from the United States and has never lived there, he is unquestionably a member of the jazz guild. ${ }^{693}$ His pedigree includes extended sideman duties with Don Cherry and George Russell, and he was for a number of years a member of a quartet that included Keith Jarrett. ${ }^{694}$ Many of his albums are highly regarded - as jazz - by music commentators. ${ }^{695}$ In his contemporary practice Jan Garbarek draws on his foundation in jazz performance (and in particular, the cultivation of an individual voice and a

692 Sarath, Improvisation, Creativity and Consciousness, 2.

693 For the most part, discourse on jazz tends to ignore the music outside of North America. Among recent publications David Ake, Charles Garrett and Daniel Goldmark (in Jazz/Not Jazz) justify their position by referring to the United States's 'continued position as arbiter of global jazz tastes'.

${ }^{694}$ Although Jarrett was the nominal leader of the group and composed the music, the group was in fact closer to a collective (as Jarrett has said). I would add that Jarrett essentially hitched his wagon to a star in enlisting these musicians. Pianist Bobo Stenson (who co-led the GarbarekStenson quartet prior to the formation of Jarrett's so-called European Quartet with Garbarek) has remarked on Jarrett's dragooning of his former colleagues. See Griffiths and Lake, Horizons Touched, 262.

${ }^{695}$ For example, see Cook and Morton, Penguin Guide to Jazz, 523-525. 
commitment to collaborative, improvised practice) and combines that approach with traditional Norwegian musics as well as musical traditions from other parts of the globe.

His appropriation and utilisation of these other genres has been catholic and open, and has been achieved by means of improvisational collaboration with musicians expert in those genres. Garbarek has not sought to conform to the strict values of these traditions (he stated 'it was absolutely necessary for me to play the music my own way') but he has rather sought to create an accommodation between his playing and sound, and the various traditions and musicians he has encountered. In this respect, I believe Garbarek is following what is potentially one of the most fruitful avenues for jazz musicians (or any musician committed to creativity, for that matter) to pursue in our increasingly connected world. Garbarek has said:

One of the great aspects of jazz is that it's very open. It invites all sorts of people of any kind of background to take part. You can apply any personal input, coming from whatever part of the world and its possible to find a way that will work in the jazz idiom. That's what I see as the major force of this music. It's been more and more evident in the last 10 years [up to 1986]. We have players from any part of the world now doing their own, shall we say, native version. They find their own direction, influenced by their own culture, but still using the very strong basic element of jazz. ${ }^{696}$

This gels with the view adopted by sociolinguist Elizabeth Peterson.

In choosing to use English or play jazz, the adopting culture makes English or jazz all its own, just as we no longer think of pasta as being Chinese or Rubik's cube as being Czech. English and jazz are both viewed in the world at large as tools of expression, not as something that is "owned" by anyone. While a farmer's wife in Texas may think that she has some innately endowed ownership of English by virtue of the fact that she was born into it, she has no control over the version of English a university student uses in an internet chat room in Sri Lanka. English, and jazz, is like the wayward child that has flown the coop; it has taken on grandiose proportions that take it outside the realm of those who think they can lay claim to it by birthright. For both the farmer's wife and the student, the use of English serves the same purpose, which is at the same time both weighted with significance and utterly commonplace: it is simply a tool for expression, a means of both creating and expressing their relationship to the reality around them.697

As with jazz, so it is with Jan Garbarek. Garbarek's procedures are those of a jazz musician, but he has largely abandoned the stylistic signatures of jazz; gone for

\footnotetext{
${ }^{696}$ Quoted in Michael Borne, 'Jan Garbarek's Scandinavian Design', Downbeat (July 1986), 26.

${ }^{697}$ Quoted in Nicholson, Is Jazz Dead?, 173-174.
} 
example is a dependence on 4/4 swing, the bebop language, allegiance to the African-American blues tradition. In place of these recognisable style features are what I have called the core procedures of jazz. While some of the rhythmic aspects and vocalised instrumental techniques of jazz are present in Garbarek's playing, the aspects of his music I wish to emphasise (and that have arguably contributed significantly to his international reputation) are his allegiance to the processes that creativity research has shown to be conducive to creative outcomes. Examination of the practices (rather than just the products) of exemplary jazz musicians in this thesis has revealed that they too faithfully adopted these processes: development and expression of an individual voice (both in terms of sound and approach); a commitment to interactive, improvised group performance techniques; appropriation and transformation of music from both within and outside of the jazz traditions. The first of these has made Garbarek immediately recognisable to knowledgeable listeners, the second and third have enabled the creation of a remarkably diverse body of music that has offered new ideas to jazz, and to music more generally. All three processes populate the intersection set that exists between jazz practice and creative practice.

\section{Conclusion}

Margaret Bowden's taxonomy of creative practice can be elegantly applied to the evolution of jazz. Early jazz was characterised by combination creativity. Existing musical styles - ragtime, popular dance music, blues and spirituals mingled to form the early New Orleans jazz style. The first obvious example of transformation creativity occurred when Sidney Bechet and Louis Armstrong emerged as the first virtuoso improvisers of jazz, with the consequence that the focus of the music shifted from an ensemble form to one which showcased soloists. As time went on there was reasonably continuous exploratory creativity with occasional ruptures that occurred as a result of combination creativity - the emergence of Latin jazz styles in the 1940s and 50s for example - or transformational creativity - for example Ornette Coleman's move away from fixed forms and pre-determined tonal centres in the late 1950s. 
As far as I can divine, every rupture in jazz, every major new development, can be explained by a creative intervention; interventions that may be described using one or more of Bowden's categories. However, something quite interesting happened once the music had fully embraced post tonal procedures. For those who conceive of jazz as an evolving musical form that has followed, in its own noisy way, an evolutionary arc similar to that of western art music, an important question arises around what form progress might take after the emancipation of dissonance. In jazz this development occurred during the 1960s, and in 1974 jazz pianist Paul Bley said:

If you accept the fact that Albert Ayler was the last virtuoso saxophone player who played micro-tonally, bi-tonally or what-have-you, and that Cecil Taylor is the last virtuoso piano player to do these things, ad infinitum on the various instruments, [...] If you accept the fact that everything left to be done has been done and been done well, then in terms of improvising in the jazz idiom, there are only a few little corners that were overlooked that are still workable. ${ }^{698}$

Bley suggested the way forward for jazz musicians might lie in exploring the possibilities of electronic instruments. History has revealed that Bley was perhaps overly optimistic about the potential of electric instruments in jazz, and overly pessimistic about the prospects more traditional approaches held for the ongoing development of jazz performance. However, there is at least a kernel of truth in his idea that the work of jazz is done (at least in relationship to an ongoing evolution of styles), and considered in light of the reactionary rhetoric and practices that have characterised much jazz discourse in the past 30 years, should give us pause for thought.

It is for these reasons that I think the kind of music that Garbarek is pursuing is indicative of a rich avenue for jazz in the years to come. By adopting the processes that have characterised jazz since its inception (appropriation and transformation; the development and expression of an individual voice; interactive improvisational group practice) rather than depending upon the style features and emphases that have emerged from those processes (4/4 swing, the blues, certain harmonic games, bebop vocabulary, the 'Spanish tinge' and so forth) Garbarek has freed his music from the prison of style and instead

698 Klee and Smith, 'Paul Bley', 12. Bley's perspective is that of a musician trained at Julliard in the 1950s under Henry Brant, and his critique, unsurprisingly, reflects a modernist's perspective. Nevertheless, his question is a useful one. 
pursued a combination of sounds and practices expressive of his musical persona. In fact, that seems to be an explicit agenda on Garbarek's part. During the mid 1990s he claimed:

I had a feeling [in the late 1970s] that, for my own playing, jazz had reached a stage of too many abstractions removed from the source of the original folk music - the blues of Mississippi. I thought it might be time to look back and see what there was in the beginning and find out if there might be other paths to be taken. If we, as a new generation - as we were then - players with totally different backgrounds, looked to the sources and made our own steps from there, the music might grow in a new way. There might be a new branch. 699

The syncretism evident in Garbarek's music and the richness that emerges from his mixing of disparate elements has certainly led to music that is singular, affecting and deeply communicative to audiences around the world. Don Cherry pursued a similar muse, and one of the groups most representative of Cherry's ambitions in this direction is Codona, the trio he co-led with North American multi-instrumentalist Colin Walcott and Brazilian percussionist Nana Vasconcelos. In 2013 jazz commentator Brian Morton, writing for Wire magazine, asked, 'Could [Codona] be the most influential group of the last 30 years?' Even if Garbarek's music does not prove to have a deeply lasting imprint on the cultural matrix, it should be no surprise if the practices he has adopted and developed - practices that are applicable wherever in the world they might be applied - continue to be influential, and prove to be a hallmark of future jazz. It is to future jazz, and the Aotearoa/New Zealand contexts in which I hope to see such music enacted that I now turn.

${ }^{699}$ Quoted in Tucker, Jan Garbarek, 235. 


\section{Afterword: Conclusions and Implications}

With this thesis I have sought to map current understandings of creativity particularly as it occurs in group settings - onto current understandings of the work of musicians considered significant to the field of jazz. Current research suggests creativity depends upon a number of clearly defined processes and dispositions. The correspondences I have identified between this research and jazz (exemplified in the historical case studies included in this thesis) suggests that the processes that significantly contribute to jazz as creative practice among the musicians examined include: improvised and interactive group action; appropriation and transformation of materials from outside of jazz and inherited materials from within the tradition. Further, I have laid out that the success of these two processes partially fuels, and is in turn is made more successful by, the cultivation and expression of individual musical voices.

If these findings are reasonable and generalisable, then it seems to me there is a disconnect between what appear to be the most essential features of jazz as a creative practice - those teased out in the case studies - and jazz as it is presented in some journalistic, pedagogical and popular discourses - where discussion has tended to focus on style features and has only superficially engaged processes. ${ }^{700}$ In part, it is this disconnect that fuelled what have been termed the jazz wars of the 1990s and early 2000s, where a 'death of jazz' discourse was rehearsed by numerous writers, and some musicians too. ${ }^{701} \mathrm{~A}$ strong subtext of this most recent manifestation of the 'death of jazz' discourse

\footnotetext{
700 For example, both swing and improvisation are fundamental to common definitions of and discussions about jazz, and both might be parsed as verbs - as processes - rather than as nouns. However, much journalistic, popular and pedagogical writing tends to freeze the products of these processes as artifacts exemplifying a 'style' - what Frank Zappa would call 'a jazz noise' rather than drawing attention to the collaborative contexts in which the processes are collectively enacted - circumstances that emphasise the extremely contingent nature of these products.
}

701 This came to something of a head with the broadcast of Ken Burns: Jazz by PBS in 2001. The problem with this series (as I see it) is not the story it told - it's a good story - but rather with the authority the claims of the writers and contributors to the series seemed to assume because of the context in which they were made: a major series on PBS with tremendous public profile, accompanying books and CDs and the apparent endorsement of numerous culturally privileged institutions (National Endowment for the Humanities, National Endowment for the Arts, the MacArthur Foundation). The story the series tells is not wrong, but the authority with which it was told tended to imply that it was the only story. As the thrust of this thesis (and the work of many other writers) suggests, that is not the case. 
was that if musicians, writers, commentators and educators lost sight of the values that originally animated jazz - that drove the music during periods of its most pronounced development - the music would calcify. ${ }^{702}$ The work of this thesis allows us to draw conclusions about salient features of some of the incontestably great jazz of the past, and use these conclusions to inform our thinking about what might be required to foster the ongoing development of jazz as a creative music. It's possible that many facets of the broader jazz discourse might be enriched by the ideas promulgated here, but I think this thesis may speak most powerfully to the ways jazz is taught, and also to the ways jazz histories - which are frequently dragooned into the service of jazz education are conceived and elaborated. I specifically address jazz education and jazz histories in this afterword, although do so in light of the broader discourses within which they are situated.

\section{Conclusions}

As discussed in Chapter Two, creativity is the result of a number of reasonably well-understood processes, and the dispositions of participants who engage those processes. Further, creativity is often enacted in collective rather than solitary contexts. Group creativity, with which this thesis has been primarily concerned, is enhanced by the routine use of interactive improvisational procedures amongst groups populated by diversely gifted individuals. Creativity in these contexts is further boosted if the participants are at least somewhat familiar with one another and share common goals. It follows then, that jazz is most likely to be genuinely creative when it conforms to these communitarian principles. Such principles are clearly evident (in various ways) in the leadership practices of the musicians who populate the case studies presented: Ornette Coleman, Miles Davis, Duke Ellington and Jan Garbarek. These musicians adopted musically inclusive approaches in which leaders and their fellow musicians collaborated in a context where all were welcome to speak with their own unique voices (itself the result of creative work) and together create something new or uniquely expressive.

702 In particular: Nisenson, Blue; Nicholson, Is Jazz Dead?; Paul Bradshaw, 'Lester Bowie', Wire 34/35 (January 1987), 43-45. 
The creative processes these leaders and their collaborators engaged were historically, socially and geographically situated, not least because in each instance the music made was produced by a particular group of unique individuals. Because these musicians each made music that reflected their individual musical personae (or possessed 'a sound' or unique 'voice', a cherished value in jazz) the musical colloquy that emerged was always in some way distinctive, offering new music that reflected those musicians' historical, social, geographical moment. The music made by Miles Davis with his 1959 sextet is different from that which he made with his quintet in 1961 and different again from that produced by his 1965 group, even when playing identical repertoire. This is largely because the voices changed as the composition of the groups changed, and the resulting music was always somehow different. Even when Ornette Coleman reconvened his original quartet (with Don Cherry, Charlie Haden and Billy Higgins) in 1987, the music they made together was different from that produced thirty years earlier, because each of the players had changed, developed, matured over the intervening years - their voices had changed and so therefore did the music they made together. ${ }^{703}$

Just as musicians' artistic personae (or voices) change over time, so do the musical milieux in which they operate. By attending to their contemporary context jazz musicians have found ways to incorporate musical materials and practices exogenous to jazz, into their routine (jazz) practice. For Ornette Coleman (with Prime Time in particular), Miles Davis (particularly from about 1967 through 1972) and Jan Garbarek (across his recording career) such appropriation and transformation fuelled moments of creative re-animation in their music. Such practice is a problem-finding strategy, because these kinds of stylistic or processual incursions from outside of the terra firma of jazz lead not to predictable results but rather to new and often unforeseen pathways.

The emphasis of this thesis - primarily on process - is different from the emphasis of much of the common journalistic, pedagogical and popular

\footnotetext{
703 It is instructive to compare the quartet's music from 1959 on The Shape of Jazz To Come with that they recorded for 1987's In All Languages (Fort Worth, TX: Caravan Of Dreams CDP 85008). While some of the procedures remain in place, the later recording possesses a new and distinguishable sound.
} 
discourse on jazz which, while acknowledging processes, tend to stress the surface properties (or style features) of the music. While giving priority to style undoubtedly has some benefits, if taken to extreme such priority can have a deadening effect on music made now. If contemporary musicians only understand the products of historically 'great' jazz and not the processes that engendered them, then contemporary musicians may well only crystallise the styles of the past - codifying and reproducing them - without ever advancing on them, except perhaps in the very modest ways improved technique and superior instruments might allow.

Further, such fidelity to the products of the past will deny contemporary musicians the opportunity to seek out new terrain for the music and in doing so cultivate their own unique, contemporary voices; voices that are a product of the world they live in now, the music they encounter there, and what they make of all that. I don't doubt that there can be interactive improvisational group activity in reproducing music that is faithful to the style markers of the past, leading to modest levels of creativity. However, translating that kind of interactive improvisational group practice to musical work where musicians seek to cultivate their own contemporary voices in ways that reflect the musical currents of their modern lives is, on the basis of the case studies presented, the real legacy of Duke Ellington, Miles Davis, Ornette Coleman, Jan Garbarek and a host of other musicians lionised as 'great' in the annals of jazz. Modeling contemporary jazz practice on the products of past jazz practice can produce wonderful music, but relative to that exemplary past practice, the scope for creativity in such modern music making, and the scope for personal expression, self-knowledge and the kind of 'self creation' that Keith Negus and Michael Pickering point toward when creativity is engaged, is at best diminished. ${ }^{704} \mathrm{At}$ worst, scope for creativity in such an emulative practice may be lost altogether.

Because the ways we talk about jazz - the common discourses of jazz have an impact on the ways we think about and practise jazz, it is useful to scrutinise those discourses mindful of the lessons creativity research can reveal about the music. That is the intuition this thesis offers. As I have demonstrated, a

\footnotetext{
${ }^{704}$ Negus and Pickering, Creativity, Communication and Cultural Value, 9.
} 
range of academic literature on creativity and jazz has articulated in general terms the importance of expanding scholarly focus to encompass the processes of jazz, rather than continuing to concentrate exclusively on its products. My contribution to this literature has in part been to use the literature on creativity to propose a more specific model for understanding creative practice. My sense is that despite general scholarly acknowledgement of many of these features of jazz process, in a variety of ways, and specifically in contexts of jazz education and practise, the historic emphasis on style continues to be read as the dominant, central strand in this music. My case studies have attempted to bring to greater prominence, in a more comprehensive way, the extent to which from a certain standpoint, at least - it would also be possible to posit the process aspects of jazz as the central 'story' of jazz.

Therefore, my central argument here identifies ways in which fundamental (and perennial) creative processes can enable us to identify continuities in the jazz narrative that are currently occluded by emphasis on style-based teleological narratives. Such emphases can encourage disdain for apparently 'primitive' jazz forms; can fetishise extraordinary formal virtuosity at the expense of a more democratic conception of creativity; and can blind students to the explanatory potential of creative process across the whole history of the music. I have suggested that an excess of piety towards the products of past jazz practice can have the effect of deadening the creative potential of the music, and the two sites where I suspect this is most pernicious are in the construction of jazz histories, and in college curricula assembled in the service of jazz training. It is these two aspects of common jazz discourse I primarily focus on as I consider the implications of this work.

\section{Implications: Telling the stories and teaching the music}

Scholars Ken Prouty and Ed Sarath have suggested that jazz educators have adapted the content and emphases of jazz curricula to conform to the prevailing orientations of musical academe at large. ${ }^{705}$ Such conformity has led to dissonance between jazz in the academy (or college settings) and jazz outside of

705 Prouty, 'The “Finite” Art of Improvisation'; Sarath, Improvisation, Creativity and Consciousness, 154. 
the academy. For ethnomusicologist Bruno Nettl, almost twenty years ago now, 'The type of jazz performed in the university does not really correspond to the important types of jazz heard in the real musical world. ${ }^{706}$ As I see it there are two important factors in ways jazz has developed in educational environments that this thesis can speak to. The first is related to how jazz has been codified for consumption in the academy (and this has implications for the ways both jazz histories and instructional texts are compiled). The second factor relates to how those histories and texts led to a pedagogy that has supplanted the heuristic approaches historically significant jazz musicians - the very musicians championed by these texts - made use of in developing their art.

\section{Jazz Histories}

Jazz histories adopt narrative structures that generally lay out what happened when, identifying moments of consequential change and development in the music. ${ }^{707}$ Significantly for this thesis, these texts frequently focus on surface differences between each jazz style and its antecedents. To be sure, process is mentioned - the centrality of improvisation, the mutually constituted elements of groove and swing, individual voice - but the business end of these historical analyses are almost always style features. ${ }^{708}$

In some ways this style emphasis is inevitable. First, changes in style are the most easily heard differences between jazz of one period and another, and

\footnotetext{
706 Bruno Nettl, Heartland Excursions: Ethnomusicological Reflections on Schools of Music (Urbana: University if Illinois Press, 1995), 93. What 'the real musical world' might be for jazz musicians is not entirely clear from Nettl's remarks. I would suggest that 'the real musical world' is an extremely diverse construct, and ranges from The Glenn Miller ghost band (which makes plenty of money if concert attendance is anything to go by), to some of the most exciting jazz I have heard in recent decades where the audiences barely outnumbered the band onstage. But this also works the other way: I have attended capacity concerts by Wayne Shorter's groups and those of Tomasz Stanko where the frontiers of the music were troubled (and the audience loved it); and I have been to very boring, by-the-book jazz performances where the audience (as well as any inspiration) has stayed away.
}

${ }^{707}$ For a summary of the various approaches adopted in formulating jazz histories see DeVeaux, 'Constructing the jazz tradition', in particular 531-552.

\footnotetext{
708 Alyn Shipton's A New Jazz History to some extent breaks away from this approach, and significantly for this thesis, emphasises appropriation and transformation (for example, p.830). More focused studies of recent times, such as DeVeaux's Birth of Bebop, manage an excellent balance of social, historical, political and musical considerations, but most of the general history texts recite a progression of styles which, while often mentioning political or historical contexts, rarely adequately reconcile those considerations with the music made.
} 
are in many cases reasonably easy to quantify. However, and rather more subtly, the process of historicising the music tends to freeze it. Anthropologists Richard Brauman and Charles Briggs have suggested that 'the process of making discourse extractable, of making a stretch of linguistic production into a unit - a text - that can be lifted out of its interactional setting might be termed 'entextualisation'. ${ }^{709}$ For Keith Sawyer, 'entextualisation turns an improvised performance into a ritualised one' - from an activity where improvisation is generative to one where improvisation is at best decorative. ${ }^{710}$ Stanley Tambiah, quoted by Sawyer, suggests that ritualised forms are in danger of progressively calcifying until they become 'meaningless' forms without communicative semantic content (unless of course some event leads to a creative re-animation or paradigm shift for that activity). For this reason Sawyer prefers the term ritualisation to entextualisation, emphasising the potentially stultifying effects of turning improvised acts into reified texts. ${ }^{711}$ If jazz histories do anything, they entextualise the improvised musical responses of musicians in historically specific moments, so there is a bit of a Catch-22 here. On the one hand, commentators and teachers need histories (and I'm thinking specifically of transcriptions and other records of improvised performances in jazz, entextualisation of the stuff from which jazz is made) to illuminate the evolution of this improvised musical practice; on the other hand, such histories can freeze the contingent, social fact of an improvised performance into a text, severing it from the processes that led to its genesis. Perhaps what is needed are different kinds of histories? Or at least histories formulated in different ways thereby mitigating the effects of such entextualisation/ritualisation?

Perhaps the first obvious step to mitigate such ritualisation is for readers to be aware of the potential that textbooks, recordings and transcriptions can

\footnotetext{
${ }^{709}$ Richard Bauman and Charles Briggs, 'Poetics and Performance as critical perspectives o language and social life, in Creativity in Performance, ed. R. Keith Sawyer (Norwood, NJ: Ablex, 1997), 243. (Emphasis in original)

710 Sawyer, Group Creativity, 141.

711 This is exactly what recordings of improvised performances do. The mutually dependent nature of jazz and recording technology is a very rich trope that I would love to explore but is simply too big a question for this project. A good place to start with these questions is perhaps Evan Eisenberg's The Recording Angel: Music, Records and Culture from Aristotle to Zappa (New Haven, CT: Yale University Press), 1998.
} 
create the impression that jazz is somehow contained - captured, reified within these objects. Such reification is a potential that is actually attractive to some commentators and musicians as well as students and to teachers, because it converts contingent musical negotiations into historical facts that can be explained, analyzed, categorised and reproduced. ${ }^{712}$ Such reification offers a measure of certainty - we know good jazz when we hear it, because we have heard it before in the music of [insert name of iconic musician here] - but also potentially enforces the crystallisation of style, because if 'good jazz' is a 'thing', then it is very tempting for musicians, music students (and their teachers) to reproduce the salient (surface) features of that thing. However, if our aspiration is that jazz becomes a tool for the development of musicians with individual artistic personae who can express their reality through the music they make, then being aware of the potentially prescriptive consequences that textual records of the music of the past might enforce is a useful strategy. As this thesis has suggested, there is jazz, and there is jazz style, and they are not the same.

The second step available to educators, musicians, commentators and writers, is to explore different ways to formulate stories about the development of the music. By relating different kinds of jazz histories, different understandings about the music may emerge - understandings that place emphasis on processes that have remained constant across the music, for example. And these processes have not remained constant in spite of the changing style features of the music - the formulation is the other way around: the style features of jazz have continuously changed because the underlying processes of the music - processes that we have seen are conducive to creativity - have remained broadly consistent. ${ }^{713}$

Because the ways histories are told are so material to the ways we and subsequent generations both understand and value jazz, finding new ways to articulate jazz history is important, although it will require some new

712 To paraphrase Levine, The Jazz Theory Book, vii.

713 Recent writing on jazz by scholars using ethnographic approaches (particularly Ingrid Monson and Travis Jackson, and after Paul Berliner) are doing this very work, creating a new kind of conversation about the music that bridges the gap between scholarly discourse and what musicians say about the music. It will be exciting to watch this new conversation begin to inform popular jazz histories. 
approaches. I think the examples in the case studies in this thesis offer some ideas, however. For example, if Ellington's music were taught not as historical fact ('Paul Gonsalves played a killer, 27-chorus solo at Newport in 1956; the crowd went wild - just listen to them! - and Ellington's career took off again') but rather as historically situated moments of process ('The band had experienced something of a nadir and Ellington was a little desperate. On the night, the group was flagging, the audience was leaving, but the rhythm section got a groove on - abetted by Jo Jones backstage who was shouting encouragement and adding to the rhythm - and Gonsalves was able to hook up with that energy. He played the blues the way he always did, but the combination of the rhythm section, the band shouting encouragement and adding to the rhythm with their feet and their hands, and a weird and wonderful alchemy from the audience that night in that place - unquestionably assisted by Elaine Anderson's abandoned dancing in front of the stage $\mathrm{e}^{714}$ - lifted the performance from routine to exceptional') then we can perhaps draw closer to an understanding of jazz as the in-the-moment ensemble music it is.

Another avenue perhaps worth exploring might be an examination not of the style developments that populate most jazz histories but rather of the chain of tradition as manifest in evolving processes. For example, what can the respective practices of Thelonious Monk and Steve Lacy (both very individual jazz improvisers who worked together briefly in the 1950s) reveal to us about jazz more generally? Lacy attributed considerable credit to Monk for his own developing musical conception and yet the music they each made is quite different. Similar trajectories - from Miles Davis to John Coltrane; or Miles Davis to Keith Jarrett; or Edward Vesala and Iro Haarla (whose combined musical conception is difficult to disaggregate) to Trygve Seim - might offer telling insights into the ways very individual jazz performers have developed their unique music, because while the styles of these respective musicians are discontinuous, the processes each pair adopted share important similarities. This idea allows us to elegantly segue from a discussion of jazz histories to

714 Morton, Backstory in Blue, 158, 173-190. 
consideration of how the hypotheses this dissertation advances might be applied to jazz performance training.

\section{In the classroom}

For students in jazz education settings, an emphasis on process rather than product might become possible through focusing not only on the notes historically significant musicians played, but also on the ways those musicians worked together with others in choosing which notes to play and how to play them. Such a shift of emphasis - from matter to manner - may create opportunities for students to engage the creative processes that gave rise to what is widely regarded as historically significant music, and so arrive at new music, music that reflects their own historical, social, geographical moment. This is perhaps a crucial consideration in the new century, as jazz education now flourishes in so many sites around the globe, many of which are culturally far removed from the United States. The new cultural, political and social contexts of jazz in these settings suggests that, if jazz is to retain its creative capacities, it is necessary to find ways to help aspiring musicians to develop their own approaches to jazz: approaches that empower them and their artistic choices in their own context. Training that simply resituates their music (and by extension, 'them') in homage to supposedly 'authentic' jazz styles serves only to crystallise established styles of jazz and potentially robs those musicians' performances of expressive and creative power.

I am not suggesting that this kind of processual emphasis replace style and technique studies that are currently central to most jazz educational settings; however, I do think adopting process-oriented pedagogies can usefully complement the past-based, emulative orientation of those settings. As Ed Sarath has suggested, the rhythmic and collective improvisatory foundations of jazz are central to its traditional lineage, but embracing a wider vision of the music 'has the capacity to retain sight of these and other treasures while at the same time promoting wide-ranging creative confluence.'715

715 Sarath, Improvisation, Creativity and Consciousness, 13. For a discussion of some of the different strategies available to educators, see pp. 154-160. Sarath's book (published late in 2013 , by which stage I was well into this writing) offers insightful comment and acute ideas that 
Among approaches that prioritise process are problem-finding approaches. As we have seen, such strategies are likely to lead to creative outcomes. ${ }^{716}$ With regard to problem-finding strategies in classroom settings, Raymond Nickerson suggests:

In school settings, students typically work on problems of someone else's choosing; seldom are they challenged to find problems of their own on which to work. Presumably one of the reasons for this is the fact that having students work on "set" problems poses far less formidable challenges of administration and evaluation than does having them work on problems that they themselves find. I do not mean to discount the practical importance of this consideration or to argue that students should work only on problems of their own choosing; the suggestion is that, if they are to have a good chance of developing their creative potential, they need to have some experience in problem finding and selection, as well as in problem solving. ${ }^{717}$

As I see it, there are a number of strategies available to educators to create opportunity for this kind of problem-finding work.

First, by creating performance contexts where there is a great deal of uncertainty, teachers invite musicians collectively to develop responses to the problems posed by these contexts. Miles Davis's approach to the recording sessions that yielded In A Silent Way is exemplary in this regard. For the title track of that album (and 'It's About That Time' which forms part of a continuous suite with 'In A Silent Way'), Davis made use of material contributed by Joe Zawinul. Davis stripped this material back to the barest of sketches (much to Zawinul's chagrin ${ }^{718}$ ) and those sketches became the basis for the collectively improvised responses of the musicians present, who made use of their own unique voices to elaborate - to colour in - the compositions in the studio. The musicians did not know beforehand what the music was going to sound like, or even how they should play: as John McLaughlin reportedly said: 'I mean, what

emphasise and validate the approach I have taken with this thesis. What I offer usefully complements his trenchant arguments.

716 See the discussion on problem solving/problem finding approaches in Chapter One.

${ }^{717}$ Nickerson, 'Enhancing Creativity', 416.

718 Davis's re-arrangement of 'In A Silent Way' bothered Zawinul, who said, 'Until today I believe that Miles was wrong in taking these two chords out, because the tune does not have the climax it could have had. But there was no note in the melody changed, and no chords were stripped.'

Zawinul, quoted in Tingen, 'The Making of In A Silent Way \& Bitches Brew', 40. 
did we do? I can't tell what's going on!'719 The openness of the situation and the invitation to the musicians to work something out on the fly - problem-finding strategies - were critical to the success of this music. The importance of such problem-finding approaches, which leave musicians not quite knowing what they are doing, were emphasised by saxophonist Trevor Watts.

I once heard Duke Ellington say in an interview, "It's a good job we didn't know what we were doing." I laughed, but that instantly struck a chord with me. Too many players today do know what they're doing and they won't get any better until they get to the stage of not knowing. If you leave yourself open to what you don't consciously know, it's a way of progressing and a way of challenging the received wisdom. ${ }^{720}$

I think Watts is correct, and music that engages these kinds of problem-finding approaches is likely to lead to creative work and as such represent a cogent strategy for musicians seeking to find their own ways to play. In the classroom, as Raymond Nickerson suggests, such approaches are likely to enhance the creative potential of the students engaging them.

A second way problem-finding might be activated in the ensemble room is by encouraging musicians to view the tradition through the lens of the present, and in particular, through a lens informed by the individual tastes of the musician(s) involved. As the case studies have revealed, adopting a contemporary perspective can lead to new insights. Miles Davis's example demonstrates that adoption of a such a contemporary perspective (in his case by making use of recently developed electronic instruments and studio technique, and newly emerging rhythmic ideas from $R \& B$ and rock) provided a context in which the new mix of musical materials had not yet settled into codified, normative structures. ${ }^{721}$ Davis and his collaborators were therefore free to manipulate those musical materials and ideas in all sorts of ways, because there was as yet no established way to mix them. By introducing elements that are not already locked into existing patterns a problem is proposed: how do we fit this stuff together? Such an approach corresponds to Pat Metheny's suggestion that

\footnotetext{
719 Tingen, 'The Making of In A Silent Way \& Bitches Brew', 48.

720 Trevor Watts, quoted in Julian Cowley, 'Free your mind and your ass will follow', Wire 295 (September 2008), 40.

${ }^{721}$ A similar point is made by Sarath, Improvisation, Creativity and Consciousness, 159.
} 
musicians, as well as seeking to master the lessons of the tradition (by which I take it he is referring to the rhythmic and melodic language, and the harmonic and formal devices of celebrated jazz musicians), also seek 'to capture the sound of their OWN generation of musicians'. Aware that early in their development musicians possess 'a certain kind of energy that is really valuable, rare' and which may inspire music that sounds 'nothing like anything that has been heard before', Metheny urges students to 'Listen to THAT with the same attention and curiosity that [they] reserve for [their] heroes on record. ${ }^{722}$ Even as a master musician, Miles Davis was able to pay this kind of attention to contemporary developments and incorporate them into the sound and approach of his groups, capturing Metheny's 'rare' kind of energy. Similarly, Jan Garbarek's inclusion of musical ideas from other cultures - music that clearly inspires him - is a form of problem-finding exercise for him and his ensembles, problems that they flesh out (and perhaps to which they even propose possible solutions) in the course of performance.

A third strategy that might be beneficial for educators (and indeed any musicians seeking to propel their music into individual and creative directions) is through encouraging the composition and performance of original material, and perhaps ideally music that makes use of the 'sound of their own generation'. As I see it there are three main benefits to this approach. First, and as we saw from Duke Ellington, the composition of original material (whether alone or in collaboration with others) led to the crystallisation of Ellington's sound, both in the form of the 'Ellington Effect' and in the melodic strategies and formal and harmonic characteristics that came to typify his compositional approach. ${ }^{723}$ When musicians 'write what they hear' - try to capture in their compositions the ideas latent in their musical imaginations - their own musical proclivities are (progressively) reified in their compositions. When musicians compose and perform their own music it helps them to understand and develop their own voices, and over time allows them more clearly to project their musical persona

\footnotetext{
${ }^{722}$ Quoted in Sarath, Improvisation, Creativity and Consciousness, 157-158.

${ }^{723}$ See Ken Rattenbury's Duke Ellington, Jazz Composer for an in-depth discussion of the salient characteristics of Ellington's compositional style.
} 
into the world. Sam Rivers adopted such an approach as he sought to develop his own voice: 'I worked out my own chord substitutions, wrote my own exercises to practice... ${ }^{724}$ It is evident in the example of Ornette Coleman, where the oddly metered sections and unusual harmonic juxtapositions of his compositions reflect (and perhaps served to consolidate) his individual improvising voice.

A second benefit accrued when a musician routinely performs their own compositions is that the new music provides improvisational contexts for performances that are tailor-made for the composer's musical imagination (because the basis for the composition - whatever form it might take - and that musician's improvisations are products of the same musical imagination). ${ }^{725}$ Jan Garbarek's adaptation of Norwegian folk melody operates in this way. As we saw, when Garbarek first performed in a context that combined traditional music from Norway and jazz, 'the combination of folk music and improvising sounded so right to me.' As a result, his musical imagination developed (or perhaps grew in a direction already subtly present, but up to that point untapped) such that for Garbarek, 'I think from that moment on, the idea of having folk music aspects or folk musicians involved in this music was always there in my mind. ${ }^{726}$ As has become evident, such a desire for trans-traditional combinations has fuelled Garbarek's music in rich and unique directions, and in these contexts the transitions from Garbarek's compositions to his improvisations can at times appear seamless. ${ }^{727}$

\footnotetext{
${ }^{724}$ Sam Rivers, quoted in Palmer, Dimensions and Extensions.

725 While jazz composition is taught in most conservatories, from my observations (of four schools across two countries) and from comments made by students who have attended other undergraduate jazz programmes, student composition rarely forms a part of the repertory that is performed in ensemble classes or as an adjunct to improvisation classes. While there is certainly benefit in performing standards and jazz songs, I suggest that moving emphasis away from this established repertory and toward original student music might offer greater opportunity for individual voice formation and unique approaches to improvisation. I would further suggest this principle applies at all levels of jazz performance: does the world really need another version of 'All The Things You Are'? The Contemporary Improvisation programme at New England Conservatory does exactly this kind of work: see 'Contemporary Improvisation', <http://www.necmusic.edu/contemporary-improvisation> (6 June 2014).

726 Griffiths and Lake, Horizons Touched, 22.

727 For example, performances by the Jan Garbarek group of 'Molde Canticle: Part 2' on I Took Up The Runes, (Munich: ECM, 2000).
} 
A third benefit that comes from musicians writing their own compositions for performance and as vehicles for improvisation is that it is an effective way to incorporate ideas that musicians harvest from their contemporary perspective and milieu - assuming they are encouraged to do so as discussed above. Miles Davis composed (or co-composed with his sidemen) music that incorporated the contemporary musical ideas that interested him/them or seemed fruitful for musical exploration. Joe Zawinul's bass line on 'It's About That Time' (In A Silent Way, 1969) would have sounded entirely appropriate in the soul jazz contexts he had been working in with Cannonball Adderley, but situated in Davis's rather darker music it assumed a different complexion, one that required the musicians to find an appropriate and perhaps 'new' response. In this case the gestures of R\&B (the melodic bass line, Tony Williams' cross-stick pattern, Chick Corea's shimmering Fender Rhodes' chords), and the sombre quality that results from the spacious playing and the modal setting of the performance, combine to offer a rather different commentary on the times to Sly Stone's 'Sing a Simple Song' or Blue Mink's 'Melting Pot'.

Having musicians, and perhaps particularly student musicians, draw from the music of their own generation in identifying materials and processes to inform their jazz aligns their practice to that of past jazz masters who have reanimated the genre by this means. Just as Miles Davis drew from rock and R\&B, and Ornette Coleman drew from funk and psychedelic rock ${ }^{728}$ with his ensemble Prime Time, so younger musicians in recent years have made use of the recombinant processes of electronic dance music in offering a new take on jazz. ${ }^{729}$ Such a strategy opens jazz up to a wider range of musical practices and materials than simple adherence to the stylistic lessons of the past and invites greater diversity and a broader palette for self-expression. Adopting processes like these in the classroom will mean that the music students play will likely sound very different from the diet of standards and jazz songs that is currently

\footnotetext{
728 To my ear Prime Time sounds closer to the Grateful Dead than most other 'rock' sources. The apparent links between Coleman's music and that of the Dead are perhaps confirmed by the appearance of Dead guitarist Gerry Garcia's on Coleman's 1988 album Virgin Beauty. (New York: Portrait/Sony, 6619840.)

${ }^{729}$ For example, recordings by Norwegians Nils Petter Molvaer and Eivind Aarset, or perhaps those of French trumpeter Eric Truffaz.
} 
de rigueur in most jazz schools, and potentially pose problems for teachers in determining the best ways to assess the quality of those musicians' work. However, encouraging such approaches moves the ensemble from a problemsolving to a problem-finding paradigm, and will almost certainly lead young musicians to making music that means more to them than, say, George Gershwin's 'I Got Rhythm.' Such approaches may well also stimulate their capacity and appetite for creative music making.

This brief summary of some of the ideas that might usefully propel jazz histories and jazz pedagogies into different directions highlights the lacunae that exists between recent jazz scholarship - which in many cases emphasises the kinds of processes I have drawn attention to in this thesis (although they do not explore them from the same perspective) - and most jazz historical and educational discourses. While there are certainly aspects of the 'New Jazz Studies' 730 that have made their way into college jazz curricula (in particular jazz history syllabi), to my knowledge the understandings offered by this recent scholarship has not yet really translated into teaching practice in performance classes. ${ }^{731}$ Ed Sarath shares this observation, claiming that recent jazz scholarship 'does not impact the training of aspiring jazz musicians.'732 The prescriptive nature of the stylistic training offered by many - and perhaps most? - college programmes therefore stands apart from the processual emphasis evident in the scholarship I have cited in this thesis. ${ }^{733}$ It is not clear to me why

\footnotetext{
730 Ed Sarath capitalises this term in his description of the sub-discipline, after Robert O'Meally's (2004) edited volume and echoing the appellation 'New Musicology' that emerged during the later part of the last century. Sarath describes the 'New Jazz Studies' as scholarship evidencing 'the burgeoning interest in jazz as a vehicle for fostering cross-disciplinary creative awareness.' Improvisation, Creativity and Consciousness, 162. Robert O'Meally's edited volumes are perhaps representative of this discourse: The Jazz Cadence of American Culture, ed. Robert O'Meally (New York: Columbia University Press, 1998); Uptown Conversation: The New Jazz Studies, ed. Robert O’Meally, Brent Edwards and Farah Griffin (New York: Colombia, 2004).

731 Except in a few isolated places, and even there primarily at upper levels. For example, programmes at University of Michigan (Ann Arbor) and New England Conservatory are taking a lead here.

732 Sarath, Improvisation, Creativity and Consciousness, 163.

733 Of course some programmes do good work in this space, and in many programmes I expect there are a few teachers who promulgate the kinds of ideas I am rehearsing here. But judging by the published syllabi and repertory of such notable jazz programmes as the University of North
} 
this is the case, although it is a disappointing circumstance given what I have described as the 'real legacy' of the jazz musicians examined in this thesis. I do suspect that adopting pedagogies that embrace the kinds of uncertainty and collectivity the creativity literature advocates might lead to musical outcomes difficult to assay in conventional college curricula terms, and as such pose formidable challenges for administration and evaluation, as Raymond Nickerson suggests. ${ }^{734}$ However, and in line with Nickerson, adopting such approaches will likely give students experience in situations conducive to creative work.

\section{A benediction from Aotearoa}

As George Lewis, Gena Caponi, Ralph Ellison and others have attested, jazz (and other forms of African American cultural production) involves a balance of individual needs and responsibilities, a balance that finds its fulfillment in collective contexts. Individuals serve the needs of the ensemble - are subservient to the ensemble - while at the same time the ensemble provides the individual with a place to stand and welcomes all voices in speaking roles, creating a context that celebrates what is distinctive about each of them as individuals. It is these values we have seen valorised in the group musical practices of Ornette Coleman, Miles Davis, Duke Ellington and Jan Garbarek. And it is these values that spurred these musicians and their collaborators to produce creative music, music celebrated as 'great' in common jazz discourses.

While these practices have been shown to have considerable musical merit, I suggest that the humanist values inherent in these practices are also worth our attention. Creativity has been shown to have benefits at both individual levels and in group situations. Individually, it has been suggested that creativity affords those who engage it an opportunity to express individual free

Texas (http://jazz.unt.edu/sites/default/files/pdf/degree_plans/jazz_instrumental_06.pdf> [6 June 2014]), Julliard

(<http://catalog.juilliard.edu/preview_program.php?catoid=13\&poid=1276\&returnto=1389 $>[6$ June 2014]), Eastman School of Music

(http://www.esm.rochester.edu/registrar/policy/bm_eic/BM_Jazz_Performance.pdf $>$ [6 June

2014]) and Berklee (http://www.berklee.edu/sites/default/files/10\%20BM4.PERF\%201314.pdf [6 June 2014]) and auditioning some of their flagship ensembles, it looks and sounds very much like the business-as-usual approach to jazz training - where style, codified improvisational approaches and established repertory prevail.

${ }^{734}$ Nickerson, 'Enhancing Creativity', 416. 
will and so enact a kind of self-discovery or self-making. ${ }^{735}$ In collective contexts creativity is most effectively achieved when all of the unique, individual voices present are afforded the opportunity to contribute whatever they can to the mix. Jazz (at least as I am defining it here) is an exemplary site for creativity because - when it is really happening - it not only encourages, but also requires individual agency operating in egalitarian collective contexts. It is this principle that I think Albert Murray emphasises when he suggests that the 'blues aesthetic' - which he believes is crystallised in jazz - is in fact 'equipment for living' and as such draws attention to values necessary for collective life. ${ }^{736}$ With this metaphor, Murray suggests that the blues aesthetic - with its communitarian values - is not only essential for jazz (and as I have argued, essential for jazz as creative practice) but also offers us cogent lessons about how people can live together.

These ideas find a powerful corollary in Māori cultural values in Aotearoa/New Zealand, values that can inform our choices toward wise living. The two ideas that I link to jazz are Tūrangawaewae, and Marae.

Tūrangawaewae translates literally as tūranga (standing place), and waewae (feet). It is most often translated as 'a place to stand'. 'Tūrangawaewae are places where we feel especially empowered and connected. They are our foundation, our place in the world, our home. ${ }^{737}$ A marae is a tribal forum, and is the place where Māori custom is given ultimate expression. 'For each person, the marae is the place where their ancestors are present, where they spend their formative years and learn important lessons. They gain the right to stand upon their marae and proclaim their views about the world and life.'738

\footnotetext{
735 Rowson, 'How are we disposed to be creative?' 85-86; Negus and Pickering, Creativity, Communication and Cultural Value, 8-9.

736 Roberta MacGuire, 'Dewey's pragmatism extended', in Albert Murray and the Aesthetic Imagination of a Nation, ed. Barbara Baker (Tuscaloosa, AL: University of Alabama Press, 2010),108-109.

737 Te Ahukaramū Charles Royal. 'Papatūānuku - the land - Tūrangawaewae - a place to stand', Te Ara - the Encyclopedia of New Zealand (Updated 22 September 2012), <http://www.TeAra.govt.nz/en/papatuanuku-the-land/page-5.> (3 June 2014).

738 Ibid.
} 
I began this thesis by suggesting that jazz was not just intriguing or remarkable or beautiful, but actually important. For me, that importance is partly about the wonderful music that jazz musicians have made together across the past century. But it is also about the ways our engagement with jazz (as listeners, as performers, as teachers) offers us a place to stand, a place that both marks us out as individual while at the same time marks us as belonging to a community. For those who play the music, jazz is both Tūrangawaewae - a place to stand - and the marae - a place where our ancestors are present and from which we can proclaim our views about the world and life. From this place of communion - the place where the voices of individuals join in a colloquy where the total is greater than the sum of the parts - the shape of jazz to come, has emerged, and, ceteris paribus, will continue to emerge. From this communion there also emerges a collateral benefit - or perhaps the greatest benefit depending upon the view one takes. In contexts where all voices are invited to speak, where all voices need to be heard for the best work to be achieved, we find Albert Murray's equipment for living, and a model for collaborative work that we can apply to life beyond the bandstand, beyond the ensemble classroom, beyond the jam session. Sometimes collaborative work fails, sometimes it leads to very ordinary routine outcomes, but just occasionally it yields solutions to impasse and reveals the way ahead. In all cases, but perhaps especially in these moments of new insight, jazz becomes an example and a metaphor for a way all can live and work together in our troubled world.

Naku te rourou nau te rourou ka ora ai te iwi 739

739 With your basket and my basket the people will live. Woodward Maori: 'Maori Proverbs: Whakatauki' (Updated 5 February 2014), < http://www.maori.cl/Proverbs.htm> (3 June 2014). 


\section{Appendix 1: Transcriptions}

1. Ornette Coleman's solo on 'Garden of Souls' from New York is Now (1968)

2. Russell Procope's solo on 'Mood Indigo' from Masterpieces by Ellington (1952)

3. Russell Procope's solo on 'Mood Indigo' from The Private Collection (1958)

4. Russell Procope’s solo on 'Mood Indigo' from 'Live' Guard Radio Sessions (1962)

5. Russell Procope's solo on 'Mood Indigo' from New York, New York (19701972) 
The Garden of Souls | New York Is Now [1968]

Ornette Coleman Solo: 1:40 minutes
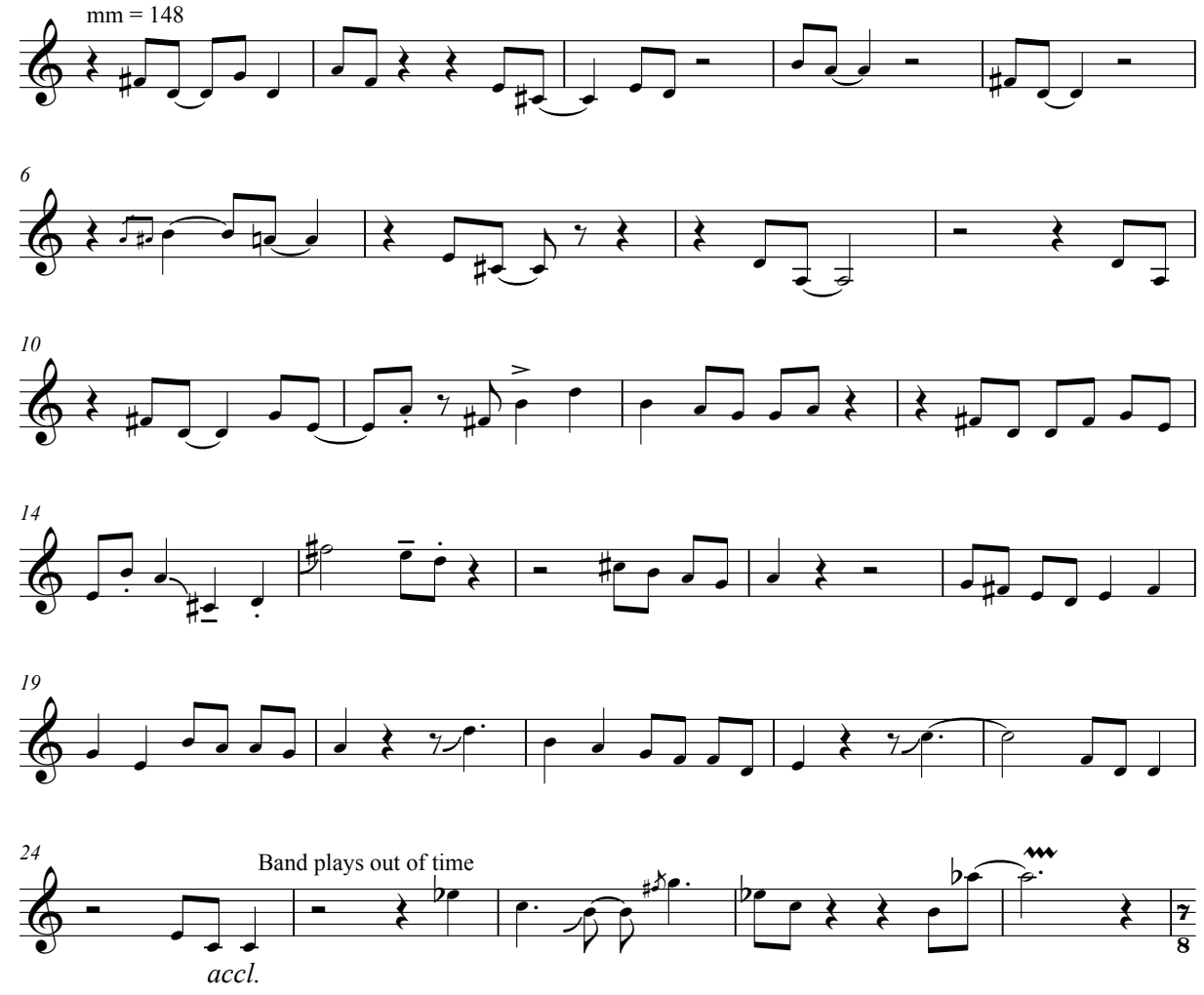

New tempo $\mathrm{mm}=218$

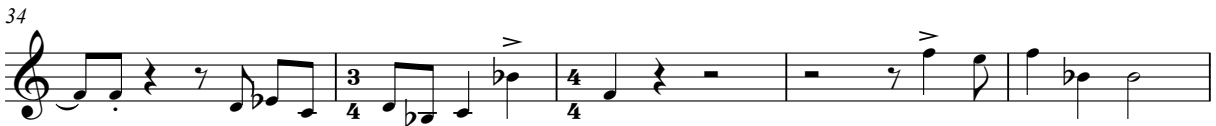
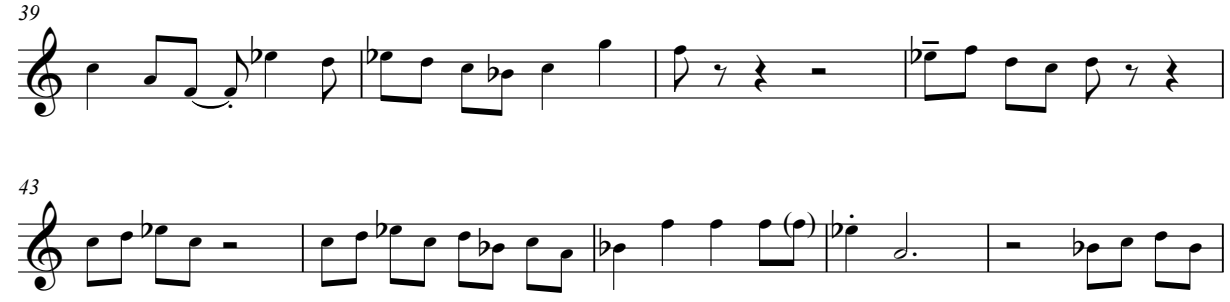

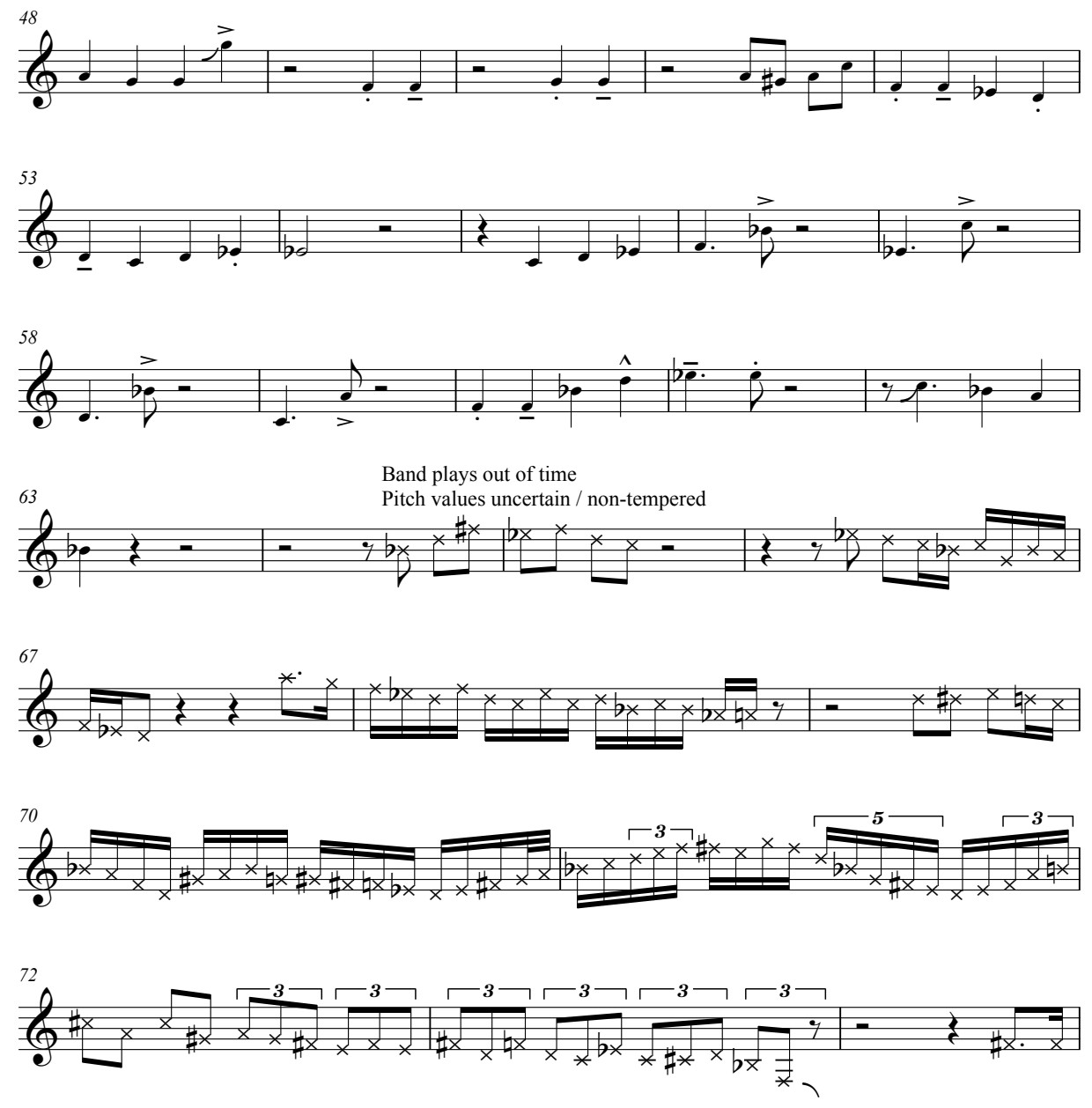

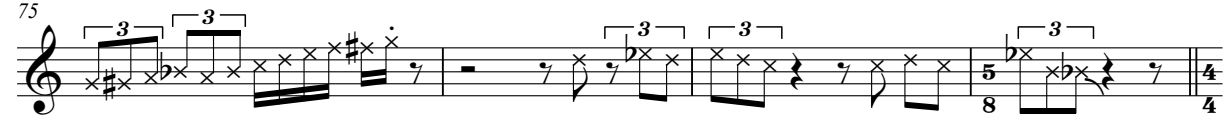

New Tempo mm = 144

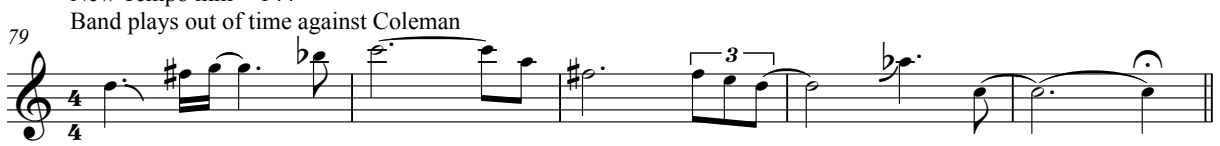

New Tempo $\mathrm{mm}=166$

Band plays in time with Coleman 


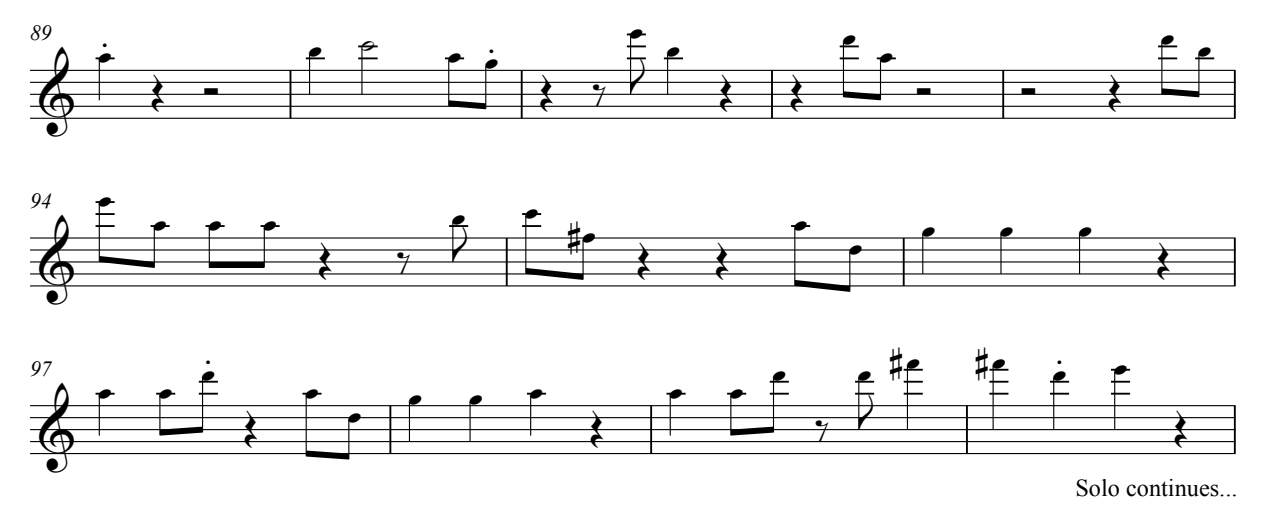

256 
Mood Indigo | Masterpieces By Ellington [1952]

Russell Procope solo: 1:02 minuntes
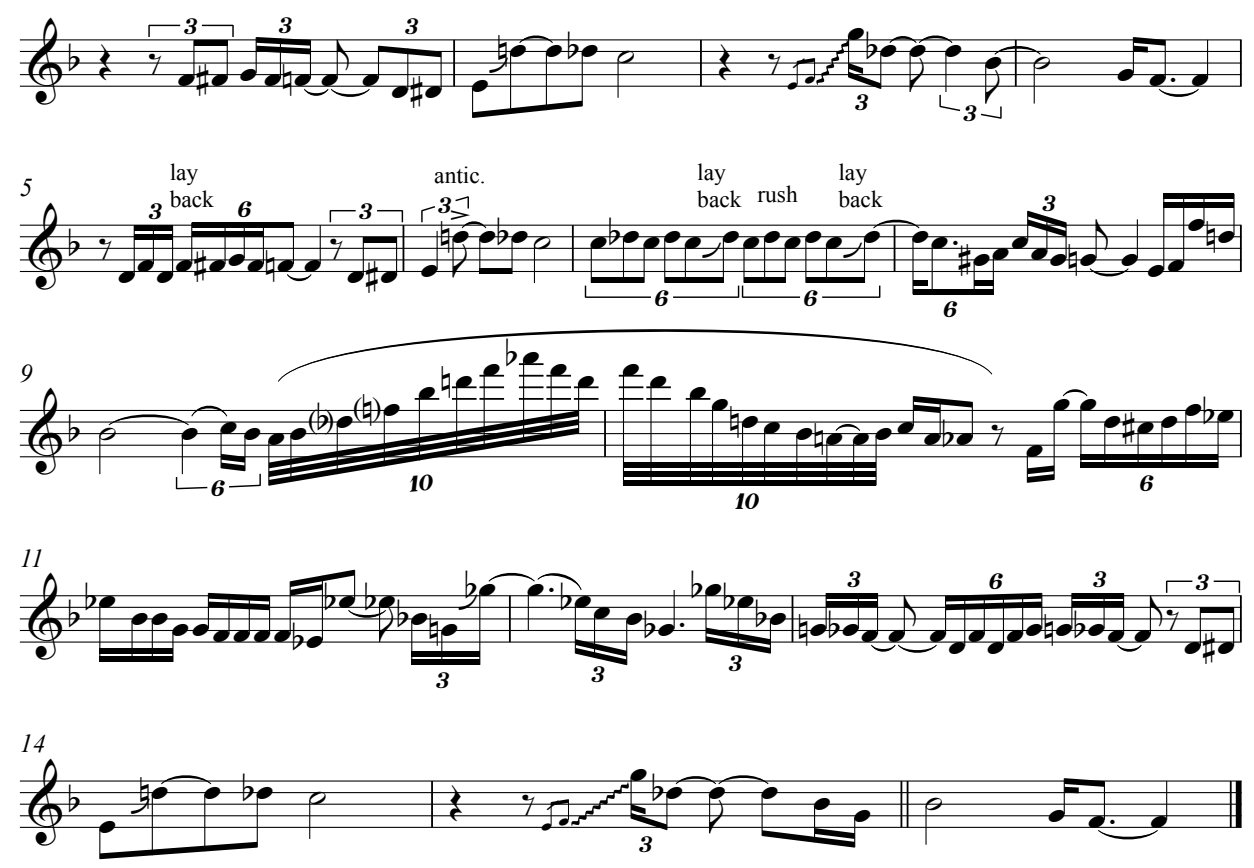
Mood Ingido | The Private Collection [1958]

Russell Procope solo: 1:35 minutes
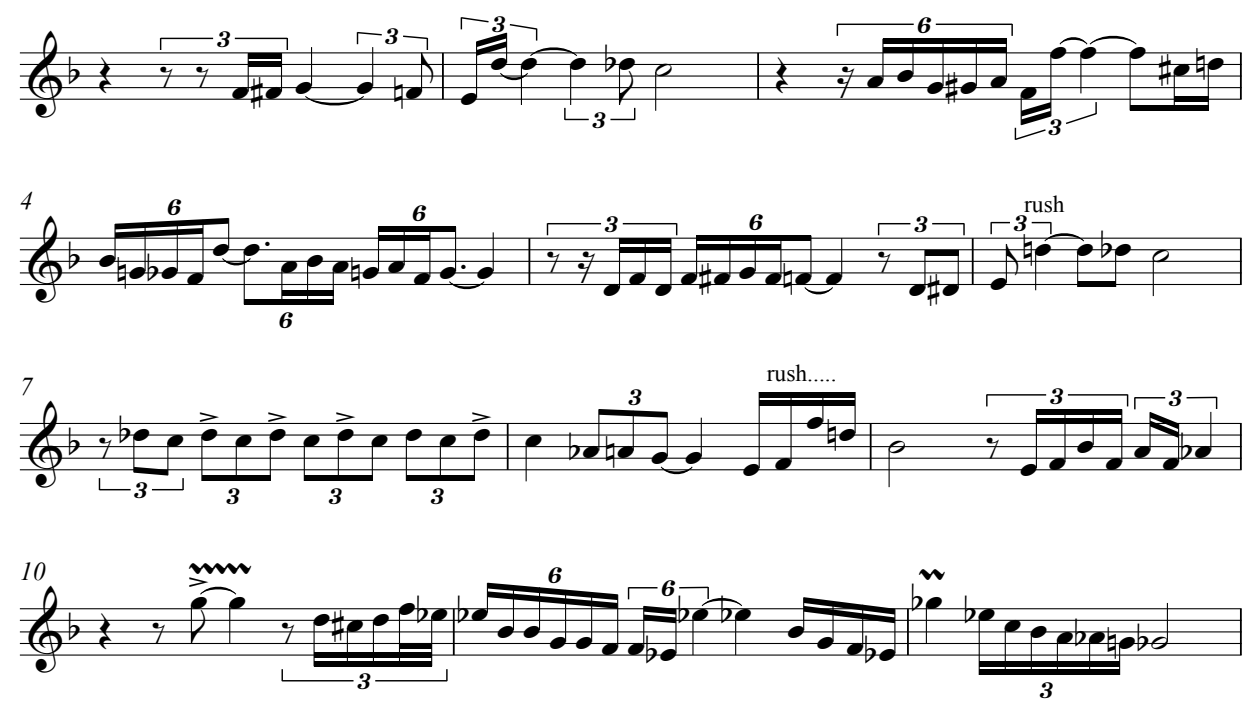

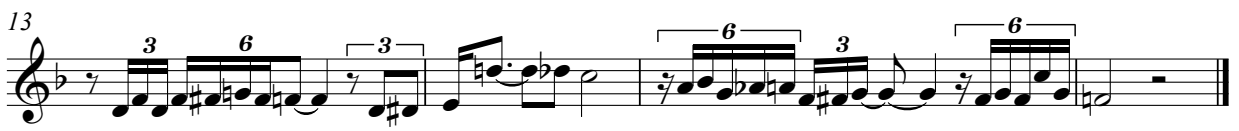


Mood Indigo | 'Live' Guard Radio Sessions [1962]
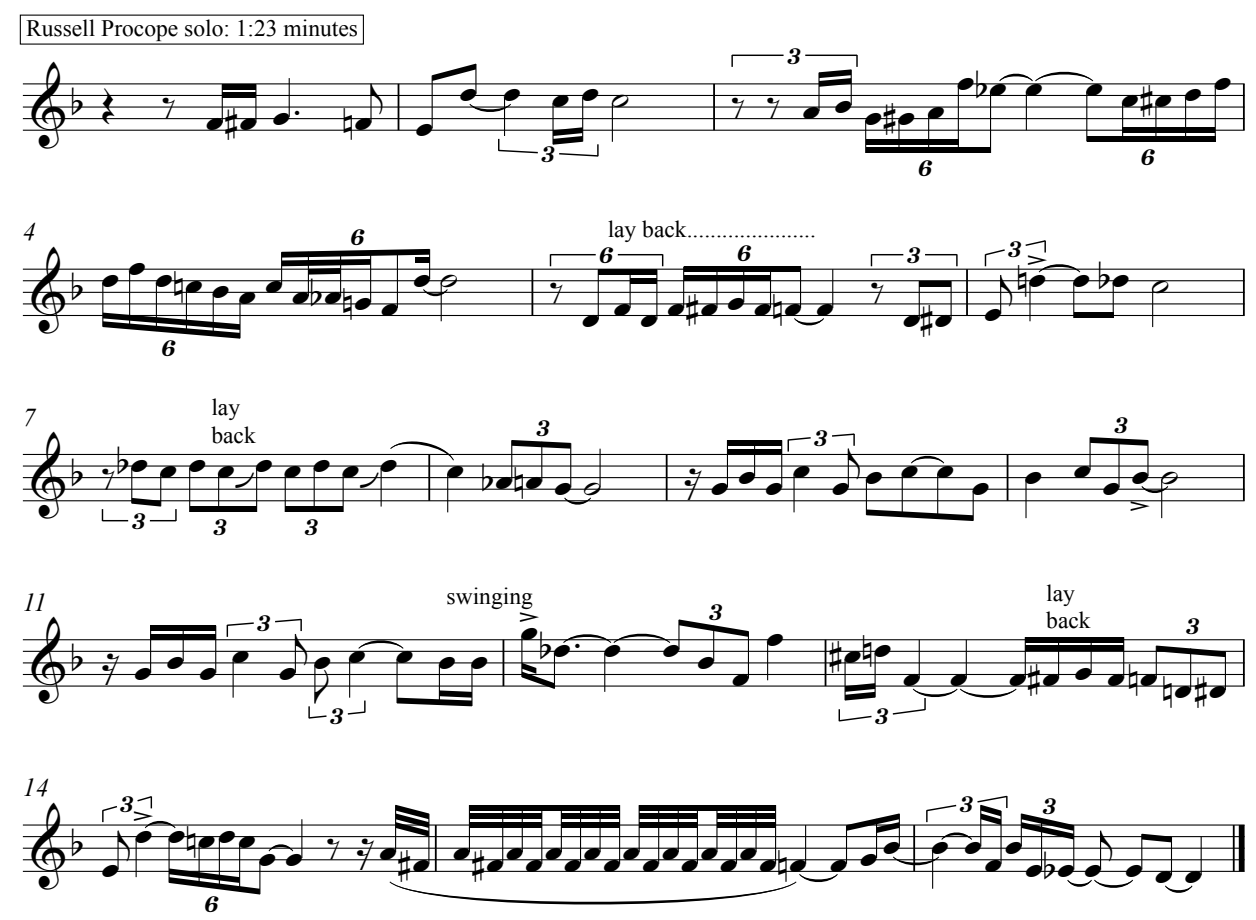
Mood Indigo | New York New York [1970-1972]

Russell Procope solo: 0:58 minutes

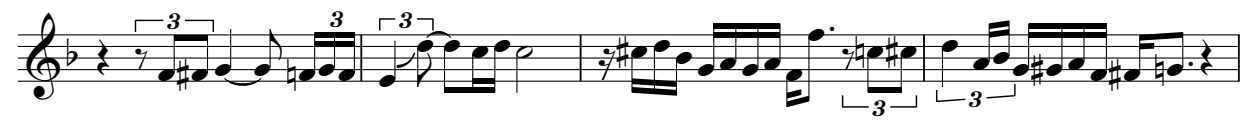

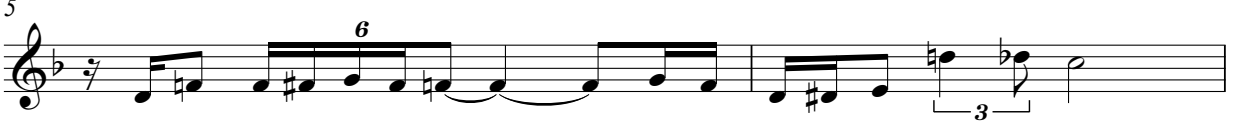

(freely.......
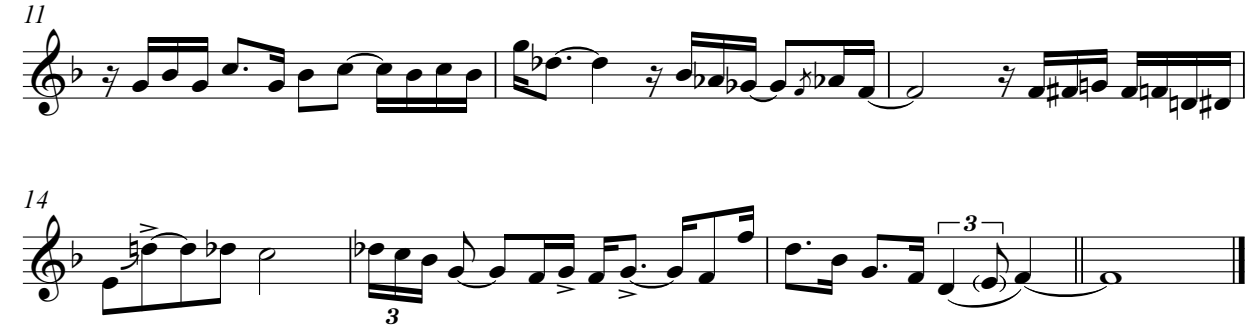


\section{Sources}

\section{Selected Discography}

Coleman, Ornette. In All languages. Fort Worth TX: Caravan of Dreams 85008, 1987.

Coleman, Ornette. New York is Now. New Jersey: Blue Note 784287 2, 1968.

Coleman, Ornette. The Music of Ornette Coleman: Something Else!!!! Los Angeles: Contemporary 7551, 1958.

Coleman, Ornette. The Shape of Jazz to Come. New York: Atlantic 1317, 1959.

Davis, Miles. Birth of the Cool. New York: Capitol T 792, 1957.

Davis, Miles. Bitches Brew. New York: Columbia C2J 40577, 1970.

Davis, Miles. Filles de Kilimanjaro. New York: Columbia CS 9750, 1968.

Davis, Miles. In A Silent Way. New York: Columbia CJ 40580, 1969.

Davis, Miles. Nefertiti. New York: Columbia CS 9594, 1967.

Davis, Miles. Sketches of Spain. New York: Columbia/Legacy CJ 40578, 1960.

Ellington, Duke. The Blanton Webster Band. Paris: Bluebird (3) - 5659-2-RB, 1986.

Ellington, Duke. Della Reece with Duke Ellington and his Orchestra. New York: Jazzband EBCB2110-2 (rec. 1962), 2013.

Ellington, Duke. Duke Ellington: New York, New York. New York: Storyville 1018402 (rec. 1970-1972), 2008.

Ellington, Duke. Ellington at Newport 1956. New York: Columbia/Legacy 64932, 1999.

Ellington, Duke. Masterpieces by Ellington. New York: Columbia/Sony 4694072, 1950.

Ellington, Duke. The Private Collection, Vol. 6: Dance Dates, California, 1958. New York: Rhino, 1989.

Evans, Bill. Trio 64. Los Angeles: Verve 8578, 1964.

Evans, Bill. Consecration. New York: Milestone, 8MCD 4436-2, 2002 (rec. 1980).

Garbarek, Jan, and Garnås, Agnes Buen. Rosenfole. Munich: ECM 1402, 1989.

Garbarek, Jan. Dansere. Munich: ECM 1075, 1975. 
Garbarek, Jan. Dis. Munich: ECM 1093, 1977.

Garbarek, Jan. Eventyr. Munich: ECM 1200, 1981.

Garbarek, Jan. Madar. Munich: ECM 1515, 1994.

Jarrett, Keith. My Song. Munich: ECM 1115, 1977.

\section{Filmography}

Burns, Ken. Jazz. New York: PBS, 2000.

Carter, Terry. A Duke Named Ellington. Los Angeles: Council for Positive Images, Inc., 1988.

Clarke, Shirley. Ornette Coleman: Made in America. New Jersey: Milestone Films, 1984.

Irvin, John. The Boys and Girl from County Clare. Isle of Man Film, 2003.

Lerner, Murray. Electric Miles: A Different Kind of Blue. London: Eagle Rock Entertainment, 2004.

Robinson, Ken. 'How school kills creativity.' TED: Talks (February 2006), http://www.ted.com/talks/ken_robinson_says_schools_kill_creativity.html>. 17 February 2014.

\section{Broadcasts}

Gould, Glenn. The Idea of North. Toronto: Canada Broadcasting Company (28 December 1967)

<http://www.cbc.ca/player/Radio/More+Shows/Glenn+Gould++The+CBC+Legacy/Audio/1960s/ID/2110447480/> 14 May 2014.

\section{Bibliography}

Agawu, Kofi. 'The Invention of "African Rhythm"'. Journal of the American Musicological Society 48/3 (Autumn 1995), 380-395.

Aikin, Jim. "Bill Evans", Contemporary Keyboard 6/6 (June 1980), 44-55. 
Ake, David. 'Re-Masculating Jazz: Ornette Coleman, "Lonely Woman," and the New York Jazz Scene in the Late 1950s'. American Music 12/1 (Spring 1998) 2544.

Ake, David. Jazz Matters. Berkeley: University of California Press, 2010.

Ake, David, and Garrett, Charles, and Goldmark, Daniel. Jazz/Not Jazz. Berkeley: University of California Press, 2012.

Amabile, Teresa. "How to kill creativity". Harvard Business Review (September 1998), 77-87.

Arieti, Silvano. Creativity: The Magic Synthesis. New York: Basic Books, 1976.

Bakhtin, Mikhail. The Dialogic Imagination: Four Essays. Austin: University of Texas, 1981.

Baraka, Amari. 'Miles Davis: One of the great mother fuckers', in A Miles Davis Reader. Ed. Bill Kirchener. Washington: Smithsonian, 1997, 63-73.

Barthes, Roland. Image - Music - Text. New York: Hill and Wang, 1977.

Bartók, Béla. 'The influence of peasant music on modern music'. In Béla Bartók Essays, ed. Benjamin Sichoff. Lincoln: University of Nebraska Press, 1976. 340344.

Bastien, David, and Hostager, Todd. 'Cooperation as communicative accomplishment: A symbolic interaction analysis of an improvised Jazz Concert'. Communication Studies 43/2 (1992), 92-104.

Bauman, Robert, and Briggs, Charles. 'Poetics and Performance as critical perspectives o language and social life'. In Creativity in Performance. Ed. R. Keith Sawyer, Norwood, NJ: Ablex, 1997, 227-264.

Becker, Howard. 'The Etiquette of Improvisation'. Mind, Culture, and Activity, 7 (2000), 171-76, 197-200.

Becker, Howard. Art Worlds. Berkeley: University of California Press, 1982.

Belgrad, Daniel. The Culture of Spontaneity: Improvisation and the Arts in Postwar America. Chicago: University of Chicago Press, 1998.

Berliner, Paul. Thinking in Jazz: The Infinite Art of Improvisation. Chicago: University of Chicago Press, 1994.

Bhabha, Homi. The Location of Culture. New York: Routledge, 1994.

Bigard, Barney. With Louis and Duke: The autobiography of a Jazz Clarinetist. New York: Oxford, 1986.

Blesh, Ruby. Shining Trumpets: A History of Jazz. New York: Alfred Knopf, 1946. 
Block, Steven. 'Pitch-Class Transformation in Free Jazz'. Music Theory Spectrum 12/2 (Autumn 1990) 181-202.

Boden, Margaret. 'Creativity: How does it work?' In The Idea of Creativity, ed. Michael Krausz, Dennis Dutton, and Karen Bardsley, Boston: Brill, 2009, 237250.

Borne, Michael. 'Jan Garbarek's Scandinavian Design'. Downbeat (July 1986), 2526.

Borneman, Ernest. ' Bop Will Kill Business Unless It Kills Itself First'-Louis Armstrong'. Downbeat (7 April 1948)

$<$ http://www.downbeat.com/default.asp?sect=stories\&subsect=story_detail\&si d=1048>. 7 April 2014.

Bradshaw, Paul. 'Lester Bowie'. Wire 34/35 (January 1987), 43-45.

Brofsky, Howard. 'Miles Davis and My Funny Valentine: The Evolution of a Solo'. Black Music Research Journal 3 (1983), 23-45.

Brownell, John. 'Analytical Models of Jazz Improvisation'. Jazz Research 26 (1994), 9-29.

Burnham, Scott. Beethoven: Hero. Princeton NJ: Princeton University Press, 2000.

Butterfield, Matthew. 'Participatory discrepancies and the perception of beats in jazz'. Music Perception: An Interdisciplinary Journal 27/3 (February 2010), 157176.

Caponi, Gena. 'Introduction: The case for an African American Aesthetic'. In Signifyin(g), Sanctifyin', \& Slam Dunking: A Reader in African American Expressive Culture, (ed.) Gena Caponi, Amherst: University of Michigan, 1999, 1-43.

Carneiro, Robert. 'A Theory of the Origin of the State'. Science 169 (1970), 733738.

Carr, Ian. Keith Jarrett: The man and his music. New York: Da Capo, 1991.

Carr, Ian. Miles Davis: The Definitive Biography. New York: Thunder's Mouth Press, 1998.

Carr, Ian, Fairweather, Digby, and Priestly, Brian. The Rough Guide to Jazz. London: Rough Guides, 2004.

Chambers, Jack. Milestones: The Music And Times Of Miles Davis. New York: Da Capo Press, 1998.

Cheng, Chi-Ying, Sanchez, Jeffrey, and Lee, Fiona. 'Connecting the dots within Creative Performance and Identity Integration'. Journal for the Association for Psychological Science 19/11 (2008), 1178-1184. 
Chernoff, John Miller. African Rhythm and African Sensibility. Chicago: Chicago University Press, 1979.

Claxton, Guy. 'Wisdom: Advanced Creativity?' In Creativity, wisdom, and trusteeship: exploring the role of education, ed. Anna Craft, Howard Gardner and Guy Claxton. Thousand Oaks, CA: Corwin Press, 2008, 35-48.

Collier, James L. The Making of Jazz: A comprehensive history. London: Delacorte, 1979.

Collins, Billy, and Amabile, Teresa. 'Motivation and Creativity'. In Handbook of Creativity, ed. Robert Sternberg. Cambridge: Cambridge University Press, 1999, 297-312.

Cook, Richard. It's About That Time: Miles Davis on and off record. London: Oxford, 2007.

Cook, Richard and Morton, Brian. The Penguin Guide to Recorded Jazz. London: Penguin, 2011.

Coopersmith, Stanley. The Antecedents of Self-esteem. San Francisco: Freeman, 1967.

Cope, David. Computer Models of Musical Creativity. Cambridge, MA: MIT Press, 2006.

Cowley, Julian. 'Free your mind and your ass will follow'. The Wire 295 (2008), 34-40.

Craft, Anna. 'Tensions in Creativity and Education: Enter wisdom and trusteeship?'. In Creativity, wisdom, and trusteeship: exploring the role of education, ed. Anna Craft, Howard Gardner and Guy Claxton. Thousand Oaks, CA: Corwin Press, 2008, 16-34.

Crouch, Stanley. "Play The Right Thing”. In The Miles Davis Companion, ed. Gary Garner, New York: Schirmer, 1990, 21-40.

Crouch, Stanley. Considering Genius. New York: Basic Books, 2006.

Csikszentmihalyi. Mihaly. Flow: The Psychology of Optimal Experience. New York: Harper \& Row, 1990.

Csikszentmihalyi, Mihaly. Creativity. New York: HarperCollins, 1996.

Dahlhaus, Carl. Between Romanticism and Modernism: Four Studies in the Music of the Later Nineteenth Century. Berkeley: University of California Press, 1980.

Dance, Stanley. The World of Duke Ellington. New York: Da Capo, 2000.

Darter, Tom and Doerschuk. 'Chick Corea.' Contemporary Keyboard (July, 1983), 54-60. 
Davis, Francis. 'Ornette's Permanent Revolution'. The Atlantic Monthly 257/3 (September 1985) 99-102.

Davis, Miles, and Troupe, Quincy. The Autobiography. New York: Simon and Schuster, 1989.

DeBono, Edward. Lateral Thinking. New York: Harper Colophon, 1973.

Deliege, Irene and Wiggins, Geraint (eds.). Musical Creativity: Multidisciplinary Research in Theory and Practice. London: Psychology Press, 2006.

Demmers, Joanne. Steal This Music. Athens: The University of Georgia Press, 2006.

DeVeaux, Scott. 'Constructing the Jazz Tradition'. Black American Literature Forum 25/3 (Fall, 1991), 525-560.

DeVeaux, Scott. The Birth of Bebop: A social and musical history. Berkeley: University of California Press, 1997.

Dyer, Geoff. But Beautiful. New York: North Point Press, 1996.

Gerald Early. 'The Art of the Muscle: Miles Davis as American Knight and American Knave.' In Miles Davis and American Culture, ed. Gerald Early. Missouri Historical Society, 2001, 3-23.

Eisenberg, Evan. The Recording Angel: Music, Records and Culture from Aristotle to Zappa. New Haven, CT: Yale University Press, 1998.

Ellington, Duke. Music is my Mistress. New York: Doubleday, 1973.

Ellison, Ralph. Shadow and Act. New York: Random House, 1964.

Ettema, James and Whitney, Charles. Individuals in Mass Media Organisations: Creativity and Constraint. London: Sage, 1982.

Feld, Steven. 'From Schizophonia to Schisomogenesis: The Discourses and Practices of World Music and World Beat'. In The Traffic in Culture: Refiguring Art and Anthropology, ed. George Marcus and Fred Meyers. Berkeley: University of California, 1995, 96-126.

Feldman, Morton and Friedman, Bernard. Give My Regards to Eighth Street: Collected Writings of Morton Feldman. Cambridge: Exact Change, 2000.

Fernandez, Raul. From Afro-Cuban Rhythms to Latin Jazz. Berkeley: University of California Press, 2006.

Finke, Ronald, Ward, Thomas, and Smith, Steven. Creative Cognition: Theory, Research, and Applications. Cambridge: Bradford Books, 1996.

Florida, Richard. 'Why Creative Workers Are Good For The Economy.' The Atlantic. (September 13, 2013) <http://www.theatlanticcities.com/jobs-and- 
economy/2013/09/real-reason-creative-workers-are-good-economy/6804/>. 17 February 2014.

Floyd, Samuel. The Power of Black Music: Interpreting its history from Africa to the United States. New York: Oxford University Press, 1995.

Fusilli, Jim. John McLaughlin: From Miles Davis Protégé to 'Old Punk.' Wall Street Journal (26 March 2014),

<http://online.wsj.com/news/articles/SB10001424052702303779504579463 164133136046?mg=reno64wsj\&url=http\%3A\%2F\%2Fonline.wsj.com\%2Farticl e\%2FSB10001424052702303779504579463164133136046.html>. 31 March, 2014.

Giddens, Gary. 'Red Garland's Texas Cocktail'. The Village Voice (3 April 1978), 49-50.

Gilroy, Paul. The Black Atlantic. Cambridge: Harvard University Press, 1993.

Ginell, Cary. Walk Tall: The Life and Music of Julian "Cannonball" Adderley.. Milwaukee: Hal Leonard, 2013.

Gioia, Ted. The History of Jazz. Oxford: Oxford University Press, 1997.

Gioia, Ted. The Imperfect Art. Stanford: Standard Alumni Association with Oxford University Press, 1988.

Gladwell, Malcolm. The Tipping Point: How little things can make a big difference. Boston: Back Bay Books, 2002.

Gladwell, Malcolm. Outliers: The Story of Success. New York: Little, Brown and Company, 2008.

Go, I-Huei. 'Ornette Coleman'. New York Observer. (19 December 2005), <http://observer.com/2005/12/ornette-coleman-2/>. 18 March 2014.

Goddard, Chris. Jazz away from home. New York: Paddington Press, 1979.

Goehr, Lydia. The Imaginary Museum of Musical Works: An essay in the philosophy of music. Oxford: Oxford University Press, 2007.

Goodman, John. Mingus Speaks. Berkeley: University of California Press, 2013.

Green, Lucy. Music, Gender, Education. Cambridge: Cambridge University Press, 1997.

Gridley, Mark. Jazz Styles. Harlow (UK): Pearson, 1994.

Griffiths, Paul, and Lake, Steve. Horizons Touched. London: Granta, 2007.

Guilford, Joy P. The nature of human intelligence. Columbus. OH.: McGraw-Hill, 1967. 
Gumperz, John. Discourse Strategies. New York: Cambridge University Press, 1982.

Gushee, Larry. 'Lester Young's “Shoeshine Boy”.' International Musicological Society, 12 ${ }^{\text {th }}$ Congress (1977), 151-69.

Hall, Fred. It's About Time: The Dave Brubeck Story. Fayetteville: University of Arkansas Press, 1996.

Hancock, Herbie. 'The 2014 Norton Lectures'. 3 February 2014

<http://vimeo.com/86264725>. 11 April 2014.

Harris, Jerome. 'Jazz on the global stage.' In The African Diaspora: A Musical Perspective, ed. Ingrid Monson, New York: Garland, 2000, 101-134.

Heining, Duncan. George Russell: The Story of an American Composer. Lanham, MA: Scarecrow Press, 2009.

Hennessey, Beth and Amabile, Teresa. 'The conditions of creativity'. In The Nature of Creativity: Contemporary Psychological Perspectives, ed. Robert Sternberg, Cambridge: Cambridge University Press, 1988. 11-38.

Hentoff, Nat. 'The truth is marching in: an interview with Albert and Don Ayler'. Downbeat 33/23 (November 17, 1966), 40.

Hodson, Robert. Interaction, Improvisation and Interplay in Jazz. New York: Routledge, 2007.

Howland, John. Ellington Uptown: Duke Ellington, James P. Johnson, and the Birth of Concert Jazz. Ann Arbor: University of Michigan Press, 2009.

Hytönen-Ng, Elina. Experiencing 'Flow' in Jazz Performance. Farnham: Ashgate, 2013.

Iverson, Ethan. 'This is our Mystic'. Do The Math (19 September, 2010), <http://dothemath.typepad.com/dtm/this-is-our-mystic.html>. 17 March 2014.

Jackson, Travis. Blowin' the Blues Away: Performance and Meaning on the New York Jazz Scene. Berkeley: University of California Press, 2012.

Jackson, Travis. 'Jazz Performance as Ritual'. In The African Diaspora: A Musical Perspective, ed. Ingrid Monson, New York: Garland, 2000, 23-82.

Jeffrey, Bob and Craft, Anna. 'The unversalisation of creativity'. In Creativity in Education, ed. Anna Craft and Bob Jeffrey and Mike Leibling. London: Continuum, 2001, 1-13.

Jewell, Derek. Duke: A Portrait of Duke Ellington. London: Elm Tree, 1977.

Johnson, Bruce. 'Hear me talkin' to ya: problems of jazz discourse'. Popular Music 12/1 (1993), 1-12. 
Johnson-Laird, Philip. 'Freedom and constraint in creativity'. In The Nature of Creativity, ed. Robert Sternberg, New York: Cambridge University Press, 1988. 202-219.

Jost, Ekkehard. Free jazz. New York: Da Capo, 1974.

Kahn, Ashley. Kind Of Blue: The making of the Miles Davis masterpiece. New York: Da Capo, 2000.

Kahn, Ashley. 'Blue Clues: Kind of Blue'. Jazztimes, 30 (September 2000), 72-79, 193.

Kahn, Ashley. A Love Supreme: The Story of John Coltrane's Signature Album. New York: Penguin, 2002.

Kant, Larry. 'Provocative Opinion: The Death of Jazz'. Black Music Research Journal 10/1 (Spring 1990) 76-81.

Kaplan, Fred. 1959: The Year Everything Changed. Hoboken, NJ: John Wiley and Sons, 2009.

Kaufman, James. Creativity 101. New York: Springer Publishing Company, 2009.

Keil, Charles. 'The theory of participatory discrepancies: A progress report'. Ethnomusicology, 39 (1995), 1-19.

Keith, Hamish. Native Wit. Auckland: Random House, 2008.

Kernfeld, Barry. 'Two Coltranes'. Annual Review of Jazz Studies 2 (1983), 7-66.

Kernfeld, Barry. Ed. The New Grove Dictionary of Jazz. London: MacMillan, 1988.

Klee, Joe and Smith, Will. 'Paul Bley'. Downbeat 41/1 (17 January 1974), 12-13.

Koestler, Arthur. The act of creation. New York: MacMillan, 1964 [Reprinted 1975].

Kuhn, Thomas. The structure of scientific revolutions. Chicago: Chicago University Press, 1962, 2012.

LaFaro-Fernandez, Helene. Jade Visions: The life and Music of Scott LaFaro. Denton, TX: University of North Texas Press, 2009.

Levine, Mark. The Jazz Theory Book. Petaluma, CA: Sher Music, 1995.

Levy, Joe and Van Zandt, Steven. Rolling Stone's 500 Greatest Albums. London: Turnaround, 2005.

Lewis, George. 'Improvised Music After 1950: Afrological and Eurological Perspectives'. In The Other Side of Nowhere: Jazz, improvisation, and communities in dialogue, ed. David Fischlin and Ajay Heble, Middleton, Connecticut: Wesleyan University Press, 2004, 131-162. 
Lewis, George. A Power Stronger than itself. Chicago: University of Chicago Press, 2008.

Litweiler, John. Ornette Coleman: A Harmolodic Life. New York: William Morrow, 1993.

Litweiler, John. The Freedom Principle: Jazz After 1958. New York: Morrow, 1984.

Lopez, Paul. The Rise of a Jazz Art World. Cambridge: Cambridge, 2002.

Lott, Eric. 'Double V, double-time: Bebop's politics and style'. Calloo 36 (Summer 1988), 597-605.

Lyons, Len. The Great Jazz Pianists: Speaking of their Lives and Music. New York: William Morrow, 1983.

Macguire, Roberta. 'Dewey's Pragmatism Extended: Education and Aesthetic Practice in Train Whistle Guitar.' In Albert Murray and the Aesthetic Imagination of a Nation, ed. Barbara Baker, Tuscaloosa, AL: University of Alabama Press, 2010, 102-113.

Mandel, Howard. Miles, Ornette, Cecil: Jazz Beyond Jazz. New York: Routledge, 2008.

Marks, Morton. 'Uncovering ritual structures in contemporary America'. In Religious movements in contemporary America, ed. Irving Zaretsky and Mark Leone. Princeton, NJ: Princeton University Press, 1974, 60-129.

Marsalis, Wynton. 'Jazz as a model of democratic action'. <http://www.discovery.com/tv-shows/curiosity/topics/wynton-marsalis-jazzas-a-model-of-democratic-action.htm>. 6 May 2014.

Martin, Henry. Jazz: The First 100 Years. London: Cengage Learning, 2011.

Martin, Henry. 'The Nature of Re-composition: Miles Davis and 'Stella By Starlight". Annual Review of Jazz Studies 9 (1997-1998), 77-92.

Mayer, Marissa. 'Fifty years of creativity research'. In Handbook of Creativity, ed. Robert Sternberg, Cambridge: Cambridge University Press, 1999. 449-460.

Mazzola, Guerimo, Park, Joomi and Thalmann, Florian. Musical Creativity: Strategies and Tools in Composition and Improvisation. New York: Springer Publishing Company, 2011.

Means, Lauren, and Primack, Bret. (1979). "Mike Nock: Journeyman Keyboardist Rediscovers Acoustic Jazz". Contemporary Keyboard 5/9 (September, 1979), 1821.

Meehan, Norman. Serious Fun: The Life and Music of Mike Nock. Wellington: Victoria University Press, 2010. 
Meehan, Norman. Time Will Tell: Conversations with Paul Bley. Berkeley: Berkeley Hills Books, 2003.

Metzer, David. 'Shadow Play: The Spiritual in Duke Ellington's "Black and Tan Fantasy",' Black Music Research Journal 17/2 (Autumn 1997), 137-158.

Meyers, Marc. Why Jazz Happened. Berkeley: University of California Press, 2012.

Monson, Ingrid. Freedom Sounds: Civil Rights Call Out to Jazz and Africa. Oxford: Oxford University Press, 2007.

Monson, Ingrid. 'Introduction'. In The African Diaspora: A musical perspective, ed. Ingrid Monson, New York: Garland Publishing, 2000 (a), 1-20.

Monson, Ingrid. 'Art Blakey's African Diaspora'. In The African Diaspora: A musical perspective, ed. Ingrid Monson, New York: Garland Publishing, 2000 (b), 324-347.

Monson, Ingrid. 'Riffs, Repetition, and Globalization'. Ethnomusicology, 43/1 (1999), 31-65.

Monson, Ingrid. Saying Something: Jazz Improvisation and Interaction. Chicago: University of Chicago Press, 1996.

Morrison, Alan. 'You Gotta be Original, Man'. In A Lester Young Reader, ed. Lewis Porter, Washington: Smithsonian Institution, 1991, 131-135.

Morton, Brian. 'The Primer: Don Cherry'. Wire 353 (July 2013), 40-49.

Morton, John Fass. Backstory in Blue: Ellington at Newport '56. New Brunswick NJ: Rutger's University Press, 2008.

Murray, Albert. Stomping the Blues. New York: McGraw-Hill, 1976.

Murray, Albert. 'Improvisation and the Creative Process'. In The Jazz Cadence of American Culture, ed. Robert O’Meally, New York: Columbia University Press, 1998, 111-113.

Negus, Keith and Pickering, Michael. Creativity, Communication and Cultural Value. London: Sage, 2004.

Negus, Keith and Pickering, Michael. 'Creativity and musical experience'. In Popular Music Studies, ed. David Hesmondhalgh and Keith Negus, London: Arnold, 2002, 178-190.

Nettl, Bruno. Heartland Excursions: Ethnomusicological Reflections on Schools of Music. Urbana: University if Illinois Press, 1995.

Nicholson, Stuart. Is Jazz Dead (or has it moved to a new address)? New York: Routledge, 2005.

Nicholson, Stuart. Jazz Rock: A History. New York: Schirmer, 1998. 
Nickerson, Raymond. 'Enhancing Creativity'. In Handbook of Creativity, ed. Robert Sternberg, Cambridge: Cambridge University Press, 1999, 392-430.

Nisenson, Eric. Blue: The Murder of Jazz. New York: Da Capo, 2000.

Nisenson, Eric. The Making of Kind of Blue: Miles Davis and his Masterpiece. New York: St. Martins Press, 2000.

O’Meally, Robert. (ed.) The Jazz Cadence of American Culture. New York: Columbia University Press, 1998.

O'Meally, Robert, Edwards, Brent, and Griffin, Farah (eds.). Uptown Conversation: The New Jazz Studies. New York: Colombia, 2004.

Owens, Thomas. Charlie Parker: Techniques of improvisation. PhD dissertation. UMI, 1974.

Owens, Thomas. Bebop: The music and its players. New York: Oxford University Press, 1995.

Palmer, Robert. [Liner notes], in Rivers, Sam. Dimensions and Extensions. New York: Blue Note BST 84261. 1987.

Palmer, Robert. [Liner notes], in Coleman, Ornette, Beauty is a Rare Thing; [liner notes] in Ornette Coleman: The Complete Atlantic Recordings. New York: Atlantic R2 71410, 1993.

Parkhurst, Howard. 'Confusion, lack of consensus, and the definition of creativity as a construct'. Journal of creative behavior 33 (1999), 1-21.

Paul, Annie. 'What the jazz greats knew about creativity'. Time (12 March 2012), <http://ideas.time.com/2012/03/21/learning-creativity-from-the-jazzgreats/>. 29 April 2014.

Pepper, Art, and Pepper, Laurie. Straight Life: The Story of Art Pepper. New York: Da Capo, 2009.

Perkins, David. The Mind's Best Work. Cambridge, MA: Harvard University Press, 1981.

Peterson, Lloyd. Music and the Creative Spirit: Innovators in Jazz, Improvisation and the Avant Garde. Lanhan MA: The Scarecrow Press, 2006.

Piazza, Tom. The Guide to Classic Recorded Jazz. Iowa City: University of Iowa Press, 1995.

Pickering, Michael, and Negus, Keith. 'Rethinking Creative Genius'. Popular Music 23/2 (2004), 198-203.

Paul Plsek. 'Models for the Creative Process' (1996) <http://www.directedcreativity.com/pages/WPModels.html>. 24 March 2014. 
Plucker, Jonathan, Beghetto, Ronald and Dow, Graham. 'Why isn't creativity more important to educational psychologists? Potential, pitfalls, and future directions in creativity research'. Educational Psychologist 39 (2004), 83-96.

Plucker, Jonathan and Beghetto, Ronald. 'Why Creativity is Domain General, Why it Looks Domain Specific, and Why the Distinction Does Not Matter'. In Creativity: From Potential to Realization , ed. Robert Sternberg, Elena Grigorenko and Jerome Singer, Washington DC: American Psychological Association, 2004, 153-167.

Porter, Eric. What is this thing called Jazz? Berkeley: University of California Press, 2002.

Potter, Gary. 'Analyzing Improvised Jazz', College Music Symposium 32 (1990), 143-60.

Priest, Thomas. 'Using Creativity Assessment Experience to Nurture and Predict Compositional Creativity'. Journal of Research in Music Education 49/3 (Autumn 2001), 245-257.

Priestly, Brian. Mingus: A Critical Biography. New York: Da Capo, 1982.

Prouty, Ken. 'The "Finite" Art of Improvisation: Pedagogy and Power in Jazz Education'. Critical Studies in Improvisation 4/1 (2008),

<http://www.criticalimprov.com/article/view/346/966>. 4 March 2014.

Radano, Ronald. Lying Up A Nation: Race and Black Music. Chicago: University of Chicago Press, 2003.

Ragogna, Mike. Tribute To Miles: A Conversation With Herbie Hancock. (24 June 2011) <http://www.huffingtonpost.com/mike-ragogna/tribute-to-miles-aconver_b_883658.html>. 26 March 2014.

Raphael-Hernandez, Heike. Blackening Europe: The African American Presence. Florence, KY: Routledge, 2012.

Ratliff, Ben. Coltrane: the story of a sound. New York: Farrar, Straus and Giroux, 2007.

Rattenbury, Ken. Duke Ellington, Jazz Composer. New Haven: Yale, 1993.

Reeves, Scott. Creative Improvisation. New Jersey: Prentice Hall, 1988.

Rhyammar, Lars and Brolin, Catarina. 'Creativity Research: Historical considerations and main lines of development'. Scandinavian Journal of Education Research 43/3 (1999), 259-237.

Rinzler, Paul. The Contradictions of Jazz. Lanham, MA: The Scarecrow Press, 2008.

Roberts, John S. Black Music of Two Worlds. New York: William Morrow, 1972. 
Rowson, Jonathan. 'How are we disposed to be creative?' In Creativity, wisdom, and trusteeship: exploring the role of education, ed. Anna Craft, Howard Gardner and Guy Claxton. Thousand Oaks, CA: Corwin Press, 2008, 84-95.

Royal, Te Ahukaramū Charles. 'Papatūānuku - the land - Tūrangawaewae - a place to stand', Te Ara - the Encyclopedia of New Zealand (Updated 22

September 2012) <http://www.TeAra.govt.nz/en/papatuanuku-the-land/page5.>. 3 June 2014.

Runco, Mark. Creativity. Theories and Themes: Research, development and practice. San Diego: Elsevier Academic Press, 2007.

Russell, George. The Lydian chromatic concept of tonal organization. Brookline, MA: Concept Publishing Company, 2008.

Sancton, Thomas. 'Horns of Plenty'. Time (22 October 1990), 64-71.

Sarath, Ed. Improvisation, Creativity and Consciousness. Albany: SUNY Press, 2013.

Sarath, Ed. 'A New Look at Improvisation'. Journal of Music Theory 40/1 (Spring, 1996), 1-38.

Sawyer, R. Keith. Group Genius. New York: Basic Books, 2007.

Sawyer, R. Keith. Explaining Creativity: The Science of Human Innovation. New York : Oxford University Press, 2006.

Sawyer, R. Keith. Group Creativity: Music, Theatre, Collaboration. London: Lawrence Erlbaum Associates, 2003.

Schafer, William. Brass Bands and New Orleans jazz. Baton Rouge: Louisiana State University Press, 1977.

Schiff, Ronald. Wayne Shorter: Artist Transcriptions. Miami: Warner Brothers, 2000.

Schuller, Gunther. Musings: The musical worlds of Gunther Schuller. New York: Da Capo, 1986.

Schuller, Gunther. Early Jazz: Its roots and musical development. New York: Oxford, 1968.

Schuller, Gunther. A Collection off the Compositions of Ornette Coleman. New York: MJQ Music, 1961.

Schwarz ,Benjamin. 'The end of Jazz: How America's most vibrant music became a relic'. The Atlantic (November 2012)

<http://www.theatlantic.com/magazine/archive/2012/11/the-end-ofjazz/309112/>. 7 April 2014. 
Shapiro, Nat and Hentoff, Nat. Hear Me Talkin' To Ya: The story of jazz as told by the men who made it. New York: Dover, 1955.

Shipton. Alyn. A New History of Jazz. London: Continuum, 2001.

Sidran, Ben. Talking Jazz. New York: Da Capo, 1995.

Simonton, Dean. 'Thematic fame, melodic originality, and musical zeitgeist: A biographical and transhistorical content analysis'. Journal of Personality and Social Psychology 38 (1980), 972-983.

Simonton, Dean. 'Creative Wisdom: Similarities, contrasts, integration and application'. In Creativity, wisdom, and trusteeship: exploring the role of education, ed. Anna Craft, Howard Gardner and Guy Claxton. Thousand Oaks, CA: Corwin Press, 2008, 68-76.

Simonton, Dean. 'Creative cultures, nations, and civilizations'. In Group Creativity: Innovation Through Collaboration, ed. Paul Paulus and Bernard Nijstad, Oxford: Oxford University Press, 2003, 304-325.

Sloboda, John. The Musical Mind: The cognative psychology of music. New York: Oxford University Press, 1985.

Small, Christopher. Music of the Common Tongue: Survival and celebration in Afro-American Music. New York: Riverrun Press, 1987.

Smith, Christopher. 'A Sense of the Possible: Miles Davis and the Semiotics of Improvised'. TDR 39/3 (Autumn, 1995), 41-55.

Smith, Jeremy. Sound, Mediation, and Meaning in Miles Davis's "A Tribute to Jack Johnson". PhD Dissertation, Duke. UMI, 2008.

Solis, Gabriel. 'A unique chunk of jazz reality': Authorship, musical work concepts and Thelonious Monk's live recordings from The Five Spot'. Ethnomusicology 48/3 (Fall, 2004), 315-347.

Southern, Eileen. The Music of Black Americans. New York: W.H. Norton, 1983.

Sternberg, Robert. 'The development of creativity as a decision making process'. In Creativity and Development, ed. R Keith Sawyer, Vera John-Steiner and Seana Moran, New York: Oxford University Press, 2003, 91-138.

Sternberg, Robert. 'A three-facet model of creativity'. In The Nature of Creativity, ed. Robert Sternberg, New York: Cambridge University Press, 1988, 125-147.

Sternberg, Robert, Kaufman, James and Pretz, Jean. The creativity conundrum. Philadelphia: Psychology Press, 2001.

Sternberg, Robert and Lubart, Todd. 'The concept of creativity: prospects and paradigms'. In Handbook of Creativity, ed. Robert Sternberg, Cambridge: Cambridge University Press, 1999, 3-15. 
Stewart, James. 'Introduction to Black Aesthetics in Music'. In The Black Aesthetic, ed. Addson Gayle, New York: Doubleday, 1971, 81-96.

Stewart, Rex. Jazz Masters of the Thirties. New York: Da Capo, 1980.

Sullivan, Timothy, and Willingham, Lee (eds.). Creativity and Music Education. Montreal: Canadian Music Educators' Association, 2003.

Szwed, John. So What: The life of Miles Davis. New York: Simon and Schuster, 2002.

Tambiah, Stanley. Culture, Thought and Action. An anthropological perspective. Cambridge: Harvard University Press, 1985

Taruskin, Richard. Music in the Early Twentieth Century: The Oxford History of Western Music, Volume 4. Oxford: Oxford University Press, 2010.

Taruskin, Richard. 'The Poietic Fallacy'. The Musical Times 145/1886 (Spring 2004), 7-34.

Tate, Greg. 'Black Artists Group'. Wire 329 (July 2011), 56-7.

Taylor, Calvin. 'Various approaches to and definitions of creativity'. In The nature of creativity, ed. Robert Sternberg, New York: Cambridge University Press, 1988, 99-121.

Teachout, Terry. Duke: The life of Duke Ellington. London: Robson Press, 2013.

Tingen, Paul. 'The Making of In A Silent Way \& Bitches Brew'. Mojo 94 (September 2001), 48.

Tingen, Paul. Miles Beyond: Electric Explorations of Miles Davis, 1967-1991. London: Billboard Books, 2001.

Togashi, Nobuaki, Matsubayashi, Kohji and Hatta, Masayuki. Miles Davis Discography (2001-2003) <http://www.jazzdisco.org/milesdavis/discography/>. 20 March 2014.

Tomlinson, Gary. 'Miles Davis, Musical Dialogician'. Black Music Research Journal 22 [Supplement Best of BMRJ] (2002), 71-105.

Torrance, E. Paul. Torrance test of Creative Thinking: Directions manual and scoring guide. Bensenville, IL: Scholastic testing Service, 1966.

Toiviainen, Petri. 'Review [untitled]'. Music Perception: An Interdisciplinary Journal 25/3 (February 2008), 257-260.

Toynbee, Jason. Making Popular Music. London: Arnold, 2000.

Toynbee, Jason. 'Music, Culture, and Creativity'. In The Cultural Study of Music: a critical introduction, ed. Richard Middleton, New York: Routledge, 2003, 102112. 
Trucks, Rob. 'Chatting with Jimmy Cobb, Kind of Blue's Last Surviving Player'. The Village Voice (8 October 2008) <http://www.villagevoice.com/2008-1008/music/chatting-with-jimmy-cobb-kind-of-blue-s-last-surviving-player/>. 28 March 2014.

Tucker, Mark. The Duke Ellington Reader. London: Oxford, 1993.

Tucker, Michael. Jan Garbarek: Deep Song. Hull: University of Hull Press, 1998.

Walser, Rob. Keeping Time: Readings in Jazz History. New York: Oxford University Press, 1999.

Walser, Rob. 'Out of Notes: Signification, Interpretation, and the Problem of Miles Davis'. The Musical Quarterly 77/2 (Summer 1993), 343-365.

Ward, Brian. Just my soul responding: Rhythm and blues, black consciousness and race relations. London: UCL Press, 1998.

Ward, Thomas, Smith, Steven and Finke, Ronald. 'Creative Cognition'. In Handbook of Creativity, ed. Robert Sternberg, Cambridge: Cambridge University Press, 1999,189-212.

Washburne, Chris. 'The Clave of Jazz: A Caribbean Contribution to the Rhythmic Foundation of an African-American Music'. Black Music Research Journal 17/1 (Spring 1997), 59-80.

Welding, Pete. 'Miles Davis: Live Evil'. In The Miles Davis Reader, ed. Bill Kirchner, Washington: Smithsonian, 1997, 257-259.

White, Harry and Murphy, Michael. Musical Constructions of Nationalism: Essays on the History and Ideology of European Musical Culture, 1800-1945. Cork, Ireland: Cork University Press, 2001.

Whitehead, Kevin. Why Jazz? A concise guide. New York: Oxford University Press, 2011.

Wilf, Eitan. 'Rituals of Creativity: Tradition, Modernity, and the "Acoustic Unconscious" in a U.S. Collegiate Jazz Music Program'. American Anthropologist 114/1 (2012), 32-44.

Williams, Martin. The Jazz Tradition. New York: Oxford University Press, 1993 ( $2^{\text {nd }}$ edition).

Williams, Raymond. The Long Revolution. Harmonsworth: Penguin, 1961.

Williams, Richard. The Blue Moment: Miles Davis's Kind of Blue and the Remaking of Modern Music. London: W.W. Norton, 2012.

Wilson, Olly. "The significance of the relationship between Afro-American and West African Music'. Black Music Perspective in Music 2/1 (Spring 1974), 3-22. 
Wilson, Olly. 'Black Music as an Art Form'. Black Music Research Journal 3 (1983), $1-22$.

Wilson, Olly. 'The Heterogeneous Sound Ideal in African-American Music'. In New Perspectives of Music: Essays in Honor of Eileen Southern, ed. Josephine Wright and Samuel Floyd, Warren, MI: Harmonie Press, 1992, 327-338.

Wilson, Peter Niklas. Ornette Coleman: His life and music. Berkeley: Berkeley Hills Books, 1999.

Winner, Langdon. 'Miles Davis: Bitches Brew'. Rolling Stone (28 May 1970), $<$ http://www.rollingstone.com/music/albumreviews/bitches-brew19700528>. 27 March 2014.

Young, James and Matheson, Carl. 'The Metaphysics of Jazz'. The Journal of Aesthetics and Art Criticism 58/2 Improvisation in the Arts (Spring, 2000) 125133.

Zappa, Frank, and Occhiogrosso, Peter. The Real Frank Zappa Book. New York: Touchstone, 1990.

No by-line. '100 Jazz Profiles: Jan Garbarek'. (No date) <http://www.bbc.co.uk/radio3/jazz/profiles/jan_garbarek.shtml>. 25 July 2013.

No by-line. 'Charlie Haden: with Ornette Coleman'. (No date) <http://www.charliehadenmusic.com/music/ornette-coleman>. 17 March 2014.

No by-line. 'Duke Ellington records his first big hit: "Mood Indigo".'

$<$ http://www.history.com/this-day-in-history/duke-ellington-records-his-firstbig-hit-quotmood-indigoquot>. 6 May 2014.

No by-line. 'Jan Garbarek.' ECM Records. (No date) <http://www.worldmix.nu/2007/documents/garbarek_bio.pdf>. 15 May 2014.

No by-line. 'Jan Johansson: Heptagon Records'. (No date) <http://www.heptagon.se>. 15 May 2014.

No by-line. 'Maori Proverbs: Whakataukì'. (Updated 5 February 2014) < http://www.maori.cl/Proverbs.htm>. 3 June 2014.

No by-line. 'New Orleans Jazz Festival'. <http://lineup.nojazzfest.com>. 4 April 2014.

No by-line. 'Ornette Coleman: The Seeker'. Magnet Magazine (1 May 2007) $<$ http://www.magnetmagazine.com/2007/01/05/ornette-coleman-theseeker/>. 18 March 2014.

No by-line. 'This Day in History'. (No date) <http://www.history.com/this-day- 
in-history/duke-ellington-records-his-first-big-hit-quotmood-indigoquot>. 17February 2014. 